\title{
Long-chain polyunsaturated fatty acids in preterm infants : influence of pre- and postnatal supplies
}

Citation for published version (APA):

Foreman-van Drongelen, M. M. H. P. (1996). Long-chain polyunsaturated fatty acids in preterm infants : influence of pre- and postnatal supplies. [Doctoral Thesis, Maastricht University]. Krips Repro. https://doi.org/10.26481/dis.19960614mf

Document status and date:

Published: 01/01/1996

DOI:

10.26481/dis.19960614mf

Document Version:

Publisher's PDF, also known as Version of record

\section{Please check the document version of this publication:}

- A submitted manuscript is the version of the article upon submission and before peer-review. There can be important differences between the submitted version and the official published version of record.

People interested in the research are advised to contact the author for the final version of the publication, or visit the DOI to the publisher's website.

- The final author version and the galley proof are versions of the publication after peer review.

- The final published version features the final layout of the paper including the volume, issue and page numbers.

Link to publication

\footnotetext{
General rights rights.

- You may freely distribute the URL identifying the publication in the public portal. please follow below link for the End User Agreement:

www.umlib.nl/taverne-license

Take down policy

If you believe that this document breaches copyright please contact us at:

repository@maastrichtuniversity.nl

providing details and we will investigate your claim.
}

Copyright and moral rights for the publications made accessible in the public portal are retained by the authors and/or other copyright owners and it is a condition of accessing publications that users recognise and abide by the legal requirements associated with these

- Users may download and print one copy of any publication from the public portal for the purpose of private study or research.

- You may not further distribute the material or use it for any profit-making activity or commercial gain

If the publication is distributed under the terms of Article $25 \mathrm{fa}$ of the Dutch Copyright Act, indicated by the "Taverne" license above, 


\section{LONG-CHAIN POLYUNSATURATED FATTY ACIDS IN PRETERM INFANTS}

INFLUENCE OF PRE- AND POSTNATAL SUPPLIES 
Omslagoniwerp en -realisatie: Peter van Drongelen Layoui-realisatie en lijngrafieken: Tim Foreman Druk: Datawyse Maastricht / Krips Repro Meppel 


\title{
LONG-CHAIN POLYUNSATURATED FATTY ACIDS IN PRETERM INFANTS
}

\author{
INFLUENCE OF PRE- AND POSTNATAL SUPPLIES
}

\section{PROEFSCHRIFT}

ter verkrijging van de graad van doctor aan de Rijksuniversiteit Limburg te Maastricht, op gezag van de Rector Magnificus, Prof. mr. M.J. Cohen, volgens het besluit van het College van Dekanen, in het openbaar te verdedigen op vrijdag 14 juni 1996 om 16.00 uur

door

Magritha Maria Hubertina Petra Foreman-van Drongelen geboren op 30 augustus 1965 te Maastricht 


\section{Promotores:}

Prof. dr. G. Hornstra

Prof. dr. C.E. Blanco

\section{Co-promotores:}

Dr. T.H.M. Hasaart

Dr. A.C. van Houwelingen

\section{Beoordelingscommissie:}

Prof. dr. G.J. van der Vusse (voorzitter)

Prof. dr. S.E. Carlson (University of Tennessee, Memphis, USA)

Prof. dr. M.P. van Dieijen-Visser

Prof. dr. H.N. Lafeber (Vrije Universiteit Amsterdam)

Prof. dr. J. Troost

Studies described in this thesis were financially supported by Nutricia BV, Zoetermeer, The Netherlands.

Financial support by the Netherlands Heart Foundation for the publication of this thesis is gratefully acknowledged.

The author also wishes to express her gratitude to the Foundation Dr. Ir. J.H.J. van de Laar, the Foundation Promotion Paediatrics (Stichting Bevordering Kindergeneeskunde), and Nutricia BV for subsidizing the publication costs. 
Aan mijn ouders

Voor Yuri, Meryl en Tim 



\section{Contents}

Fatty acid nomenclature and abbreviations $\ldots \ldots \ldots \ldots \ldots \ldots \ldots \ldots \ldots \ldots$ ix

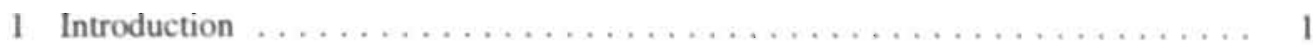

1.1 Parent essential fatty acids and their longer-chain derivatives $\ldots \ldots \ldots \ldots \ldots \ldots \ldots \ldots$ ।

1.2 Long-chain polyunsaturated fatty acids during pre- and postnatal life $\ldots \ldots \ldots \ldots \ldots \ldots 4$

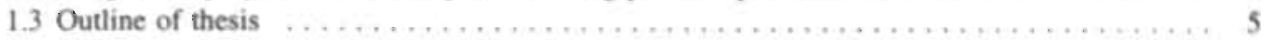

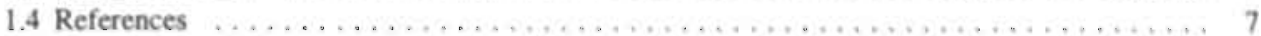

2 Comparison between the essential fatty acid status of preterm and full-term infants, measured in umbilical vessel walls $\ldots \ldots \ldots \ldots \ldots \ldots \ldots \ldots \ldots \ldots, 13$

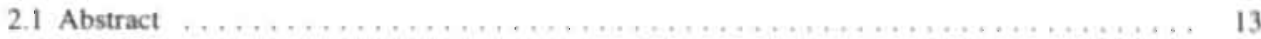

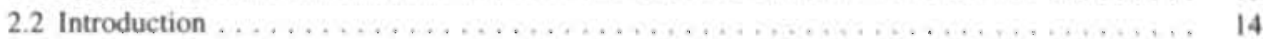

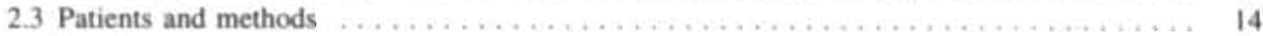

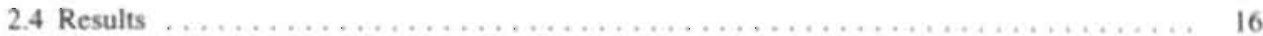

2.5 Discussion ............................................. 19

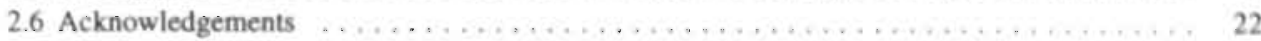

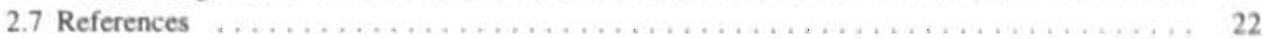

3 Essential fatty acid profile of fetal plasma phospholipids; comparison with postnatal

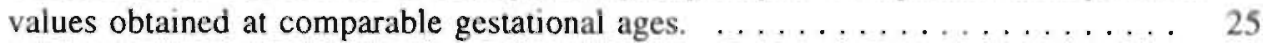

3.1 Abstract . . . . . . . . . . . . . . . . . . . . . . . . . . . . . . . 25

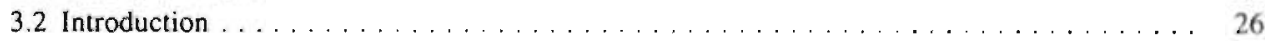

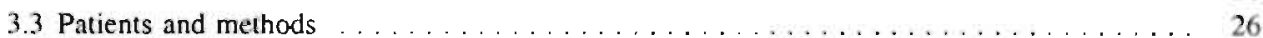

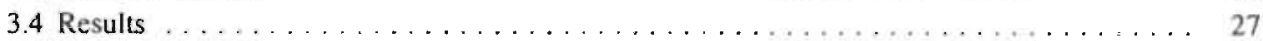

3.5 Discussion ....................................... 29

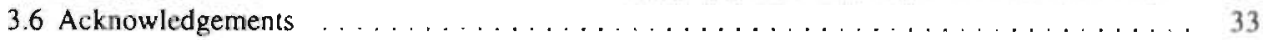

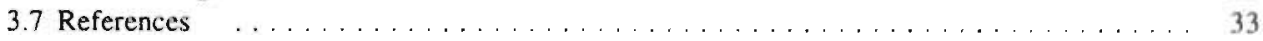

4 Essential fatty acid status measured in umbilical vesscl walls of infants born after a

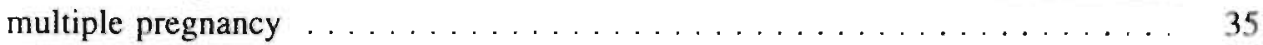

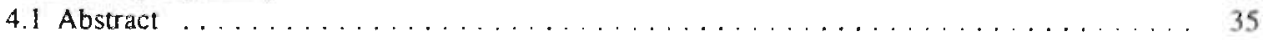

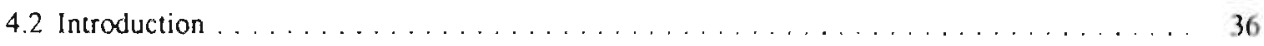

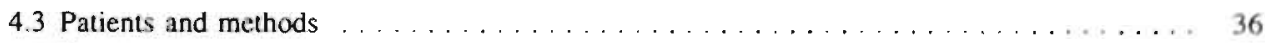

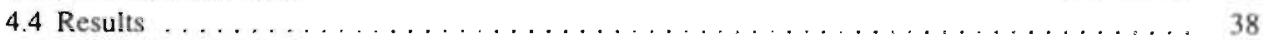

4.5 Discussion ................................ 41

4.6 Acknowledgements $\ldots \ldots \ldots \ldots \ldots \ldots \ldots \ldots \ldots \ldots \ldots \ldots \ldots \ldots \ldots \ldots \ldots \ldots \ldots \ldots, 43$

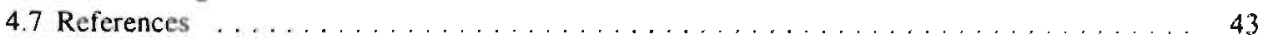

5 Comparability of fatty acid profiles of venous and capillary plasma and red blood

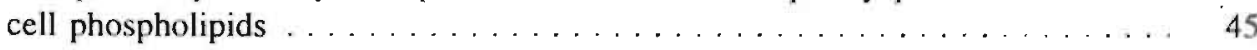

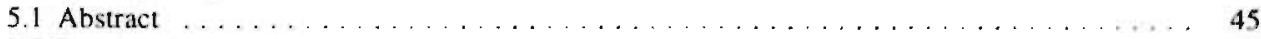

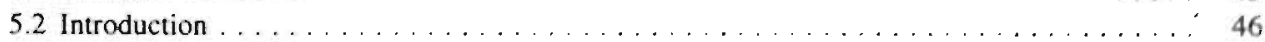

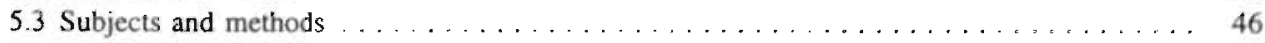

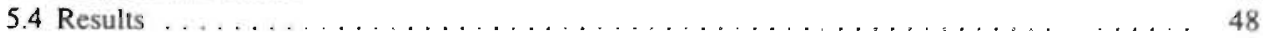

5.5 Discussion . . . . . . . . . . . . . . . . . . . . . . . . . 52

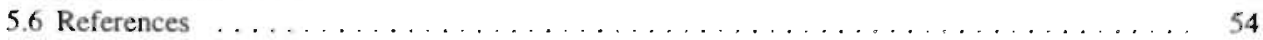


6 Long-chain polyene status of preterm infants with regard to the fatty acid composition of their diet: comparison between absolute and relative fatty acid amounts in plasma and red blood cell phospholipids . . . . . . . . . . . . 57

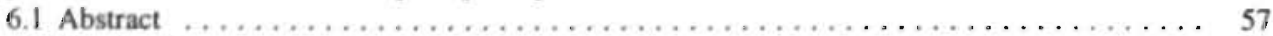

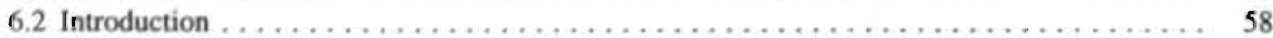

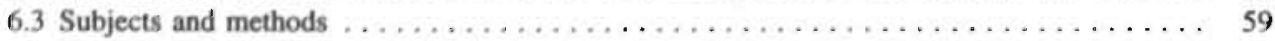

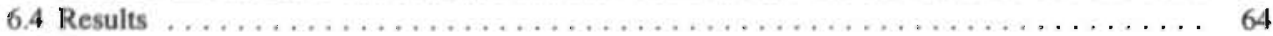

6.5 Discussion ........................................ 66

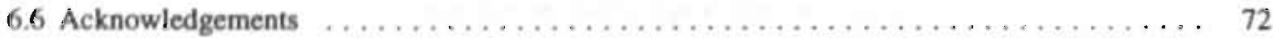

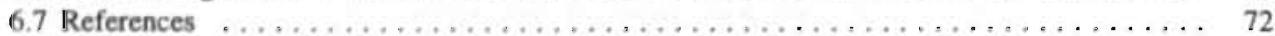

7 Long-chain polyunsaturated fatty acids in preterm infants: status at birth and its influence on postnatal levels . . . . . . . . . . . . . . . . . . . 75

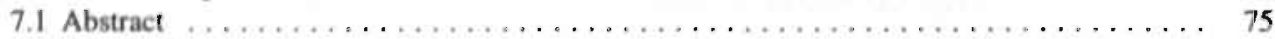

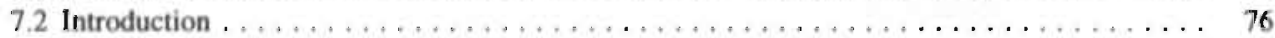

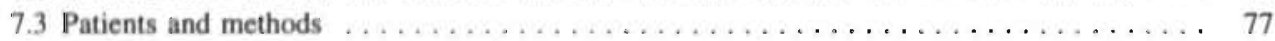

7.4 Results ....................................... 80

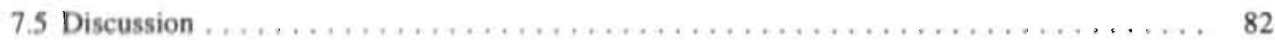

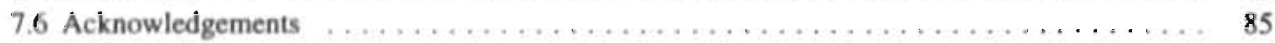

7.7 References $\ldots \ldots \ldots \ldots \ldots \ldots \ldots \ldots \ldots \ldots \ldots \ldots \ldots \ldots \ldots \ldots \ldots \ldots . \ldots \ldots \ldots$

8 Influence of feeding artificial formulas containing docosahexaenoic and arachidonic acids on the postnatal long-chain polyunsaturated fatty acid status of healthy preterm

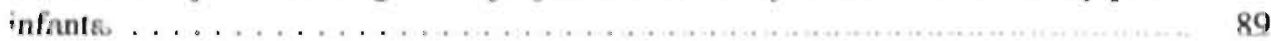

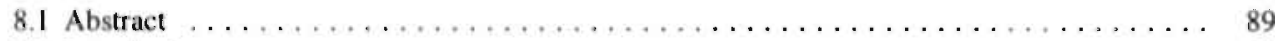

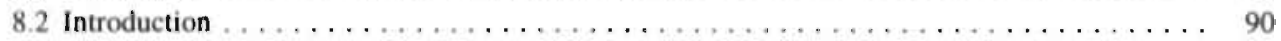

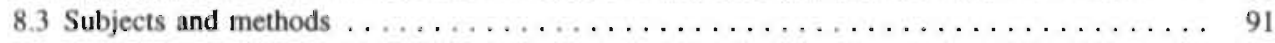

8.4 Results . . . . . . . . . . . . . . . . . . . . . . . . . . . . 95

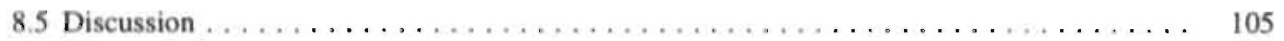

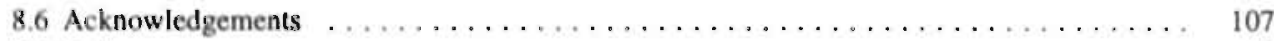

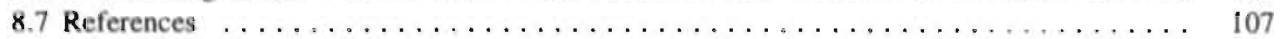

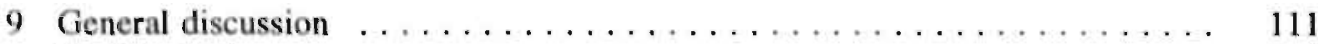

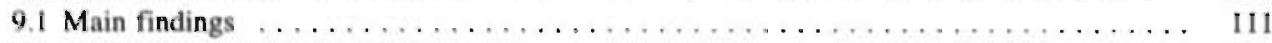

9.2 Methodological considerations . . . . . . . . . . . . . . . . . . 117

9.3. Supplementation of essential fatty acids, the longer-chain derivatives in particular, during pre-

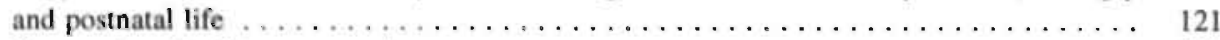

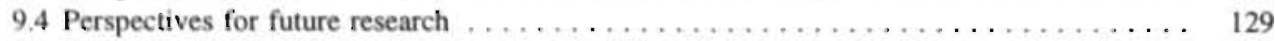

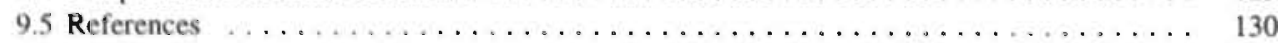

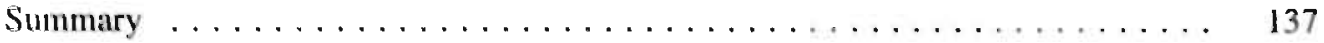

Samenvatting ................................ 141

Met dank aan.............................. 147

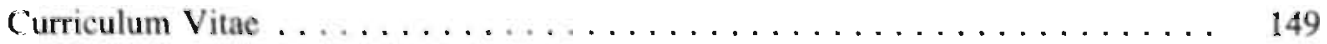

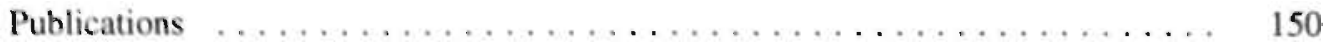




\section{Fatty acid nomenclature and abbreviations}

19:0

$18: 1 n-9$

$18: 2 n-6$

$18: 3 n-3$

20:3n-6

20:3n-9

$22: 3 n-9$

$20: 4 n-6$

$22: 4 n-6$

20:5n-3

22:5n-6

$22: 6 n-3$

AF

BPD

C

CADI

CASI

C-AF

CZS

EDTA

EFA

EFADI

ERG

FAME

FL

$G A$

$\mathrm{HC}$

$\mathrm{HM}$

IV

IVH

LCP

LCP-AF

MDI

MUFA

ND

NS

PC

PDI

PE nonadecanoic acid

oleic acid

linoleic acid

$\alpha$-linolenic acid

dihomo- $\gamma$-linolenic acid

Mead acid

dihomo-Mead acid

arachidonic acid

adrenic acid

eicosapentaenoic acid

Osbond acid

docosahexaenoic acid (cervonic acid)

artificial formula

bronchopulmonary dysplasia

capillary

cervonic acid deficiency index $(22: 5 n-6 / 22: 4 n-6)$

cervonic acid sufficiency index (22:6n-3/22:5n-6)

conventional artificial formula

centraal zenuwstelsel (central nervous system)

ethylenediaminetetracetic acid

essential fatty acid

essential fatty acid deficiency index (20:3n-9/20:4n-6)

electroretinogram

fatty acid methyl ester

fosfolipide (phospholipid)

gestational age

head circumference

human milk

intravenous

intraventricular haemorrhage

long-chain polyunsaturated fatty acid (long-chain polyene)

artificial formula enriched with long-chain polyunsaturated fatty

acids

(Bayley) Mental Development Index

monounsaturated fatty acid

none detected

not significant

phosphatidylcholine

(Bayley) Psychomutor Develosment Index

phosphatidylethanoline 
PG

prostaglandin

PL

phospholipid

PUFA

RBC

polyunsaturated fatty acid

SAFA

red blood cell

SD

saturated fatty acid

SGA

standard deviation

UI

small for gestational age

unsaturation index [sum of (number of double bonds * \% level of fatty acid)]

V venous

VEP

visual evoked potential 


\section{Introduction}

In the Netherlands, about $7 \%$ of live-born infants are born preterm, that is within 37 weeks of gestation [1]. Over the past few decades, the overall prognosis of these vulnerable infants, born as early as after 26 weeks of pregnancy, has improved substantially thanks to medical and technical advances in perinatal care, especially regarding the management of cardio-respiratory problems in the early neonatal period $[2-4]$. Another factor which has contributed to the decreased mortality and morbidity of preterm infants is the increased knowledge of their particular nutritional needs, for the preterm infant's gastro-intestinal tract and metabolic make-up are immature and insufficiently prepared to properly digest, absorb and metabolize nutrients. To achieve optimal growth and development, preterm infants do not only have special requirements for fluid, amino acids, vitamins, minerals and energy, but also for specific, so-called essential fatty acids (EFAs), which are necessary for maintaining particular body functions even more so than for providing the infant with energy.

\subsection{Parent essential fatty acids and their longer-chain derivatives}

That certain fatty acids, besides their importance as a source of energy, also have specific, essential biologic functions, was first revealed by the pioneering work of Burr and Burr [5,6]. They observed retarded growth, scaly skin, impaired fertility, increased transepidermal loss of water, and even death in rats maintained on a fat-free but otherwise adequate diet for several weeks. Inclusion of small amounts of linoleic acid $\left(18: 2 n-6^{1}\right)$ or $\alpha$-linolenic acid (18:3n-3) in the diet was found to alleviate these deficiency symptoms $[5,6]$, so they coined the term 'essential fatty acids' for these fatty acids that were obviously not synthesized in the animal organism, but had to be derived from the diet for normal physiological function. It was, however, not until several decades later, that EFAs were conclusively proven to be indispensable to human infants [7-9] and adults [10-12].

Humans cannot synthesize $18: 2 n-6$ and 18:3n-3 de novo, because, unlike plants, they lack $\Delta 12$ - and $\Delta 15$-desaturases. However, the human body is capable of converting these parent EFAs to their longer-chain and more unsaturated derivatives through alternate desaturation and elongation $[13,14]$, using the same enzymes as catalysts for the equivalent steps in the $n-7, n-9, n-6$, and $n-3$ fatty acid pathways (figure 1.1.). The rate of synthesis of these so-called long-chain polyunsaturated fatty acids (LCPS, having a chain length of at least 20 carbon atoms, and at least one more double bond than their parent EFA) of the $n-6$ and $n-3$

'In this thesis, the nomenclature used for fatty acids is as follows: the number of carbon atoms, followed by a colon and the number of unsaturated, double bonds; the fatty acid family is identified by designation of the first double bond from the methyl- $n$ terminus of the fatty acid carbon chain. 
families is limited by the activity of $\Delta 6$-desaturase [15]. The substrate affinity of this enzyme is known to be determined by the number of double bonds in the substrate and is in the order 18:3n-3>18:2n-6>18:1n-9 (oleic acid) [16]. The activity of the desaturases is also dependent on the concentrations of the substrate ( $\Delta 6$-desaturase) and product ( $\Delta 6$ and $\Delta 5$-desaturases) of the reaction, as well as several other nutritional and hormonal factors $[17,18]$. Only recently, the final conversion step was demonstrated not use a single enzyme (' $\Delta 4$-desaturase') as catalyst, but to occur via elongation, $\Delta 6$-desaturation and retroconversion by peroxisomal $\beta$-oxidation [19]. Interconversion between the fatty acids of the various families is not possible in mammalian tissue, because the necessary enzymes are not available.

Although a proportion of the EFAs supplied to the body, paricularly of $18: 2 n-6$ and 18:3n-3, is used to provide energy, many of the important biologic functions of EFAs are related to their incorporation into phospholipids (PLS), and other structural units of biomembranes. The specific presence of adequate 18:2n-6 levels in skin sphyngolipids has been demonstrated to be indispensable to maintaining the integrity of the epidermal water barrier $[20,21]$. The essentiality of $18: 3 n-3$ seems to be mainly related to its role as a precursor of $n-3$ LCPS. The major LCP of the $n-3$ series, docosahexaenoic acid (22:6n-3, also named cervonic acid), together with the major LCP of the n-6 series, arachidonic acid (20:4n-6), is present in substantial amounts in the human brain [22-24] and retina [25]. Besides, 20:4n-6 and two additional LCPs, dihomo- $\gamma$-linolenic acid $(20: 3 n-6)$ and eicosapentaenoic acid (20:5n-3), are substrates for the production of prostaglandins and other eicosanoids [26-28], which have important bioregulatory functions [29-33].

When the amount of EFAs supplied to or present in the body is unable to cover its EFA demands, 'surrogate' fatty acids are synthesized instead. Because the presence of such fatty acids in tissue lipids is a sign of an absolute or relative shortage of the parent EFAs and their longer-chain derivatives, they are named EFA deficiency indicators. A well-known indicator of a general EFA deficiency is Mead acid (eicosatrienoic acid, 20:3n-9) [34,35], since it is synthesized from 18:1n-9 when insufficient amounts of the parent EFAs 18:2n-6 and $18: 3 n-3$, and/or their LCPS are present to, respectively, occupy or inhibit the $\Delta 6$-desaturase. Based on this metabolic principle, the ratio of 20:3n-9 to $20: 4 n-6$ (triene/tetraene ratio or EFA deficiency index) was introduced as an EFA deficiency marker [36].

Another fatty acid commonly regarded as an EFA deficiency indicator is the ultimate desaturation and elongation product of $18: 2 n-6$, Osbond acid $(22: 5 n-6)^{2}$. The production of this fatty acid is increased in case of an isolated shortage of $22: 6 n-3$. Since the formation of 22:5n-6 also depends on the availability of its immediate precursor adrenic acid (22:4n-6), the ratio of $22: 5 n-6$ to $22: 4 n-6$, also called the cervonic acid deficiency index (CADI), is also used as a marker of 22:6n-3 (cervonic acid) deficiency [38,39].

The full systematic name of this fatty acid is 4,7,10,13,16-docosapentaenoic acid, which cannot be shortened to docosapentaenoic acid, because of the existence of 7,10,13,16,19-docosapentaenoic acid (22:5n-3). As an alternative for the comprehensive designation of 22:5n-6, G. Hornstra proposed [37] to name this fatty acid after the person who first synthesized it, J.M. Osbond [Chem Ind (London) 1959:1288: J Chem Soc 1961:2779 (synth)]. 


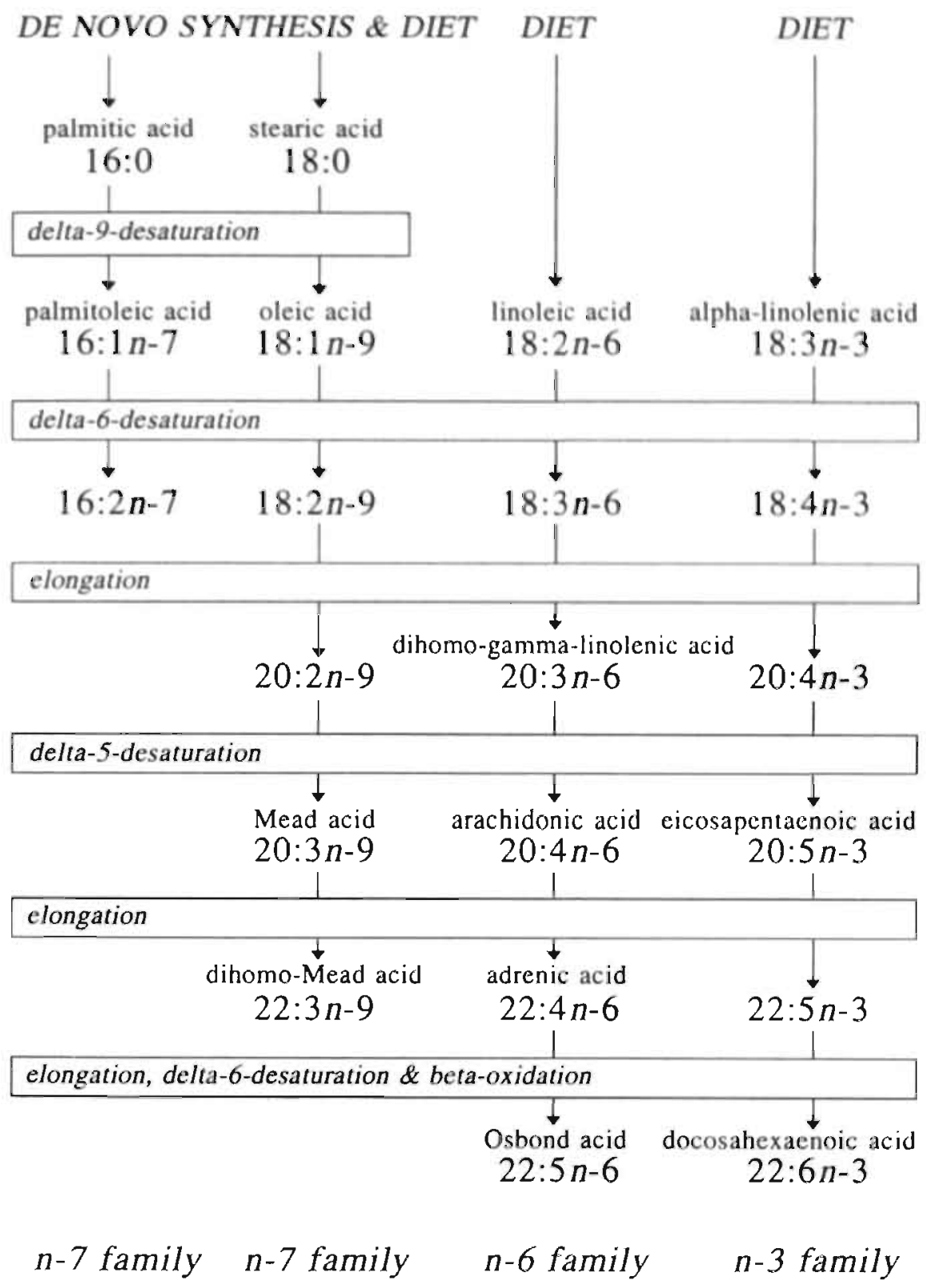

Figure 1.1. The main pathways of fatty acid synthesis and conversion. 


\subsection{Long-chain polyunsaturated fatty acids during pre- and postnatal life}

Considering the indispensability of EFAs to normal human body growth and function, adequate EFA levels are of particular importance during the limited periods of most rapid tissue and organ growth and development, that is during the last months of fetal and the first months of postnatal life [40]. Quantities of EFAs required daily for intrauterine de novo tissue synthesis have been estimated to be about $400 \mathrm{mg} / \mathrm{kg}$ body weight of $n-6$ EFAs and $50 \mathrm{mg} / \mathrm{kg}$ body weight of $n-3$ EFAs. [41]. That the EFAs preferentially needed by the developing fetus are the longer chain derivatives, was suggested by the observation of Crawford and co-workers [42] that levels of the parent EFAs 18:2n-6 and 18:3n-3 decreased, and levels of their n-6 and n-3 LCPs increased in the PLs from maternal blood to cord blood, fetal liver and to fetal brain; a phenomenon which they termed 'biomagnification'. A significant portion of these LCPs, especially of $22: 6 n-3$ and $20: 4 n-6$, is used for incorporation in neural tissue, particularly during ce!l division [43]. Most of the development of the human brain takes place in utero and during the first two years of life [44], and about $70 \%$ of brain cells divide before birth. Indeed, $22: 6 n-3$ and $20: 4 n-6$ have been shown to accumulate rapidly in neural tissue during the last trimester of gestation $[45,46]$, and their accretion has been found to continue throughout the first two years of postnatal life [47].

The exact way or ways in which the growing and developing fetus obtains the required EFAs is not yet known. Obviously, the fetus cannot synthesize the parent EFAs, which, therefore, have to be derived from the maternal circulation. The LCPs, however, can potenlially be obtained either directly from the maternal circulation by passage across the placenta, or by conversion from 18:2n-6 and $18: 3 n-3$ in placental or fetal tissue [48]. Yet, since the information available on fetal fatty acid biochemistry indicates that the desaturase activity in fetal liver microsomes is low [49], and that in human placental tissue is low [50] or even not detectable [49,51], the direct LCP supply by the maternal circulation appears to be the most likely option. Irrespective of the way in which the fetus obtains the necessary LCPs, studies of EFA levels in umbilical cord vessel walls of full-term infants have raised doulb!s as to whether the intrauterine supply of EFAs, including LCPS, adequately covers the demands by the fetus, in particular because the umbilical artery vessel walls were found to contain substantial amounts of the EFA deficiency indicator 20:3n-9 [37,51,52].

As stated at the beginning of this introduction, in about $7 \%$ of advanced pregnancies, the physiological courses of fetal growth and development are interrupted by (very) preterm delivery. Consequently, preterm infants, unlike full-term infants, cannot benefit from the maternal and placental EFA supply during the last trimester of pregnancy when handling the demands of their still growing and developing brain and body. Instead, during this period of very rapid brain growth. they are dependent on their own dietary supply through either human milk, which contains smal! but significant amounts of 22:6n-3, 20:4n-6. and other LCPs, or commercially available artificial formulas, the majority of which does not contain any but trace amounts of LCPS [54,55]. An appropriate postnatal dietary LCP supply to preterm infants is all the more important, since these infants have very limited fatty acid 
stores $[41,56,57]$ and are born with lower EFA levels in their plasma than infants carried to term [58].

The first studies of the influence of either breast or bottle-feeding on the EFA status of newborn infants were conducted in full-term infants, and in these studies higher LCP levels were observed in the infants raised on their own mother's milk $[59,60]$. A number of studies in preterm populations have since reported that conventional formulas, even when they do contain substantial amounts: of the parent EFAs 18:2n-6 and 18:3n-3, are unable to maintain postnatal 22:6n-3 and 20:4n-6 levels in plasma and red blood cell (RBC) lipids at levels observed after feeding preterm human milk [61-63]. Probably, the desaturase capacity of (preterm) newborns is too limited to guarantee and adequate supply of $n-3$ and $n-6$ LCPs solely through metabolic conversion of the two parent EFAs. $[49,57]$. The potential importance of maintaining adequate LCP levels during development was indicated by various animal studies, in which dietary EFA and LCP levels were found to influence visual and cognitive functions in rats and rhesus monkeys $[39,64-66]$. These observations prompted the first cautious attempts to reduce the differences between the biochemical LCP status of human milk and formula-fed infants by adding LCPS to the diets of formula-fed infants $[63,67,68]$.

\subsection{Outline of thesis}

So far, this introduction consisted of a brief review of the information on EFAs in general and the role of LCPS during development in particular, that was available from the literature at the time the studies described in this thesis were initiated. Even though the research carried out thus far supported the relevance of an adequate LCP supply for proper development, especially for the vulnerable preterm infant, a number of important questions were still unanswered. The primary aim of this thesis was to extend the existing knowledge on the biochemical LCP status of the preterm infant and how this status is influenced by the (potentially limited) pre- and postnatal supplies of EFAS, the longer-chain derivatives in particular. More specifically, a number of protocols were developed to study the following itums:

\subsubsection{Supply of long-chain polyunsaturated fatty acids during intrauterine life}

\section{Long-chain polyunsaturated fatty acid status of preterm infants at birth}

The EFA profiles of umbilical cord vessel walls (reflecting the fetall EFA status) of preterm infants are evaluated in Chapter 2 by comparing them with those of infants carried to term. Besides, the potential relations among cord vessel wall EFA levels, gestational age (GA) at birth, and parameters of prenatal growth are studied. The EFA status is assessed in umbilical cord vessel walls, since their EFA profile is considered a longer-term representation of the EFA supply to (cord vein) and return flow from (cord arteries) the fetus [53,69]. The PL fraction is studied especially, because PLs are structural lipids, which are the richest source of polyunsaturated fatty acids (PUFAs), including EFAs in general and LCPS in particular. In addition, changes in PUFA profile are most pronounced in PLs [18]. 
Essential fatty acid status at birth as a reflection of the fetal essential fatty acid status

As in Chapter 2, studies on the fetal EFA and LCP status are usually based on material (umbilical plasma, RBCs and/or cord vessel walls) collected after delivery $[37,53,58,69-71]$. However, to what extent the EFA status at birth is an accurate reflection of the fetal EFA status, is virtually unknown. Therefore, the PL-associated EFA profiles of plasma obtained through fetal blood sampling, giving more direct information on the fetal EFA. status, and of plasma collected from the umbilical cord shortly after delivery at a similar GA are compared in Chapter 3. Moreover, these plasma data are used to better understand the differences between the cord vessel wall EFA profiles of preterm and full-term infants that are described in Chapter 2.

\section{Essential fatty acid status of infants born after a multiple pregnancy}

A major cause of preterm delivery is multiple pregnancy [72]. If the low efa status, reported for full-term infants born after an uneventful, singleton pregnancy [37,51,52], is caused by a limited maternal EFA supply, the higher total fetal EFA demand associated with a multiple pregnancy would result in an even lower biochemical EFA status of the infants born after a multiple pregnancy. To study whether the maternal EFA supply is a limiting factor in the neonatal EFA status indeed, the EFA profiles of umbilical artery and vein wall PLS of 30 pairs of twins, 7 sets triplets, and one set of quintuplets are compared with those of 94 infants born after a singleton pregnancy in Chapter $\mathbf{4}$.

\subsubsection{Postnatal long-chain polyunsaturated fatty acid status of preterm infants}

\section{Influence of feeding human milk or conventional arificial formulas}

The first of the two main studies of the influence of the postnatal dietary LCP supply on the postnatal LCP status of preterm infants is described in Chapter 6. During the first four weeks of postnatal life, patterns of weekly changes in the LCP status of 12 human milk-fed infants and of 27 infants raised on a conventional artificial formula, lacking LCPS, are compared. Special emphasis is given to the evaluation of effects on the two major LCPS, 22:6n-3 and 20:4n-6. Fatty acid values in plasma and RBC PLS are expressed in terms of both absolute amounts (ing/1 plasma or RBC suspension) and the usual relative levels (mg/100 mg total fatty acids), in view of the potential additional information that can be obtained from the first.

The observations described in Chapter 6 and similar findings by others [61-63] of a significant influence of the postnatal dietary LCP supply on the postnatal LCP status of preterm infants, gave rise to the questions addressed in the following two chapters of this thesis:

Influence of prenatal long-chain polyunsaturated fatty acid supply

Whether postnatal LCP values in preterm infants are also significantly affected by the LCP supply during intrauterine life is studied in Chapter 7, again with special emphasis on 22:6n-3 and 20:4n-6. To this end, the LCP status at preterm birth (measured in the umbilical ariery wall PLS, and in umbilical plasma or RBC PLS) which results from the prenatal LCP supply, and the postnatal diet (human-milk or conventional artificial formula), representing the postnatal LCP supply, are related to the LCP status measured in plasma or RBC PLS collected from the preterm infants in the period during which they were actually due to be 
born (37-42 weeks GA). In addition, the exploration conducted in Chapter 2 of the relations among EFA status, GA, and growth parameters at birth is extended by also studying LCP levels in umbilical plasma and RBC PLS.

Influence of feeding conventional artificial formulas or formulas enriched with 22:6n-3 and 20:4n-6.

The results of a randomized controlled intervention study of the potentially favourably effects on the LCP status of supplying formula-fed preterm infants with an artificial formula containing both $22: 6 n-3$ and $20: 4 n-6$ in levels present in human milk until three months after their initially expected date of delivery, are described in Chapter $\mathbf{8}$. When this study was initiated, results of other studies using LCP-supplemented formulas were available $[63,67,68,73]$. but these were of short duration and/or focused on $n-3$ LCP addition only. In our study, blood LCP levels of 15 infants fed on the LCP-enriched study formula were compared with those of 16 infants receiving a conventional formula (lacking LCPs) and with those of a group of 12 preterm infants raised on human milk.

\subsubsection{Methodological considerations}

Comparability of fatty acid profiles of venous and capillary plasma and red' blood cell phospholipids

The influence of the postnatal dietary LCP supply on the postnatal LCP status of preterm infants was studied in plasma and RBC PLS of blood samples collected at regular intervals after birth (Chapters 6 and 8 ). To reduce the burden placed on the participating infants, the required blood samples were to be collected in conjunction with diagnostic punctures, which are part of the routine clinical management at the neonatology ward. Since the blood obtained in this manner can be of venous or capillary origin, the fatty acid profiles of these two types of blood have to be comparable in order to obtain reliable information on the dietary influences. Since information on this comparability appeared unavailable, the PL. associated fatty acid profiles of plasma and RBC PLs from blood obtained by venous and by capillary puncture are compared in Chapter 5. In addition, the effects of storage at $-20{ }^{\circ} \mathrm{C}$ for a maximum of four weeks are evaluated, since all blood samples of a preterm infant were to be analyzed simultaneously to ensure uniformity of analytic conditions. For ethical reasons this study was not performed in young infants but in 8 healthy adult volunteers.

Finally, the major findings of the above-mentioned studies and their implications for current views and future research are discussed in Chapter 9.

\subsection{References}

1. Herngreen WP, Reerink JD, v Noord-Zaanstra BM, Verloove-Vanhorick SP, Ruys JH. SMOCC: Design of a representative cohort-study of live-born infants in the Netherlands. Eur J Publ Health 1992;2:117-22.

2. Van Zeben-Van der Aa TM, Verloove-Vanhorick SP, Brand R, Ruys RH. Morbidity of very low birthweight infants at corrected age of two years in a geographically defined population. Report from project on preterm and small for gestational age infants in the Netherlands. Lancet. 1989;1:253-5. 
3. Den Ouden L, Verloove-Vanhorick SP, Van Zeben-Van der Aa DM, Brand R, Ruys JH. Neonatal neurological dysfunction in a cohort of very preterm and/or very low birthweight infants relation to other perinatal factors and outcome at 2 years. Neuropediatrics 1990;21:66-71.

4. Veen S, Ens-Dokkum MH, Schreuder AM, Verloove-Vanhorick SP, Brand R, Ruys JH. Impairments, disabilities, and handicaps of very preterm and very-low-birthweight infants at five years of age. Lancet 1991;338:33-6.

5. Burr GO, Burr MM. A new deficiency disease produced by the rigid exclusion of fat from the diet. J Biol Chem 1929;82:345-67.

6. Burr GO, Burr MM. The nature and role of the fatty acids essential in nutrition. J Biol Chem 1930;86:587-621.

7. Hansen AE, Haggard ME, Boelsche AN, Adam DJD, Wiese HF. Essential fatty acids in infant nutrition. III Clinical manifestations of linoleic acid deficiency. J Nutr 1958;66:565-76.

8. Hansen AE, Wiese HF, Boelsche AN, Haggard ME, Adam DJD, Davis H. Role of linoleic acid in infant nutrition, clinical and chemical study of 428 infants fed on milk mixtures varying in kind and amount of fat. Pediatr Suppl 1963;2:171-92.

9. Holman RT, Carter WO, Wiese HF. The essential fatty acid requirement of infants and the assessment of their dietary intake of lineolate by serum fatty acid analysis. Am J Clin Nutr 1964:14:70-5.

10. Collins FD, Sinclair AJ, Royle JP, Coates, DA, Maynard AT, Leonard RF. Plasma lipids in human linoleic acid deficiency. Nutr Metab 1971;13:150-67.

11. Wene JD, Connor WE, Denbesten L. The development of essential fatty acid deficiency in healthy men fed fat-free diets intravenously and orally. J Clin Invest 1975;56:127-34.

12. Hirono H, Suzuki H, Igarashi Y, Konno T. Essential fatty acid deficiency induced by total parenteral nutrition and medium chain triglycerides feeding. Am J Clin Nutr 1979;30:1670-6.

13. Klenk E, Mohrhauer H. Metabolism of polyunsaturated fatty acids in the rat. Z Physiol Chem 1960;320:218-32.

14. Marcel YL, Christiansen K, Holman RT. The preferred metabolic pathway from linoleic acid to arachidonic acid in vitro. Biochim Biophys Acta 1968;164:25-35.

15. Brenner RR. Regulatory function of $\Delta 6$-desaturase, key enzyme of polyunsaturated fatty acid synthesis. Adv Exp Med Biol 1977:83:85-101.

16. Holman RT. Nutritional and metabolic interrelationships between fatty acids. Fed Proc 1964;23:1062-7.

17. Brenner RR. Nutritional and hormonal factors influencing desaturation of essential fatty acids. Prog Lipid Res 1981;20: ' !-7.

18. Holman RT. Control of polyunsaturated fatty acids in tissue lipids. J Am Coll Nutr 1986;5:183211.

19. Voss A, Reinhart M, Sankarappa S, Sprecher H. The metabolism of 7,10,13,16,19-docosapentaenoic acid to 4,7,10,13,16,19-docosahexaenoic acid in rat liver is independent of a 4-desaturase. J Biol Chem 1991;266:19995-20000.

20. Hansen HS, Jensen B. Essential function of linoleic acid esterified in acylglucosylceramide and acylceramide in maintaining the epidermal water barrier. Evidence from feeding studies with oleate, lineolate, arachidonate, culombinate and $\alpha$-linolenate. Biochim Biophys Acta 1985;834 :357-63.

21. Hansen HS. The essential nature of linoleic acid in mammals. TIBS 1986; !1:263-5.

22. Svennerholm L. Distribution and fatty acid composition of phosphoglycerides in normal human brain. J Lipid Res 1968;9:570-9.

23. Martinez M, Conde C, Ballabriga A. Some chemical aspects of human brain development. II. Phosphoglyceride fatty acids. Pediatr Res 1974:74:93-102. 
24. Sastry PS. Lipids of nervous tissue: composition and metabolism. Progr Lipid Res 1985;24:69. 176.

25. Fliesler SJ. Anderson RE. Chemistry and metabolism of lipids in the vertebrate retina. Progr Lipid Res 1983;22:79-131.

26. Bergstrōm S, Danielsson H, Samuelsson B. The enzymatic formation of prostaglandin $E_{2}$ from arachidonic acid. Biochim Biophys Acta 1964;90:207-10.

27. van Dorp DA, Beerthuis RK, Nugteren DH, Vonkeman $\mathrm{K}$. The biosynthesis of prostaglandins. Biochim Biophys Acta 1964;90:204-7.

28. Struyck CB, Beerthuis RK, Pabon HJJ, van, Dorp DA. Specificity of the enzyme conversion of polyunsaturated fatty acids into prostaglandins. Recl Trav Chim Pay-Bas 1966;85:1233-50.

29. Dusting GJ, Moncada S, Vane JR. Prostaglandins, their intermediates and precursors: cardiovascular actions and regulatory roles in normal and abnormal circulatory systems. Prog Cardiovasc Diseases 1979;21:405-23.

30. Gorman RR. Modulation of human platelet function by prostacyclin and thromboxane A2. Fed Proc 1979:38:83-8.

31. Mitchell MD. Mechanisms of human parturition: role of prostaglandins and related compounds. Adv Prostag Thromb Leuk Res 1985;15:613-5.

32. Kitterman JA. Arachidonic acid metabolism and control of breathing in the fetus and newborn. Semin Perinatol 1987;11:43-52.

33. Ruzicka T. The physiology and pathophysiology of eicosanoids in the skin. Eicosanoids 1988;1:59-72.

34. Fulco AJ, Mead JF, Metabolism of essential fatty acids. VIII. Origin of 5,8,11-eicosatrienoic acid in the fat-deficient rat. J Biol Chem 1959;234:1411-6.

35. Mead JF. The metabolism of the polyunsaturated fatty acids. Prog Chem Fats Other Lipids 1970;9:159-92.

36. Holman RT. The ratio of trienoic:tetraenoic acids in tissue lipids as a measure of essential fatty acid requirement. J Nutr 1960;70:405-10.

37. Holman RT. The deficiency of essential fatty acids. In: Kunau W, Holman RT, eds. Polyunsaturated fatty acids. Champaign (IL): Am Oil Chem Soc 1977;4:163-82.

38. Neuringer M, Connor WE, Lin DS, Barstad L, Luck S. Biochemical and functional effects of prenatal and postnatal $w 3$ fatty acid deficiency on retina and brain in rhesus monkeys. Proc Nati Acad Sci USA 1986;83:4021-5.

39. Galli C, Socini A. Dietary lipids in pre- and post-natal development. In: Dietary fats and health, EG Perkins, WJ Visek, editors. Champaign, Illinois: Am Oil Chem Soc 1983;16:2.78-301.

40. Clandinin MT, Chappell JE, Heim T, Swyer PR. Chance GW. Fatty acid utilization in perinatal de novo synthesis of tissues. Early Hum Dev 1981;5:355-66.

41. Crawford MA, Hassam AG, Williams G, Whitehouse. WL. Essential fatty acids and fetal brain growth. Lancet 1976;i:452-3.

42. Sinclair AJ, Crawford MA. The accumulation of arachidonate and docosahexaenoate in the developing rat brain. J Neurochim 1972;19:1753-8.

43. Dobbing J. Vulnerable periods of brain development. In: Elliott K, Knight K, eds. Lipids, malnutrition and the developing brain. Amsterdam: Elsevier, A Ciba Foundation symposium 1972:9-29.

44. Clandinin MT, Chappell JE, Leong S, Heim T, Swyer PR, Chance G.W. Intrauterine fatty acid accretion rates in human brain: implications for fatty acid requirements. Early Hum Dev 1980;4:$121-9$. 
45. Martinez M, Ballabriga A, Gil-Gibernou JJ. Lipids of the developing human retina: I. Total fatty acids, plasmalogens, and fatty acid composition of ethanolamine and choline phosphoglycerides. J Neurosci Res 1988;20:484-90.

46. Clandinin MT, Chappell JE, Leong S, Heim T, Swyer PR, Chance G.W. Extrauterine fatty acid accretion in infant brain: implications for fatty acid requirements. Early Hum Dev 1980;4:131-8.

47. Coleman RA. The role of the placenta in lipid metabolism and transport. Sem Perinat 1989;13:180-91.

48. Chambaz J "Ravel D, Manier M-C, Pepin D, Mulliez N, Bereziat G. Essential fatty acid interconversion in the human fetal liver. Biol Neonate 1985;47:136-40.

49. Zimmerman T, Winkler L, Moller U, Schubert H, Goetze E. Synthesis of arachidonic acid in the human placenta. Biol Neonate 1979:35:209-12.

50. Booth $\mathrm{C}$, Elphick MC, Hendrickse W, Hull D. Investigation of $\left[{ }^{14} \mathrm{C}\right]$ linoleic acid conversion into $\left[{ }^{14} \mathrm{C}\right]$ arachidonic acid and placental transfer of linoleic and palmitic acids across the perfused human placenta. J Dev Physiol 1981:3:177-89.

51. Ongari MA, Ritter JM, Orchard MA, Waddell KA, Blair IA, Lewis PJ. Correlation of prostacyclin synthesis by human umbilical artery with status of essential fatty acid. Am J Obstet Gynecol 1984;149:455-60.

52. Hornstra G, Houwelingen AC v, Simonis M, Gerrard JM. Fatty acid composition of umbilical arteries and veins: possible implications for the fetal EFA-status. Lipids 1989;24:51 1-7.

53. Al MDM, Hornstra G, van der Schouw YT, Bulstra-Ramakers MTEW, Huisjes HJ. Biochemical EFA status of mothers and their neonates after normal pregnancy. Early Hum Dev 1990;24:23948.

54. Jensen RG, Hagerty MM, McMahon KE. Lipids of human milk and infant formulas: a review. Am J Clin Nutr 1978;31:990-1016.

55. Lammi-Keefe CJ, Jensen RG. Lipids in human milk: a review. 2: Composition and fat-soluble vitamins. J Pediatr Gastroenterol Nutr 1984;3:172-98.

56. Friedman Z. Essential fatty acids revisited. Am J Dis Child 1980;134:397-408.

57. Clandinin MT, Chappell JE, Heim T, Swyer PR, Chance GW. Fatty acid accretion in fetal and neonatal liver: implications for fatty acid requirements. Early Hum Dev 1981;5:7-14.

58. Friedman Z, Danon A, Lamberth EL, Mann WJ. Cord blood fatty acid composition in infants and their mothers during the third trimester. J Pediatr 1978;92:461-6.

59. Sanders TAB, Naismith DJ. A comparison of the influence of breast-feeding and bottle-feeding on the fatty acid composition of the erythrocytes. Br J Nutr 1979:41:619-23.

60. Putnam JC, Carlson. SE, DeVoe PW, Barness LA. The effect of variations in dietary fatty acids on the fatty acid composition of erythrocyte phosphatidylcholine and phosphatidylethanolamine in human infants. Am J Clin Nutr 1982;36:106-14.

61. Carlson SE, Rhodes PG, Ferguson MG. Docosahexaenoic acid status of preterm infants at birth and following feeding with human milk or formula. Am J Clin Nutr 1986;44:798-804.

62. Pita ML, Fernández MR, De-Lucchi C, Medina A, Martínez-Valverde A, Uauy R, Gil A. Changes in the fatty acids pattern of red blood cell phospholipids induced by type of milk, dietary nucleotide supplementation, and postnatal age in preterm infants. J Pediatr Gastroenterol Nutr 1988:7:740-7.

63. Koletzko B, Schmidt E, Bremer HJ, Haug M, Harzer G. Effects of dietary long chain polyunsaturated fatty acids on the essential fatty acid status of premature infants. Eur J Pediatr 1989;148:669-75,

64. Neuringer M, Connor WE, Van Petten C, Barstad L. Dietary omega-3 fatty acid deficiency and visual loss in infant rhesus monkeys. J Clin Invest 1984;73:272-6. 
65. Watanabe I. Kato M, Aonuma H, Hashimoto A, Naito Y, Moriuchi A, Okuyama H. Effect of dietary alpha-linolenate/linoleate balance on the lipid composition and electroretinographic responses in rats. Adv Biosci 1987;62:563-70.

66. Bourre J-M. Francois M. Youyou A, Dumont O. Piciotti M, Pascal G, Durand G. The effects of dietary $\alpha$-linolenic acid on the composition of nerve membranes, enzymatic activity, amplitude of electrophysiological parameters, resistance to poisons and performance of learning tasks in rats. J Nutr 1989;119:1880-92.

67. Carlson SE, Rhodes PG, Rao VS. Goldgar DE. Effect of fish-oil supplementation on the n-3 fatty acid content of red blood cell membranes in preterm infants. Pediatr Res 1987:21:507-10.

68. Liu C-CF, Carlson SE, Rhodes PG, Rao VS, Meydrech EF. Increase in plasma phospholipid docosahexaenoic and eicosapentaenoic acids as a reflection of their intake and mode of administration. Pediatr Res 1987;22:292-296.

69. Crawford MA, Doyle W, Drury P, Lennon A, Costleloe K, Leighfield M. n-6 and n-3 fatty acids during early human development. J Int Med 1989;225:159-69S.

70. Berg Hansen I, Friis-Hansen B, Clausen J. The fatty acid composition of umbilical cord serum, infant serum and maternal serum and its relation to the diet. Zeitschrift fur Emalhrungswissenschaft 1969;9:352-63.

71. Olegård R, Svennerholm L. Fatty acid composition of plasma and red cell phosphoglycerides in full term infants and their mothers. Acta Prediatr Scand 1970;59:637-47.

72. Kloosterman GJ. De meerlingzwangerschap (Dutch). In: Kloosterman GJ, chief ed. De Voortplanting van de mens. Bussum, The Netherlands: Uitgeversmaatschappij Centen, 1983:211-9.

73. Carlson SE, Cooke RJ, Rhodes PG, Peeples JM, Werkman SH, Tolley EA. Long-term feeding of formulas high in linolenic acid and marine oil to very low birth weight infants: phospholipid fatty acids. Pediatr Res 1991;30:404-12. 



\title{
Comparison between the essential fatty acid status of preterm and full-term infants, measured in umbilical vessel walls
}

\author{
Magritha M.H.P. Foreman-v. Drongelen', Monique D.M. Al', Adriana C. v. \\ Houwelingen', Carlos E. Blanco ${ }^{2}$, and Gerard Hornstra'
}

'Department of Human Biology, University of Limburg, Maastricht, The Netherlands

${ }^{2}$ Department of Neonatology, University Hospital Maastricht, The Netherlands

Early Human Development 1995;42:241-25!

\subsection{Abstract}

The essential fatty acid (El:A) cumposition of umbilical vessel walls is increasingly being studied as a longer-term reflection of the fetal EFA status. We evaluated the EFA content of umbilical artery and vein vessel walls in 43 preterm infants and compared it with that of 43 full-term cord vessels. In addition, relations among cord vessel wall fatty acid composition, gestational age (GA) at birth, and anthropometric parameters at birth (weight, head circumference, and length) were explored in the preterm infants. Generally, $n-6$ and $n-3$ EFA levels were lower, while levels of EFA deficiency markers were higher in preterm than in term cords, both in the walls of the draining arteries and the supplying vein. In preterm cords, significant correlations were observed between GA at birth and levels of $n-6$ and $n-3$ EFAS (positive) and EFA deficiency markers (negative). Birth weight showed significant ( $P \leq 0.01)$, positive correlations with n-6 and n-3 EFA levels in the cord artery walls of preterm infants, all after correction for GA at birth. In conclusion, substantial differences between the EFA profiles of preterm and full-tenn cord vessel walls indicate a lower biochemical EFA status of the preterm than of the term fetus. The lower preterm EFA values might be a reflection of a physiologically lower EFA demand for growth and development of the preterm fetus than of the term fetus. 


\subsection{Introduction}

In recent years, nutritional researchers have adopted the essential fatty acid (EFA) profile of umbilical vessel walls as a tool for studying the fetal EFA status. Considering the absence of vasa vasorum for human umbilical vessels and the inability of human tissue to synthesize EFAs de novo, EFAs present in the umbilical vessel walls must have been derived from the blood flowing through them. Consequently, and because of the relatively slow turnover of vessel wall phospholipids (PLS), the EFA composition of the umbilical vein wall PLS can be regarded as a longer-term representation of the EFA supply to the fetus. Similarly, the EFA profile of the umbilical artery wall PLs can be considered a longer-term reflection of the EFA content of the return flow from the fetus to the mother and, as such, an indication of the fetal EFA status.

The first studies that evaluated the EFA content of umbilical vessel walls suggested that the biochemical EFA status of healthy, full-term infants, born after an uncomplicated pregnancy might not be optimal: substantial amounts of Mead acid (20:3n-9) were observed, particularly in the umbilical artery [1-3]. This 20:3n-9 is considered a reliable marker of EFA deficiency [4], since it is synthesized when insufficient amounts of the EFAs $\alpha$-linolenic acid (18:3n-3) and linoleic acid (18:2n-6) are present to occupy the $\Delta 6$-desaturase. In addition, levels of 18:2n-6 were found to be low in umbilical vessel wall PLs when compared to adult colonic vessel wall PLS [2]. Moreover, the PLS of the draining arteries generally contained significantly less long-chain polyunsaturated fatty acids (LCPS, formed from the parent EFAS $18: 2 n-6$ (n-6 LCPS) and 18:3n-3 (n-3 LCPS) through alternate desaturation and elongation) than the wall of the supplying vein $[2,3,5]$. Considering the growing evidence that these LCPS are of essential importance for a normal development of brain and visual function [6-9], a sub-optimal EFA status at birth could have important implications for postnatal life. Besides, cord vessel wall levels of EFAS and their deficiency indicators have been reported to be related to parameters of antenatal growth [10-12; Chapter 7].

So far, all studies regarding the EFA composition of cord vessel walls were carried out in full-term infants, or in infants born after at least 36 weeks of pregnancy [11]: To our knowledge, data on cords of younger preterm infants are not yet available. Therefore, we studied the fatty acid compositions of preterm umbilical artery and vein walls and compared these with the fatty acid profiles of cord vessel walls of a full-term population. In addition, we evaluated relations among preterm cord vessel wall fatty acid composition, gestational age (GA) at birth, and anthropometric parameters at birth (weight, head circumference (HC), and length).

\subsection{Patients and methods}

\subsubsection{Infants}

The total population studied comprised 43 preterm infants (GA: 26-36 weeks, birth weight: $650-1860 \mathrm{~g}$ ) and 43 full-term infants (GA: $37-41$ weeks, birth weight: $2630-4130 \mathrm{~g}$ ). All infants were born in the same period, after a singleton pregnancy. Relevant clinical characteristics of both study populations are listed in table 2.1. GA was confirmed by menstrual history and early ultrasound dating, and by Dubowitz score [13] if the former information 
Table 2.1. Clinical characteristics of study populations (mean \pm SD).

\begin{tabular}{lll}
\hline & preterm infants $(\mathrm{n}=43)$ & full-term infants $(\mathrm{n}=43)$ \\
\hline maternal age (years) & $28.3 \pm 5.6$ & $28.8 \pm 4.9$ \\
primipara $(\mathrm{n})$ & $24(55.8 \%)$ & $35(81.4 \%)^{a}$ \\
gestational age at birth (wks.days) & $31.0 \pm 2.4$ & $40.0 \pm 1.0^{b}$ \\
birth weight $(\mathrm{g})$ & $1412 \pm 321$ & $3288 \pm 348^{b}$ \\
head circumference at birth $(\mathrm{cm})$ & $27.9 \pm 2.6$ & $34.1 \pm 1.3^{b}$ \\
length at birth $(\mathrm{cm})$ & $40.2 \pm 3.1$ & $49.9 \pm 1.9^{b}$ \\
pH umbilical artery blood & $7.22 \pm 0.12$ & $7.23 \pm 0.09$ \\
male : female $(\mathrm{n})$ & $23: 20$ & $26: 17$ \\
\hline
\end{tabular}

Significance level for statistical difference between preterm and term infants:

"chi-square test: $\mathrm{P}=0.01$,

two-tailed Student's. t-test: $\mathrm{P}<0.0005$.

was missing or doubtful. The infants all had a birth weight appropriate for gestational age, that is above the 2.3rd percentile of the Amsterdam growth charts [14], and were free from metabolic disease and congenital malformations. Approximately $15 \mathrm{~cm}$ of umbilical cord was collected from each infant immediately after delivery.

Birth weights were assessed, shortly after delivery, on a calibrated infant scale and recorded to the nearest $5 \mathrm{~g}$. HC and crown-heel length of the term newborns were measured, with a measuring tape, shortly after delivery. For the preterm infants, this was done on the third day of life to reduce the effects of head moulding at birth on $\mathrm{HC}$ and of intra-uterine body position (eg breech position) on length. For the measurement of HC, the measuring tape was placed over the most pronounced parts of the occiput and the forehead. Crownheel length was measured with the infants in supine position. Both measurements were recorded to the nearest millimetre.

The study was approved by the medical ethics committee of the University Hospital of Maastricht and written informed consent was obtained from one or both parents.

\subsubsection{Laboratory analysis}

Umbilical vessel wall samples were prepared and analyzed as described previously [12,15; Chapters 6,7]. At the start of the analysis, approximately $40 \mu \mathrm{g}$ of 1,2-dinonadecanoyl phosphatidylcholine [PC- $(19: 0)_{2}$ ] was added to every sample as an internal standard to quantify fatty acid amounts present in the PL fraction of the umbilical arteries and vein. Absolute fatty acid amounts were expressed as $\mathrm{mg} / \mathrm{kg}$ dry weight of cord vessel wall tissue, relative fatty acid levels as \% (wt/wt) of total fatty acid methylesters.

In total, 26 fatty acids were identified. Since this study focuses on the EFA status, only the following relevant 8 fatty acids and 6 fatty acid combinations are reported: $20: 3 n-9$, dihomo-Mead acid (22:3n-9), 18:2n-6, dihomo- $\gamma$-linolenic acid (20:3n-6), arachidonic acid $(20: 4 n-6)$, adrenic acid $(22: 4 n-6)$, Osbond acid $(22: 5 n-6)$, docosahexaenoic acid (22:6n-3, 
also named cervonic acid), $\Sigma$ SAFA (sum of all saturated fatty acids), $\Sigma$ MUFA (sum of all monounsaturated fatty acids), $\Sigma$ PUFA (sum of all polyunsaturated fatty acids), $\Sigma n-9$ PUFA (sum of all PUFAs of the $n-9$ series), $\Sigma n-6$ LCP (sum of the LCPS of the $n-6$ series, and $\Sigma$ $n-3$ LCP (sum of the LCPS of the $n-3$ series).

In addition, three indices were calculated to describe the functional EFA status. The EFA status index, defined as the ratio of the sum of all fatty acids of the $n-3$ and $n-6$ series to the sum of all fatty acids of the $n-7$ and $n-9$ series $\left(\sum n-3+n-6 / \Sigma n-7+n-9\right)$ [5] was used because a sufficient supply of $n-3$ and $n-6$ fatty acids will limit the desaturation of the nonessentiall $n-7$ and $n-9$ MUFAs to their respective PUFAs. For a similar reason, the classic triene/tetraene ratio (EFA deficiency index, EFADI): 20:3n-9/20:4n-6 [16] was calculated. The cervonic acid deficiency index (CADI), defined as the ratio of $22: 5 n-6$ to its immediate precursor 22:4n-6, was calculated because a shortage of 22:6n-3 (cervonic acid) is accompanied by an increased conversion of $22: 4 n-6$ to $22: 5 n-6$, leading to higher CADI values [17,18].

\subsubsection{Data analysis}

Data are presented as mean \pm standard deviation, unless mentioned otherwise. Fatty acid levels in the umbilical vessel walls of preterm and term infants, as well as continuous clinical variables, were compared using the two-tailed Student's t-test. Discrete clinical variables were compared with the chi-square test.

In the preterm study group, relations among fatty acid levels in the umbilical vessel walls, GA at birth, and anthropometric parameters at birth were explored using linear regression (Pearson correlation coefficients). Significant correlations between the EFA profile of preterm infants and anthropometric parameters at birth were corrected for GA at birth by multiple regression analysis.

In view of the relatively large number of comparisons made, differences with $\mathrm{P}$-values $\leq 0.01$ were considered significant.

\subsection{Results}

\subsubsection{Essential fatty acid profiles of preterm and full-term cord vessel walls}

The total fatty acid concentration ( $\mathrm{mg} / \mathrm{kg}$ dry weight) in the artery wall PLs was significantly higher in the preterm than in the full-term study group (table 2.2.). This was mainly due to higher amounts of MUFAs in the preterm cords. Moreover, the absolute amount of the EFA deficiency marker 20:3n-9 was significantly higher in the preterm cord artery walls. The concentrations of most $n-6$ and $n-3$ PUFAs were significantly lower in the preterm artery PLs, the only exceptions being 18:2n-6 (no significant difference) and the 22:6n-3 deficiency marker 22:5n-6, the concentration of which was higher in preterm artery PLS.

For the non-essential fatty acid concentrations, results obtained in vein wall PLs were comparable with those in the artery walls. For most essential PUFAs, however, the intergroup differences did not reach statistical significance, except for $22: 4 n-6$ (reduced in preterm cords), and $18: 2 n-6$ and $22: 5 n-6$ (both higher in preterm cords). 
Table 2.2. Absolute (mg/kg dry weight) fatty acid compositions of cord vessel wall phospholipids of preterm $(n=43)$ and full-term $(n=43)$ infants (mean \pm SD).

\begin{tabular}{|c|c|c|c|c|}
\hline \multirow[b]{2}{*}{ fatty acid" } & \multicolumn{2}{|l|}{ umbilical artery } & \multicolumn{2}{|l|}{ umbilical vein } \\
\hline & preterm & full-term & preterm & full-term \\
\hline total & $16348 \pm 3242$ & $14722 \pm 2121^{b}$ & $17878 \pm 3317$ & $15330 \pm 2012^{d}$ \\
\hline I SAFA & $7591 \pm 1504$ & $6930 \pm 1024$ & $8438 \pm 1672$ & $7316 \pm 919^{1}$ \\
\hline$\Sigma$ MUFA & $4115 \pm 1108$ & $2768 \pm 567^{d}$ & $3434 \pm 803$ & $2259 \pm 380^{d}$ \\
\hline I PUFA & $4641 \pm 933$ & $5023 \pm 751$ & $6005 \pm 1123$ & $5755 \pm 849$ \\
\hline $20: 3 n-9$ & $562 \pm 162$ & $450 \pm 168^{c}$ & $170 \pm 86$ & $66 \pm 33^{d}$ \\
\hline $22: 3 n-9$ & $239 \pm 105$ & $224 \pm 85$ & $113 \pm 59$ & $55 \pm 25^{d}$ \\
\hline$\sum n-9$ PUFA & $801 \pm 232$ & $674 \pm 247$ & $283 \pm 131$ & $121 \pm 56^{d}$ \\
\hline $18: 2 n-6$ & $171 \pm 94$ & $202 \pm 54$ & $393 \pm 123$ & $306 \pm 79^{d}$ \\
\hline $20: 3 n-6$ & $144 \pm 45$ & $187 \pm 48^{d}$ & $259 \pm 73$ & $270 \pm 72$ \\
\hline $20: 4 n-6$ & $1836 \pm 446$ & $2137 \pm 397^{r}$ & $2866 \pm 591$ & $2871 \pm 441$ \\
\hline $22: 4 n-6$ & $342 \pm 96$ & $446 \pm 110^{d}$ & $615 \pm 177$ & $800 \pm 160^{d}$ \\
\hline $22: 5 n-6$ & $602 \pm 164$ & $483 \pm 103^{d}$ & $652 \pm 220$ & $420 \pm 108^{d}$ \\
\hline$\sum n-6$ & $3151 \pm 715$ & $3519 \pm 614$ & $4950 \pm 1018$ & $4828 \pm 702$ \\
\hline$\sum n-6$ LCP & $2927 \pm 647$ & $3316 \pm 584^{c}$ & $4396 \pm 884$ & $4522 \pm 672$ \\
\hline $22: 6 n-3$ & $689 \pm 186$ & $831 \pm 184^{\circ}$ & $773 \pm 195$ & $805 \pm 182$ \\
\hline$\sum n-3+n-6$ & $3840 \pm 866$ & $4349 \pm 744^{c}$ & $5722 \pm 1140$ & $5633 \pm 834$ \\
\hline$\sum n=3+n-6$ LCP & $3616 \pm 800$ & $4147 \pm 715^{\circ}$ & $5168 \pm 1012$ & $5328 \pm 810$ \\
\hline
\end{tabular}

"SAFA = saturated fatty acids; MUFA $=$ monounsaturated fatty acids; PUFA = polyunsaturated fatty acids; $n-9$ PUFA $=20: 3 n-9,22: 3 n-9 ; n-6=$ fatty acids of the $n-6$ series; $n-6$ LCP $=$ long-chain PUFAs of the $n-6$ series (18$: 3 n-6,20: 3 n-6,20: 4 n-6,22: 4 n-6,22: 5 n-6) ; n-3+n-6=n-6+22: 6 n-3$ and $n-3+n-6$ LCP $=n-6$ LCP+22:6n-3 (no other fatty acids of the $n-3$ series were present in detectable amounts).

Significance level for difference between preterm and full-term infants (two-tailed Student's t-test): ${ }^{b} \mathrm{P}<0.01,{ }^{c} \mathrm{P}<0.005,{ }^{d} \mathrm{P}<0.0005$.

The results for the relative fatty acid levels (\%: (wt/wt), table 2.3.) were grossly comparable with those for absolute amounts, although particularly for the vein wall PLS, more intergroup differences were significant. Again, most $n-6$ and $n-3$ PIFA levels were significantly lower in the preterm than in the term population, the only exception being 22:5n-6, which was significantly higher in the preterm cords.

The EFA status index (ratio of $\sum n-3+n-6$ to $\sum n-7+n-9$ ) was significantly reduced in the preterm cord vessel wall PLs. This observation was confirmed by the EFA deficiency index (EFADI, ratio of 20:3n-9 to 20:4n-6) and the cervonic acid deficiency index (CADI, ratio of $22: 5 n-6$ to $22: 4 n-6$ ), which both were significantly higher in preterm artery and vein walls. 
Table 2.3. relative (weight \%) fatty acid composition of cord. vessel wall phospholipids of preterm ( $n=43$ ) and full-term $(n=43)$ infants (mean \pm SD).

\begin{tabular}{|c|c|c|c|c|}
\hline \multirow[b]{2}{*}{ fatty acid ${ }^{a}$} & \multicolumn{2}{|c|}{ umbilical artery } & \multicolumn{2}{|c|}{ umbilical vein } \\
\hline & preterm & full-term & preterm & full-term \\
\hline$\Sigma$ SAFA & $46.6 \pm 3.5$ & $47.1 \pm 1.3$ & $47.1 \pm 1.6$ & $47.8 \pm 1.7$ \\
\hline$\Sigma$ MUFA & $24.9 \pm 3.3$ & $18.8 \pm 2.3^{d i}$ & $19.2 \pm 2.5$ & $14.7 \pm 1.2^{d}$ \\
\hline$\sum$ PUFA & $28.5 \pm 3.1$ & $34.2 \pm 2.4^{d}$ & $33.7 \pm 2.7$ & $37.5 \pm 1.9^{d}$ \\
\hline $20: 3 n-9$ & $3.43 \pm 0.77$ & $3.05 \pm 1.00$ & $0.96 \pm 0.49$ & $0.43 \pm 0.21^{\alpha}$ \\
\hline $22: 3 n-9$ & $1.47 \pm 0.60$ & $1.51 \pm 0.49$ & $0.64 \pm 0.33$ & $0.36 \pm 0.16^{8}$ \\
\hline$\sum n-9$ PUFA & $4.90 \pm 1.11$ & $4.56 \pm 1.45$ & $1.61 \pm 0.74$ & $0.78 \pm 0.36^{\circ}$ \\
\hline $18: 2 n-6$ & $1.03 \pm 0.45$ & $1.37 \pm 0.31^{d}$ & $2.20 \pm 0.56$ & $2.01 \pm 0.53$ \\
\hline $20: 3 n-6$ & $0.89 \pm 0.23$ & $1.26 \pm 0.24^{d}$ & $1.44 \pm 0.27$ & $1.74 \pm 0.34^{d}$ \\
\hline $20: 4 n-6$ & $11.3 \pm 2.0$ & $14.6 \pm 2.2^{d}$ & $16.1 \pm 2.3$ & $18.7 \pm 1.6^{d}$ \\
\hline $22: 4 n-6$ & $2.13 \pm 0.63$ & $3.04 \pm 0.63^{d}$ & $3.46 \pm 0.79$ & $5.22 \pm 0.80^{\circ}$ \\
\hline $22: 5 n-6$ & $3.69 \pm 0.74$ & $3.29 \pm 0.57^{d}$ & $3.60 \pm 0.89$ & $2.73 \pm 0.63^{d}$ \\
\hline$\Sigma n-6$ & $19.4 \pm 3.0$ & $24.0 \pm 3.0^{d}$ & $27.7 \pm 3.00$ & $31.5 \pm 1.8^{d}$ \\
\hline$\sum n-6 . L C P$ & $18.0 \pm 2.8$ & $22.2 \pm 2.9^{d}$ & $24.6 \pm 2.6$ & $28.4 \pm 1.9^{d}$ \\
\hline $22: 6 n-3$ & $4.24 \pm 0.93$ & $5.64 \pm 0.89^{d}$ & $4.33 \pm 0.87$ & $5.23 \pm 0.84^{d}$ \\
\hline$\sum n-3+n-6$ & $23.6 \pm 3.7$ & $291.6 \pm 3.3^{d^{d}}$ & $32.1 \pm 3.2$ & $36,7 \pm 2.0^{d}$ \\
\hline$\sum n-3+n-6$ LCP & $22.3 \pm 3.5$ & $27.8 \pm 3.3^{d}$ & $29.0 \pm 2.9$ & $33.7 \pm 2.2^{d}$ \\
\hline EFA status & $0.82 \pm 0.21$ & $1.32 \pm 0.35^{d}$ & $1.60 \pm 0.39$ & $2.40 \pm 0.31^{d}$ \\
\hline EFADI & $0.32 \pm 0.10$ & $0.22 \pm 0.10^{d}$ & $0.06 \pm 0.04$ & $0.02 \pm 0.01^{d}$ \\
\hline CADI & $1.86 \pm 0.62$ & $1.12 \pm 0.27^{d}$ & $1.13 \pm 0.49$ & $0.54 \pm 0.17^{d}$ \\
\hline
\end{tabular}

Legend as in table 2.2. In addition:

"EFAstatus $=$ essential fatty acid status: $\left(\sum n-3+n-6\right) /\left(\sum n-7+n-9\right)$; EFADI= EFA deficiency index: $20: 4 n-6 / 20-$ $: 3 n-9 ; \mathrm{CADI}=$ cervonic acid $(22: 6 n-3)$ deficiency index $: 22: 5 n-6 / 22: 4 n-6$.

\subsubsection{Relation between essential fatty acid profiles of preterm cord vessel walls and gestational age at birth}

For the majority of the fatty acids or combinations of fatty acids reported, relative levels in the artery and vein wall PLS were found to be significantly related to GA at birth. In general, arterial and venous levels of fatty acids of the $n-6$ series increased with advancing $\mathrm{GA}(\mathrm{P}<0.0005)$, with the exception of $22: 5 n-6$ levels, which were negatively correlated with $\mathrm{GA}$ at birth $(\mathrm{P}<0.0005)$. Venous levels of the EFA. deficiency-indicating $n-9$ PUFAs generally decreased with advancing GA $(P<0.005)$. Similar relations were observed for absolute amounts, but these reached significance for only a limited number of fatty acids. 
The three indices calculated confirmed the changes observed for the individual fatty acids, with the EFADI $(\mathrm{P}<0.0005)$ and $\mathrm{CADI}(\mathrm{P}<0.001)$ decreasing and the EFA status index $(\mathrm{P}<0.0005)$ increasing with advancing $G A$, both in arterial and venous cord vessel walls.

\subsubsection{Relation between essential fatty acid profiles of preterm cord vessel walls and prenatal growth}

Information on birth weight was available for all preterm infants. Data on HC and length were not available for eight and seven preterm infants, respectively. Partial correlation coefficients for significant relations between the EFA profile measured in preterm cord vessel walls and the anthropometric parameters, all corrected for GA at birth, are given in table 2.4. In all cases, a significant positive relation was observed between GA at birth and the anthropometric parameter.

Birth weight was positively correlated to arterial concentrations of both $n-6$ and $n-3$ LCPS. Length at birth was positively correlated to the arterial concentration of $22: 6 n-3$. No significant correlations were observed between the venous EFA content and any of the anthropometric parameters.

\subsection{Discussion}

This study demonstrates that the EFA status measured in arterial and venous cord vessel wall PLS of preterm infants is considerably different from that measured in cord vessel walls of full-term newborns (tahles 2.2. and 2.3.). The n-6 and n-3 L.CP contents of preterm cords were significantly lower than those of term cords, while values for EFA deficiency markers, such as $20: 3 n-9,22: 5 n-6$, EFADI $(20: 3 n-9 / 20: 4 n-6)$ and CADI $(22: 5 n-6 / 22: 4 n-6)$ were significantly higher in preterm than in term cords. In both study groups, most differences between arterial and venous fatty acid values were significantly different from zero (data not shown) and their directions were comparable to those observed in earlier studies in full-term cord vessel walls $[2,3,5]$.

Based on the observations in arterial vessel wall PLs (indicating the fetal EFA status) the biochemical EFA status of downstream preterm fetal tissue is substantially lower than that of the term fetus. However, the EFA supply to the preterm fetus, as reflected by the relative EFA contents of the umbilical vein, is lower as well. For a proper interpretation of these findings, it is important to realize that, in this study, cord fatty acid profiles were found to be related to GA at birth. These relations were explored in the preterm study group only, because the range of GA at birth in the term population (4 weeks, compared with 10 weeks of the preterm cords) was considered too small to detect the potential correlations with EFA status. Data from both study groups were not combined to avoid spurious correlations. With advancing GA, the EFA content increased, while values for EFA deficiency markers decreased, which is in accordance with the differences observed between mean fatty acid values in preterm and term cords. In fact, when correcting the inter-group differences for $\mathrm{GA}$ at birth, many were no longer significant, which indicates that differences between the EFA profiles of preterm and term cords can, at least partly, be explained by the relations existing between fatty acid levels and GA at birth. 
Table 2.4. Correlations, $(\mathrm{P}<0.05)$ between fatty acid content of cord vessel walls and parameters of prenatal growth in preterm infants.

\begin{tabular}{|c|c|c|c|}
\hline & Fatty acid" & partial $r^{b}$ & $\mathrm{P}_{2}$-value ${ }^{c}$ \\
\hline \multicolumn{4}{|l|}{ birth weight $(n=43)$} \\
\hline \multirow[t]{7}{*}{ umbilical artery (mg/kg dry wt) } & $20: 4 n-6$ & +334 & $0.03^{c}$ \\
\hline & $22: 4 n-6$ & +.379 & $0.01^{d}$ \\
\hline & $\sum n-6$ & +.358 & $0.02^{r}$ \\
\hline & $\sum n-6$ LCP & +362 & $0.02^{e}$ \\
\hline & $22: 6 n-3$ & +.470 & $0.002^{*}$ \\
\hline & $\sum n-3+n-6$ & +.397 & $0.01^{e}$ \\
\hline & $\sum n-3+w-6, L C P$ & +.402 & $0.008^{e}$ \\
\hline umbilical artery (wt \%) & $22: 6 n-3$ & +.364 & $0.02^{d}$ \\
\hline \multicolumn{4}{|l|}{ head circumference at birth $(n=35)$} \\
\hline umbilical artery (mg/kg dry wt) & $22: 4 n-6$ & +.398 & $0.02^{e}$ \\
\hline \multicolumn{4}{|l|}{ iength at birth $(\mathrm{n}=36)$} \\
\hline \multirow[t]{2}{*}{ umbilical artery (mg/kg dry wt) } & $22: 6 n-3$ & +.448 & $0.007^{t}$ \\
\hline & $\sum n-3+n-6$ LCP & +.384 & $0.02^{e}$ \\
\hline umbilical artery (wi \%) & $22: 6 n-3$ & +378 & $0.03^{d}$ \\
\hline
\end{tabular}

aSee table 2.2 .

${ }^{b}$ Regression equation calculated:

anihropometric parameter $=\mathrm{A}+\mathrm{B}_{1}{ }^{*}$ fatty acid level in vessel wall $+\mathrm{B}_{2}{ }^{*} \mathrm{GA}$ at birth.

'Significant correlations (PSO.01) are in bold face.

Significant positive correlation between anthropometric parameter and gestational age at birth:

${ }^{d} \mathrm{P}_{2} \leq 0.001, \mathrm{P}_{2} \leq 0.0001$.

The significant, positive correlations found for arterial and venous EFA levels with GA at birth, could be considered a reflection of the maternal response (increased supply) to the increasing fetal demands for these fatty acids, necessary for brain and body growth, during the last trimester of pregnancy. Increasing $n-3$ EFA levels with increasing pregnancy duration are also in line with the hypothesis of Olsen and co-workers [19] that a higher maternal dietary n-3 intake, resulting in increased circulating n-3 LCP levels, might prolong gestation through a down-regulation of the formation of dienoic prostaglandins involved in the triggering of parturition; they found this view supported by the results of a recent intervention study [20]. On the other hand, van Houwelingen and co-workers [21; Chapter 
3] observed a significant positive correlation between plasma $n-3$ levels and $\mathrm{GA}$ in samples obtained through fetal blood sampling during continuing pregnancies.

The decreasing values of EFA deficiency markers (n-9 PUFAs, 22:5n-6, EFADI, CADI) found with advancing GA might suggest an increasing adequacy of the EFA supply towards term. However, interpreting the EFA compositions of umbilical cord vessel walls on the basis of biochemical relations in adult material has been the subject of debate. For example, Sanders and Reddy [22] recently postulated that the presence of 20:3n-9 in cord artery walls may not reflect an EFA deficiency, but rather a high activity of the conversion system (overactive $\Delta 6$-desaturase) in the arterial wall. A. number of observations in this and other studies, however, are not in line with this hypothesis. Firstly, the information available on fetal fatty acid biochemistry indicates that the desaturase activity in fetal liver microsomes is low [23], and that in (fetal) placental tissue is low [24] or even not detectable [23,25]. Secondly, the higher 20:3n-9 content of preterm than of full-term cord vessels would indicate a decreasing activity of the fatty acid desaturation system during progressing pregnancy. However, microsomal synthesis of LCPs was shown to increase with advancing $\mathrm{GA}$ in piglet liver and brain [26]. Finally, in case of a highly active desaturase system, the conversion of oleic acid (18:1n-9) to 20:3n-9 would be accompanied by the conversion of $18: 2 n-6$ and $18: 3 n-3$ to their LCPs, leading to higher amounts of $n-9$ as well as $n-6$ and $n-3$ longer-chain derivatives. However, when relating cord levels of $20: 3 n-9$ to those of $20: 4 n-6$ (major n-6 LCP), significant negative correlations between these two fatty acids were observed both in our preterm (artery: $r=-0.45, P=0.002$; vein: $r=-0.63, P<0.0005$ ) and in our full-term (artery: $r=-0.79, \mathrm{P}<0.0005$ ) study populations.

The results of the present study suggest that the apparently lower EFA. status of the preterm litus when compared to the term fetus is, at least partly, related to the earlier stage of body and brain growth and development of the preterm infant, and the lower EFA demands that are associated with this phase. Yet, in view of the importance of LCPs for normal brain and visual development [6-9], the lower EFA and LCP status in preterm infants, as observed in the present study deserves to be further explored. This is the more so since, recently, a lower neonatal $20: 4 n-6$ and $22: 6 n-3$ status at preterm delivery was demonstrated to result in a lower postnatal $20: 4 n-6$ and $22: 6 n-3$ status, irrespective of the type of the postnatal diet (human milk which contains LCPS, or a conventional artificial formula which lacks LCPS) [12; Chapter 7].

An additional objective of the present study was to explore the relations between the overall EFA profile of preterm arterial and venous cord vessel walls and parameters of prenatal growth. After correction for GA at birth, arterial concentrations of both $n-3$ and $n-6$ LCPS were found to be positively related to birth weight, while the arterial $22: 6 n-3$ concentration was positively related to length at birth as well. These findings are supported by a number of positive relations between $n-6$ and n-3 LCPS and weight, HC, or length at birth which tended to be significant (table 2.4.: $P<0.02$ or 0.03 ; significance level was set at $\mathrm{P} \leq 0.01$ ), and illustrate the importance of LCPS for proper antenatal growth. The fatty acid composition of the PLS of the supplying vein was unrelated to any of the parameters of prenatal growth. This could indicate that varying arnounts of the supplied EFAs are used as 'building bricks' for structural growth. 
A few other studies have addressed the potential relations between the EFA status measured in umbilical vessel walls and parameters of prenatal growth. Felton and coworkers [11] reported significant correlations with growth of both arterial and venous $n-6$ and $n-3$ fatty acid levels. Crawford and co-workers [10] stressed the importance of the highly significant correlations they observed for the EFADI and the CADI measured in the umbilical artery wall with both weight and HC at birth. However, the above-mentioned correlations: were: reported without mentioning a correction for GA at birth. This correction proved to be of substantial influence on the relations observed in our study population: strong correlations between prenatal growth and deficiency indicators as well as venous fatty acid levels were completely attributable to $\mathrm{GA}$ at birth.

In conclusion, we report substantial differences between the EFA profiles of preterm and full-term cord vessel walls, indicating a lower biochemical EFA status in the preterm than in the term fetus. In addition, the EFA composition of preterm cord vessel walls was found to be related to GA at birth as well as to parameters of prenatal growth. The lower preterm EFA values could very well be a reflection of a physiologically lower demand for EFAs, necessary for growth and development, of the preterm fetus when compared to the term fetus.

\subsection{Acknowledgements}

The authors wish to express their appreciation for the skilled assistance obtained from Mrs. M. M. G. Simonis (fatty acid analyses of umbilical vessel wall samples). They gratefully acknowledge the help obtained from the medical and nursing personnel of the departments of Obstetrics of the University Hospital Maastricht, the School for Midwifery in Kerkrade and the De Wever Hospital in Heerlen, The Netherlands (collection of umbilical cords). They also thank all parents for their co-operation.

\subsection{References}

1. Ongari MA, Rittei JM, Orchard MA, Waddell KA, Blair IA, Lewis PJ Correlation of prostacyclin synthesis by human umbilical artery with status of essential fatty acid. Am J Obstet Gynecol 1984;149:455-60.

2. Homstra G, Houwelingen AC v, Simonis M. Gerrard JM. Fatty acid composition of umbilical atteries and veins: possible implications for the fetal EFA-status. Lipids 1989;24:51 1-7.

3. Al MDM. Homsira G, van der Schouw YT, Bulstia-Ramakers MTEW, Huisjes HJ. Biochemical EFA status of mothers and their neonates after normal pregnancy. Early Hum Dev 1990;24:23948 .

4. Mead JF. The metabolism of the polyunsaturated fatty acids. Prog Chem Fats Other Lipids. 1970:9:159-92.

5. Hornstra G. Al MDM. Gerrard JM. Simonis MMG. Essential fatty acid status of neonates born to Inuit mothers: comparison with Caucasian neonates and effect of diet. Prostaglandins Leukotrienes and Essent Fatty Acids 1992;45:125-30.

6. Uauy RD, Birch DG, Birch EE, Tyson JE, Hoffman DR. Effect of dietary omega-3 fatty acids on retinal function of very-low-birth-weight neonates. Pediatr Res 1990;28:485-92. 
7. Birch E, Birch D, Hoffman D, Hale L, Everett M, Uauy R. Breast-feeding and optimal visual development. J Pediatr Ophthalmol Strabismus 1993;30:33-8.

8. Carlson SE, Werkman SH, Rhodes PG, Tolley EA. Visual-acuity development in healthy preterm infants: effect of marine-oil supplementation. Am I Clin Nutr 1993;58:35-42.

9. Makrides M, Simmer K, Goggin M, Gibson RA. Erythrocyte docosahexaenoic acid correlates with the visual response of healthy term infants. Pediatr Res 1993;33:425-7.

10. Crawford MA, Costeloe K, Doyle W, Leighfield MJ, Lennon EA, Meadows N. Potential diagnostic value of the umbilical artery as a definition of neural fatty acid status of the fetus during its growth: the umbilical artery as a diagnostic tool. Biochem Soc Trans 1990;18:761-6.

11. Felton CV. Chang TC, Crook D, Marsh M, Robson SC, Spencer JAD. Umbilical vessel wall fatty acids after normal and retarded fetal growth. Arch Disease Child 1994;70:F36-9.

12. Foreman-v Drongelen MMHP, Houwelingen AC v, Kester ADM, Hasaart THM, Blanco CE, Hornstra G. Long-chain polyunsaturated fatty acids in preterm infants: status at birth and its influence on postnatal levels. J Pediatr 1995;126:611-8.

13. Dubowitz LMS, Dubowitz V, Goldberg C. Clinical assessment of gestational age in the newborn infant. J Pediatr 1970;77:1-10.

14. Kloosterman GJ. On intrauterine growth, the significance of prenatal care. Int J Gynaccol Obstet 1970;8:895-912.

15. Foreman-v Drongelen MMHP, Houwelingen AC v, Kester ADM, de Jong AEP, Blanco CE, Hasaart THM, Hornstra G. Long-chain polyene status of preterm infants with regard to the fatty acid composition of their diet: comparison between absolute and relative fatty acid levels in plasma and erythrocyte phospholipids. Br J Nutr 1995;73:405-22.

16. Holman RT. The ratio of trienoic:tetraenoic acids in tissue lipids as a measure of essential latty acid requirement. J Nutr 1960;70:405-10.

17. Holman RT. The deficiency of essential fatty acids. In: Kunau W. Holman RT, eds. Polyunsaturated fatty acids. Champaign (IL): Am Oil Chem Soc 1977;4:163-82.

18. Neuringer M, Connor WE, Lin DS, Barstad L. Luck S. Biochemical and functional effects of prenatal and postnatal $w 3$ fatty acid deficiency on retina and brain in rhesus monkeys. Proc Natl Acad Sci USA 1986;83:4021-5.

19. Olsen SF, Hansen HS, Sørensen TIA, Jensen B, Secher NJ, Sommer S. Knudsen LB. Intake of marine fat, rich in (n-3)-polyunsalurated fatty acids, may increase birth weight by prolonging gestation. Lancet 1986;ii:367-9.

20. Olsen SF, Dalby Sørensen J, Secher NJ, Hedegaard M, Brink Henriksen T, Hansen HS, Grant A. Randomised controlled trial of effect of fish-oil supplementation on pregnancy duration. Lancet 1992:339:1003-7.

21. Houwelingen AC v, Foreman-v Drongelen MMHP, Al MDM, Hornstra G, Niculini U. Fetal essential fatty acid status during gestation. Am J Clin Nutí 1993;57:815S.

22. Sanders $T A B$, Reddy $S$. The influence of a vegetarian diet on the fatty acid composition of human milk and the essential fatty acid status of the infant. J Pediat 1992;120.71-7S.

23. Chambaz J, Ravel D, Manier M-C, Pepin D, Mulliez N, Eereziat G. Essential fatty acid interconversion in the human fetal liver. Biol Neonate 1985;47:136-40.

24. Zimmerman T, Winkler L, Mö!ler U, Schubert H, Goetze E. Synthesis of arachidonic acid in the human placenta. Biol Neonate 1979;35:209-12.

25. Booth C, Elphick MC, Hendrickse W. Hul! D. Investigation of $\left[{ }^{14} \mathrm{C}\right]$ linoleic acid conversion into $\left.{ }^{14} \mathrm{C}\right]$ arachidonic acid and placental transfer of linoleic and palmitic acids across the perfused human placenta. J Dev Physiol 1981:3:177-89.

26. Clandinin MT, Wong C, Hacker RR. Synthesis of chain-desaturation products of linoleic acid by liver and brain microsomes during development of the pig. Biochem J 1985:226:305-9. 



\title{
Essential fatty acid profile of fetal plasma phospholipids; comparison with postnatal values obtained at comparable gestational ages.
}

\author{
Adriana C. v. Houwelingen', Magritha M.H.P. Foreman-v. Drongelen', \\ Umberto Nicolini ${ }^{3}$, Kypros H. Nicolaides ${ }^{4}$, Monique D.M. Al ${ }^{1}$, Arnold D.M. \\ Kester $^{2}$, Gerard Hornstra ${ }^{1}$. \\ 'Department of Human Biology and ${ }^{2}$ Department of Methodology and Statistics, \\ University of Limburg, Maastricht, The Netherlands \\ ${ }^{3}$ Clinica Obstetrico-Ginecologica dell' Universita' di Milano, Italy \\ "Harris Birthright Research Centre for Fetal Medicine, Kings College Hospital, London, \\ U.K.
}

Based on paper accepted for publication. in Early Human Development

\subsection{Abstract}

Hardly any direct information is available on the EFA status of the fetus during intrauterine development. Therefore, we studied 86 umbilical plasma samples obtained by transabdominal puncture during ongoing pregnancies (gestational age (GA): 18-39 weeks). These were compared with 51 samples of umbilical cord blood that were collected immediately after birth (GA: 28-39 weeks). The total amount (mg/i) of fatty acids in fetal plasma phospholipids (PLS) did not change during gestation. The relative level (weight $\%$ ) of linoleic acid $(18: 2 n-6)$ showed a slight increase $(P<0.05)$ during fetal maturation. Values for arachidonic acid $(20: 4 n-6)$ decreased $(P<0.0001)$, while those for docosahexaenoic acid $(22: 6 n-3)$ increased (mg/l: $\mathrm{P}<0.005, \%: \mathrm{P}<0.0001$ ) when pregnancy progressed. The overall EFA status increased, but the functional 22:6n-3 status appeared to decline with advancing GA. The EFA profiles of fetal samples were generally comparable with postnatal results of infants born at similar CiAs. However, the 18:2n-6 status of the fetus was lower than that of the neonate. The same was true for the overall EFA status. The results of this study indicate that the low EFA values observed in preterm infants at birth, are a developmentally related phenomenon. 


\subsection{Introduction}

Fetal development is associated with a high demand for essential fatty acids (EFAs), but the development of each organ system follows a specific course in time and, consequently, the fetal demand is not necessarily constant throughout pregnancy. Brain and retina are very rich in EFAs, and a sufficient supply of these fatty acids during pregnancy and the neonatal period is of great importance. Data in primates show that an insufficient amount of $n-3$ fatty acids at a critical stage in brain and retinal development results in a long term impairment of brain and retinal function $[1,2]$. Studies in human infants have observed the same phenomenon $[3,4]$.

Hardly any direct information is available with respect to the EFA status of the fetus during its development in utero. Some data are available on the fatty acid composition of fetal tissue obtained via elective abortion during the first trimester of pregnancy [5]. So far, the fetal EFA status has mainly been assessed in materials collected after birth [6-9]. These studies have shown that the EFA status in plasma PLS of normal neonates is different from that of adults. This applies to linoleic acid (18:2n-6, lower), arachidonic acid (20:4n-6: relative levels higher " absolute amounts lower) and docosahexaenoic acid (22:6n-3, also called cervonic acid: relative levels higher) in particular [6,7]. Data on the fatty acid composition at birth are also available for preterm neonates $[8,10$; Chapter 2]: EFA values are lower in preterm than in full-term infants. It is unknown, however, whether the results in materials collected after delivery are comparable to fetal plasma fatty acid compositions during ongoing pregnancies at similar GAs.

Therefore, in this study the EFA profile of umbilical plasma samples obtained by fetal blood sampling, was compared to the EFA profile of umbilical plasma samples obtained immediately after birth at comparable GAs. The fatty acid composition of the plasma PL fraction was analyzed, because PLS are the richest source of polyunsaturated fatty acids (PUFAS), including EFAs, and changes in the PUFA profile are most pronounced in the PLS [11], making them the preferable plasma lipid parameter. To our knowledge this is the first time that the fatty acid compositions of prenatal blood samples are reported as absolute amounts.

\subsection{Patients and methods}

\subsubsection{Study population}

The study population consisted of pregnant women referred to the participating centres for fetal blood sampling because of fetal karyotyping or expected pregnancy complications. Oniy singleton pregnancies were included. Blood sampling of the fetal umbilical vein was performed by transabdominal puncture under ultrasound guidance without maternal fasting or sedation. About $1 \mathrm{ml}$ of fetal blood was collected in an EDTA-containing tube.

Eighty six blood samples were obtained through fetal blood sampling during pregnancy (range 18-39 completed weeks of gestation) among which 10 samples were taken at elective caesarean sections performed at term (37-39 weeks). In 55 women we were able to collect a maternal blood sample from an antecubitall vein at the same time the fetal blood sampling was performed. 
For comparison, 51 postnatal blood samples were taken from the umbilical vein, 34 immediately after preterm childbirth (GAs ranging from 28 to 36 completed weeks of gestation) and 17 immediately after term childbirth (GAs comparable to those of the caesarean sections). The study was approved by the local Medical Ethics Committees. All participating women gave their written informed consent.

\subsubsection{Fatty acid analysis}

After separation from the red blood cells by centrifugation, the plasma samples were kept in tubes closed under nitrogen, and stored at $-80^{\circ} \mathrm{C}$ until transportation to Maastricht for analysis. The EFA status was studied by determining the absolute (mg/) and relative ( $\%$ (wt/wt) of total fatty acids) fatty acid composition of plasma PLs as described before [7]. At the start of the analysis, approximately $40 \mu \mathrm{g}$ of 1,2-dinonadecanoyl phosphatidylcholine [PC $\left.(19: 0)_{2}\right]$ was added to every sample as an internal standard for quantification of the absolute amounts of fatty acids present.

Three indices were calculated to describe the functional EFA status. The overall EFA status, or EFA status index, defined as the sum of all n-6 and n-3 (essential) fatty acids divided by the sum of all $n-7$ and $n-9$ (non essential) fatty acids, was used because a sufficient supply of EFAs will limit the desaturation of the non EFAs [9]. The cervonic acid sufficiency index. (CASI=22:6n-3/Osbond acid, 22:5n-6) was calculated, because a shortage of $22: 6 n-3$ is accompanied by an increased conversion of adrenic acid (22:4n-6) to $22: 5 n-6$, leading to lower CASI values. Moreover, we calculated the cervonic acid deficiency index ( $\mathrm{CADI}=22: 5 n-6 / 22: 4 n-6$ ), because the amount of $22: 5 n-6$ also depends on the amount of its precursor $22: 4 n-6[2,12]$.

\subsubsection{Data analysis}

Results of the fatty acid composition of the fetal plasma samples are presented as mean \pm standard deviation, after classification into five groups on the basis of increasing GA. Changes in the fetal fatty acid levels during gestation were evaluated using multiple regression analysis, to correct for the possible influence of the centre at which the blood was collected. Maternal values were related to the values of their fetus by linear regression (Pearson correlation coefficients). Multiple regression analysis was also used to compare the plasma samples taken before birth (fetal samples, only GA 28.39 weeks, $n=36$ ) and umbilical plasma samples taken directly after birth (postnatal values, GA 28-39 weeks, $n=51$ ), with correction for GA at the time of blood collection.

P-values $<0.05$ were considered significant.

\subsection{Results}

\subsubsection{Fatty acid changes in fetal plasma samples during pregnancy}

Absolute and relative fatty acid compositions of plasma PLS, isolated from fetal blood samples taken during ongoing pregnancies are given in table 3.1. The total amount of PL-associated fatty acids in plasma did not change during gestation. The same was observed for the absolute amount of 18:2n-6. The relative amount of 18:2n-6 showed a slight increase $(\mathrm{P}<0.05)$ during gestation. Absolute and relative amounts of $20: 4 n-6$ and eicosa- 
Table 3.1. Fatty acid composition (mean \pm SD) of fetal plasma phospholipids obtained by transabdominal puncture during ongoing pregnancies (except for 37-39 weeks gestational age (GA): obtained during elective caesarean sections).

\begin{tabular}{|c|c|c|c|c|c|c|}
\hline & fatty acid ${ }^{a}$ & $\begin{array}{c}18-22 \text { wks } \\
(n=36)\end{array}$ & $\begin{array}{c}23-27 \text { wks } \\
(n=14)\end{array}$ & $\begin{array}{c}28-32 \text { wks GA } \\
(n=13)\end{array}$ & $\begin{array}{c}33-36 \text { wks GA } \\
(n=13)\end{array}$ & $\begin{array}{c}37-39 \text { wks GA } \\
(n=10)\end{array}$ \\
\hline \multirow[t]{12}{*}{$\mathrm{mg} / \mathrm{l}$} & total & $573 \pm[41$ & $524 \pm 70$ & $608 \pm 187$ & $479 \pm 236$ & $586 \pm 106$ \\
\hline & $\Sigma$ SAFA & $252 \pm 64$ & $237 \pm 28$ & $281 \pm 86$ & $222 \pm 106$ & $279 \pm 52$ \\
\hline & $\Sigma$ MUFA & $104 \pm 36$ & $89 \pm 25$ & $109 \pm 40$ & $76 \pm .45$ & $83 \pm 18^{b}$ \\
\hline & $20: 3 n-9$ & $4.7 \pm 2.0$ & $4.8 \pm 1.9$ & $6.4 \pm 5.4$ & $4.7 \pm 2.3$ & $5.6 \pm 1.7$ \\
\hline & $18: 2 n-6$ & $35 \pm 11$ & $32.6 \pm 6.5$ & $44 \pm 22$ & $39 \pm 23$ & $41 \pm 12$ \\
\hline & $20: 4 n-6$ & $120 \pm 27$ & $110 \pm 11$ & $103 \pm 38$ & $82 \pm 39$ & $94 \pm 19^{\prime}$ \\
\hline & $22: 5 n-6$ & $2.0 \pm 1.1$ & $1.89 \pm 0.71$ & $3.3 \pm 1.5$ & $3.2 \pm 2.4$ & $3.9 \pm 1.2^{f}$ \\
\hline & $\sum n-6$ & $181 \pm 38$ & $169 \pm 19$ & $182 \pm 71$ & $153 \pm 75$ & $175 \pm 39$ \\
\hline & $\Sigma n-6 . L C P$ & $143 \pm 30$ & $133 \pm 13$ & $133 \pm 49$ & $109 \pm 52$ & $129 \pm 26^{b}$ \\
\hline & $20: 5 n-3$ & $2.6 \pm 1.9$ & $1.53 \pm 0.82$ & $1.42 \pm 0.87$ & $0.94 \pm 0.94$ & $2.0 \pm \mathrm{i} \cdot 1^{c}$ \\
\hline & $22: 6 n-3$ & $21.4 \pm 5.9$ & $20.3 \pm 3.6$ & $23 \pm 11$ & $19 \pm 10$ & $34.5 \pm 5.7^{d}$ \\
\hline & $\sum n-3$ LCP & $25.9 \pm 7.3$ & $23.2 \pm 4.0$ & $26 \pm 12$ & $22 \pm 12$ & $39.3 \pm 6.7^{b}$ \\
\hline \multirow[t]{14}{*}{ wt \% } & $\Sigma$ SAFA & $44.1 \pm 2.0$ & $45.2 \pm 1.2$ & $46.5 \pm 2.6$ & $46.7 \pm 2.5$ & $47.6 \pm 1.9^{\prime}$ \\
\hline & $\Sigma$ MUFA & $17.9 \pm 2.7$ & $16.6 \pm 2.6$ & $18.8 \pm 6.1$ & $15.8 \pm 2.8$ & $14.0 \pm 1.5^{d}$ \\
\hline & $20: 3 n-9$ & $0.81 \pm 0.28$ & $0.90 \pm 0.32$ & $1.10 \pm 0.83$ & $1.11 \pm 0.50$ & $1.0 \pm 3.0$ \\
\hline & $18: 2 n-6$ & $6.2 \pm 1.3$ & $6.20 \pm 0.87$ & $6.6 \pm 2.4$ & $7.9 \pm 1.4$ & $6.8 \pm 1.2^{b}$ \\
\hline & $20: 4 n-6$ & $21.1 \pm 2.2$ & $21.1 \pm 1.3$ & $16.6 \pm 3.6$ & $16.8 \pm 2.2$ & $16.0 \pm 1.3^{\prime}$ \\
\hline & $22: 5 n-6$ & $0.35 \pm 0.18$ & $0.36 \pm 0.12$ & $0.61 \pm 0.33$ & $0.73 \pm 0.39$ & $0.67 \pm 0.19^{\prime}$ \\
\hline & $\sum n-6$ & $31.8 \pm 2.6$ & $32.3 \pm 1.6$ & $28.8 \pm 6.3$ & $31.7 \pm 2.4$ & $29.7 \pm 2.9$ \\
\hline & $\sum n-6 . \mathrm{LCP}$ & $25.4 \pm 2.1$ & $25.9 \pm 1.5$ & $21.8 \pm 4.2$ & $23.4 \pm 2.1$ & $22.5 \pm 2.2^{e}$ \\
\hline & $20: 5 n-3$ & $0.43 \pm 0.26$ & $0.30 \pm 0.16$ & $0.20 \pm 0.12$ & $0.18 \pm 0.12$ & $0.34 \pm 0.20^{d}$ \\
\hline & $22: 6 n-3$ & $3.75 \pm 0.59$ & $3.90 \pm 0.74$ & $3.6 \pm 1.1$ & $4.00 \pm 0.50$ & $6.0 \pm 1.4$ \\
\hline & $\Sigma n-3$ LCP & $4.54 \pm 0.65$ & $4.46 \pm 0.82$ & $4.1 \pm 1.2$ & $4.47 \pm 0.61$ & $6.9 \pm 1.6^{\prime}$ \\
\hline & EFA status & $2.09 \pm 0.41$ & $2.27 \pm 0.43$ & $1.98 \pm 0.80$ & $2.36 \pm 0.47$ & $2.64 \pm 0.42^{d}$ \\
\hline & CADI & $0.93 \pm 0.44$ & $0.83 \pm 0.24$ & $1.11 \pm 0.55$ & $1.27 \pm 0.51$ & $1.05 \pm 0.29^{b}$ \\
\hline & CASI & $12.8 \pm 5.5$ & $11.7 \pm 4.5$ & $8.4 \pm 5.5$ & $7.3 \pm 4.1$ & $9.8^{\prime} \pm 3.8^{\circ}$ \\
\hline
\end{tabular}

${ }^{a}$ SAFA $=$ saturated fatty acids; MUFA = monounsaturated fatty acids; $n-6=$ fatty acids of the $n-6$ series; $n-6$ LCP= longchain polyunsaturated fatty acids (PUFAs) of the $n-6$ series $(18: 3 n-6,20: 3 n-6,20: 4 n-6,22: 4 n-6,22: 5 n-6) ; n-3$ LCP= long-chain PUFAs of the $n-3$ series $(20: 4 n-3,20: 5 n-3,22: 6 n-3)$ : EFA status= essential fatty acid status: $\left(\sum n-3+n-\right.$ $6) /(2 n-7+n-9) ;$ EFADI $=$ EFA deficiency index: $20: 4 n-6 / 20: 3 n-9 ; C A D I=$ cervonic acid $(22: 6 n-3)$ deficiency index: $22: 5 n-6 / 22: 4 n-6 ; \mathrm{CASI}=$ cervonic acid sufficiency index: $22: 6 n-3 / 22: 5 n-6$.

Significeance level for relation between fatty acid value and gestational age at blood collection, corrected for influeree of participating centre by multiple regression analysis:

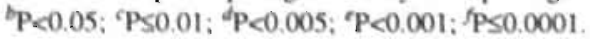


pentaenoic acid (20:5n-3) decreased with fetal maturation (table 3.1.). Absolute and relative amounts of 22:6n-3 increased with increasing GA. ( $\mathrm{P}<0.005$, and $\mathrm{P}<0.0001$ respectively).

The contents of $22: 5 n-6$, which is a deficiency indicator for $22: 6 n-3$, as well as values for the CADI increased $(\mathrm{P}<0.0001$, and $\mathrm{P}<0.05$, respectively), whereas the CASI decreased $(\mathrm{P}<0.001)$ during gestation. The overall EFA status in fetal plasma PLs increased with increasing pregnancy duration $(\mathrm{P}<0.005)$.

\subsubsection{Relation of maternal plasima fatty acid values with the values of their fetus}

The average fatty acid composition of the maternal plasma samples is given in table 3.2 . Hardly any significant relations were found between the maternal fatty acids in plasma PLs and GA at blood collection. For most fatty acids, relative maternal levels were significantly and positively correlated with the corresponding fetal values. For the absolute amounts, hardly any significant relations between maternal and fetal fatty acid values were found.

\subsubsection{Comparison between fetal and postnatal plasma fatty acid values}

When comparing the values of fetal plasma samples collected at GAs of 28-39 weeks $(n=36$, table 3.1.) with postnatal results of infants, born at similar GAs ( $n=51$, table: 3.3.), no significant differences were observed for the total amount of PL-associated fatty acids. The same applied to most of the absolute amounts of the individual EFAs. The absolute $(\mathrm{P}<0.05)$ and relative $(\mathrm{P}<0.0001)$ 18:2n-6 levels in fetal plasma were lower than those in umbilical plasma of postnatal samples. Relative levels of $n-6$ fatty acids were lower $(\mathrm{P}<0.005)$ in fetal plasma and the values for the indicator of a general EFA deficiency, Mead acid (20:3n-9) were higher in fetal than in postnatal plasma $(\mathrm{mg} / 1$ : $P<0.05$, and $\%$ (wt/wt): $P<0.001$ ). In addition, the overall fetal EFA status was slightly lower $(\mathrm{P}<0.05)$ in fetal plasma than in postnatal plasma.

\subsection{Discussion}

The main findings of this study are that the EFA status of the fetus is not stable during its development, but changes with GA in a fatty acid specific way (fig 3.1.) and that fetal plasma EFA values are similar or slightly lower than infant plasma EFA values directly after birth at a comparable GA.

In this study, the participating (pregnant) women were referred to the centres for fetal blood sampling because of fetal karyotyping or expected pregnancy complications. Fortunately, the majority of the fetus turned out to be normal ( $80 \%)$. No differences in fatty acid profiles were observed between normal and abnormal fetus (data not shown). Therefore, the results of the latter population were not excluded from the data set.

That the relative plasma level of $n-6$ long-chain PUFAS (LCPS) exceeds that of their precursor 18:2n-6, seems to be a specific feature of the fetus [5] and the newborn [6-8] since it has never been observed in normal adults. The relatively high $n-6$ LCP status in plasma PLS is a favourable situation for the developing human being, especially during the last trimester of pregnancy when, in addition to 22:6n-3, high quantities of the major $n-6$ LCP, $20: 4 n-6$ are needed for growth and development of neural tissue $[13,14]$. 
Table 3.2. Fatty acid composition of plasma phospholipids from mothers subjected to fetal blood sampling $(\mathrm{n}=55)$ and the relation with corresponding fetal values.

\begin{tabular}{|c|c|c|c|c|}
\hline & fatty acid ${ }^{a}$ & mean $\pm S D$ & $r$ & $\mathrm{P}_{2}$-value \\
\hline \multirow[t]{12}{*}{$\mathrm{mg} / \mathrm{l}$} & total & $1624 \pm 292$ & 0.03 & NS \\
\hline & ¿ SAFA & $720 \pm 134$ & 0.07 & NS \\
\hline & $\Sigma$ MUFA & $235 \pm 58$ & 0.13 & NS \\
\hline & $20: 3 n-9$ & $6.8 \pm 2.4$ & 0.25 & NS \\
\hline & $18: 2 n-6$ & $313 \pm 70$ & 0.27 & 0.04 \\
\hline & $20: 4 n-6$ & $135 \pm 31$ & 0.08 & NS \\
\hline & $22: 5 n-6$ & $8.2 \pm 3.9$ & 0.20 & NS \\
\hline & $\sum n-6$ & $529 \pm 96$ & 0.05 & NS \\
\hline & $\sum n-6 L C P$ & $201 \pm 53$ & 0.11 & NS \\
\hline & $20: 5 n-3$ & $7.2 \pm 4.1$ & 0.44 & 0.0007 \\
\hline & $22: 6 n-3$ & $71 \pm 23$ & 0.19 & NS \\
\hline & $\sum n-3$ LCP & $90 \pm 28$ & 0.24 & NS \\
\hline \multirow[t]{14}{*}{$\%$ (wt/wt) } & $\Sigma$ SAFA & $44.4 \pm 1.7$ & 0.52 & $<0.0001$ \\
\hline & $\Sigma$ MUFA & $14.3 i \pm 2.2$ & 0.45 & 0.0007 \\
\hline & $20: 3 n-9$ & $0.42 \pm 0.14$ & 0.42 & 0.001 \\
\hline & $18: 2 n-6$ & $19.3 i \pm 2.6$ & 0.53 & $<0.0001$ \\
\hline & $20: 4 n-6$ & $8.4 \pm 1.5$ & 0.08 & NSi \\
\hline & $22: 5 n-6$ & $0.50 \pm 0.19$ & 0.28 & 0.04 \\
\hline & $\sum n-6$ & $32.7 \pm 2.1$ & 0.72 & $<0.0001$ \\
\hline & $\sum n-6$ LCP & $12.9 \pm 1.8$ & 0.18 & NS \\
\hline & $20: 5 n-3$ & $0.44 . \pm 0.23$ & 0.40 & 0.003 \\
\hline & $22: 6 n-3$ & $4.4 \pm 1.7$ & $0.28:$ & 0.04 \\
\hline & $\Sigma, n-3$ LCP & $5.5 \pm 1.3$ & 0.32 & 0.02 \\
\hline & EFA status & $2.73 \pm 0.48$ & 0.41 & 0.002 \\
\hline & CADI & $1.40 \pm 0.40$ & 0.72 & $<0.0001$ \\
\hline & CASI & $10.1 \pm 5.2$ & 0.51 & $<0.000 \|$ \\
\hline
\end{tabular}

as in table 3.1.

${ }^{b}$ Significance level for relation between maternal and fetal fatty acid values (linear regression).

The relative level of 18:2n-6 shawed a slight increase during gestation. Apparently, the decrease in 18:2n-6, as observed in fetal tissue during the first trimester of pregnancy [5], does not continue in plasma during the 2 nd and 3 rd trimester. An important specific physiological function of 18:2n-6 is maintaining the water barrier of the skin [15]. We speculate 
Table 3.3. Fatty acid composition (mean \pm SD) of umbilical cord plasma phospholipids collected shortly after delivery at various gestational ages (GAs).

\begin{tabular}{|c|c|c|c|c|}
\hline & fatty acid ${ }^{a}$ & $\begin{array}{l}28-32 \text { wks GA } \\
(n=23)\end{array}$ & $\begin{array}{l}33.36 \text { wks GA } \\
(n=11)\end{array}$ & $\begin{array}{l}37-39 \text { wks } G A \\
(n=17)\end{array}$ \\
\hline \multirow[t]{12}{*}{ mg/l } & total & $603 \pm 163$ & $538 \pm 162$ & $556 \pm 99$ \\
\hline & ¿ SAFA & $277 \pm 74$ & $247 \pm 80$ & $253 \pm 45$ \\
\hline & $\Sigma$ MUFA & $95 \pm 27$ & $78 \pm 27$ & $80 \pm 19$ \\
\hline & $20: 3 n-9$ & $4.5 \pm 2.4$ & $3.3 \pm 2.8$ & $4.2 \pm 2.1^{b}$ \\
\hline & $18: 2 n-6$ & $53 \pm 19$ & $47 \pm 18$ & $48 \pm 13^{b}$ \\
\hline & $20: 4 n-6$ & $105 \pm 30$ & $89 \pm 27$ & $89 \pm 16$ \\
\hline & $22: 5 n-6$ & $3.5 \pm 1.6$ & $3.5 \pm 1.7$ & $4.4 \pm 1.5$ \\
\hline & $\sum n-6$ & $194 \pm 57$ & $174 \pm 54$ & $180 \pm 34$ \\
\hline & $\sum n-6$ LCP & $136 \pm 39$ & $122 \pm 35$ & $125 \pm 21$ \\
\hline & $20: 5 n-3$ & $1.7 \pm 1.3$ & $1.43 \pm 0.83$ & $1.42 \pm 0.45$ \\
\hline & $22: 6 n-3$ & $23 \pm 7.3$ & $26 \pm 7.2$ & $28 \pm 5.3$ \\
\hline & $\sum n-3$ LCP & $27 \pm 8.7$ & $30 \pm 7.8$ & $32 \pm 5.8$ \\
\hline \multirow[t]{14}{*}{$\%(w t / w t)$} & $\Sigma$ SAFA & $45.9 \pm 1.7$ & $45.8 \pm 2.2$ & $45.4 \pm 2.1^{c}$ \\
\hline & $\Sigma$ MUFA & $15.8 \pm 2.2$ & $14.7 \pm 3.5$ & $14.3 \pm 2.2$ \\
\hline & $20: 3 n-9$ & $0.73 \pm 0.34$ & $0.58 \pm 0.35$ & $0.74 \pm 0.30 \mathrm{r}$ \\
\hline & $18: 2 n-6$ & $8.6 \pm 1.5$ & $8.6 \pm 1.0$ & $8.6 \pm 1.0^{\prime}$ \\
\hline & $20: 4 n-6$ & $17.5 \pm 2.0$ & $16.8 \pm 2.1$ & $16.0 \pm 1.4$ \\
\hline & $22: 5 n-6$ & $0.58 \pm 0.20$ & $0.66 \pm 0.21$ & $0.79 \pm 0.20$ \\
\hline & $\sum n-6$ & $32.0 \pm 2.0$ & $32.2 \pm 1.6$ & $32.3 \pm 1.2^{d}$ \\
\hline & $\sum n-6 \mathrm{LCP}$ & $23.1 \pm 2.2$ & $23.3 \pm 1.4$ & $22.6 \pm 1.2$ \\
\hline & $20: 5 n-3$ & $0.27 \pm 0.19$ & $0.26 \pm 0.15$ & $0.25 \pm 0.08$ \\
\hline & $22: 6 n-3$ & $3.9 \pm 1.0$ & $5.0 \pm 1.2$ & $5.13 \pm 0.71$ \\
\hline & $\sum n-3$ LCP & $4.5 \pm 1.1$ & $5.7 \pm 1.2$ & $5.82 \pm 0.78$ \\
\hline & EFA status & $2.36 \pm 0.44$ & $2.74 \pm 0.72$ & $2.73 \pm 0.43^{b}$ \\
\hline & CADI & $0.95 \pm 0.32$ & $1.05 \pm 0.33$ & $1.13 \pm 0.28$ \\
\hline & CASI & $7.6 \pm 3.1$ & $8.2 \pm 2.4$ & $7.1 \pm 2.6$ \\
\hline
\end{tabular}

For legend see table 3.1 .

${ }^{b-f}$ Significance level for difference between fetal (see table 3.1.) and neonatal fatty acid values, corrected for gestational age at blood collection by muluple regression analysis (only gestational age range 28-39 weeks).

that in the fetus which is surrounded with amniotic fluid, this function is likely to be of minor importance and, therefore, the fetus might not need the normal adult level of 18:2n-6. 


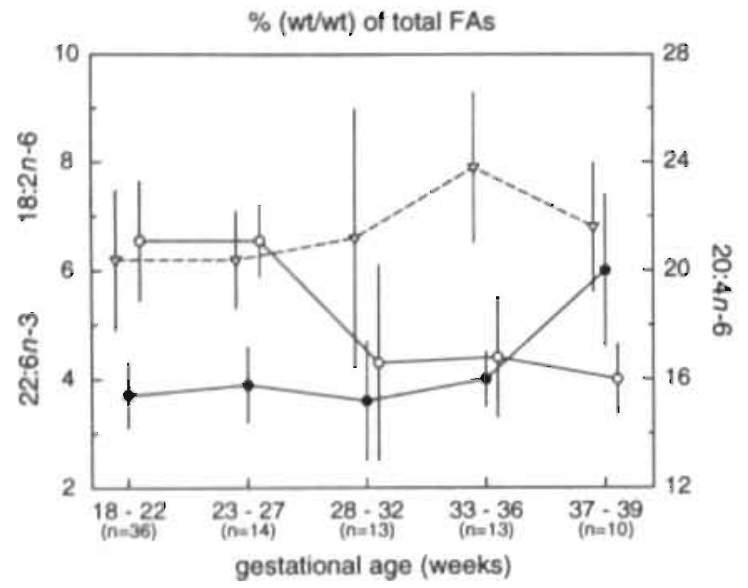

Figure 3.1. Relative levels (wt \%, mean \pm SD) for 18:2n-6 (- $\nabla--), 20: 4 n-6(-\mathrm{O}-)$, and 22:6n-3 ( - in fetal plasma phospholipids.

In this respect, the slightly increasing 18:2n-6 levell observed with advancing gestation could be considered a first sign of adaption to postnatal life.

As is also known from postnatal values [7,8,16; Chapter 7], 22:6n-3 values in fetal plasma PLs were found to increase during pregnancy. However, this observation differs from that by Crastes de Paulet and coworkers [17], who did not report an increase in relative levels of 22:6n-3 in fetal plasma total lipids during gestation. Apart from possible differences between their and our study populations, these different results could be reconciled by assuming that the levels of $22: 6 n-3$ in the other lipid fractions decrease with increasing GA. For the cholesterol fraction this is unlikely, since fatty acids attached to cholesterol are mainly derived from plasma PLs by the lecithin-cholesterol acyltransferase (LCAT) reaction [18]. Indeed, Hoving et al [19] observed that the levels of 22:6n-3 in umbilical plasma cholesterolesters increased during a similar period of gestation. Perhaps, more fluctuating 22:6n-3 levels in the triglycerides and free fatty acids have obscured the rise of 22:6n-3 in the samples studied by Crastes de Paulet and colleagues.

Although the fetal plasma 22:6n-3 values increased as pregnancy progressed, the CADI and CASI values indicated a lowering of the functional $22: 6 n-3$ status during fetal maturation, suggesting that the increased availability of $22: 6 n-3$ might not be sufficient to cover the increasing fetal demand. This might be the result of a relative shortage of maternal $22: 6 n-3$. During normal pregnancy, the maternal $22: 6 n-3$ status has been shown to decrease [7], which may result from the maternal attempt to meet the high fetal demand for $22: 6 n-3$. Recently, it has been demonstrated that the maternal 22:6n-3 status can be enhanced by increasing the intake of n-3 fatty acids during pregnancy [20].

A highly significant relation was observed between the majority of the maternal and fetal plasma fatty acid values (table 3.2.). Consequently, differences between the EFA status of the mothers that were subjected to fetal blood sampling and of the mothers of the newborn infants, would be a confounding factor in the comparison of fetal with neonatal EFA 
values. However, no significant differences in plasma PL fatty acid composition were observed for both groups of mothers (data not shown).

During the third trimester of pregnancy, the EFA profile in PLS from fetal plasma, sampled during ongoing pregnancy, was generally comparable with that of the postnatal umbilical plasma samples of term and preterm infants. Consequently, the differences between the fatty acid compositions of plasma PLS of term and preterm infants are comparable to the differences observed for fetal samples taken at the same GAs. Thus, the lower EFA status of the preterm infant when compared to the term infant $[8,10$; Chapter 2] is likely to be a developmentally related phenomenon, possibly associated with the lower EFA requirements of the preterm fetus for brain and body growth. The higher 18:2n-6 level observed directly after birth might, again, be a sign of adaption to postnatal life. The slight differences in fatty acid composition of the plasma PLs observed between fetal and postnatal samples might also be due to an influence of delivery, because, in general "comparable differences were observed between fetal blood samples taken at caesarean sections and samples taken after a vaginal birth at comparable GAs.

In conclusion, our results demonstrate that the EFA profile of the fetus is not stable during its development, but changes with pregnancy duration in a fatty acid specific way (fig 3.1.). This implies that a proper interpretation of the fetal EFA status during its development needs consideration of GA. Moreover, the unborn fetus has an EFA profile, which is generally similar to that of newborn infants when measured directly after birth at comparable GAS. This indicates that the relatively low EFA values at birth of preterm infants are of developmental origin. Besides, the plasma EFA profile measured after delivery appears to be a reasonably adequate reflection of the fetal plasma EFA profile.

\subsection{Acknowledgements}

The authors would like to thank Dr. J. van Vugt, Department of Obstetrics and Gynaecology, Free University of Amsterdam, The Netherlands for his participation in this study.

\subsection{References}

1. Innis SM. Essential fatty acids in growth and development. Prog Lipid Res 1991;30:39-103.

2. Neuringer M, Connor WE, Lin DS, Barstad L, Luck S. Biochemical and functional effects of prenatal and postnatal $w 3$ fatty acid deficiency on retina and brain in rhesus monkeys. Proc Natl Acad Sci USA 1986;83:4021-5.

3. Uauy R, Birch E, Birch D, Peirano P. Visual and brain function measurements in studies of $n-3$ fatty acid requirements of infants. J Pediatr 1992;120:S168-80.

4. Carlson SE, Werkman SH, Rhodes PG. Tolley EA. Visual-acuity development in healthy preterm infants: effect of marine-oil supplementation. Am J Clin Nutr 1993;58:35-42.

5. Houwelingen AC v, Puls J, Hornstra G. Fetal essential fatty acid status during early human development; relation with matemal EFA status. Early Hum Dev 1992;31:97-111.

6. Al MDM, Hornstra G, van der Scholsw YT, Bulstra-Ramakers MTEW, Huisjes HJ. Biochemical EFA status of mothers and their neonates after normal pregnancy. Early Hum Dev 1990;24:23948.

7. Al MDM, Houwelingen AC v, Kester ADM, Hasaart THM, Jong, AEP de, Hornstra G. Maternal essential fatty acid patterns during normal pregnancy and their relationship with the neonatal essential fatty acid status. Br J Nutr 1995;74:55-68. 
8. Friedman Z, Danon A, Lamberth EL, Mann WJ. Cord blood fatty acid composition in infants and their mothers during the third trimester. J Pediatr 1978;92:461-6.

9. Hornstra G, Al MDM, Gerrard JM, Simonis MMG. Essential fatty acid status of neonates born to Inuit mothers: comparison with Caucasian neonates and effect of diet. Prostaglandins Leukotrienes and Essent Fatty Acids 1992;45:125-30.

10. Foreman-v Drongelen MMHP, Al MDM, Houwelingen AC v, Blanco CE, Hornstra G. Comparison between the essential fatty acid status of preterm and full-term infants, measured in umbilical vessel walls. Early Hum Dev 1995;75:55-68.

11. Holman RT. Control of polyunsaturated fatty acids. J Am Coll Nutr 1986;5:183-211

12. Holman RT. The deficiency of essential fatty acids. In: Kunau W, Holman RT, eds. Polyunsaturated fatty acids. Champaign (IL): Am Oil Chem Soc 1977;4:163-82.

13. Clandinin MT, Chappell JE, Leong S, Heim T, Swyer PR, Chance G.W. Intrauterine fatty acid accretion rates in human brain: implications for fatty acid requirements. Early Hum Dev 1980;4:$121-9$.

14. Martinez M. Tissue levels of polyunsaturated fatty acids during early human development. J Pediatr 1992;120:SI29-38.

15. Hansen HS, Jensen B. Essential function of linoleic acid esterified in acylglucosylceramide and acylceramide in maintaining the epidermal water barrier. Evidence from feeding studies with oleate, lineolate, arachidonate, columbinate and $\alpha$-linolenate. Biochim Biophys Acta 1985;834:357-63.

16. Foreman-v Drongelen MMHP. Houwelingen AC v, Kester ADM, Hasaart THM, Blanco CE, Hornstra G. Long-chain polyunsaturated fatty acids in preterm infants: status at birth and its influence on postnatal levels. J Pediatr 1995;126:611-8.

17. Crastes de Paulet P. Sarda P, Boulot P, Crastes de Paulet A. Fatty acid blood composition in foetal and maternal plasma. In: Essential Fatty acids and Human Nutrition, Eds J Ghisolfi and G Putet. John Libbey Europtext. Paris, France 1992:65-77.

18. Subbaiah PV, Monshizadegan H. Substrate specificity of human plasma lecithin-cholesterol acyliransferase towards molecular species of phosphatidyicholine in native plasma. Biochim Biophys Acta 1988:963:445-55.

19. Hoving ED, Beusekom CM v, Mijboer HJ, Muskiet FAJ. Gestational age dependency of essential fatty acids in cord plasma cholesterol esters and triglycerides. Pediatr Res 1994;35:461-9.

20. Houwelingen AC v, Dalby Sørensen J, Hornstra G, Simonis MMG, Boris J, Olsen S, Secher NJ. Essential fatty acid status in neonates after fish oil supplementation during pregnancy. $\mathrm{Br} \mathrm{J}$ Nutr 1995; $74: 723-31$. 


\title{
Essential fatty acid status measured in umbilical vessel walls of infants born after a multiple pregnancy
}

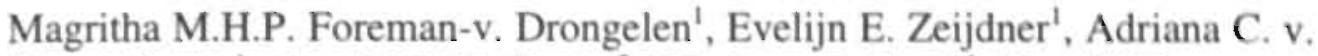 \\ Houwelingen $^{1}$, Arnold D.M. Kester ${ }^{2}$, Monique D.M. Al', Tom H.M. \\ Hasaart ${ }^{3}$, and Gerard Hornstra'.
}

'Department of Human Biology and '2Department of Methodology and Statistics, University of Limburg, Maastricht, The Netherlands

${ }^{3}$ Department of Obstetrics and Gynaecology, University Hospital Maastricht, The Netherlands

Early Human Development, in press

\subsection{Abstract}

The essential fatty acid (EFA) status of full-term infants born after an uneventful, singleton pregnancy has been reported to be marginal. If this low EFA status is caused by a limiting maternal EFA supply, the higher total fetal EFA demand associated with a multiple pregnancy would result in an even lower EFA status of the infants born after a multiple pregnancy. Therefore, we compared the EFA status at birth of 30 pairs of twins, 7 sets of triplets, and one set of quintuplets with that of 94 infants (51 preterm, 43 full-term) born after a singleton pregnancy. Phospholipid (PL)-associated EFA profiles of the umbilical vessel walls, considered a longer-term reflection of the fetal EFA status, were studied. After correction for gestational age (GA) at birth, levels of $n-6$ and $n-3$ EFAs were generally lower, while levels of EFA-deficiency indicating $n$-9 polyunsaturated fatty acids (PUFAs) were significantly higher both in the draining umbilical arteries and the supplying veins of infants born after a multiple pregnancy. EFA profiles of twins and triplets were similar, but the average EFA status of the set of quintuplets was lower than that of twins and triplets. In conclusion, the observation that the EFA status of infants born after a multiple pregnancy is lower than that of infants born after a singleton pregnancy supports the view that the maternal EFA supply to the fetus is limiting. Considering the importance of EFAs, the longer-chain derivatives in particular, for proper growth and development, this finding warrants further studies of the adequacy of the maternal EFA intake during pregnancy. 


\subsection{Introduction}

The EFAs of the $n-3$ and $n-6$ series are known to be indispensable to normal human cell function (for reviews, see: $[1,2]$ ). As such, EFAs, and particularly their long-chain polyunsaturated derivatives (LCPS: fatty acids with a chain length $\geq 20 \mathrm{C}$, derived from the parent EFAs $\alpha$-linolenic acid $(18: 3 n-3)$ and linoleic acid $(18: 2 n-6)$ through alternate desaturation and elongation), are also of considerable importance in fetal and infant development. LCPs, especially docosahexaenoic acid (cervonic acid, 22:6n-3) and arachidonic acid (20:4n-6), are present in large quantities in nervous tissue [3-6] and a growing number of studies in human infants indicate their necessity for normal brain and visual development and function [7-11]. In addition, the LCP status has been reported to be related to parameters of prenatal growth [12-17; Chapter 2].

Human tissue cannot synthesize the parent EFAs, so these have to be taken up by the diet. Obviously, the human fetus must derive the necessary EFAs from the maternal circulation through placental transfer. The maternal EFA supply to the fetus will be dependent. on the dietary EFA intake of the mother, the degree of metabolic conversion of dietary EFAS in her body, the amounts and types of EFAs present in her stores, and her ability to mobilize these stored EFAs. The biochemical EFA. status at birth of healthy full-term infants, born after an uncomplicated singleton pregnancy has been suggested to be marginal [18-20], in particular because substantial quantities of Mead acid (20:3n-9) were found in their umbilical artery vessel walls. This fatty acid is considered a reliable indicator of EFA deficiency [2i], since it is formed from oleic acid $(18: 1 n-9)$ when insufficient amounts of the parent EFAs $18: 3 n-3$ and $18: 2 n-6$ and/or their LCPS are present to, respectively, occupy and inhibil the $\Delta 6$-desaturase. This low EFA status of the full-term newborn could be the result of a limiting maternal EFA supply to the growing and developing fetus. If such is the case, the higher total fetal EFA demand associated with a multiple pregnancy, may, at one point or another, lead to an even lower fetal EFA status during a multiple pregnancy than during a singleton pregnancy.

Therefore, we decided to assess the EFA status at birth of infants born after a multiple pregnancy by comparing it with that of infants born after a singleton pregnancy. To this, end, EFA levels in the PL fraction of umbilical cord artery and vein vessel walls were studied, because their EFA profiles are considered a longer-term representation of the EFA supply to (vein) [19] and return flow from (arteries) the fetus [19,22].

\subsection{Patients and methods \\ 4.3.1 Infants}

The population of newborn infants born after a multiple pregnancy comprised 30 pairs of twins, 7 sets of triplets, as well as one set of quintuplets. The quintuplets, all triplets and 24 pairs of twins were born preterm (GA: 23-36 wks, birth weight: $570-2650 \mathrm{~g}$ ), while the remaining 6 pairs of twins were carried to term (GA: $37-41$ wks, birth weight: $1850-3210$ g). 51 Preterm infants (GA: $26-36$ wks, birth weight: $650-1860 \mathrm{~g}$ ) and 43 full-term infants (GA: $37-41$ wks, birth weight: $2630-4130 \mathrm{~g}$ ), born in the same period, but after a singleton pregnancy, served as controls. GA was confirmed by menstrual history and early ultrasound 
Table 4.1. Clinical characteristics of study populations (mean \pm SD).

\begin{tabular}{lllll}
\hline & $\begin{array}{l}\text { singletons } \\
(\mathrm{n}=94)\end{array}$ & $\begin{array}{l}\text { twins } \\
\left(\mathrm{n}=30^{*} 2\right)\end{array}$ & $\begin{array}{l}\text { triplets } \\
(\mathrm{n}=7 * 3)\end{array}$ & $\begin{array}{l}\text { quintuplets } \\
(\mathrm{n}=1 * 5)\end{array}$ \\
\hline maternal age $(\mathrm{y})$ & $29 \pm 5.2$ & $29 \pm 5.2$ & $29 \pm 2.6$ & 31 \\
primipara $(\mathrm{n})$ & $65(69.1 \%)$ & $20(66.6 \%)$ & $2(28.6 \%)$ & 0 \\
gestational age (weeks.days) & $35.3 \pm 4.5$ & $32.0 \pm 4.4$ & $31.0 \pm 3.2$ & 29.4 \\
birth weight $(\mathrm{g})$ & $2268 \pm 997$ & $1545 \pm 687$ & $1486 \pm 521$ & $1256 \pm 143$ \\
SGA $(\mathrm{P}<2.3)^{*}(\mathrm{n})$ & $8(8.5 \%)$ & $7(11.6 \%)$ & $0(0.0 \%)$ & $0(0.0 \%)$ \\
\hline
\end{tabular}

"SGA = small for gestational age (birth weight below 2.3rd percentile (P) of the Amsterdam growth charts [36]).

dating, and by Dubowitz score [23] if the former information was missing or doubtful. Relevant clinical characteristics of the study populations are given in table 4.1.

Of each infant, approximately $15 \mathrm{~cm}$ of umbilical cord was collected immediately after delivery. The study was approved by the medical ethics committees of the participating hospitals and written informed consent was obtained from one or both parents.

\subsubsection{Laboratory analysis}

Umbilical cord samples were prepared and analyzed as described previously [16; Chapter 7]. At the start of the analysis, approximately $40 \mu \mathrm{g}$ of 1,2-dinonadecanoyl phosphatidylcholine [PC(19:0) $)_{2}$ ] was added to every sample for the quantification of absolute fatty acid amounts present in the PL fraction of cord artery and vein walls ( $\mathrm{mg} / \mathrm{kg}$ dry weight of cord vessel wall tissue). Relative fatty acid levels were expressed as weight \% of total fatty acid methylesters.

In total, 26 fatty acids were identified and present in detectable amounts. Since the present study focuses on the EFA status, only the following relevant. 8 fatty acids and 6 fatty acid combinations are reported: $20: 3 n-9$, dihomo-Mead acid $(22: 3 n-9), 18: 2 n-6$, dihomo- $\gamma$ linolenic acid (20:3n-6), 20:4n-6, adrenic acid $(22: 4 n-6)$, Osbond acid $(22: 5 n-6), 22: 6 n-3, \Sigma$ SAFA (sum of all saturated fatty acids), $\Sigma$ MUFA. (sum of all monounsaturated fatty acids), $\Sigma$ PUFA, $\Sigma n-9$ PUFA (sum of all PUFAs of the $n-9$ series), $\Sigma n-6$ LCP (sum of the LCPS of the $n-6$ series, and $\Sigma n-3$ LCP (sum of the LCPS of the $n-3$ series).

In addition, three indices were calculated to describe the functional EFA status. The EFA status, defined as the ratio of the sum of all fatty acids of the $n-3$ and $n-6$ series to the sum of all fatty acids of the $n-7$ and $n-9$ series $\left(\sum n-3+n-6 / \Sigma n-7+n-9,[24]\right)$ was used because a sufficient supply of $n-3$ and $n-6$ fatty acids will limit the desaturation of the non-essential $n$ 7 and $n-9$ monoenes to their respective PUFAs. For a similar reason, the classic triene/tetraene ratio (EFA deficiency index, EFADI): 20:3n-9/20:4n-6, [25]) was calculated. The cervonic acid deficiency index (CADI), defined as the ratio of $22: 5 n-6$ to $22: 4 n-6$, was calculated 
because a shortage of $22: 6 n-3$ is accompanied by an increased conversion of $22: 4 n-6$ to $22: 5 n-6$, the 'surrogate' fatty acid for $22: 6 n-3$, leading to higher CADI values $[26,27]$.

\subsubsection{Data analysis}

Data are presented as mean and standard deviation unless mentioned otherwise. Data of the one set of quintuplets were not included in the statistical analyses.

Since the EFA status measured in cord vessel walls is known to be related to GA at birth [15-17,28; Chapter 2], fatty acid levels in the umbilical artery and vein vessel walls of infants born after a multiple pregnancy and after a singleton pregnancy were compared using multiple regression analysis to correct for GA at birth. Dummy variables were used to indicate whether infants were born after a multiple or a singleton pregnancy and whether they were one of twins or of triplets. For sets of twins and triplets, the average level of a given fatty acid for each pair or trio of infants was calculated and used in these statistical analyses. For three pairs of twins, umbilical cord material was available from only one infant, the fatty acid levels of which were used as averages for the pair. For one set of triplets, the umbilical vein sample of one of the infants was lost during fatty acid analysis, and the average fatty acid levels were based on those of the two remaining samples.

P-values $<0.05$ were considered to reflect a significant difference.

\subsection{Results}

\subsubsection{Umbilical artery walls}

Since the total concentration ( $\mathrm{mg} / \mathrm{kg}$ dry weight) of PL-associated fatty acids was similar for all study populations, only relative fatty acid levels (weight \%) were compared (table 4.2.). The majority of the fatty acid levels and all indices reported were significantly related to GA at birth.

Cord ariery vessel walls of infants born after a multiple (twin or triplet) pregnancy contained significantly lower levels of $18: 2 n-6$ and of its main LCP 20:4n-6, as well as of the major LCP of the n-3 series, 22:6n-3 (its parent EFA 18:3n-3 was not present in detectable amounts) than infants born after a singleton pregnancy. Levels of the EFA deficiency indicator 20:3n-9 and its elongation product 22:3n-9, as well as the total amount of MUFAS were significantly higher in twins and triplets. The EFA status index was significantly lower, while the EFADI was significantly higher in cord artery walls of infants born after a multiple pregnancy than in those of infants born after a singleton pregnancy. The values for the indicators of a specific 22:6n-3 deficiency, the CADI and the fatty acid 22:5n-6, were similar in all study populations.

The fatty acid profiles of twins and triplets were not significantly different. In the set of quintuplets, the average levels of $18: 2 n-6,20: 4 n-6$, and $22: 6 n-3$ were $35 \%, 27 \%$, and $40 \%$ lower, respectively, than those in the twins and triplets. Levels of the PUFAs of the $n-9$ series were clearly higher (up to $86 \%$ ) in the quintuplets than in the twins and triplets. These differences between the cord artery fatty acid profiles of the set of quintuplets and of the other infants born after a multiple pregnancy were reflected by the EFA status index ( $48 \%$ lower in quintuplets) and the EFADI ( $77 \%$ higher in quintuplets), but not by the CADI. 
Table 4.2. Relative (weight $\%)^{a}$ fatty acid composition of cord artery vessel wall phospholipids of study populations (mean $\pm S D$, except for set of quintuplets: average value of the five infants).

\begin{tabular}{|c|c|c|c|c|}
\hline Fatty acid & $\begin{array}{l}\text { singletons } \\
\qquad(n=94)\end{array}$ & $\begin{array}{l}\text { pairs of twins } \\
\qquad(n=30)\end{array}$ & $\begin{array}{c}\text { sets of triplets } \\
\qquad(n=7)\end{array}$ & $\begin{array}{l}\text { set of quintuplets } \\
\qquad(n=1)\end{array}$ \\
\hline$\Sigma$ SAFA & $46.8 \pm 2.6$ & $46.1 \pm 1.9$ & $45.16 \pm 0.33$ & 44.8 \\
\hline$\Sigma$ MUFA & $21.7 \pm 4.1^{8}$ & $25.9 \pm 4.3$ & $26.9 \pm 1.6$ & 30.7 \\
\hline$\Sigma$ PUFA & $31.5 \pm 3.9^{d}$ & $28.0 \pm 4.0$ & $28.0 \pm 1.6$ & 24.6 \\
\hline $20: 3 n-9$ & $3.21 \pm 0.88^{d}$ & $3.77 \pm 0.98$ & $4.17 \pm 0.34$ & 5.44 \\
\hline $22: 3 n-9$ & $1.44 \pm 0.57^{\circ}$ & $1.66 \pm 0.56$ & $1.99 \pm 0.17$ & 3.21 \\
\hline$\sum_{n-9}$ PUFA & $4.7 \pm 1.3^{e}$ & $5.4 \pm 1.3$ & $6.16 \pm 0.47$ & 8.7 \\
\hline $18: 2 n-6$ & $1.22 \pm 0.41^{x}$ & $0.84 \pm 0.27$ & $0.83 \pm 0.22$ & 0.54 \\
\hline $20: 3 n-6$ & $1.08 \pm 0.29$ & $0.89 \pm 0.27$ & $0.94 \pm 0.27$ & 0.59 \\
\hline $20: 4 n-6$ & $13.1 \pm 2.6^{6}$ & $10.9 \pm 2.7$ & $10.5 \pm 1.1$ & 7.9 \\
\hline $22: 4 n-6$ & $2.60 \pm 0.76$ & $2.11 \pm 0.65$ & $1.97 \pm 0.28$ & 1.51 \\
\hline $22: 5 n-6$ & $3.51 \pm 0.69$ & $3.45 \pm 0.60$ & $3.64 \pm 0.49$ & 2.74 \\
\hline$\sum n-6$ & $21.91 \pm 3.7^{d}$ & $18.6 \pm 4.0$ & $18.3 \pm 1.6$ & 13.6 \\
\hline$\sum n-6$ LCP & $20.3 \pm 3.5^{c}$ & $17.4 \pm 3.7$ & $17.1 \pm 1.4$ & 12.8 \\
\hline $22: 6 n-3$ & $4.95 \pm 1.14^{e}$ & $4.02 \pm 0.96$ & $3.57 \pm 0.57$ & 2.36 \\
\hline$\sum n-3+n-6$ & $26.8 \pm 4.6^{f}$ & $22.6 \pm 4.8$ & $21.91 \pm 1.9$ & 15.9 \\
\hline$\sum n-3+n-6$ LCP & $25.3 \pm 4.3^{F}$ & $21.4 \pm 4.5$ & $20.6 \pm 1.8$ & 15.1 \\
\hline EFA status & $1.08 \pm 0.37^{d}$ & $0.78 \pm 0.33$ & $0.67 \pm 0.10$ & 0.40 \\
\hline EFADI & $0.26 \pm 0.11^{8}$ & $0.38 \pm 0.15$ & $0.41 \pm 0.07$ & 0.69 \\
\hline CADI & $1.48 \pm 0.59$ & $1.78 \pm 0.53$ & $1.90 \pm 0.41$ & 1.86 \\
\hline total $\left.\right|^{a}$ & $15579 \pm 2755$ & $16634 \pm 1767$ & $18366 \pm 1320$ & 16170 \\
\hline
\end{tabular}

"total amount of phospholipid-associated fatty acids expressed as mg/kg dry weight.

${ }^{b} \Sigma$ SAFA $=$ sum of all saturated fatty acids; $\Sigma$ MUFA $=$ sum of all monounsaturated fatty acids; $\Sigma$ PUFA $=$ sum of all polyunsaturated fatty acids; $\Sigma, n-9$ PUFA $=$ sum of all PUFAs of the $n-9$ series $(20: 3 n-9,22: 3 n-9) ; \Sigma, n-6=$ sum of all fatty acids of the $n-6$ series; $\Sigma n-6 L C P=$ sum of all long-chain PUFAs (PUFAs with a chain length $\geq 20 C_{\text {, derived from parent }}$ essential fatty acids through alternate desaturation and elongation) of the $n-6$ series $(20: 3 n-6,20: 4 n-6,22: 4 n-6,22: 5 n-6)$, $\sum n-3+n-6=\sum n-6+22: 6 n-3$ (no other fatty acids of the $n-3$ series were present in detectable amounts); $\Sigma n-3+n-6$ $L C P=\sum n-6 L C P+22: 6 n-3$. EFA status= essential fatty acid status: $\left(\sum n-3+n-6\right) /\left(\sum n-7+n-9\right)$; EFADI $=$ essential fatty acid deficiency index: $20: 4 n-6 / 20: 3 n-9 ; \mathrm{CADI}=$ cervonic acid $(22: 6 n-3)$ deficiency index: $22: 5 n-6 / 22: 4 n-6$.

Significance level for difference between infants borm after singleton and after multiple (twin, triplet) pregnancy (multiple regression analysis with correction for gestational age (GA) at birth):

${ }^{\mathrm{C}} \mathrm{P}<0.05$, ${ }^{\mathrm{P}} \mathrm{P}<0.02,{ }^{\mathrm{P}} \mathrm{P}<0.01,{ }^{\mathrm{P}} \mathrm{P}<0.005,{ }^{\mathrm{P}} \mathrm{P}<0.001$, ${ }^{\mathrm{h}} \mathrm{P} \leq 0.0001$.

Except for $\Sigma$ SAFA and $22: 3 n-9$, fatty acid levels and indices reported were significantly related to GA at birth: $P$. $<0.0001$, except for 22:5n-6: $\mathrm{P}<0.02, \Sigma$ n-9 PUFA: $\mathrm{P}<0.01$, and 20:3n-9: $\mathrm{P}<0.001$. 


\subsubsection{Umbilical vein walls}

As with the cord artery vessel walls, the total fatty acid concentrations of the three groups were not significantly different, so only relative fatty acid levels were compared (table 4.3.). All but one of the fatty acid levels and indices reported were significantly related to GA at birth.

Table 4.3. Relative (weight \%) ${ }^{a}$ fatty acid composition of cord vein vessel wall phospholipids of study populations (mean $\pm S D$, except for set of quintuplets: average value of the five infants).

\begin{tabular}{|c|c|c|c|c|}
\hline Falty acid ${ }^{b}$ & $\begin{array}{l}\text { singletons } \\
\qquad(n=94)\end{array}$ & $\begin{array}{l}\text { pairs of twins } \\
\qquad(\mathrm{n}=30)\end{array}$ & $\begin{array}{l}\text { sets of triplets } \\
\qquad(n=7)\end{array}$ & $\begin{array}{l}\text { set of quintuplets } \\
\qquad(n=1)\end{array}$ \\
\hline$\Sigma$ SAFA & $47.4 \pm 1.7^{d}$ & $46.3 \pm 2.1$ & $45.6 \pm 1.5$ & 44.5 \\
\hline$\Sigma$ MUFA & $16.9 \pm 2.9^{h}$ & $20.2 \pm 3.4$ & $21.0 \pm 1.7$ & 25.6 \\
\hline$\Sigma$ PUFA & $35.7 \pm 3.0$ & $33.9 \pm 3.6$ & $33.4 \pm 1.8$ & 29.9 \\
\hline $20: 3 n-9$ & $0.67 \pm 0.45^{h}$ & $1.32 \pm 0.79$ & $1.25 \pm 0.58$ & 3.06 \\
\hline $22: 3 n-9$ & $0.48 \pm 0.30^{\circ}$ & $0.82 \pm 0.45$ & $0.92 \pm 0.26$ & 1.91 \\
\hline$\Sigma n-9$ PUFA & $1.16 \pm 0.70^{h}$ & $2.2 \pm 1.2$ & $2.18 \pm 0.81$ & 4.97 \\
\hline $18: 2 n-6$ & $2.19 \pm 0.62^{f}$ & $1.82 \pm 0.44$ & $1.89 \pm 0.42$ & 1.15 \\
\hline $20: 3 n-6$ & $1.59 \pm 0.35$ & $1.48 \pm 0.35$ & $1.59 \pm 0.41$ & 1.35 \\
\hline $20: 4 n-6$ & $17.6 \pm 2.4$ & $15.8 \pm 2.8$ & $15.5 \pm 1.2$ & 12.4 \\
\hline $22: 4 n-6$ & $4.3 \pm 1.2$ & $3.6 \pm 1.2$ & $3.43 \pm 0.74$ & 2.23 \\
\hline $22: 5 n-6$ & $3.09 \pm 0.90^{c}$ & $3.75 \pm 0.87$ & $3.99 \pm 0.91$ & 4.18 \\
\hline$\sum n-6$ & $29.8 \pm 3.1$ & $27.4 \pm 4.3$ & $27.4 \pm 2.0$ & 21.9 \\
\hline$\sum n-6 \mathrm{LCP}$ & $26.6 \pm 2.9$ & $24.6 \pm 3.7$ & $24.5 \pm 1.5$ & 20.2 \\
\hline $22: 6 n-3$ & $4.76 \pm 0.95$ & $4.38 \pm 0.64$ & $3.78 \pm 0.58$ & 3.12 \\
\hline$\sum n-3+n-6$ & $34.6 \pm 3.5$ & $31.8 \pm 4.6$ & $31.2 \pm 2.2$ & 25.0 \\
\hline$\sum n-3+n-6$ LCP & $31.4 \pm 3.5$ & $29.0 \pm 4.1$ & $28.3 \pm 1.8$ & 23.3 \\
\hline EFA status & $2.02 \pm 0.53^{f}$ & $1.53 \pm 0.51$ & $1.38 \pm 0.23$ & 0.82 \\
\hline EFADI & $0.04 \pm 0.03^{h}$ & $0.10 \pm 0.07$ & $0.09 \pm 0.05$ & 0.25 \\
\hline CADI & $0.82 \pm 0.46^{c}$ & $1.23 \pm 0.65$ & $1.26 \pm 0.53$ & 1.94 \\
\hline total $^{a}$ & $16654 \pm 2910$ & $17569 \pm 2048$ & $18504 \pm 1964$ & 19146 \\
\hline
\end{tabular}

Legend as in table 4.2 .

Except for $18: 2 n-6$, fatty acid levels and indices reported were significantly related to GA at birth: $P$ $<0.0001$, except for $\Sigma$ SAFA: $P<0.02$. 
The umbilical vein walls of infants born after a multiple pregnancy contained significantly less 18:2n-6 and significantly more n-9 PUFAs and more MUFAs than infants born after a singleton pregnancy. The EFA status index was lower and the EFADI higher in twins and triplets. While levels of 22:6n-3 were similar in all study populations, values for its specific deficiency indicators, 22:5n-6 and the CADI, were significantly higher in the umbilical vein walls of infants born after a multiple pregnancy.

Fatty acid profiles in venous cord vessel walls of twins and triplets were comparable. In the one set of quintuplets, levels for 18:2n-6, 20:4n-6 and 22:6n-3 were between 20 and $30 \%$ lower than the mean levels for these fatty acids in twins and triplets. Venous $n-9$ PUFA levels of the quintuplet were more than twice as high as those in the other infants born after a multiple pregnancy. The differences mentioned were reflected in all three functional indices calculated.

\subsection{Discussion}

The results of this study show that the EFA status, measured in cord vessel wall PL.s, of infants born after a multiple pregnancy is different from that of infants born after a singleton pregnancy (tables 4.2. and 4.3.). After correction for GA at birth, $n-6$ and n-3 EFA levels were generally lower, while values for EFA deficiency indicating fatty acids and EFA deficiency indicating fatty acid indices were higher in twins and triplets than in infants born after a singleton pregnancy. Most differences between arterial and venous fatty acid values in each study population were significantly different from zero (data not shown) and their directions were comparable to those observed in earlier studies [17,19,20,24; Chapter 2].

Results in the cord artery wall PLS (the EFA profile of which is considered a longer-term representation of the EFA return flow from fetus to mother, and as such of the fetal EFA status) indicate that the general EFA status of downstream fetal tissue during a multiple pregnancy is considerably lower than that during a singleton pregnancy. To our knowledge, only one recent other study reporting EFA data of infants born after a multiple pregnancy is available for comparison: Hoving and co-workers [29] measured umbilical plasma cholesterol ester and triglyceride fatty acid levels (molar \%) in one preterm and two term twins. Although these data were not analyzed statistically, average EFA and LCP levels of each pair appeared to be in the lower range of those of 38 infants born at various GAs after a singleton pregnancy, which were studied simultaneously.

The differences observed between the EFA profiles of infants born after a singleton and after a multiple pregnancy support the hypothesis that the maternal EFA. supply to the fetus is limiting. This hypothesis is also confirmed by the results in the cord vein walls (the EFA. profile of which is regarded a longer-term reflection of the EFA supply from mother to fetus). The daily amounts of n-6 and n-3 EFAs used. for intrauterine de novo synthesis of tissues have been estimated to be about 400 and $50 \mathrm{mg} / \mathrm{kg}$ of body weight, respectively [30]. Based on calculations by Crawford and co-workers [31], women with a singleton pregnancy would have to increase their daily dietary EFA intake by about 1.5 energy \% to adequately cover these demands of the fetus, as well as those of the accreting placental and maternal tissues. This amount is roughly similar to that recommended to pregnant women by the Food and Nutrition Council [32] in the Netherlands. No specific guidelines, however, 
have been formulated for women having a multiple pregnancy. Moreover, results of a recent longitudinal study [33] of the maternal EFA status during and after an uneventful, singleton pregnancy indicated that the pregnant women had drawn on their EFA stores to supply their fetuses with the necessary quantities of EFAs, 22:6n-3 in particular.

When assuming that the lower EFA status of infants born after a multiple pregnancy results from the fact that the limited maternal EFA supply has to be shared by more than one fetus, EFA levels in sets of triplets would be expected to be lower than those in the pairs of twins. Yet, in the present study, umbilical artery and vein wall fatty acid profiles of these two subpopulations were comparable. The average EFA status of the one set of quintuplets studied, however, was substantially lower than that of the other infants born after a multiple pregnancy. Because the differences between the EFA profiles of the set of quintuplets and those of the twins and triplets could not be verified statistically, they could not be corrected for an effect of GA. Nevertheless, considering their magnitude, a complete dependency of these differences on this confounder seems highly unlikely.

Crawford and co-workers [12] and Hoving and co-workers [29] observed higher EFA levels in the heaviest infants of the one pair of twins (umbilical artery vessel walls) and the three pairs of twins (umbilical plasma) they, respectively, studied. In the present study of a considerably larger group of infants born after a multiple pregnancy, no significant differences were observed between the EFA and LCP levels of the lightest and heaviest infants of a set of twins or triplets, except for 22:6n-3 in the umbilical vein wall, which was significantly lower in the lightest infants $(\mathrm{P}=0.04)$.

Multiple pregnancy is one of the major causes of preterm delivery [34]. PL-associated EFA and LCP levels in umbilical plasma [35] and umbilical vessel walls [17; Chapter 2] of preterm infants born after a singleton pregnancy have been found to be lower than those of infants carried to term. This lower LCP status may be related to the lower physiological demand for these fatty acids of the preterm fetus, considering the earlier stage of its brain and body growth. However, the added effect of a lower EFA and LCP status as a result of multiple pregnancy (all differences between infants born after multiple and singleton pregnancy were corrected for GA at birth), may be a reason for concern with respect to the adequacy of the EFA and LCP status of preterm twins and triplets. Particularly since, in preterm infants, a lower LCP status at birth has been shown to result in a lower postnatal LCP status, irrespective of the type of postnatal diet the infants received [16; Chapter 7]. Considering the importance of LCPs for normal brain and visual development [7-11], the results of the present study warrant further consideration and evaluation of the need for supplying women who carry more than one infant with additional $n-3$ and $n-6$ parent EFAs and/or LCPs during their pregnancy.

In conclusion, the biochemical EFA status, measured in umbilical cord vessel walls of infants born after a multiple pregnancy is lower than that of a comparable group of infants born after a singleton pregnancy, indicating that the pregnant women have difficulty coping with the EFA demands of the multiple developing and growing fetuses. In view of the importance of EFAs, particularly the longer-chain derivatives for proper growth and development, this observation warrants further studies of the adequacy of the maternal EFA intake during a multiple pregnancy. 


\subsection{Acknowledgements}

The authors wish to express their appreciation for the skilled assistance obtained from Mrs. H. Aydeniz (preparation of umbilical vessel wall samples), and Mrs. M. M. G. Simonis and the Analytical Biochemical Laboratory in Assen. The Netherlands (fatty acid analyses of umbilical vessel wall samples). They gratefully acknowledge the help obtained from the medical and nursing personnel of the departments of Obstetrics of the University Hospital Maastricht, the School for Midwifery in Kerkrade and the De Wever Hospital in Heerlen, The Netherlands (collection of umbilical cords).

\subsection{References}

1. Innis SM. Essential fatty acids in growth and development. Prog Lipid Res 1991;30:39-103.

2. Sardesai VM. Nutritional. role of polyunsaturated fatty acids. J Nutr Biochem 1992;3:154-66.

3. Svennerholm L. Distribution and fatty acid composition of phosphoglycerides in normal human brain. J Lipid Res 1968;9:570-9.

4. Martinez M, Conde C and Ballabriga A. Some chemical aspects of human brain development. II. Phosphoglyceride fatty acids. Pediatr Res 1974;74:93-102.

5. Fliesler SJ and Anderson RE. Chemistry and metabolism of lipids in the vertebrate retina. Progress Lipid Res 1983;22:79-131.

6. Sastry PS. Lipids of nervous tissue: composition and metabolism. Progress Lipid Res 1985;24:69. 176.

7. Uauy RD, Birch DG, Birch EE, Tyson JE and Hoffman DR. Effect of dietary omega-3 fatty acids on retinal function of very-low-birth-weight neonates. Pediatr Res 1990;28:485-92.

8. Birch DG, Birch EE, Hoffman DR, Uauy R. Retinal development in very low birth weight infants fed diets differing in omega-3 fatty acids. Invest Ophthalmol Vis Sci 1992;33:2365-3276.

9. Birch EE, Birch DG, Hoffman DR, Uauy R. Dietary essential fatty acid supply and visual acuity development. Invest Ophthalmol Vis Science 1992;33:3242-3253.

10. Carlson SE, Werkman SH, Rhodes PG and Tolley EA. Visual-acuity development in healthy preterm infants: effect of marine-oil supplementation. Am J Clin Nutr 1993;58:35-42.

11. Makrides $\mathbf{M}$, Simmer K, Goggin $\mathbf{M}$ and Gibson RA. Erythrocyte docosahexaenoic acid correlates with the visual responise of healthy term infants. Pediatr Res 1993:33:425-7.

12. Crawford MA, Costeloe K, Doyle W, Leighfield MJ, Lennon EA, Meadows N. Potential diagnostic value of the umbilical artery as a definition of neural fatty acid status of the fetus during its growth: the umbilical artery as a diagnostic tool. Biochem Soc Trans 1990;18:761-6.

13. Koletzko B and Braun M. Arachidonic acid and early human growth: is there a relation? Ann Nutr Metab 1991;35:128-31.

14. Leaf $\mathrm{AA}$, Leighfield. MJ, Costeloe $\mathrm{KL}$. Crawford MA. Long-chain poiyunsaturated fatty acids and fetal growth. Early Hum Dev 1992;30:183-91.

15. Felton CV. Chang TC, Crook D, Marsh M, Robșon SC, Spencer JAD. Umbilical vessel wali fatty acids after normal and retarded fetal growth. Arch Disease Child 1994;70:F36-9.

16. Forernan-v Drongelen MMHP, Houwelingen AC $v_{\text {v }}$ Kester A.DM, Hasaart THM, Blanco CE, Hornistra G. Long-chain polyunsaturated fatty acids in preterm infants: status at birth and its influence on postnatali levels. J Pediatr 1995;126:811-8.

17. Foreman-v Drongelen MMHP, Al MDM, v Houwelingen AC, Blanco CE, Hornstra G. Comparison between the essential fatty acid status of preterm and full-term infants, measured in umbilical vessel walls. Early Hum Dev 1995;42:241-251. 
18. Ongari MA, Ritter JM, Orchard MA, Waddell KA, Blair IA, Lewis PJ. Correlation of prostacyclin synthesis by human umbilical artery with status of essential fatty acid. Am J Obstet Gynecol 1984;149:455-60.

19. Hornstra G, Houwelingen AC v, Simonis M, Gerrard JM. Fatty acid composition of umbilical arteries and veins: possible implications for the fetal EFA-status. Lipids 1989;24:511-7.

20. Al MDM, Hornstra G, van der Schouw YT, Bulstra-Ramakers MTEW, Huisjes HJ. Biochemical EFA status of mothers and their neonates after normal pregnancy. Early Hum Dev 1990;24:23948.

21. Mead JF. The metabolism of the polyunsaturated fatty acids. Prog Chem Fats Other Lipids 1970;9:159-92.

22. Crawford MA, Doyle W, Drury P, Lennon A, Costleloe K, Leighfield M. n-6 and n-3 fatty acids during early human development. J Int Med 1989;225:159-69S1.

23. Dubowitz LMS, Dubowitz V, Goldberg C. Clinical assessment of gestational age in the newborn infant. J Pediatr 1970;77:1-10.

24. Hornstra G, Al MDM, Gerrard JM, Simonis MMG. Essential fatty acid status of neonates born to Inuit mothers: comparison with Caucasian neonates and effect of diet. Prostaglandins Leukotrienes and essential fatty acids 1992;45:125-30.

25. Holman RT. The ratio of trienoic:tetraenoic acids in tissue lipids as a measure of essential fatty acid requirement. J Nutr 1960;70;405-10.

26. Holman RT. The deficiency of essential fatty acids. In: Kunau W, Holman RT, eds. Polyunsaturated fatty acids. Champaign (IL): Am Oil Chem Soc 1977;4:163-82.

27. Neuringer M, Connor WE, Lin DS, Barstad L, Luck S. Biochemical and functional effects of prenatal and postnatal w3 fatty acid deficiency on retina and brain in rhesus monkeys. Proc Natl Acad Sci USA 1986;83:4021-25.

28. Al MDM, v Houwelingen AC, Badart-Smook A, Hasaart THM, Roumen FJME, Hornstra G. The essential fatty acid status of mother and child in pregnancy-induced hypertension: a prospective longitudinal study. Am J Obstet Gynecol 1995, in press.

29. Hoving EB, v Beusekom M, Nijeboer HJ, Muskiet FAJ, Gestational age dependency of essential fatty acids in cord plasma cholesterol esters and triglycerides. Pediatr Res 1994;35:461-9.

30. Clandinin MT, Chappell JE, Heim T, Swyer PR, Chance GW. Fatty acid utilization in perinatal de novo synthesis of tissues. Early Hum Dev 1981;5:355-66.

31. Crawford MA, Hassam AG, Stevens PA. Essential fatty acid requirements in pregnancy and lactation with special reference to brain development. Progr Lipid Res 1981;20:31-40.

32. Food and Nutrition Council. Guidelines for a healthy diet. Recommendations drawn up by the committee on guidelines for a healthy diet. The Hague: Food and Nutrition Council, 1986.

33. Al MDM, v Houwelingen AC, Kester ADM, Hasaart THM, de Jong AEP, Hornstra, G. Maternal essential fatty acid patterns during normal pregnancy and their relationships with the neonatal essential fatty acid status. Br J Nutr 1995:74:55-68.

34. Kloosterman GJ. De Meerlingzwangerschap (Dutch). In: Kloosterman GJ, chief ed. De Voortplanting van de mens. Bussum, The Netherlands: Uitgeversmaatschappij Centen, 1983:211-9.

35. Friedman Z, Danon A, Lamberth EL, Mann WJ. Cord blood fatty acid composition in infants and in their mothers during the third trimester. J Pediatr 1978;92:461-6.

36. Kloosterman GJ. On intrauterine growth, the significance of prenatal care. Int J Gynaecol Obstet 1970;8:895-912. 


\title{
Comparability of fatty acid profiles of venous and capillary plasma and red blood cell phospholipids
}

\author{
Magritha M.H.P. Foreman-v. Drongelen', Suzie J. Otto', Adriana C. v. \\ Houwelingen', Arnold D.M. Kester', Quila C.M. Schlundt Bodien' ${ }^{\prime}$ and \\ Gerard Hornstra!.
}

Departments of ${ }^{1}$ Human Biology and ${ }^{2}$ Methodology and Statistics, University of Limburg, Maastricht, The Netherlands

\subsection{Abstract}

In eight healthy volunteers, fatty acid concentrations in plasma and red blood cell (RBC) phospholipids (PLS) isolated from venous and from capillary blood were compared. To evaluate the effect of storage, lipids were extracted on the day of blood collection and after one and four weeks of storage at $-20^{\circ} \mathrm{C}$. Plasma fatty acid profiles from venous and capillary blood were comparable and not affected by up to four weeks of storage. RBC fatty acid concentrations from venous and capillary blood were comparable after up to one week of storage before lipid extraction. However after four weeks of storage, the total amount of PLassociated fatty acids in capillary RBCs was decreased to half the initial value. This decline. was mainly caused by a decrease of almost $90 \%$ in the concentration of polyunsaturated fatty acids (PUFAs) and was not observed in venous RBCs. Consequently, highly significant differences developed between the fatty acid profiles of venous and capillary RBCs. L.oss of RBC membrane structural integrity may have added to the higher susceptibility to lipid loss. of RBCs collected by capillary puncture. In conclusion, plasma PL-associated fatty acid profiles of venous and of capillary blood are comparable and unaffected by storage at $-20^{\circ} \mathrm{C}$ until lipid extraction for at least four weeks. The fatty acid compositions of, particularly capillary, RBC suspensions stored for more than one week are affected by lipid loss and, therefore, unreliable. 


\subsection{Introduction}

When the effects of the dietary essential fatty acid (EFA) intake on the human EFA status are studied, blood samples are usually collected through venous puncture. In our recent study of dietary influences on the EFA status of preterm infants in plasma and RBC PL [1; Chapter 6], the necessary blood samples were collected in connection with diagnostic punctures, which are part of the routine clinical monitoring at the neonatal care unit. In a large portion of these punctures, the blood is of capillary origin, usually collected by heelprick. Since weekly blood samples were to be collected from the participating infants for at least four weeks after birth, it was more than probable that a set of samples collected over time would contain both venous and capillary blood.

Consequently, to obtain reliable information on dietary influences, the fatty acid profiles of venous and capillary plasma and RBC PLs should be comparable. To our knowledge, no detailed information on this particular subject is available in the literature. The few studies relating to the comparability of venous and capillary plasma for more general analyses of the major lipid classes have yielded ambiguous results [2,3]. Therefore, the primary aim of the present study was to compare PL-associated fatty acid profiles of plasma and RBCs, collected through either venous or capillary puncture. Moreover, since all blood samples of a given study subject were to be analyzed simultaneously to ensure uniformity of analytic conditions, the different storing times of the various blood samples should not influence the resưtrs. Thereiore, we also evaiuated the effects of storage at $-20^{\circ} \mathrm{C}$ for a period up to four weeks on both venous and capillary plasma and RBC PLS.

\subsection{Subjects and methods}

\subsubsection{Experimental design}

For ethical reasons, we decided not to perform this study in young infants. In stead, eight healthy aduits ( 3 males, 5 females), who were all employees or students at our department, volunteered to participate in this study. Informed consent was obtained from all participants. Every subject donated two blood samples: five $\mathrm{ml}$ of venous blood were drawn from an antecubital vein, and approximately two $\mathrm{ml}$ of capillary blood were collected by finger-prick. The blood samples were collected in EDTA-containing tubes to prevent coagulation. The plasma was separated from the RBCs by centrifugation. RBCs were washed twice with EDTA-containing saline ( $\mathrm{Na}_{2}$ EDTA, $2 \mathrm{H}_{2} \mathrm{O} 28.64 \mathrm{~g}$, $\mathrm{NaCl} 7.00 \mathrm{~g}, \mathrm{H}_{2} \mathrm{O} 1000.0 \mathrm{ml}$ ). Each plasma or RBC sample was divided into three duplicate samples. To evaluate a possible effect of storage on the fatty acid content of the blood samples, extractions of the lipids of the three sets of venous and capillary blood samples were done at the day of collection, or one or four weeks thereafter. The tubes containing plasma or RBC suspension were closed under a stream of nitrogen to prevent oxidation and stored at $-20^{\circ} \mathrm{C}$ until analysis.

\subsubsection{Fatty acid analysis}

To ensure uniformity of analytic conditions, the venous and capillary blood samples were analyzed simultaneously.

Al the start of the analysis, approximately $40.0 \mu \mathrm{g}$ 1,2-dinonadecanoyl phosphatidylcholine (PC- $[19: 0]_{2}$ ) were added to every sample as internal standard. Total lipid extracts of 100 
$\mu \mathrm{l}$ of plasma or RBC suspension were prepared according to the method of Bligh and Dyer [4]. The phospholipid (PL) fractions of plasma and RBCS were isolated by solid phase extraction on an aminopropyl-silica column [5]. The PLs were saponified and the fatty acids converted to the corresponding methyl esters by reaction with $14 \%$ boron trifluoride in methanol at $100{ }^{\circ} \mathrm{C}$ for one hour [6]. To all organic solvents, butylated hydroxytoluene (50 $\mathrm{mg} / \mathrm{L}$ ) was added as an anti-oxidant. The fatty acid composition of the PLs was determined by gas liquid chromatography as described before [1], only modified by the use of a CP-Sil 88 column (Chrompack ${ }^{\circ}$, Middelburg. The Netherlands). Fatty acid amounts present in the PL fraction were quantified based on the amount of 19:0 internal standard fatty acid methyl ester recovered and expressed as mg/l plasma or RBC suspension.

In total, 35 fatty acids were identified. In this paper, only the following relevant 8 fatty acids and 5 fatty acid combinations are reported: linoleic acid (18:2n-6), dihomo- $\gamma$-linolenic acid (20:3n-6), arachidonic acid (20:4n-6), adrenic acid (22:4n-6), Osbond acid (22:5n-6), eicosapentaenoic acid (20:5n-3), docosahexaenoic acid (22:6n-3), $\Sigma$ SAFA (sum of all saturated fatty acids), $\Sigma$ MUFA (sum of all monounsaturated fatty acids), $\Sigma$ PUFA, $\Sigma n-6$ LCP (sum of the long chain polyunsaturated fatty acids (LCPs) formed from the parent EFA 18: $2 n-6$ through alternate desaturation and elongation), and $\Sigma n-3$ LCP (sum of the LCPs formed from the parent EFA $\alpha$-linolenic acid (18:3n-3) through alternate desaturation and elongation). In addition, two indices were calculated: the unsaturation index [UI, sum of (number ó doubié bonus * \% level or tatiy acid)] [7], anu the EFA status $(2 n-6+n-3 / 2 n=$ $7+n-9)[8]$.

\subsubsection{Data analysis}

Fatty acid concentrations are presented as medians and interquartile ranges. Fatty acid concentrations of venous and capillary plasma and RBC PLS were compared for each of the three intervals between blood sampling and lipid extraction (zero days, one week and four weeks). In addition, both for venous and capillary plasma and RBC samples, fatty acid con centrations in samples of which lipids were extracted one or four weeks after blood collection were compared with fatty acid concentrations in samples extracted on the day of blood sampling. Because of the number of subjects studied, differences between venous and capillary blood samples were evaluated by calculating the non-parametric $95 \%$ confidence intervals of the ratio of the capillary to the venous concentration of a given fatty acid [9]. Similarly, differences between stored samples and samples that were analyzed on the day of blood collection were evaluated by calculating the non-parametric $95 \%$ confidence intervals of the ratio of the concentration of a given fatty acid after one or four weeks of storage to its concentration after immediate lipid exiraction. The average value of each set of duplicate samples was used in these calculations. All 95\% confidence intervals were calculated based on the two-tailed Wilcoxon signed ranks test and after a log transformation of the ratios to obtain a symmetrical distribution. The intervals thus obtained were then transformed back by taking the exponents of the range limits.

To present the results of the statistical analyses, fatty acid data of venous RBCs stored for one or four weeks are also presented as the percentage level of their concentration at day 0 . Furthermore, fatty acid data of capillary RBCs at day 0 , week 1 and 4 are expressed as the percentage leve! of their venous RBC concentrations at those times, while those at 
week 1 and 4 are also expressed as percentage level of the capillary RBC concentration at day 0 . For these percentage levels, the above-mentioned $95 \%$ confidence intervals are given, preceded by the Hodges-Lehmann estimate [10], which is a non-parametric estimate of the actual ratio of the various samples. This Hodges-Lehmann estimate is comparable t $\mathrm{o}_{\text {, }}$ but more accurate than the median.

If the ratio of one (relative level $=100 \%$ ) was not within the $95 \%$ confidence interval o btained, samples were considered to be significantly different.

\subsection{Results}

In general, the fatly acid profiles of venous and capillary plasma PLS were comparable and unaffected by one or four weeks of storage at $-20{ }^{\circ} \mathrm{C}$ before lipid extraction (table 5.1.). Sometimes, the lower limit of the $95 \%$ confidence interval was just above the $100 \%$ level.

The fatty acid profiles of venous and capillary RBC PLs did not differ when lipids were extracted on the day of blood collection or one week thereafter (see table 5.2. for fatty acid concentrations and table 5.3. for accompanying confidence intervals). For venous RBCs, on e or four weeks of storage before lipid extraction, generally, did not result in significantly different fatty acid concentrations, when compared to those of samples that were extracted on the day of collection. The only exceptions were the concentration of 22:6n-3 and the $v$ alues for the two indices calculated, which were significantly decreased after four weeks o f storage, with the $100 \%$ level lying just above the upper limit of the $95 \%$ confidence interval.

Fatty acid profiles of capillary RBC PL samples were similar when stored for zero days or one week until lipid extraction. However, after four weeks of storage, substantial differences from the initial values were observed. The total amount of PL-associated fatty acids decreased to almost half the initial value and was significantly lower than that in venous RBCs stored for four weeks. This decline mainly resulted from a decline of nearly $90 \%$ in the concentration of polyunsaturated fatty acids ( $\Sigma$ PUFA). Compared to their values after immediate lipid extraction, $\Sigma$ MUFA and $\Sigma$ SAFA concentrations in capillary RBC samples stored for four weeks were $40 \%$ and $20 \%$ lower, respectively. As a restilt, capillary RBC concentrations of $\Sigma$ PUFA and, to a lesser extent, $\Sigma$ MUFA and $\Sigma$ SAFA were lower than their venous concentrations.

Within the group of PUFAs, the largest decrease was observed in the LCPS, particularly those of the $n-6$, series. After four weeks of storage. the concentration of $\Sigma n-6$ LCP, on average, was decreased to merely $4 \%$ of its initial concentration, while that of the parent EFA 18:2n-6 decreased to $17 \%$ of its value after immediate lipid extraction. The concentration of $\Sigma n-3$ LCPS declined to $10 \%$ of its initial value; the parent EFA 18:3n-3 was not present in detectable amounts. Consequently, after four weeks of storage, all capillary LCP concentrations were significantly lower than the venous concentrations with the upper limit of the $95 \%$ confidence interval well below the $100 \%$ level.

Values for both the unsaturation index and the EFA status were also significantly decreased in capillary RBC PLS after four weeks of storage, again reflecting the loss of mainly highly unsaturated fatty acids. 
Table 5.1. Absolute fatty acid composition of venous and capillary plasma phospholipids, with lipid extraction done on the day of collection (day 0), or 1 week, or 4 weeks thereafter [median (interquartile range)].

\begin{tabular}{|c|c|c|c|c|c|c|}
\hline \multirow{2}{*}{$\begin{array}{l}\text { fatty acid } \\
\mathrm{mg} / \mathrm{l}\end{array}$} & \multicolumn{2}{|c|}{ day 0} & \multicolumn{2}{|c|}{ week 1} & \multicolumn{2}{|c|}{ week 4} \\
\hline & venous $(n=8)$ & capillary ( $n=8)$ & venous $(n=8)$ & capillary $(n=7)$ & venous $(n=8)$ & capillary $(n=8)$ \\
\hline total & $1209(453)$ & $1250(398)^{b}$ & $1260(212)$ & $1260(141)$ & $1254(232)$ & $1267(272)$ \\
\hline ESAFA & $583(199)$ & $604(171)^{b}$ & $595(111)$ & $588(84)$ & $611(105)$ & $602(114)$ \\
\hline$\Sigma$ MUFA & $138(45)$ & $149(49)^{b}$ & $150(42)$ & $157(34)$ & $153(38)$ & $156(35)$ \\
\hline$\Sigma$ PUFA & $473(162)$ & $481(167)$ & $503(87)$ & $494(80)$ & $520(155)$ & $524(146)^{c}$ \\
\hline $18: 2 n-6$ & $290(84)$ & $293(83)$ & $289(49)$ & $272(66)$ & $306(84)^{6}$ & $313(81)^{r}$ \\
\hline $20: 3 n-6$ & $27.5(5.2)$ & $28.9(6.5)$ & $30.4(7.6)$ & 33 (11) & 29 (11) & $29.4(9.6)$ \\
\hline $20: 4 n-6$ & $101(20)$ & $103 .(24)$ & $110(35)$ & $103(34)$ & $115(36)$ & $116(36)$ \\
\hline $22: 4 n-6$ & $2.6(1.7)$ & $2.7(2.0)$ & $3.1(1.9)$ & $3.1(2.4)$ & $3.2(1.8)^{c}$ & $3.2(1.3)^{r}$ \\
\hline $22: 5 n-6$ & $2.1(1.2)$ & $2.2(1.0)$ & $2.6(1.1)$ & $2.8(1.3)$ & $2.4(1.4)$ & $2.3(1.2)$ \\
\hline$\Sigma_{n-6 \mathrm{LCP}}$ & $135(23)$ & $138(24)$ & $146(36)$ & $144(43.7)$ & 143 (39) & $141(43)$ \\
\hline $20: 5 n-3 i$ & $6.0(5.9)$ & $6.5(6.1)$ & $7.5(7.4)$ & $7.5(7.1)$ & $7.6(7.3)^{6}$ & $7.4(6.9)^{5}$ \\
\hline $22: 5 n-3$ & $5.8(2.8)$ & $5.8(3.0)$ & $5.7(4.1)$ & $5.3(4.7)$ & $6.0(4.0)$ & $6.1(3.5)$ \\
\hline $22: 6 n-3$ & $32.9(9.3)$ & $35(12)$ & $35(15)$ & $31(18)$ & $39(12)$ & $39(11)^{f}$ \\
\hline$\Sigma_{n-3 \mathrm{LCP}}$ & $45(13)$ & $48(12)$ & $49(16)$ & $46(17)$ & $51(16)$ & $52(16)^{f}$ \\
\hline ut & $124.9(5.1)$ & $123.6(8.7)$ & $124.6(7.8)$ & $124(14)$ & $129(13)$ & $129(14)$ \\
\hline EFA status & $2.93(0.71)$ & $2.92(0.44)$ & $3.06(0.58)$ & $2.94(0.50)$ & $3.04(0.68)$ & $2.91(0.75)$ \\
\hline
\end{tabular}

${ }^{a} \mathrm{SAFA}=$ saturated fatty acids; MUFA $=$ monounsaturated fatty acids; PUFA $=$ polyunsaturated fatty acids; $n-6$ LCP $=$ long-chain PUFAs (LCPs) of the $n-6$ series $(20: 3 n-6,20: 4 n-6,22: 4 n-6,22: 5 n-6) ; n-3$ LCP $=$ LCPS of the $n-3$ series $(20: 5 n-3,22: 6 n-3) ; U]=$ Unsaturation Index: sum of (number of doubie bonds * \% level of fatty acid): EFA status $=$ essential fatty acid status: $\left(\sum n-6+n-3\right) /\left(\sum_{n-7}+n-9\right)$.

Statistical differences:

bratio of capillary to venous concentration: $100 \%$ level just below lower limit of non-parametric $95 \%$ confidence interval;

'ratio of concentration at week 4 to that at day 0: 100\% level just below lower limit of non-parametric 95\% confidence interval 
Table 5.2. Absolute fatty acid composition of venous and capillary red blood cell phospholipids, with lipid extraction done on the day of collection (day 0), or 1 week, or 4 weeks thereafter [median (interquartile range)].

\begin{tabular}{|c|c|c|c|c|c|c|}
\hline \multirow{2}{*}{$\begin{array}{l}\text { fatty acid } \\
\mathrm{mg} / \mathrm{l}\end{array}$} & \multicolumn{2}{|c|}{ day 0} & \multicolumn{2}{|c|}{ week 1} & \multicolumn{2}{|c|}{ week 4} \\
\hline & venous $(n=8)$ & capillary $(n=8)$ & venous $(n=8)$ & capillary $(n=6)$ & venous $(n=8)$ & capillary $(n=8)$ \\
\hline total & $882(346)$ & $841(282)$ & 914 (196) & $893(164)$ & $811(241)$ & $462(137)$ \\
\hline$\Sigma$ SAFA & $407(140)$ & $396(121)$ & $422(78)$ & $421(78)$ & $393(111)$ & $330(82)$ \\
\hline$\Sigma$ MUFA & $166(74)$ & $162(59)$ & $177(42)$ & $172(42)$ & $176(59)$ & $103(29)$ \\
\hline$\Sigma$ PUFA & $297(133)$ & $271(101)$ & $301(60)$ & $293(51)$ & $261(77)$ & $33(26)$ \\
\hline $18: 2 n-6$ & $119(39)$ & $117(20)$ & $116(25)$ & $123(27)$ & $112(44)$ & $18(12)$ \\
\hline $20: 3 n-6$ & $11.2(4.6)$ & $10.6(4.5)$ & $12.7(4.2)$ & $12.3(3.8)$ & $9.4(4.4)$ & $0.99(1.06)$ \\
\hline $20: 4 n-6$ & $91(46)$ & $83(36)$ & $103(28)$ & $99(17)$ & $78(21)$ & $2.5(7.6)$ \\
\hline $22: 4 n-6$ & $21(17)$ & $20(15)$ & $24.8(8.6)$ & $25.3(9.5)$ & $20.9(7.8)$ & {$[.7(1.3)$} \\
\hline $22: 5 n \cdot 6$ & $2.6(1.9)$ & $2.3(1.7)$ & $3.2(1.8)$ & $3.2 .(2.4)$ & $2.5(1.5)$ & NDi \\
\hline$\sum n-6$ LCP & $125(73)$ & $113(58)$ & $148(36)$ & $135(25)$ & $109(33)$ & $6.1(7.9)$ \\
\hline $20: 5 n-3$ & $4.1(2.7)$ & $4.1(2.5)$ & $7.5(7.4)$ & $7.5(7.1)$ & $3.4(3.4)$ & NDi \\
\hline $22: 5 n-3$ & $13.2 .(4.4)$ & $12.1(3.1)$ & $13.1(5.3)$ & $13.4(5.5)$ & $13.3(4.5)$ & $2.10(0.91)$ \\
\hline $22: 6 n-3$ & $27(14)$ & $27(12)$ & $35(15)$ & $31(18)$ & $18(14)$ & $2.5(1.8)$ \\
\hline$\sum n-3 \mathrm{LCP}$ & $46(18)$ & $44(17)$ & 46 (19) & $45(19)$ & $35(12)$ & $4.4(4.0)$ \\
\hline ui & $131(12)$ & $131(10)$ & $129.0(8.8)$ & $132(13)$ & II $8(20)$ & $50(13)$ \\
\hline EFA status & $1.70(0.17)$ & $1.72(0.15)$ & $1.73(0.24)$ & $1.74(0.11)$ & $1.49(0.55)$ & $0.35(0.12)$ \\
\hline
\end{tabular}

$a_{\text {as }}$ in table 5.1 . in addition: $\mathrm{ND}=$ none detected $(<0.1 \%$ (wt/wt) of total fatty acid methyl esters). For statistical differences: see table 5.3. 
Table 5.3. Comparison of fatty acid compositions of venous (V) and capillary (C) rod blood cell (RBC) phospholipids, with lipid extraction done on the day of collection (day 0), or 1 week (wk 1), or 4 weeks (wk 4) thereafter [venous RBC day 0: median (interquartile range), others: HodgesLehmann estimate $\left.(95 \% \text { confidence interval })^{a}\right]$.

\begin{tabular}{|c|c|c|c|c|c|c|c|c|}
\hline fatty acid" & $\begin{array}{c}V \text { day } 0(m / 2) \\
\qquad(n=8)\end{array}$ & $\begin{array}{c}C \text { day } 0 \mathrm{~V} \text { day } 0^{\circ} \\
\text { too? }(\mathrm{u}=8)\end{array}$ & $\begin{array}{c}\text { V wh } L / \text { V day } 0^{*} \\
100 \%(n=8)\end{array}$ & $\begin{array}{c}\text { c whk lic day } 0 . \\
\text { loo\% }(n=6)\end{array}$ & 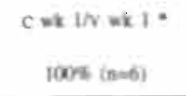 & $\begin{array}{l}r \text { wk } 4 / \mathrm{V} \text { day } 0^{\circ} \\
\text { tors (nes) }\end{array}$ & 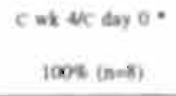 & 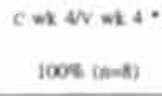 \\
\hline fotal & $882(346)$ & $97.2(90.5-106.5)$ & $106.9(8.8 .123 .9)$ & $107.6(93.6 .124 .4)$ & 93.1050 .101 .60 & $90.5(00.2 .1176)$ & $530(0.264)$ & $586(43.1-74.1)$ \\
\hline I SAFA & $407(140)$ & $98.1(91,3.106 .4)$ & $107.1(87.8-120.9)$ & $1066(95.41213)$ & $93.7(84+101.1)$ & $96.5023-12493$ & $79.6(65.3 .96 .1)$ & 78. (64.5.9.3) \\
\hline 2 MUTA & $106(7.4)$ & $96.9(90.8-108.6)$ & $108.7(84.9 .126 .5)$ & $104.4(95.5-120.2)$ & $93.5(80.6-98.9)$ & $95.4(73.9-1233)$ & $59.8(49.80 .6)$ & $61.5(47.1-82.6)$ \\
\hline$\sum$ MFA & $297(133)$ & $94.8(89.3-105.6)$ & $106.7(81.1 .128 .7)$ & $111.0(89.8 \cdot 130.8)$ & 91.6 (36.1.102 5$)$ & $\$ 17054-112.13$ & $123(9.4-16.4)$ & $185(2.433)$ \\
\hline $18: 2 n-6$ & $119(39)$ & $96.5(89.7 .106 .5)$ & $1045(84.4-122.6)$ & $106.6(91,0-121.0)$ & 92.9 (45.7.102.9) & $\mathrm{ks} 2(47.1-1213)$ & $17.1(12.20 .9)$ & $19.2(12.4 .3 .5)$ \\
\hline $20 \cdot 3 n-6$ & $112(46)$ & $96.1(89.0-109.7)$ & $105.2(82.9 .122 .3)$ & $107.9(865-121.8)$ & $912(84.6 .102 .2)$ & $10.9(345-1075)$ & $6.9(2.6-12.1)$ & $2.5(2.1 .30 .9)$ \\
\hline $20 \cdot 4 n-6$ & $91(46)$ & $96.4(88.2 .107 .6)$ & $107.4(79.8 .134 .5)$ & $112.4(91.2 .139 .7)$ & $93.2(86.7 .1039)$ & $\$ 13(19,4-1144)$ & $1.4(0.2 .1 .0)$ & $26(0.2 .16 .7)$ \\
\hline $22: 4 n \cdot 6$ & 21 (17) & $94.6(87.2 .105 .2)$ & $108.9(80.4-137.7)$ & $118.2(89.9 \cdot 143.5)$ & 93.7 (52.6.101.5) & nos (09,6.1205) & $6(4.6 .9)$ & 7.708 .203 \\
\hline $22: \sin 6$ & $26(1.9)$ & $95.5(89+107.0)$ & $108.4(820-138.0)$ & $1145(85,4-1446)$ & $943(02.9-102.2)$ & Q8.6(13) $8-1277)$ & 4.2 (1.5.9.2) & $56(26.23 .4)$ \\
\hline$I=6 . \mathrm{LS}$ & t2s (72) & $96.0(88.4-1077)$ & $107.5(8.0 .133 .6)$ & $113.1(91.0-138.1)$ & $92.4(85.9-103.2)$ & $02.1(22.9 .113 .3)$ & 27 (1.8.9.5) & $0.7(1.7 .22 .4)$ \\
\hline $20.5 n \cdot 3$ & $4+(2.7)$ & $99.6(94.6-107.6)$ & $108.3(81.7-131.3)$ & $107.2(88.3 .130 .6)$ & $90.700 .3 .1009)$ & $4.202-12305$ & $32(1.0-10.2)$ & $53(14+309)$ \\
\hline $22 \cdot \ln \cdot 3$ & $13(44)$ & $942(85.0-104.4)$ & $105.7(79.7-1330)$ & $1133(871-1449)$ & $93.1(20.0 .1007)$ & 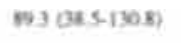 & $17.3(9.1 .227)$ & $17.9(5.4-4.7)$ \\
\hline $22 \cdot 6 n-3$ & 27 (14) & $95.5(91.6-1044)$ & $1032(79.1-136.6)$ & $1139(85.8-139.8)$ & $944(240.100 .7)$ & $55.5(17.8 .962)$ & $5.6(5.5 .159)$ & IE. $(6.6527)$ \\
\hline $2 n-3$ Ler & $40(18)$ & $95.6(90 .+103.5)$ & $1047(79.6-132.0)$ & $1130(86+140,8)$ & $93.9(02.402 .6)$ & $0.5(244.1043)$ & $10.3(7.7 .16 .6)$ & 187 as. -40.4 \\
\hline is & $131(12)$ & $992(979-101.0)$ & $90,8(95,4-1054)$ & $103.9(96.9-105.9)$ & 1002 (97.9.1027) & 913 (s7.9.9. & $38 .(56-41.1)$ & 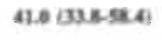 \\
\hline Exh status & $1.70(0.17)$ & $907(97,6-118.8)$ & $\Phi_{1}(93+1053)$ & $1053(93.9-109.9)$ & $1008,005,106.4)$ & $\operatorname{ses}(41.1-98 x)$ & $19.4(16.7-219)$ & $253(152-46)$ \\
\hline
\end{tabular}

"Non-parametric Hodges-Lehmann estimates and $95 \%$ confidence intervals, calculated based on the two-tailed Wilcoxon signed ranks test and after a $\log$ transformation of the ratios to obtain a symmetrical distribution.

$95 \%$ Confidence intervals indicating significant differences ( $100 \%$ level outside limits) are printed in bold face.

As in table 5.1 . 


\subsection{Discussion}

The results of this study show that, after four weeks of storage at $-20^{\circ} \mathrm{C}$ before lipid extraction, fatty acid profiles in RBC PLs isolated from venous and from capillary blood are no longer comparable. This is the result of substantial losses of fatty acids, and of PUFAs in particular, mainly in capillary RBCs. The fatty acid profiles of venous and capillary plasma PLs are unaffected by four weeks of storage and remain to be essentially similar.

The good comparability of the fatty acid compositions of venous and capillary plasma PLs enables an accurate evaluation of dietary influences in longitudinal sample sets consisting of both venous and capillary plasma, as was the case in our dietary study in preterm infants [1]. Particularly in this type of study, which is increasingly being done, the abovementioned observation can contribute to a reduction of the burden that extra blood punctures impose on the participating infants.

A few studies have evaluated changes in the PL-associated fatty acid profile of venous plasma samples that were stored for longer periods (up to one year) under conditions similar to ours $[11,12]$. Hirsch and co-workers [11] identified the limited number of 6 fatty acids, of which 18:2n-6 and 20:4n-6 were the only PUFAs, and found a significantly decreased percentage level of 20:4n-6. De Jong [12] and co-workers reported a few significant decreases of individual fatty acid levels, that were independent of the degree of unsaturation.

Loss of PL-associated PUFAs from RBCS as a consequence of storage at temperatures below $0{ }^{\circ} \mathrm{C}$ has also been reported by others [13-15]. Autoxidation of PUFAs is the obvious major cause for the changes observed in the fatty acid content of stored RBC samples. Iron, which is largely present in haemoglobin, is a catalyst in the process of lipid peroxidation, both in the initiation and propagation stages [16-20]. Indeed, in contrast to his observations in intact RBCs, Ways [14] reported that the PL content of haemoglobin free RBC ghosts was not affected by storage under the same conditions.

However in the present study, the pronounced decrease of the PUFAs in the capillary samples was accompanied by reduced concentrations of SAFAS and MUFAS, which are unlikely to be caused by autoxidation. Breakdown of PLs by phospholipases as an explanaiion for these SAFA and MUFA losses seems improbable, because this requires the presence of calcium, which will have been removed by the substantial amounts of EDTA that were present both in the tubes in which the blood samples were collected and in the solution with which the RBCs were washed. A reduced recovery, particularly during the extraction step of fatty acid analysis. [21], of PLs containing a SAFA or MUFA chain next to an oxidized PUFA chain, which is more polar than an unaffected PUFA chain, seems a more possible cause. Anyway, the observation of decreased SAFA and MUFA concentrations stresses the additional information that can be obtained from evaluating absolute fatty acid data. In figure 5.1., effects of storage on the absolute and relative ( $\%$ (wt/wt) of total fatty acids) SAFA, MUFA and PUFA values in venous and capillary RBC PLs are visualized. After four weeks of storage, relative levels of $\Sigma$ SAFA and $\Sigma$ MUFA were increased in stead of decreased, which would suggest a shift in the fatty acid content of the RBCs, rather than a loss of all types of fatty acids, which is what really happened. 

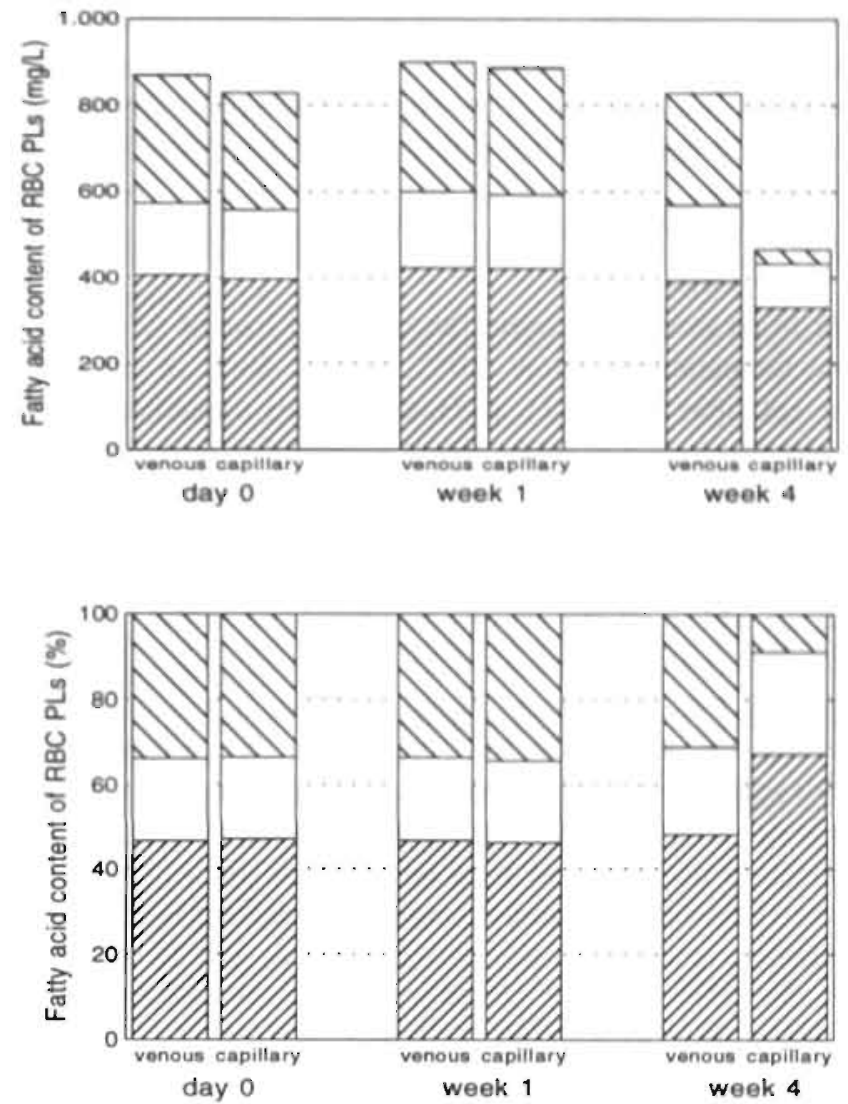

$\square$ I SAFA $\square \boldsymbol{\Sigma}$ MUFA $\square \boldsymbol{\Sigma}$ PUFA

Figure 5.1. Absolute (upper) and relative (lower) fatty acid composition of capillary and venous red blood cell suspensions, stored at $-20^{\circ} \mathrm{C}$ for zero days, one week or foui weeks before lipid extraction. $\Sigma$ SAFA $=$ sum of all saturated fatty acids; $\Sigma$ MUFA $=$ sum of all monounsaturated fatty acids; $\Sigma$. PUFA $=$ sum of all polyunsaturated fatty acids.

The most striking finding of the present study is not that of multiple significant fatty acid losses, but the fact that these losses were mainly observed in the capillary RBC samples. When performing a capillary puncture, the blood is driven into a tube with considerable manual pressure, leading to more damage to the RBC membrane than when performing a venous puncture. In fact, all of the capillary and none of the venous samples collected in our study showed signs of haemolysis as a result of this loss of RBC membrane structural integrity, which may enhance RBC susceptibility for lipid peroxidation in a number of ways. Firstly, the tissue damage can result in the release of otherwise sequestered 
iron, which thus becomes available for the radical reactions involved in autoxidation [20]. Secondly, the structural insulation that proteins give to autoxidisable lipids [22] as well as the protective structural organization of the lipids themselves [23] are disturbed. In any event, also in the present study, venous RBC PLs were not completely unaffected by four weeks of storage: the 22:6n-3 concentration and the unsaturation index and EFA status index were even significantly reduced. Moreover, the $95 \%$ confidence intervals of all PUFAs were wide, with a low lower limit.

Attempts ought to be made to prevent the observed loss of RBC fatty acids. Storage of RBC suspensions at temperatures below $-20^{\circ} \mathrm{C}$, e.g. at $-50^{\circ} \mathrm{C}$ or even $-80^{\circ} \mathrm{C}$, will perhaps delay, but not prevent lipid loss (A.C. v. Houwelingen, unpublished data). Based on the concept of iron-induced oxidation as the major cause of lipid loss from stored RBCs, one option is to remove haemoglobin from the RBC lipids by preparing red cell ghosts [14] or lipid extracts from the RBCs within one week after blood sampling. Dodge and Philips [13] observed no changes in RBC extracts stored in the presence of butylated hydroxytoluene, an anti-oxidant which we add to all the organic solvents used in the fatty acid analysis. However, if one wishes all steps of the analyses to be simultaneous for a series of consecutive RBC samples, storage of RBC suspensions is unavoidable. In this case, autoxidation may be prevented by handling and storing the RBC samples in the presence of a chelating agent, preferably desferrioxamine [24], which binds iron and thus prevents it from promoting lipid peroxidation. Desferrioxamsne has been demonstrated to erfecuvefy prevent or at feast reduce lipid peroxidation in various in vitro and in vivo studies [24-27]. However, further studies are needed to determine its effectiveness in preventing lipid loss from RBC samples stored for longer periods at temperatures below $0{ }^{\circ} \mathrm{C}$, as will be the case in many dietary studies.

In conclusion, the results of this study show that plasma PL-associated fatty acid profiles of venous and of capillary blood are comparable and unaffected by storage at $-20^{\circ} \mathrm{C}$ until lipid extraction for up to four weeks. When stored for more than one week until lipid extraction, the fatty acid content of RBC suspensions, particularly when of capillary origin, will be affected by lipid loss, with the largest decreases observed in the highly unsaturated fatiy acids. This makes these RBC samples unsuitable for a proper evaluation of dietary effects.

\subsection{References}

1. Foreman- $v$ Drongelen MMHP, Houwelingen AC v, Kester ADM, de Jong AEP, Blanco CE, Hasaar THM, Hornstra G. Long chain polyene status of preterm infants with regard to the fatty acid composition of their diet: comparison between absolute and relative fatty acid levels in plasma and erythrocyte phospholipids. Br J Nutr; 73:405-22.

2. Kupke IR, Zeugner S, Gottschalk A, Kather B. Differences in lipid and lipoprotein concentrations of capillary and venous blood samples. Clin Chem Acta 1979;97:279-83.

3. Thielmann K, Rühling K, Schauer I, Heller R. Traut H. Suitability and recovery of capillary blood plasma for lipid determinations (in German). Acta Biol Med Germ 1979:38:1115-1121.

4. Bligh EG. Dyer WJ. A rapid method for total lipid extraction and purification. Can J Biochem Physiol 1959:37:911-917.

5. Kaluzny MA, Duncan LA, Merritt MV, Epps DE. Rapid separation of lipid classes in high yield and purity using bonded phase columns. J Lipid Res 1985;26:135-40. 
6. Morrisson WR, Smith LM. Preparation of fatty acid methyl esters and dimethylacetals from lipids with borontrifluoride-methanol. J Lipid Res 1964:5:600-8.

7. Farias RN, Bloj B, Morero RD, Sineriz F, Trucco RE. Regulation of allosteric membrane-bound enzymes through changes in membrane lipid composition. Biochem Biophys Acta 1975;415:231. 51.

8. Hornstra G, Al MDM, Gerrard JM, Simonis MMG. Essential fatty acid status of neonates born to Inuit mothers: comparison with Caucasian neonates and effect of diet. Prostaglandins Leukotrienes Essent Fatty Acids 1992;45:125-30.

9. Brown BW, Hollander M. Statistics: A Biomedical Introduction, 1st edn. John Wiley and Sons, New York 1977:317-9.

10. Lehmann EL. Nonparametrics, 1st edn. Holden-Day, New York 1975:180.

11. Hirsch EZ, Slivka S, Gibbons AP. Stability of fatty acids in hyperlipoproteinemic plasma during long-term storage. Clin Chem 1976;22:445-8.

12. de Jong AEP, van den Berg TS, Nijmeijer-Couprie A, Goedhart JP, Oosting E. Long-term aspects of phospholipidic analysis of fatty acid methyl esters by use of nonpolar capillary gas chromatography. Am. J Clin Nutr 1993;57:\$813.

13. Dodge JT, Philips GB. Autoxidation as a cause of altered lipid distribution in extracts from human red cells. J Lipid Res 1966;7:387-95.

14. Ways PO. Degradation of glycerophosphatides during storage of saline-washed, saline-suspended red cells at $-20^{\circ} \mathrm{C}$. J Lipid Res 1967;8:518-21.

15. Glatz JFC, Soffers AEMF, Katan MB. Fatty acid composition of serum cholesteryl esters and erythrocyte membranes as indicators of linoleic acid intake in man. Am J Clin Nutr 1989;49:26976.

16. Halliwell B. Superoxide-dependent formation of hydroxyll radicals in the presence of iron-salts. FEBS Lett 1978;96:238-43.

17. Aust SD, Morehouse LA, Thomas CE. Role of metals in oxygen radical reactions. J Free Radical Biol Med 1985; 1:3-25.

18. Halliwell B, Gutteridge JMC. Oxygen free radicals and iron in relation to biology and medicine: Some problems and concepts. Arch Biochem Biophys 1986;246:501-14.

19. Chiu D, Kuypers F, Lubin B. Lipid peroxidation in human red cells. Semin Hematol 1989;26:257-76.

20. Gutteridge JMC. Iron and oxygen: a biologically damaging mixture. Acta Pædiat Scand Suppl 1989:361:78-85.

21. Christie WW. Lipid Analysis, 2nd edn. Pergamon Press, Oxford 1982:17-9.

22. Stocks J, Kemp M, Dormandy TL. Increased susceptibility of red-blood-cell lipids to autoxidation in hæmolytic states. Lancet 1971;i:266-9.

23. Halliwell B, Gutteridge JMC. Free Radicals, in Biology and Medicine, 2nd edn. Clarendon Press, Oxford 1989:234-6.

24. Gutteridge JMC, Richmond R, Halliwell B. Inhibition of the iron-catalysed formation of hydroxy! radicals from superoxide and of lipid peroxidation by desferrioxamine. Biochem J 1979;184:469. 72.

25. Fuller BJ, Lunec J, Healing G, Simpkin S, Green CJ. Reduction of susceptibility to lipid peroxidation by desferrioxamine in rabbit kidneys subjected to 24 -hour cold ischemia and reperfusion. Transplantation 1987;43:604-6.

26. Menasché P. Antebi H, Alcindor L-G, Teiger E, Perez G, Giudicelli Y, Nordmann R, Piwnica A. Iron chelation by deferoxamine inhibits lipid peroxidation during cardiopulmonary bypass in humans. Circulation 1990;82:SIV390-6. 
Chapter 5

27. Knight JA, Voorhees RP, Martin L. The effect of metal chelators on lipid peroxidation in stored erythrocytes. Ann Clin Lab Sci 1992;22:207-13. 


\title{
Long-chain polyene status of preterm infants with regard to the fatty acid composition of their diet: comparison between absolute and relative fatty acid amounts in plasma and red blood cell phospholipids
}

\author{
Magritha M.H.P. Foreman-van Drongelen', Adriana C. v. Houwelingen', \\ Arnold D.M. Kester ${ }^{2}$, André E.P. de Jong ${ }^{3}$, Carlos E. Blanco ${ }^{4}$, Tom H.M. \\ Hasaart ${ }^{5}$ and Gerard Hornstra! \\ ${ }^{1,2}$ Departments of 'Human Biology and ${ }^{2}$ Methodology and Statistics, University of Lim- \\ burg, Maastricht, The Netherlands \\ ${ }^{3}$ Analytical Biochemical Laboratory, Assen, The Netherlands \\ ${ }^{45}$ Departments of "Neonatology and ${ }^{5} \mathrm{Obstetrics}$ and Gynaecology, University Hospital \\ Maastricht, Maastricht, The Netherlands
}

British Journal of Nutrition 1995;73:405-422

\subsection{Abstract}

The long-chain polyene, or long-chain polyunsaturated fatty acid (LCP) status of 39 preterm infants (birthweight $<1800 \mathrm{~g}$ ) was evaluated. Twenty-șeven infants were fed on an artificial formula, 12 received their own mother's breast milk. Fatty acid compositions of both plasma and red blood cell (RBC) phospholipids (PLS) were determined in umbilical venous blood and in weekly postnatal blood samples until the 28 th day of life. Individual fatty acid levels were expressed as absolute quantities ( $\mathrm{mg}$ fatty acid/I plasma or RBC suspension) and as relative (weight \%) values. The changes with time in the absolute values for 22:6n-3 and 20:4n-6 in plasma were strikingly different from those of the relative values for these fatty acids. In plasma PLs the inter-group differences in the absolute postnatal values for $22: 6 n-3(P<0.0005)$ and $20: 4 n-6,(P<0.05)$ and the relative values for 22:6n-3 $(\mathrm{P}<0.02)$ were significant, with lower fatty acid values in the formula fed infants. In RBC PLs, no significant inter-group differences in the postnatal $22: 6 n-3$ and $20: 4 n-6$ values were found. Based on the assumption that it is desirable for formula-fed infants to achieve postnatal plasma LCP values at least comparable with those found in infants fed on human milk, the findings of the present study indicate that both $n-3$ and $n-6$ LCPs should be added 
to preterm infant formulas. Moreover, the additional importance of absolute fatty acid levels was demonstrated, although analytical procedures need to be standardized to enable effective comparison of results from different research groups.

\subsection{Introduction}

The demand of the fetal and neonatal brain for docosahexaenoic acid (cervonic acid, 22:6n-3) and arachidonic acid (20:4n-6) shows a substantial increase during the last trimester of pregnancy and the first months of postnatal life [1,2]. Therefore, an adequate supply of these LCPS (essential fatty acids (EFAs) with a chain length of 20 carbon atoms or more), which are two of the most abundant structural fatty acids in the brain $[3,4]$ as well as in the retina [5], is required both pre- and postnatally.

Conventional artificial formulas, unlike human milk, do not contain any but trace amounts of $22: 6 n-3,20: 4 n-6$ and other LCPS [6-8]. Substantial amounts of the parent EFAS linoleic acid (18:2n-6) and $\alpha$-linolenic acid (18:3n-3) are present in artificial formulas [6-8]. However, the desaturase capacity of newborns is probably too limited to guarantee an adequate supply of $n-3$ and $n-6$ LCPs solely through metabolic conversion of these two fatty acids $[9,10]$. Since neonatal LCP stores, particularly those of preterm newborns, are very limited as well $[2,11]$, the use of conventional formulas could result in a considerable deterioration of the LCP status after birth. eșecially in children who are born nreterm. The occurrence of such a deterioration has indeed been reported in a number of studies [12-15]. Further investigations have demonstrated that adding $n-3$ or $n-3$ and $n-6$ LCPS to the artificial formulas results in a substantial reduction of this deterioration [14,15-17].

The conclusions of the majority of these studies were based on relative fatty acid values (that is either weight or molar percent of total fatty acids) for plasma [14] or RBC lipid fractions $[12,13,16]$. The impression obtained from relative values, however, can be strikingly different from that obtained from absolute amounts. For example, while relative values for 20:4n-6 and 22:6n-3 are higher in cord plasma PLs than in maternal plasma, absolute quantities ( $\mathrm{mg} / \mathrm{l}$ plasma) are significantly lower. This is due to a considerably lower PL concentration in cord blood [18]. In addition, when comparing preterm infants fed on an artificial formula with preterm infants receiving fat-free parenteral nutrition, a larger increase between birth and the 3rd day of life in the ratio of $20: 3 n-9$ to $20: 4 n-6$ (commonly used as biochemical evidence of EFA deficiency) was observed in the latter group. This was not associated with lower absolute amounts of $n-3$ and $n-6$ LCPS in this group [19]. Thus, absolute fatty acid values may very well provide additional information on the LCP status of preterm infants, as influenced by their nutritional EFA intake.

To evaluate this assumption, the postnatal pattern of the LCP status, with special emphasis on 22:6n-3 and 20:4n-6, of preterm infants fed on conventional artificial formulas was compared with that of preterm infants receiving their own mother's breast milk. The LCP patterns of both plasma and RBC PLs were studied. PLs are structural lipids, which are the richest source of polyunsaturated fatty acids (PUFAs), including LCPS. In addition, changes in PUFA profile are most pronounced in PLS [20]. The fatty acid values were expressed as absolute quantities ( $\mathrm{mg} / \mathrm{l}$ plasma or RBC suspension) and as relative values ( $\%$ (wt/wt) of total fatty acids). 


\subsection{Subjects and methods}

\subsubsection{Experimental design}

\section{Subjects}

Thirty-nine infants, born before the 37 th week of gestation and free from metabolic disease and major congenital malformations, participated in this study. Gestational age was confirmed by menstrual history and early ultrasound dating, and by Dubowitz score [21] if the former information was missing or doubtful. The infants had to have a birthweight of $1800 \mathrm{~g}$ or less, because larger infants were likely to be discharged before the intended duration of the study (4 weeks). Immediately after delivery (day 0), approximately $3 \mathrm{ml}$ umbilical venous blood was collected. Thereafter, the EFA status of the infants was monitored until they were discharged or transferred to a non-participating hospital. For this purpose, a weekly sample of approximately $0.5 \mathrm{ml}$ of capillary or venous blood was collected in conjunction with a diagnostic puncture. These diagnostic punctures were part of the routine clinical monitoring of all preterm infants at the neonatology ward and were done mainly to evaluate the electrolyte status, blood glucose, triglyceride and amino acid levels and the red and white blood cell count. Because frequent oral feeds are given (every 2-3 hours) to preterm infants, blood samples could not be collected after fasting, but were taken between $I$ and 1.5 hour after a feed. The study was approved by the Medical Ethics Conmittee of the participating hospitals and written informed consent was obtained from one or both parents.

The children were admitted to the neonatal care unit, where they were cared for in an incubator until being transferred to a crib at a weight of $2000 \mathrm{~g}$. If the infants were in satisfactory clinical condition they were discharged at a weight of $2400 \mathrm{~g}$. Clinical care was provided by the attending neonatologists and resident physicians, according to current standards; this included respiratory support through continuous positive airway pressure or intubation and mechanical ventilation, if necessary. Careful records of these and other clinical details were made. Weight was recorded daily.

Some infants received intravenous RBC and plasma infusions at different limes during the treatment. Since these preparations contain significant amounts of $22: 6 n-3$ and $20: 4 n-6$, the time of infusion and the amount administered were recorded carefully. Furthermore, neonatal blood samples were always collected 24 hours or more after an infusion.

The most important clinical and nutritional characteristics of the study groups are shown in table 6.1. No significant differences were found for any of these features.

\section{Diets}

Until the infants were on full enteral feeding they received parenteral nutrition, containing the appropriate amounts of carbohydrates $(210 \mathrm{~kJ} / \mathrm{kg} / \mathrm{d})$, amino acids $(50 \mathrm{~kJ} / \mathrm{kg} / \mathrm{d})$, vitamins, and minerals. In addition, up to $95 \mathrm{~kJ} / \mathrm{kg} / \mathrm{d}$ of intravenous lipids (Intralipid $10 \%$. and $20 \%$, Vitalipid ${ }^{*}$ ) were given as a source of fat. Since these preparations proved to contain up to 0.2 and $0.3 \%$ (wt/wt) of $22: 6 n-3$ and 20:4n-6 respectively (M.M.H.P. Foreman-v Drongelen, unpublished results), the amounts given were registered. 
Table 6.1. Clinical and nutritional characteristics of human milk (HM) and artificial formula (AF) study groups $^{a}$.

\begin{tabular}{|c|c|c|}
\hline & HM group $(n=12)$ & AF group $(n=27)$ \\
\hline maternal age $(y)$ & $29.0(28.0-32.0)$ & $28.0(24.5-30.5)$ \\
\hline primipara $^{b^{b}}$ & $7(58.3 \%)$ & $14(51.9 \%)$ \\
\hline gestational age (weeks.days) & $31.2(29.5-34.1)$ & $30.5(29.0-34.3)$ \\
\hline birth weight $(\mathrm{g})$ & $1415(1065-1615)$ & $1400(1120-1720)$ \\
\hline weight gain day $0-28(\mathrm{~g} / \mathrm{kg} /$ day $)$ & $10.1(7.4-12.9)$ & $12.1(9.3-14.7)$ \\
\hline $\operatorname{SGA}^{c}(\mathrm{P}<2.3)^{b}$ & $3(25.0 \%)$ & $5(18.5 \%)$ \\
\hline IV lipids (kJ/kg/day) & $23.8(15.4-52.2)$ & $16.2(6.7-31.6)$ \\
\hline IV plasma $(\mathrm{ml})^{d}$ & $10.4(12.4)$ & $21.8(32.3)$ \\
\hline IV $\operatorname{RBCs}^{\epsilon}(\mathrm{ml})^{d}$ & $14.5(20.7)$ & $27.8(35.0)$ \\
\hline enteral intake ( $\mathrm{kJ} / \mathrm{kg} /$ day) & $298(222-416)$ & $261(240-368)$ \\
\hline age at first enteral intake (days) & $4.0(3.0-6.5)$ & $6.0(3.0-8.0)$ \\
\hline age at full cnteral intake (days) & $14.5(11.0-19.5)$ & $13.0(9.0-22.0)$ \\
\hline vent. support (days) ${ }^{c, e}$ & $3.0(5 ; .2)$ & $5.0(10.4)$ \\
\hline vent. support $>24 \mathrm{~h}^{b, e}$ & $6(50.0 \%)$ & $11(44.8 \%)$ \\
\hline $\mathrm{BPD}^{B . c}$ & $0(0.0 \%)$ & $2(7.4 \%)$ \\
\hline sepsis $^{b}$ & $4(33.3 \%)$ & $4(14.8 \%)$ \\
\hline $\mathrm{IVH} \mathrm{H}^{b, c}$ & $0(0.0 \%)$ & $4(14.8 \%)$ \\
\hline
\end{tabular}

"Median (interquartile range) except for ${ }^{b}$ number of subjects and ${ }^{d}$ mean \pm SD.

${ }^{\prime} \mathrm{SGA}=$ small for gestational age (birth weight below the $2.3 \mathrm{rd}$ percentile of the Amsterdam growth charts [44]), IV = intravenous, RBCs= red blood cells,

$\mathrm{BPD}=$ bronchopulmonary dysplasia, $\mathrm{IVH}=$ intraventricular haemorrhage.

'ventilatory support included mechanical ventilation and continuous positive airway pressure.

When the infants were able to tolerate enteral feedings, they were given (initially expressed) preterm human milk obtained from their own mothers, in case they decided to breastfeed. These infants $(n=12)$ formed the human milk group. Incidentally, $5 \mathrm{~g}$ preterm formula powder (preterm formula A, table 6.2.) per $100 \mathrm{ml}$ of preterm human milk was added to increase an infant's energy intake, in case there was no satisfactory growth on breast milk alone. When the mother was unable to express enough milk, an appropriate formula was supplied to cover the nutritional demand of her child. If the intake of artificial formula exceeded 25 percent $(\mathrm{vol} / \mathrm{vol})$ of the total enteral intake, the infant was excluded from the human milk group. If the mother did not wish to provide breast milk, the infant was introduced to enteral feeding with a special preterm infant formula (A or B, table 6.2.) used on the ward. At a weight of $2100-2200 \mathrm{~g}$ the preterm infant formula was replaced by a regular infant formula (C or D, table 6.2.). All formulas given were commercially available. These infants $(n=27)$, who did not receive any human milk, formed the artificial 
Table 6.2. Fatty acid composition (own analyses) of total lipids of preterm human milka (HM) and preterm and term artificial formulas (AFs).

\begin{tabular}{|c|c|c|c|c|c|}
\hline \multirow{2}{*}{$\begin{array}{l}\text { Fatty acid } \\
\% \text { (wt/wt) }\end{array}$} & \multirow{2}{*}{$\begin{array}{l}\text { preterm HM } \\
(\mathrm{n}=11)\end{array}$} & \multicolumn{2}{|c|}{ preterm AF } & \multicolumn{2}{|c|}{ term AF } \\
\hline & & A & B & c & D \\
\hline ¿ SAFA & $44.3 \cdot(41.5-49.9)$ & 53.6 & 54.4 & 54.7 & 45.6 \\
\hline$\Sigma$ MUFA & $36.9(32.4-39.1)$ & 29.2 & 26.5 & 33.5 & 37.7 \\
\hline$\sum n-9$ PUFA & ND & ND & 0.10 & ND & ND \\
\hline $18: 2 n-6$ & $12.2(10.8-15.2)$ & 15.6 & 18.1 & 10.8 & 16.3 \\
\hline $20: 4 n-6$ & $0.58(0.48-0.70)$ & ND & ND & ND & ND \\
\hline$\sum n-6$ LCP & $1.86(1.57-2.12)$ & ND & 0.13 & ND & ND \\
\hline $18: 3 n-3$ & $1.01(0.90-1.25)$ & 1.47 & 0.62 & 0.77 & 0.34 \\
\hline $22: 6 n-3$ & $0.36(0.30-0.44)$ & ND & ND & ND & ND \\
\hline$\Sigma n-3$ LCP & $0.79(0.71-0.86)$ & ND & 0.16 & ND & ND \\
\hline
\end{tabular}

"Median (interquartile range) of average content during the study period (day 0 to day 28).

${ }^{b} \mathrm{SAFA}=$ saturated fatty acids, MUFA $=$ monounsaturated fatty acids, PUFA $=$ polyunsaturated fatty acids, $n-6$ $L C P=$ sum of $n-6$ long-chain polyenes $(20: 2 n-6,20: 3 n-6,20: 4 n-6,22: 2 n-6,22: 4 n-6,22: 5 n-6$ and $24: 2 n-6), n$ 3 LCP $=$ sum of $n-3$ long-chain polyenes $(20: 4 n-3,20: 3 n-3,20: 5 n-3,22: 3 n-3,22: 5 n-3$ and $22: 6 n-3)$.

${ }^{c} \mathrm{ND}=$ none detected (less than $0.1 \%$ (w/ wt) of total fatty acid methyl esters).

formula group. The discrepancy between the number of subjects in the human milk group $(n=12)$ and the formula group $(n=27)$ reflects the general distribution of the type of oral nutrition given within the preterm population at the Neonatology Departments of the participating hospitals.

Enteral feeds were administered through a nasal tube, until the infant was able to drink from a bottle or his or her mother's breast. The majority of the infants received their first enteral intake during the first week of life and they were on full enteral feeding of $420-500$ $\mathrm{kJ} / \mathrm{kg} / \mathrm{d}$ at, on average, the 14th day of life (table 6.1.).

To obtain accurate information on the dietary EFA intake of the participating infants, a 1 $\mathrm{ml}$ sample for fatty acid analysis was taken from every bottle of expressed milk after homogenization. Furthermore, the volumes consumed from every bottle of expressed breast milk and the volumes and types of formula given were recorded carefully by the nursing personnel.

\subsubsection{Laboratory analysis}

\section{Blood samples}

These were collected in tubes containing EDTA to prevent coagulation. The plasma,was separated from the RBCs by centrifugation. RBCs were washed twice with EDTA-containing saline $\left(\mathrm{Na}_{2} \mathrm{EDTA}, 2 \mathrm{H}_{2} \mathrm{O} 28.64 \mathrm{~g}, \mathrm{NaCl} 7.00 \mathrm{~g}, \mathrm{H}_{2} \mathrm{O} 1000.0 \mathrm{ml}\right.$ ). The tubes containing 
plasma or RBC suspension were closed under a stream of nitrogen to prevent oxidation and stored at $-80^{\circ} \mathrm{C}$ until analysis.

\section{Milk samples}

Individual human milk samples were collected in fat-free glass tubes, containing $2 \mu \mathrm{l}$ of the antioxidant butylhydroxytoluene $(500 \mathrm{mg} / \mathrm{l}$ methanol $)$, after which they were stored at $-80^{\circ} \mathrm{C}$.

Based on the volumes consumed from the corresponding bottles of expressed milk, the appropriate amounts of the individual samples were pooled into one representative weekly sample, which was used for fatty acid analysis. This pooling was carried out according to the guidelines of the International Dairy Federation [22] for the preparation of a test sample. The weekly samples were stored at $-80^{\circ} \mathrm{C}$ until fatty acid analysis.

\section{Fatty acid analysis}

To ensure uniformity of analytical conditions, all blood samples of a given study subject were analyzed simultaneously as soon as the subject had completed the study. The same applied to the weekly human milk samples.

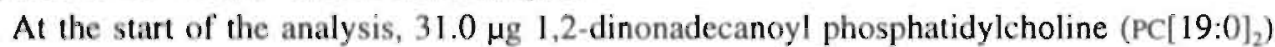
was added to every sample as internal standard. Total lipid extracts of plasma and RBC were prepared using a modified Folch extraction; 50-100 $\mu$ samples of plasma or RBC suspension were added to $3 \mathrm{ml}$ methanol-chloroform $(1: 2$, vol:vol $)[23,24]$. The PL fraction was isolated by solid phase extraction on an aminopropyl-silica column [25]. The PLs were saponified and the fatty acids converted to the corresponding methyl esters by reaction with $14 \%$ boron trifluoride in methanol at $100{ }^{\circ} \mathrm{C}$ for one hour [26].

For trans-esterification of fatty acids in human milk and artificial formula, $100 \mu$ ! samples of milk were added to $2 \mathrm{ml}$ of methanol-hydrochloric acid ( $5: 1$, vol:vol) and heated at $90{ }^{\circ} \mathrm{C}$ for 4 hours. After cooling, the samples were extracted with $1 \mathrm{ml}$ iso-octane [27]. The samples were analyzed using capillary gas-liquid chromatography with flame ionisation detection, on a $50 \mathrm{~m} \times 0.25 \mathrm{~mm}$ CP-Sil $5 \mathrm{CB}$, film thickness $0.12 \mu \mathrm{m}$ (Chrompack, Middelburg. The Netherlands) column, using $\mathrm{N}_{2}$ as the carrier gas. The analyses were performed. using temperature programming which had been optimized with a reference mixture containing most of the fatty acid methyl esters (FAMEs) of interest. The standard mixture was also used to identify the FAMEs corresponding to the various peaks. Fatty acid amounts present in the PL fraction (for plasma and RBC samples) or in the total lipid fraction (for milk samples) were quantified based on the amount of 19:0 internal standard FAME recovered.

The day-to-day reproducibility of the analytical method, as indicated by the coefficient of variation of the amounts $(\mathrm{mmol} / \mathrm{l})$ measured for the main fatty acids of interest, varied between $2.1 \%$ and $3.7 \%$ in 17 plasma PL samples and between $3.7 \%$ and $6.3 \%$ in 9 RBC PL samples [28]. 


\subsubsection{Data analysis}

Study-size calculations were based on the results of Koletzko and co-workers [14] using the exact calculations provided by Systat's Design program [29]. With two groups of 10 infants an inter-group difference of $0.5 \%$ for $22: 6 n-3$ or $1.0 \%$ for $20: 4 n-6$ in plasma PLS would be detected with $90 \%$ power.

For practical reasons, not all blood samples were taken on exactly the days intended. Since we wanted to analyze values at one-week intervals, the fatty acid values were estimated at days 7, 14, 21 and 28 by linear interpolation, between the days where blood had been sampled. The time intervals between the collection of individual neonatal blood samples varied from 5 to 15 days, and, on average, less than one of the ideally-required five punctures was missing. Unless mentioned otherwise, all values are presented as medians and the upper and lower limits of the interquartile range.

Since group membership (human milk or artificial formula) was not obtained by randomization. but by maternal choice, analyses were done essentially on postnatal changes, to correct. for possible inter-group differences for values at day 0 . The interpretation of the results was similar when adjustment for values at day 0 was made using regression analysis.

The two LCPS of primary interest, $22: 6 n-3$ and 20:4n-6 were analyzed most extensively. Since after the interpolation procedure there were remaining missing observations, a repeated measures analysis of variance model was used which uses all available data. [30]. This technique is available in the BMDP package [31]. It should be noted that in conventional repeated measures analysis all patients with incomplete data have to be omitted from the analysis. When pooled over the sampling days the normality condition was reasonably satisfied, except for the absolute fatty acid amounts in plasma, where a log transformation was needed. Outcomes of this analysis are obtained as Wald tests for each considered factor: time, group and time by group. The first term (time) tests whether there are differences between days for both groups together, the second term (group) tests the mean difference between both groups. These two tests are not of primary interest. The last term (time by group) tests whether the time effect is different for the two groups. This is an overall test, however, not specifically testing inter-group differences for postnatal changes with respect to day 0 . Therefore, we present the results of the Wald tests based on the same repeated measures model, which test whether sampling day changes (postnatal changes or differences with respect to day 0 ) are different for both groups. For these analyses, P-values smaller than 0.05 were considered to reflect a significant difference.

For the other fatty acids less sophisticated, more descriptive analyses are presented. Two-tailed Mann-Whitney tests were used to compare values at day 0 and changes between day 28 and day 0 for the two study groups. Additionally, the Wilcoxon signed ranks test was used to evaluate differences between day 28 and day 0 within groups. For these supportive analyses, $\mathrm{P}<0.01$ was considered significant.

The volumes of plasma, RBCs and intravenous lipids administered in both groups and continuous clinical variables were compared using the two-tailed Mann-Whitney test. Discrete clinical variables were compared using the chi-square test. 

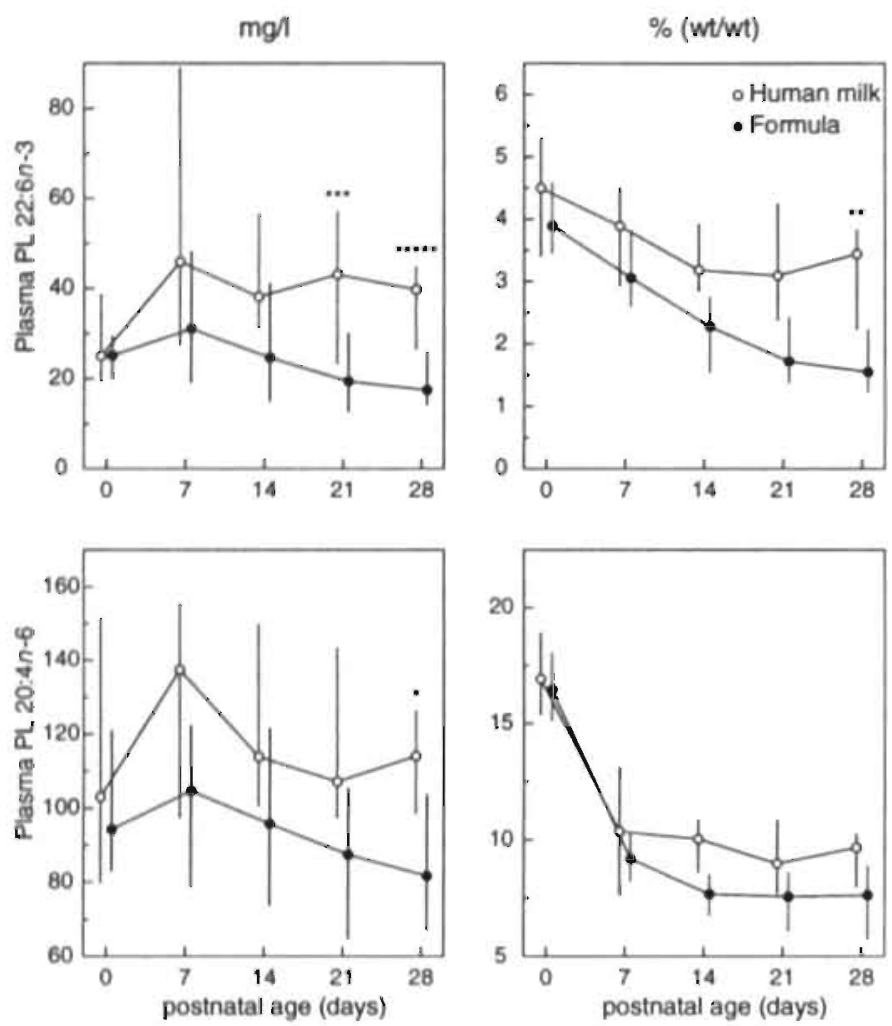

Figure 6.1. Docosahexaenoic (22:6n-3) and arachidonic (20:4n-6) acids values in plasma phospholipids (PLs). Median and interquartile range expressed as $\mathrm{mg} / \mathrm{l}$ (left) and as \% (wt/wt) of total fatty acid methylesters (right). Number of infants in human milk (HM) and artificial formula (AF) $\left(\mathrm{n}_{\mathrm{HM}} / \mathrm{n}_{\mathrm{AF}}\right)$ at day $0: 12 / 22$; day 7: 12/26; day 14: 12/26; day 21: 11/25; day 28: $9 / 20$.

Statistical differences between HM group and AF group (repeated measures analysis): "P<0.05, " $\mathrm{P}<0.02, \cdots \mathrm{P}<0.01, \cdots \cdots+\mathrm{P}<0.0005$.

\subsection{Results}

\subsubsection{Human milk and formulas}

The results of the fatty acid analyses of the various formulas and the preterm human milk (average content during the study period) are shown in table 6.2. Note that no $22: 6 n-3$, 20:4n-6 and only trace amounts of other LCPs (preterm formula B) were present in the artificial formulas. Relative levels of $22: 6 n-3,20: 4 n-6$ and the sums of $n-3$ and $n-6$ LCPS measured in human milk were comparable to those reported in other studies relating to the fatty acid composition of preterm breast milk $[7,12]$. 


\subsubsection{Plasma phospholipids}

Umbilical blood sample were not available from eight infants in the artificial formula group and one child in the human milk group. For three children in the artificial formula and the one child in the human milk group, a neonatal sample, taken within $24 \mathrm{~h}$ after birth and before any administration of plasma or red blood cells, served as a replacement. Despite restrictions placed on birthweight $(<1800 \mathrm{~g})$, three infants in the human milk group and eight infants in the artificial formula group were discharged from the neonatal care unit before the 4th week of study. One child in the human milk group and two in the artificial formula group were discharged home in good clinical condition after three weeks. The other infants were transferred to the neonatal care unit of a non-participating hospital.

The patterns of postnatal changes in absolute values for both $22: 6 n-3$ and $20: 4 n-6$ (mg/l plasma) differed markedly from those for relative fatty acid values ( $\%$ (wt/wt) of total fatty acids; figure 6.1.). The absolute values for $22: 6 n-3$ and $20: 4 n-6$ increased during the first week of life in both study groups. This increase was followed by a gradual decrease during the next three weeks of life. For both $22: 6 n-3$ and 20:4n-6, the absolute postnatal values for the human milk group were significantly different from those for the formula fed infants (repeated-measures analysis; at day 21: $\mathrm{P}<0.01$ for 22:6n-3, at day 28: $\mathrm{P}<0.0005$ for 22:6n3 and $\mathrm{P}<0.05$ for $20: 4 n-6$ ).

Relative levels declined steadily and significantly from the first to the 28 th day of life. For $22: 6 n-3$, this decline was 60.2 percent in the artificial formula group, which was more than double that in the human milk group $(23.5 \%)$, reflecting the significant difference between changes in the relative postnatal $22: 6 n-3$ values of the two study groups (repeatedmeasures analysis; at day 28: $\mathrm{P}<0.02$ ). The relative level of $20: 4 n-6$ showed a decline of $53.7 \%$ in the artificial formula group and of $42.9 \%$ in the human milk group. The relative postnatal $20: 4 n-6$ values were not significantly different in both study groups.

Differences between the absolute and relative changes from birth to the 28 th day of life were also present for the $\mathrm{n}-3$ LCPS (see table 6.3. and 6.4. for absolute and relative amounts respectively). The absolute amount for the sum of the $n-3$ LCPS ( $\Sigma n-3$ LCP) increased from day 0 to day 28 in the human milk group, whereas it declined in the artificial formula group. The change in $\Sigma n-3$ LCP (day 28 minus day 0 ) was significantly different for both groups $(\mathrm{P}<0.01)$. The relative level of $\sum n-3$ LCP declined significantly in both study populations. The decrease in the artificial formula group was significantly larger than that in the human milk group ( $\mathrm{P}<0.001)$.

Differences between the postnatal changes of absolute and relative values of $\Sigma n-6$ LCP were similar to those for $\Sigma n-3$ LCP. Changes in $\Sigma n-6$ LCP in the artificial formula group were, however, not significantly different from those in the infants fed on human milk.

\subsubsection{Red blood cell phospholipids}

The volumes of two RBC samples in the artificial formula group, one at day 14 and one at day 28 , were too small to guarantee an adequate fatty acid analysis; these samples were discarded.

The absolute and relative postnatal values for 22:6n-3 and 20:4n-6 showed more or less similar patterns (figure 6.2.). Although the postnatal decrease in the formula-fed group was 
Table 6.3. Fatty acid composition of plasma phospholipids (absolute values) ${ }^{a}$.

\begin{tabular}{|c|c|c|c|c|}
\hline \multirow{2}{*}{$\begin{array}{l}\text { Fatty acid }{ }^{b, c} \\
\mathrm{mg} /\end{array}$} & \multicolumn{2}{|c|}{ Day 0} & \multicolumn{2}{|c|}{ Day 28} \\
\hline & HM $\quad(n=12)$ & AF $(n=22)$ & $\mathrm{HM}(\mathrm{n}=9)$ & $\operatorname{AF}(n=20)$ \\
\hline total FA & $567(479-798)$ & $592(474-760)$ & $1.199(1065-1523)$ & $1166(973-1231)^{\gamma}$ \\
\hline$\Sigma$ SAFA & $260(222-368)$ & $274(223-357)$ & $534(472-674)$ & $519(436-557)^{k}$ \\
\hline$\Sigma$ MUFA & $86(58-136)$ & $90(71-109)$ & $157(130-246)$ & $182(153-197)^{k}$ \\
\hline$\sum n-9$ PUFA & $3.6 .(2.3-7.6)$ & $4.0(2.8-7.5)$ & $3.2(2.6-5.7)$ & $7.0(4.9-9.5)^{\prime}$ \\
\hline $18: 2 n-6$ & $45(38-60)$ & $51(36-68)$ & $262(222-324)^{\gamma}$ & $256(229-276)^{k}$ \\
\hline $20: 4 n-6$ & $103(80-151)$ & $94(83-121)$ & $114(99-126)$ & $82 !(67-104)^{d, j}$ \\
\hline$\sum n-6 L C P$ & $133(115-195)$ & $135(112-166)$ & $162(145-191)$ & $135(115-156)$ \\
\hline $18: 3 n-3$ & ND & ND & ND (ND-1.46) & ND (ND-1.48y \\
\hline $22: 6 n-3$ & $25.0(19.5-38.6)$ & $25.1(20.0-29.4)$ & $39.7(26.6-44.7)$ & $17.4(14.1-25.8)^{h}$ \\
\hline$\sum n-3$ LCP & $28.6(22.1-43.6)$ & $28.3(21.8-34.8)$ & $55.6(37.5-58.4)$ & $22.1\left(19.5-33.2 \gamma^{\prime}\right.$ \\
\hline
\end{tabular}

${ }^{a-4}$ As in table 6.2 .

Statistical difference between human milk group and artificial formula group (two-tailed Mann-Whitney' U test of changes in values (day 28-day 0), except for 22:6n-3 and 20:4n-6: repeated-measures analysis):

${ }^{2} \mathrm{P}<0.05,{ }^{\mathrm{P}} \mathrm{P}<0.01,{ }^{h} \mathrm{P}<0.0005$.

Statistical difference between day 28 and' day 0 (Wilcoxon rank sum W' test):

${ }^{\prime} \mathrm{P}<0.01,{ }^{k} \mathrm{P}<0.001$.

approximately twice the decrease in the human milk group, the postnatal patterns of changes in both absolute and relative values for $22: 6 n-3$ and $20: 4 n-6$ in the human milk group were not significantly different from those in the artificial formula group.

No significant differences were found between the absolute fatty acid amounts in the RBC PLS of both study groups (table 6.5.). Relative values for $22: 6 n-3$ were significantly lower in the artificial formula group (figure 6.2., table 6.6.: $\mathrm{P}<0.05$ ) at birth.

\subsection{Discussion}

The present study shows that postnatal changes in the LCP status in plasma PLS of preterm infants, as influenced by the fatty acid composition of their nutritional intake, is different depending on whether it is expressed in terms of absolute fatty acid amounts $(\mathrm{mg} / \mathrm{l})$ or as relative levels (\% (wt/wt) of total fatty acids). The absolute values showed an initial increase during the first week of life, followed by a general decline during the following weeks (figure 6.1.). Due to an even larger increase of the total amount of PL-associated fatty acids (figure 6.3. and table 6.3., values at day 0 were less than half those at day 7 and day 28), the initial increase observed for absolute quantities of $22: 6 n-3$ and $20: 4 n-6$ did not become apparent when the fatty acid values were expressed as relative values. In RBC PLs, the total amount of fatty acids present did not change markedly (figure 6.3. and 
Table 6.4. Fatty acid composition of plasma phospholipids (relative values)".

\begin{tabular}{|c|c|c|c|c|}
\hline \multirow{2}{*}{$\begin{array}{l}\text { Fatty acider } \\
\%(w / w t)\end{array}$} & \multicolumn{2}{|c|}{ Day 0} & \multicolumn{2}{|c|}{ Day 28} \\
\hline & HM $(n=12)$ & AF $(n=22)$ & HM $(n=9)$ & AF $(n=20)$ \\
\hline$\sum$ SAFA & $46.4(45.5-47.1)$ & $47.4(45.9-48.0)$ & $43.8(43.0-45.5 y$ & $44.8 \cdot\left(43.7-45.8 y^{\prime}\right.$ \\
\hline$\Sigma$ MUFA & $13.7(11.8-16.8)$ & $15.0(13.6-16.5)$ & $13.3(12.1-16.3)$ & $16.0(14.2-17.7)$ \\
\hline$\Sigma n-9$ PUFA & $0.59(0.42-1.04)$ & $0.75(0.55-1.07)$ & $0.25(0.23-0.45)$ & $0.61(0.49-0.81)$ \\
\hline $18: 2 n-6$ & $7.78(7.38-9.30)$ & $8.27(7.32-9.74)$ & $21.2(19.5-22.5)$ & $22.2 .(21.6-24.4)^{k}$ \\
\hline $20: 4 n-6$ & $16.9(15.4-18.9)$ & $16.5(15.1-18.1)$ & $9.66(7.99-10.23)$ & 7.62. $(5.76-8.88)^{d, 4}$ \\
\hline$\sum n-6 \mathrm{LCP}$ & $23.6(21.9-25.7)$ & $22.4(21.6-23.8)$ & $13.7(12.6-14.8 y$ & $12.1(10.4-13.6)^{k}$ \\
\hline $18: 3 n-3$ & ND & ND & ND (ND-0.12) & ND (ND-0.13) \\
\hline $22: 6 n-3$ & $4.50(3.41-5.31)$ & $3.89(3.45-4.60)$ & $3.44 \cdot\left(2.23-3.82 \gamma^{\prime}\right.$ & $1.55(1.24-2.22)^{6.1}$ \\
\hline$\sum n-3$ LCP & $5.07(3.83-6.18)$ & $4.49(3.94-5.53)$ & $4.56(3.08-4.75)^{\gamma}$ & $2.14(1.59-2.81)^{8.4}$ \\
\hline CADI & $1.16(0.77-1.35)$ & $1.07(0.89-1.20)$ & $0.82(0.69 .1 .02)$ & $1.26(0.94-1.69)$ \\
\hline
\end{tabular}

". As in table 6.2., in addition: $\mathrm{CADI}=$ cervonic acid (22:6n-3) deficiency index: $22: 5 n-6 / 22: 4 n-6$.

Statistical difference between human milk group and artificial formula group (two-tailed. Mann-Whitney U test for changes in values (day 28-day 0), except for 22:6n-3: repeated-measures analysis):

${ }^{d} \mathrm{P}<0.05,{ }^{\mathrm{P}}<0.02,{ }^{8} \mathrm{P}<0.001$.

Statistical difference between day 28 and day 0 (Wilcoxon rank sum $\mathrm{W}$ test):

i $\mathrm{P}<0.01,{ }^{k} \mathrm{P}<0.001$.

table 6.5.). As a result, the postnatal changes in absolute and relative values for $22: 6 n-3$ and 20:4n-6 were more or less similar (figure 6.2.).

A possible explanation for the observed increase of the total plasma PL-associated fatty acids may be the change in nutrient supply, which accomparies the transition fiom fetal life to life outside the uterus. In utero, glucose is the major nutrient, while after birth, fat becomes the main source of energy [32]. An increase in the absolute amounts of $n-3$ and $n$ 6 LCPS of plasma PLS within the first days of life was also observed in a group of 10 preterm newborn infants (gestationai age $<34 \mathrm{wks}$ ), who received only fat-free parenteral nutrition [19]. From this finding the author concluded that, in the absence of an exogenous lipid source, tissue stores of LCPS are released in response to birth. In our study, infants that were unable to tolerate enteral feedings received Intralipid ${ }^{\star}$ as an intravenous source of fat as early as the second day of life. This may also explain part of the initial increase in absolute LCPS.

Recently, further studies relating to absolute fatty acid concentrations in plasma PLs, have been published [15,17,33]. The: absolute 22:6n-3 and 20:4n-6 levels of our study populations were similar to those reported by Clandinin and co-workers [15] in a study of 34 preterm infants, receiving either their own mother's expressed milk, a conventional formula or a formula containing $n-3$ and $n-6$ LCPS. In this study, the increase in plasma PLassociated fatty acids, as observed in our study, is not found, possibly because the first 

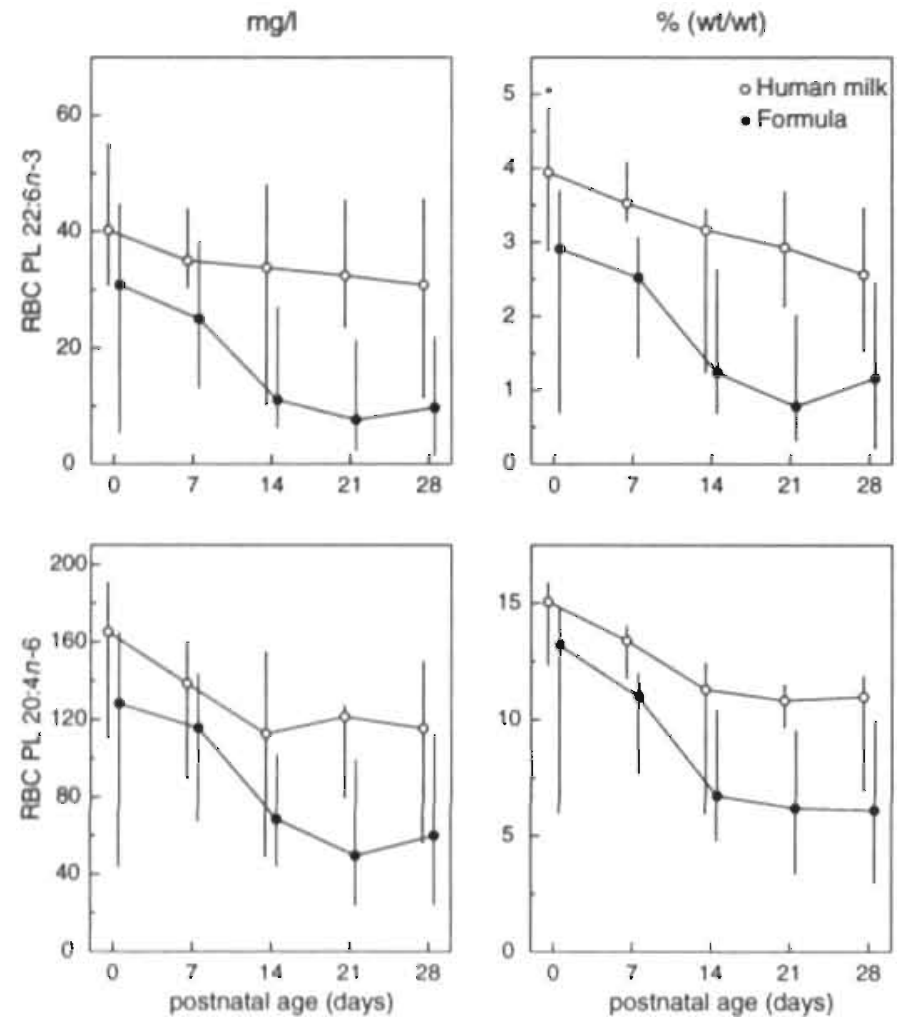

Figure 6.2. Docosahexaenoic (22:6n-3) and arachidonic (20:4n-6) acid values in red blood cell (RBC) phospholipids (PLS). Median and interquartile range expressed as mg/l (left) and as \% (wt/wt) of total fatty acid methyl esters (right), Number of infants in human milk (HM) and artificial formula (AF) $\left(\mathrm{n}_{\mathrm{HM}} / \mathrm{n}_{\mathrm{AF}}\right)$ at day $0: 12 / 22$; day $7: 12 / 26$ : day $14: 12 / 25$; day $21: 11 / 25$; day $28: 9 / 19$.

Statistical differences between HM group and AF group (Mann-Whitney U test):

"P $<0.05$.

blood sample was taken in the first week of life, most probably after this increase had occurred.

Carlson and co-workers [17,33] published absolute fatty acid concentrations in plasma phosphatidylethanolamine (PE) and/or phosphatidylcholine (PC), which together accounted for $>95.0 \%$ of total plasma phospholipids [17]. The concentrations $(\mathrm{mg} / \mathrm{l})$ of $22: 6 n-3$ and 20:4n-6 in plasma PLS of 79 preterm infants receiving either a conventional formula or a formula containing $n-3$ LCPs, were considerably lower (up to twofold for 22:6n-3 in PC and PE added together) than those reported in our study. This discrepancy may result at least partly from methodological differences. We added the internal standard at the start of the fatty acid analysis, that is before the extraction of total lipids. In this way fatty acid losses during all steps of the analysis were accounted for. Carlson and colleagues, however, added the internal standard (17:0) before the transesterification step. Consequently, fatty acid 
Table 6.5. Fatty acid composition of red blood cell phospholipids (absolute values)".

\begin{tabular}{|c|c|c|c|c|}
\hline \multirow{2}{*}{$\begin{array}{l}\text { Fatty acides } \\
\text { mg/l }\end{array}$} & \multicolumn{2}{|c|}{ Day 0} & \multicolumn{2}{|c|}{ Day 28} \\
\hline & $\mathrm{HM}(\mathrm{n}=12)$ & AF $(n=22)$ & HM $(n=9)$ & AF $(n=19)$ \\
\hline total FA & $1061(871-1232)$ & $938(727-1114)$ & $1084(909-1303)$ & $876(692-1132)$ \\
\hline$\Sigma$ SAFA & $514(435-580)$ & $496(420-556)$ & $562(448-617)$ & $429(388-530)$ \\
\hline I MUFA & $201(150-237)$ & $187(169.226)$ & $212(180-248)$ & $179(162 \cdot 217)$ \\
\hline$\Sigma n-9$ PUFA & $10.4(8.4-15.9)$ & $11.9(7.4-15.1)$ & $5.9(5.0-7.2)$ & $6.5(4.1-10.1)$ \\
\hline $18: 2 n-6$ & $49.3(36.6-54.6)$ & $43.5(26.8-53.4)$ & $131(81-149)$ & $96(77-13 !)$ \\
\hline $20: 4 n-6$ & $165(111-191)$ & $128(44-166)$ & $116(56-150)$ & $60\left(24-112 \gamma^{\gamma}\right.$ \\
\hline$\sum n-6$ LCP & $239(180-272)$ & $194(73-238)$ & $174(82-223)$ & $100(44-173 y$ \\
\hline $18: 3 n-3$ & ND & ND & $1.00(\mathrm{ND}-1.28)$ & $1.93(\mathrm{ND}-2.51)$ \\
\hline $22: 6 n-3$ & $40.2(30.7-55.0)$ & $30.9(5.4-44.8)$ & $30.8(11.4-45.6)$ & $9.7(1.5-21.9)$ \\
\hline$\sum n-3$ LCP & $45.5(35.6-62.5)$ & $36.8(6.4-54.2)$ & $43.7(14.6-61.4)$ & $14.1(2.4-36.7)$ \\
\hline
\end{tabular}

as in table 6.2 .

Statistical difference between day 28 and day 0 (Wilcoxon rank sum W test):

${ }^{j} \mathrm{P}<0.01,{ }^{k} \mathrm{P}<0.001$.

losses during lipid extraction and separation of the PLS, were not reflected in the amount of 17:0 FAME detected by gaschromatography. This could result in artefactually lower absolute values for the fatty acids present in the samples. Indeed, the total fatty acid amount present in plasma PC as reported by Carlson [33] is approximately half the total fatty acid amount present in plasma total PLs in our study. Yet, PC represents approximately $70 \%$ of total plasma PLS [34].

Relative levels of $n-3$ and $n-6$ fatty acids in plasma PLS of cord blood, as reported by Foote and co-workers [19] were similar to those measured in our present study. In contrast, the absolute $(\mathrm{mg} / \mathrm{l})$ levels of $n-3$ and $n-6$ fatty acids reported were more than ten times lower than those in our study. Detailed information on the timing of the internal standard addition, however, was not given. An overestimation of actual fatty acid amounts on our side seems highly unlikely. Using solid phase extraction on an aminopropyl-silica column, we are able to separate PLS to near homogeneity $(<1.0 \%$ contamination of PLs with triglycerides and cholesteryl esters, which is in agreement with the value of $1.15 \%$ contamination reported by Kaluzny and co-workers [25]). Besides, heptadecanoic acid (17:1n-7) is added to every sample as a standard procedure to check carry over of free fatty acids during the PL isolation procedure.

To our knowledge, no studies relating to absolute fatty acid amounts in RBC PLS of preterm infants have been published so far.

In our study we observed significant differences between both the absolute and relative postnatal LCP values in the plasma PLS of preterm infants fed their own mother's breast 
Table 6.6. Fatty acid composition of red blood cell phospholipids (relative values) ${ }^{d}$.

\begin{tabular}{|c|c|c|c|c|}
\hline \multirow{2}{*}{$\begin{array}{l}\text { Fatty acidec } \\
\%(w / w t)\end{array}$} & \multicolumn{2}{|c|}{ Day 0} & \multicolumn{2}{|c|}{ Day 28} \\
\hline & $H M(n=12)$ & AF $(n=22)$ & HM $(n=9)$ & $\operatorname{AF}(n=19)$ \\
\hline$\Sigma$ SAFA & $47.8(47.2-50.7)$ & $50.3(48.1-60.1)$ & $46.2(45.4-52.1)$ & $50.7(46.8-58.0)$ \\
\hline$\Sigma$ MUFA & $19.4(16.3-20.5)$ & $20.9(17.7-23.8)$ & $19.4(17.5-22.0)$ & $21.0(19.8-24.5)$ \\
\hline$\sum n-9$ PUFA & $1.02(0.78-1.33)$ & $1.20(0.95-1.49)$ & $0.55(0.5 \mathrm{i}-0.63)^{\prime}$ & $0.72(0.62-0.88)^{\prime}$ \\
\hline $18: 2 n-6$ & $4.60(3.93-5.39)$ & $4.11(3.56-4.82)$ & $11.1(9.5-12.0)$ & $10.8(9.6-11.9)^{k}$ \\
\hline $20: 4 n-6$ & $15.1(12.3-15.9)$ & $13.2(6.0-14.9)$ & $11.0(7.0-11.9)^{i}$ & $6.1(3.0-9.9)^{k}$ \\
\hline$\sum n-6$ LCP & $21.4(19.9-23.2)$ & $18.3(9.4-21.6)$ & $16.5(10.6-17.4)$ & $10.8(5.3-14.9)^{j}$ \\
\hline $18: 3 n-3$ & ND & ND & ND $(\mathrm{ND}-0.10)$ & $\mathrm{ND}(\mathrm{ND}-0.12)$ \\
\hline $22: 6 n-3$ & $3.94(2.88-4.81)$ & $2.91(0.69-3.69)^{d}$ & $2.56(1.53-3.46)^{i}$ & $1.16(0.22-2.46)$ \\
\hline$\Sigma n-3 \mathrm{LCP}$ & $4.47(3.34-5.60)$ & $3.28(0.88-4.42)$ & $3.89(2.23-4.56)$ & $1.55(0.34-2.96)$ \\
\hline CADI & $0.26(0.24-0.29)$ & $0.25(0.22-0.29)$ & $0.19(0.14-0.21)$ & $0.20(0.14-0.26)$ \\
\hline
\end{tabular}

a'c As in table 6.4

Statistical difference between human milk group and artificial formula group (two-tailed Mann-Whitney U test): " $\mathrm{P}<0.05$.

Statistical difference between day 28 and day 0 (Wilcoxon rank sum W test):

${ }^{i} \mathrm{P}<0.05,{ }^{j} \mathrm{P}<0.01,{ }^{k} \mathrm{P}<0.001$.

milk and those of formula-fed preterms, with lower LCP levels in the latter group (figure 6.1., tables 6.3. and 6.4.). Similar differences were not observed for RBC PLs (figure 6.2., tables 6.5 , and 6.6 ). This confirms the findings of recent studies $[15,17]$, which, over a period of 4. weeks, could not or hardly demonstrate a significant dietary influence on percentage values of $22: 6 n-3$ and $20: 4 n-6$ in RBC PLS, but did so in plasma PLs and cholesteryl esters. RBC PLs are known to have a slower turnover rate than plasma PLs, which could result in less-apparent nutritional effects over a relatively short period of time.

The nutritional effect was greater for 22:6n-3 than for 20:4n-6. Effects on 22:6n-3 status were supported by the changes in the sum of the $n-3$ LCPS. Moreover, the inter-group difference in change of the Cervonic A.cid Deficiency Index (CADI) between birth and the 28th day of life tended to be significant ( $\mathrm{P}<0.05$, significance level for supportive analyses: $\mathrm{P}<0.01$ ). Because a reduction in the amount of $22: 6 n-3$ is usually compensated for by an increased synthesis of 22:5n-6 from 22:4n-6, the ratio between these latter two fatty acids, CADI, is considered a functional parameter of the 22:6n-3 status [35,36]. Incidental RBC infusions may have influenced the dietary effect on the LCP status. In our study, the average amounts of plasma and RBCs received by the artificial formula group were approximately twice the amounts received by the human milk group (table 6.1.). Although this difference was not statistically significant, it may, nonetheless, have reduced the difference between the 20:4n-6 (and also the 22:6n-3) status of both study populations. Recently, very-low- 

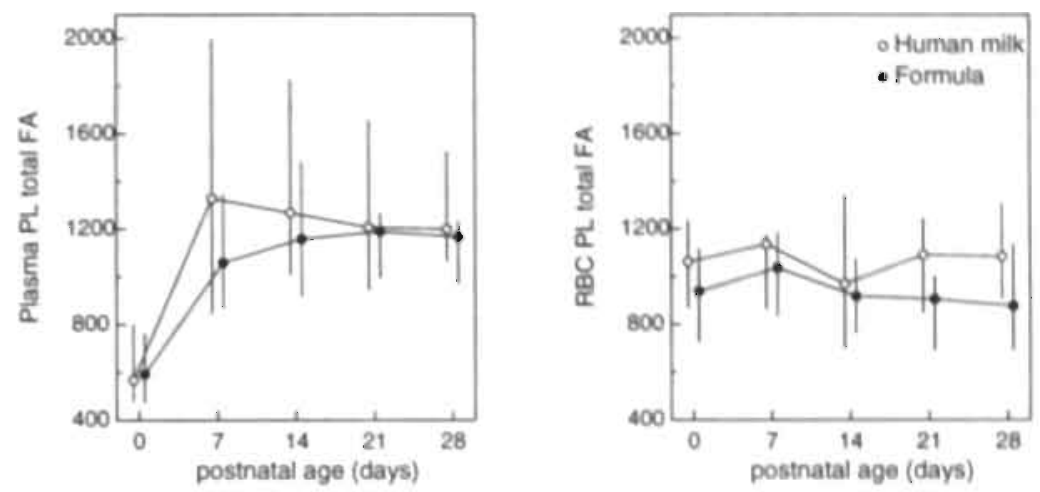

Figure 6.3. Total phospholipid. (PL)-associated fatty acids in plasma (left) and red blood. cells (RBCs, right). Median and interquartile range expressed as mg/.

Number of infants in human milk (HM) and artificial formula (AF) $\left(\mathrm{n}_{\operatorname{mag}} / \mathrm{n}_{\mathrm{N}}\right)$, in plasma at day 0: 12/22; day $7: 12 / 26$; day $14: 12 / 26$; day $21: 11 / 25$; day $28: 9 / 20$, in RBCs at day $O: 12 / 22$; day $7: 12 / 26$; day $14: 12 / 25$; day $21: 11 / 25$; day $28: 9 / 19$.

birth-weight infants $(<1500 \mathrm{~g})$, receiving more than six blood transfusions during their neonatal course, were shown to maintain higher relative plasma levels of 20:4n-6 [37], which supports the assumption that intravenous RBC and plasma infusions may be an important non-dietary source of LCPs. Moreover, substantial amounts of 18:2n-6, which can be converted to 20:4n-6, were present in the formulas. Nevertheless, the absolute 20:4n-6 status also showed a significantly larger decrease in the formula fed infants than in the infants fed human milk.

All these results, and those of others [14,15-17], indicate that the conventional artificial formulas are unable to maintain the postnatal LCP status of preterm infants at levels that can be obtained when feeding with preterm human milk. Therefore, to establish comparable 22:6n-3 and 20:4n-6 blood levels in formula and human milk-fed preterm infants, both $n-3$ and $n-6$ LCPS should be added to preterm formula $[38,39]$. Whether human milk is able to maintain an optimal LCP status in preterm infants remains to be decided. In the present study, in both plasma and RBC PLs, relative 22:6n-3 and 20:4n-6 levels decreased significantly after birth, also in the infants raised on human milk. This resulted in values well below those measured in cord blood of infants born after normal full-term pregnancy [40].

Recently, a number of publications, have reported on the influence of the $n-3$ and $n-6$ LCP dietary intake of preterm infants on several functional and anthropometric parameters. The amount of $n$ - 3 LCPs present in the enteral diet was demonstrated to have a significant effect on the function of the retina of very-low-birth-weight newborn infants [41]. Infants. having no 22:6n-3 in their formula had higher threshold and lower amplitude responses on rod electroretinogram than those receiving n-3 LCP-supplemented formula or human milk. However, the intake of $n-3$ LCP containing formula was found to be associated with poorer growth in preterm infants [42]. Furthermore, the 20:4n-6 status in plasma PC was reported to be positively correlated with postnatal growth in preterm infants through 12 months corrected postnatal age [43]. Since $n-3$ LCP' supplementation decreases the concentration of 
plasma 20:4n-6, these findings again support the necessity to add both $n-3$ and $n-6$ LCPS in balanced ratios to preterm formula.

In conclusion, the results of the present, study emphasize the additional value of the assessment of absolute fatty acid concentrations, when studying the dietary effects on the EFA status of preterm infants. Analytic procedures, however, need to be standardized to enable a more effective comparison of results from different research groups. Furthermore, the results obtained warrant further studies of the effects on the postnatal LCP status of adding both $n-3$ and $n-6$ LCPs to preterm artificial formulas in amounts comparable with those present in human milk.

\subsection{Acknowledgements}

The authors gratefully acknowledge the financial support, from Nutricia, Zoetermeer, The Netherlands. They also wish to express their appreciation for the help obtained from Mrs. J.M. Westdorp, neonatologist (clinical coordination), Mrs. M.-J. Slangen, children's laboratory of the University Hospital Maastricht (neonatal blood sampling), the nursing personnel of the departments of Neonatology of the University Hospital Maastricht, the Saint Joseph Hospital in Kerkrade and the De Wever Hospital in Heerlen, The Netherlands (practical assistance) and Miss A. van der Zijden (practical assistance).

\subsection{References}

1. Clandinin MT, Chappell $\boldsymbol{\jmath E}$, Leong $\mathrm{S}$, Heim T, Swyer PR, Chance GW, Intrauterine fatty acid accretion rates in human brain: implications for fatty acid requirements. Early Hum Dev 1980;4: 121-9.

2. Clandinin MT, Chappell JE, Leong S, Heim T, Swyer PR, Chance GW. Extrauterine fatty acid accretion in infant brain: implications for fatty acid requirements. Early Hum Dev 1980;4:131-8.

3. Svennerholm L. Distribution and fatty acid composition of phosphoglycerides in normal human brain. J Lipid Res 1968:9:570-9.

4. Sastry PS. Lipids of nervous tissue: composition and metabolism. Progress Lipid Res 1985;24:69176.

5. Fiesler $\overline{\mathrm{SJ}}$ and Anderson RE. Chemistry and metabolism of lipids in the vertebrate retina. Progress Lipid Res 1983;22:79-131.

6. Jensen RG, Hagerty MM, McMahon KE. Lipids of human milk and infant formulas: a review. Am J Clin Nutr 1978;31:990-1016.

7. Lammi-Keefe CJ, Jensen RG. Lipids in human milk: a review. 2: Composition and fat-soluble vitamins. J Pediatr Gastroenterol Nutr 1984;3:172-98.

8. Jensen RG, Ferris AM, Lammi-Keefe CJ. Lipids in human milk and infant formulas. Annual Rev Nutr 1992;12:417-41.

9. Clandinin MT, Chappell JE, Heim T, Swyer PR, Chance GW. Fatty acid accretion in fetal and neonatal liver: implications for fatty acid requirements. Early Hum Dev 1981;5:7-14.

10. Chambaz J, Ravel D, Manier M-C, Pepin D, Mulliez N, Bereziat G. Essential fatty acid interconversion in the human fetal liver. Biol Neonate 1985:47:136-140.

11. Clandinin MT, Chappell JE, Heim T, Swyer PR, Chance GW. Fatty acid utilization in perinatal de novo synthesis of tissues. Early Hum Dev 1981;5:355-66.

12. Carlson SE, Rhodes PG, Ferguson MG. Docosahexaenoic acid status of preterm infants at birth and following feeding with human milk or formula. Am J Clin Nutr 1986:44:798-804. 
13. Pita ML, Fernández MR, De-Lucchi C, Medina A, Martínez-Valverde A, Uauy R, Gil A. Changes in the fatty acids pattern of red blood cell phospholipids induced by type of milk, dietary nucleotide supplementation, and postnatal age in preterm infants. J Pediatr Gastroenterol Nutr 1988;7:740-7.

14. Koletzko B, Schmidt E, Bremer HJ, Haug M, Harzer G. Effects of dietary long-chain polyunsaturated fatty acids on the essential fatty acid status of premature infants. Eur J Pediatr 1989;148:669-75.

15. Clandinin MT, Parrott A, Van Aerde JE, Hervada AR, Lien E. Feeding preterm infants a formula containing $\mathrm{C}_{20}$ and $\mathrm{C}_{22}$ fatty acids simulates plasma phospholipid fatty acid composition of infants. fed human milk. Early Hum Dev 1992;31:41-51.

16. Carlson SE, Rhodes PG, Rao VS, Goldgar DE. Effect of fish-oil supplementation on the n-3 fatty acid content of red blood cell membranes in preterm infants. Pediatr Res 1987;21:507-10.

17. Carlson SE, Cooke RJ, Rhodes PG, Peeples JM, Werkman SH, Tolley EA. Long-term feeding of formulas high in linolenic acid and marine oil to very low birth. weight infants: phospholipid fatty acids. Pediatr Res 1991:30:404-12.

18. Hornstra G. Essential fatty acids, pregnancy and pregnancy complications: a round table discussion. In: Sinclair A, Gibson R, eds. Essential Fatty Acids and Eicosanoids: Invited papers from the Third International Congress. Champaign, Illinois: American Oil Chemist's Society. 1993:177-82.

19. Foote KD, MacKinnon MJ. Innis SM. Effect of early introduction of formula vs fat-free parenteral nutrition on essential fatty acid status of preterm infants. Am J Clin Nutr 1991;54:937.

20. Holman RT. Control of polyunsaturated fatty acids in tissue lipids. I Am Coll Nutr 1986;5:183211.

21. Dubowitz LMS, Dubowitz V, Goldberg C. Clinical assessment of gestational age in the newborm infant. I Pediatr 1970;77:1-10.

22. International Dairy Federation. Milk - Determination of fat content - Röse Gottlieb Gravimetric Method (reference method), IDF Standard 1C:1987. Brussels, Belgium: International Dairy Federation 1987.

23. Folch J, Lees M. Sloane-Stanley GH. A simple method for the isolation and purification of total lipids from animal tissues. J Biol Chem 1957:226:497-509.

24. Hoving EB, Jansen G, Volmer M, van Doormaal JJ, Muskiet FAJ. Profiling of plasma triglyceride fatty acids. as, their methyl esters by capillary gas chromatography, preceded by a rapid aminopropyl silica column chromatographic separation of lipid classes. I Chromatography 1988;434:395-409.

25. Kaluzny MA, Duncan LA, Merritt MV. Epps DE. Rapid separation of lipid classes in high yield and purity using bonded phase columns. J Lipid Res 1985:26:135-40.

26. Morrisson WR. Smith LM. Preparation of fatty acid methyl esters and dimethylacetals from lipids with borontrifluoride-methanol. J Lipid Res 1964:5:600-8.

27. van der Steege G, Muskiet FAJ, Martini IA, Hutter NH, Boersma ER. Simultaneous quantification of total medium- and long-chain fatty acids in human milk by capillary gas chromatography with split injection. J Chromatography 1987;415:1-11.

28. de Jong AEP, van den Berg TS, Nijmeijer-Couprie A, Goedhart JP. Oosting E. Long-term aspects of phospholipidic analysis of fatty acid methyl esters by use of nonpolar capillary gas chromatography. Am J Clin Nutr 1993;57:813S.

29. Dallal GE. DESIGN: A supplementary Module for Systat and Sygraph. Evanston, IL: SYSTAT, Inc 1988. 
30. Jennrich RI, Schluchter MD. Unbalanced repeated-measures models with structured covariance matrices. Biometrics [986;42:805-20.

3I. Dixon WJ [chief ed], Brown MB, Engelman L, Jennrich Rí. BMDP statistical software manual: to accompany the 1990 software release, vol 2. Berkeley: University of California Press 1990.

32. Heim T. Energy and lipid requirements of the fetus and the preterm infant. J Pediatr Gastroenterol Nutr (suppl 1) 1983;2:404-12S.

33. Carlson SE, Cooke RJ, Rhodes PG, Peeples JM. Werkman SH. Effect of vegetable and marine oils in preterm infant formulas on blood arachidonic and docosahexaenoic acids. J Pediatr 1992;120:159-67.

34. Philips GB, Dodge JT. Composition of phospholipids and phospholipid fatty acids of human plasma. Journal of Lipid Res 1967;8:676-81.

35. Holman RT. The deficiency of essential fatty acids. In: Kunau W, Holman RT, eds. Polyunsaturated fatty acids. Champaign (IL): Am. Oil Chem Soc 1977;4:163-82.

36. Neuringer M, Connor WE, Lin DS, Barstad L, Luck S. Biochemical and functional effects of prenatal and postnatai w3 fatty acid deficiency on retina and brain in rhesus monkeys. Proc: Natl Ac Sci USA 1986;83:4021-5.

37. Leaf AA, Leighfield MJ, Costeloe KL. Crawford MA. Factorsi affecting long-chain polyunsaturated fatty acid composition of plasma choline phosphoglycerides in preterm infants. J Pediatĩ Gastroenterol Nutr 1992;14:300-8.

38. Uauy R. Are w-3 fatty acids required for normal eye and brain development in the human? J Pediatr Gastroenterol Nutr 1990:1 1:296-300.

39. ESPGAN Committee on Nutrition. Comment on the content and composition of lipids in infant formulas. Acta Pxdiatr Scand 1991;80:887-96.

40. Ai MDM, Hornstra G, van der Schouw YT, Bulstra-Ramakers MTEW, Huisjes. HJ. Biochemical EFA status of mothers and their neonates after normal pregnancy. Early Hum Dev 1990;24:23948.

41. Uauy RD, Birch DG, Birch EE, Tyson JE and Hoffman DR. Effect of dietary omega-3 fatty acids on retinal function of very-low-birth-weight neonates. Pediatr Res 1990;28:485-92.

42. Carlson SE, Cooke RJ, Werkman SH, Tolley, EA. First year growth of preterm infants fed standard compared to marine oil n-3 supplemented formula. Lipids 1992;27:90I-7.

43. Carlson SE, Werkman SH, Peeples JM, Cooke RJ, Tolley' EA. Arachidonic acid status correlates with first year growth in preterm, infants. Proc Natl Ac Sci. USA 1993;90:1073-7.

44. Kloosterman GJ. On intrauterine growth, the significance of prenatal care. Int J Gynaecol Obstet 1970;8:895-912. 


\title{
Long-chain polyunsaturated fatty acids in preterm infants: status at birth and its influence on postnatal levels
}

\author{
Magritha M.H.P. Foreman-v. Drongelen', Adriana C. v. Houwelingen', \\ Arnold D.M. Kester ${ }^{2}$, Tom H.M. Hasaart ${ }^{3}$, Carlos E. Blanco ${ }^{4}$, and Gerard \\ Hornstra ${ }^{1}$.
}

${ }^{1.2}$ Departments of ${ }^{~}$ Human Biology and ${ }^{2}$ Methodology and Statistics, University of Limburg, Maastricht, The Netherlands

${ }^{3.4}$ Departments of ${ }^{3}$ Obstetrics and Gynaecology and ${ }^{4}$ Neonatology, University Hospital Maastricht, The Netherlands

Based on Journal of Pediatrics 1995;126:611-618.

\subsection{Abstract}

To determine the influence of the prenatal !ong-chain polyunsaturated fatty acid (LCP) supply on prenatal growth and on postnatal LCP levels, we studied a group of 52 preterm infants, in which we assessed the relations between the LCP status at birth (reflecting the prenatal LCP supply), gestational age (GA) and prenatal growth, and the relation between the LCP status at birth and at term postconceptional age (37-42 weeks GA). After correction for $\mathrm{GA}$ at birth, significant relations $(\mathrm{P} \leq 0.05)$ were observed between anthropometric measurements at birth (weight, head circumference (HC) and length) and LCP levels in the umbilical artery wall, the LCP content of which reflects the long-term fetal LCP status. Independent of the neonatal diet (human milk or formula), LCP levels in red blood cell (RBC) phospholipids (PL) 'at term' were positively related to levels in the umbilical artery wall (docosahexaenoic acid (22:6n-3): $\mathrm{P} \leq 0.0003$, arachidonic acid (20:4n-6): $\mathrm{P}=0.02)$. Postnatal diet significantly influenced LCP levels in plasma PLS at term (22:6n-3: $\mathrm{P} \leq 0.004,20: 4 n-6: \mathrm{P}=0.02)$; formula fed infants had lower values. We conclude that the LCP status at birth of preterm infants is related to prenatal growth. Moreover, next to the postnatal enteral diet, the LCP status at birth significantly affects LCP levels at term postconceptional age. This finding may warrant further studies of the effects of essential fatty acid (EFA)-enriched maternal diets during pregnancy on the neonatal LCP status at birth. 


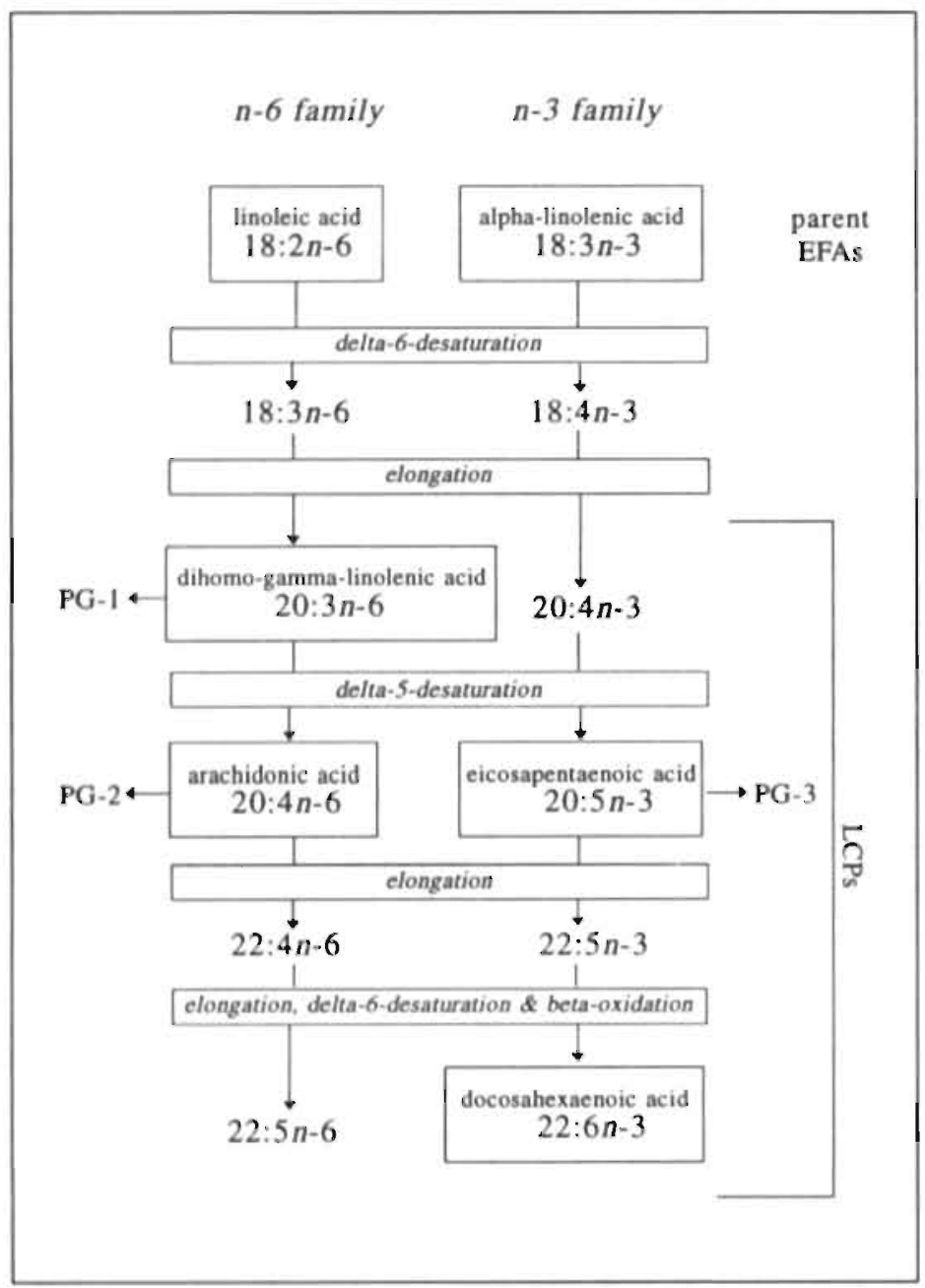

Figure 7.1.: Main pathways of $n-6$ and $n-3$ fatty acid conversion (EFAs=essential fatty acids, $P G=$ prostaglandins (and other eicosanoids), LCPs=long-chain polyunsaturated fatty acids).

\subsection{Introduction}

The LCPS (chain length of 20 carbon atoms or more and at least one double bond more than the parent EFAS, linoleic acid (18:2n-6) or $\alpha$-linolenic acid (18:3n-3), see figure 7.1.), are of major importance in fetal and infant development. The LCPs docosahexaenoic acid 
$(22: 6 n-3)$ and arachidonic acid (20:4n-6) are the predominant polyunsaturated fatty acids in the structural lipids of the human brain [1-3] and retina [4]. In addition, considerable amounts of 20:4n-6 are found in membrane PLs throughout the body. Furthermore, 20:4n-6, dihomo-gamma-linolenic acid (20:3n-6) and eicosapentaenoic acid (20:5n-3) are precursors of prostaglandins and other eicosanoids (figure 7.1.), which have important bioregulatory functions.

Dietary studies have demonstrated that preterm infants receiving a conventional artificial formula as their main source of dietary lipids, have a poorer LCP status than infants fed their own mother's milk [5-9; Chapter 6]. This discrepancy has been attributed to the presence of small but significant amounts of 22:6n-3, 20:4n-6 and other LCPs in human milk, and their absence in the majority of the commercially available artificial formulas [1012]. These formulas usually contain substantial amounts of the parent EFAs $18: 2 n-6$ and $18: 3 n-3$, which can be converted to $n-6$ and $n-3$ LCPs in the human body (figure 7.1.). However, the desaturase capacity of premature newborn infants is probably too limited to guarantee an adequate supply of LCPs solely through metabolic conversion of these two fatty acids $[13,14]$. Adding LCPs to artificial formulas proved to reduce differences between the LCP status of formula and breast-fed preterm infants [7,8,15-17]. The LCP status has also been related to anthropometric measurements, both at birth [18,19] and thereafter [20].

Leaf and colleagues [21] recently observed a positive correlation between plasma. LCP. levels at birth (reflecting the prenatal LCP supply) and those at term postconceptional age (40 wks GA). This relation was independent of the type of postnatal diet, indicating that the intra-uterine experience of the fetus may set the pattern for postnatal LCP levels [22]. However, the study was confined to plasma PLS and lacked information on the RBC fraction of the blood, the LCP content of which may be a more accurate reflection of LCP levels in the brain [23].

The aim of our study was to explore the nature of the relation between the LCP status at birth and that in the 'term period' (37-42 wks GA) in a group of preterm infants. To this end, the LCP leveis in PLs extracted from plasma, RBCs, as well as from the umbilical artery walls were studied; the latter is considered to reflect the long-term fetal LCP status $[24,25]$. In addition, the potential relations among the LCP status at birth, GA at birth, and weight, HC and length at birth were studied.

\subsection{Patients and methods}

\subsubsection{Infants}

The population studied comprised 52 preterm infants (GA $26=36 \mathrm{wks}$, birth weight 650 1860 g). The infants had no metabolic disease or congenital malformations. A $3 \mathrm{ml}$ sample of venous cord blood and approximately $15 \mathrm{~cm}$ of umbilical cord were collected immediately after delivery to provide information on the LCP' status at birth. This material was collected as part of a dietary study in preterm infants [9; Chapter 6], which was approved by the medical ethics committee of the University Hospital of Maastricht; written informed consent was obtained from one or both parents.

All infants were admitted to the neonatal care unit, where their birth weights were assessed on a calibrated infant scale and recorded to the nearest $5 \mathrm{~g}$. $\mathrm{HC}$ and crown-heel 
length were measured, to the nearest millimetre, with a tape on the third day of life. Crownheel length was measured with the infants in supine position.

Subsequently, between one and a half and two hours after a feed, $0.5 \mathrm{ml}$ neonatal blood samples were taken by venous puncture or heel-prick in conjunction with a diagnostic puncture, and collected in EDTA-containing tubes. For 28 infants, a blood sample collected at $37-42$ wks GA was available. The fatty acid data of these latter infants were used to assess the influence of the LCP status at birth on postnatal LCP levels.

The study populations are described in table 7.1. Of the infants followed until the term period, 10 received their own mother's milk and 18 a commercially available artificial formula as their main source of dietary lipids. The preterm human milk contained on average $0.34 \%(w t / w t)$ of $22: 6 n-3$ and $0.58 \%$ (wt/wt) of 20:4n-6. No detectable amounts of $22: 6 n-3,20: 4 n-6$ and other LCPs were present in the artificial formulas; their 18:2n-6 and $18: 3 n-3$ contents ranged from 10.8 to $18.1 \%$ (wt/wt) and from 0.34 to $1.47 \%$ (wt/wt), respectively [9; Chapter 6]. In the group of infants fed human milk, only two infants received less than $90 \%$ (vol/vol) human milk during the study period; their human milk intakes were 50.2 and $68.4 \%$ (vol/vol). Infants raised on artificial formulas consumed no human milk.

Until the infants were on full enteral feeding, they received parenteral nutrition according to current standards. Up to $95 \mathrm{~kJ} / \mathrm{kg} / \mathrm{d}$ of intravenous lipids (Intralipid $10 \%$ and $20 \%$, and Vitalipid ${ }^{*}$, containing up to 0.2 and $0.3 \%$ (w/ wt) of $22: 6 n-3$ and $20: 4 n-6$ respectively [9; Chapter 6]) were given as a source of fat. The majority of the infants received their first. enteral intake during the first week of life and they were on full enteral feeding of 420-500 $\mathrm{kJ} / \mathrm{kg} / \mathrm{d}$ at, on average, the 14 th day of life. Some infants also received intravenous RBC and plasma infusions as part of the treatment.

\subsubsection{Laboratory analysis}

Plasma and RBC samples were prepared as described previously [9; Chapter 6]. Umbilical cord samples were rinsed with saline $(\mathrm{NaCl}, 0.9 \% \mathrm{wt} / \mathrm{vol})$ and from segments of about $5 \mathrm{~cm}$ length, the arterial vessel walls were isolated from the surrounding tissue. The vessel walls were frozen in liquid nitrogen and pulverized in an aluminum mortar with a stainless steel pestle, which were cooled in liquid nitrogen. The pulverized samples were freeze dried. for 16 hours, followed by immediate fatty acid analysis.

At the start of this analysis, 1,2-dinonadecanoyl phosphatidylcholine ( $\mathrm{PC}[19: 0]_{2}$ ) was added to every sample as an internal standard. Samples were analyzed as described previously [9; Chapter 6], only modified by the use of the method of Bligh and Dyer [26] for the extraction of total lipids from 10-30 mg freeze dried vessel wall tissue and by the use of a CP-Sil 88 column (Chrompack ${ }^{\circledR}$. Middelburg. The Netherlands) for the separation and quantification of the fatty acid methyl esters in the vessel wall samples.

Fatty acid amounts present in the PL fraction were quantified based on the amount of 19:0 internal standard fatty acid methyl ester recovered. Absolute fatty acid levels were expressed as $\mathrm{mg} / \mathrm{l}$ plasma or RBC suspension or as $\mathrm{mg} / \mathrm{kg}$ dry weight of cord vessel wall tissue. Relative fatty acid levels were expressed as \% (wt/wt) of total fatty acid methyl esters. 
Table 7.1. Characteristics of study population".

\begin{tabular}{|c|c|c|}
\hline & $\begin{array}{l}\text { infants involved in correlations } \\
\text { at birth }(n=44)\end{array}$ & $\begin{array}{l}\text { infants followed until } \\
\text { term period }(n=28)\end{array}$ \\
\hline maternal age (y) & $28.6 \pm 4.9$ & $29.1 \pm 4.7$ \\
\hline gestational age (weeks) & $30.6 \pm 2.6$ & $32.3 \pm 2.9$ \\
\hline birth weight (g) & $1355 \pm 344$ & $1380 \pm 330$ \\
\hline head circumference $(\mathrm{cm})$ & $27.6 \pm 2.8$ & $28.1 \pm 3.0$ \\
\hline length $(\mathrm{cm})$ & $40.5 \pm 3.4$ & $40.6 \pm 3.7$ \\
\hline $\mathrm{SGA}^{b}(\mathrm{P}<2.3)^{c}$ & 0 & $8(29 \%)$ \\
\hline pH umbilical artery blood & $7.18 \pm 0.12$ & $7.16 \pm 0.12$ \\
\hline follow-up after birth (weeks) & & $6.4 \pm 2.6$ \\
\hline age at first enteral intake (days) & & $6 \pm 3$ \\
\hline age at full enteral intake (days) & & $14 \pm 8$ \\
\hline intravenous lipids $(\mathrm{kJ} / \mathrm{kg} / \mathrm{day})^{d}$ & & $22.7 \pm 18.9$ \\
\hline intravenous plasma $(\mathrm{ml})^{d}$ & & $17.4 \pm 27.6$ \\
\hline intravenous red blood cells $(\mathrm{ml})^{d}$ & & $28.4 \pm 44.3$ \\
\hline human milk:formula $a^{e}$ & & $10: 18$ \\
\hline
\end{tabular}

"mean \pm SD, except for: 'number of subjects

term period: $37-42$ weeks of gestational age, SGA= small for gestational age (birth weight percentile < 2.3).

dvalue represents average amount received per day during entire follow-up period.

\subsubsection{Data analysis}

P-values $\leq 0.05$ were considered significant. Relations between $n-3$ and $n-6$ LCP levels at birth, GA at birth, and anthropometric measurements at birth were explored using linear regression (Pearson correlation coefficients). Significant correlations between the LCP status and anthropometric measures were corrected for GA at birth, using multiple regression analysis.

The influence of the LCP status at birth on postnatal LCP levels was evaluated for the two LCPS of primary interest, $22: 6 n-3$ and 20:4n-6, by means of multiple regression analysis. The regression equation formulated was:

$$
\begin{aligned}
\text { LCPS in blood at term }=\mathrm{A} & +\mathrm{B}_{1}^{*}(\text { LCPS in cord blood }) \\
& +\mathrm{B}_{2}^{*}(\text { LCPS in umbilical artery wall }) \\
& +\mathrm{B}_{3} * \text { diet } \\
& +\mathrm{B}_{4}^{*} \text { follow-up }
\end{aligned}
$$


The dependent variable was the $22: 6 n-3$ or $20: 4 n-6$ status in the term period. As indicators of the $22: 6 n-3$ or $20: 4 n-6$ status at birth, the levels of these fatty acids in the PL fraction of venous cord blood (plasma or RBCs) and the umbilical artery walls were entered as potential explanatory variables. The potential relation between LCP status at birth and postnatal LCP levels was corrected for the type of postnatal enteral diet, which was entered as a dummy variable with zero for human milk and one for artificial formula. Moreover, the period (days) between birth and the blood sampling in the term period (follow-up) was entered as a continuous variable. Separate equations were calculated for 22:6n-3 and 20:4n6 , for the plasma and the RBC component of the blood, and for the absolute and relative fatty acid data. Using an F-test, the overall relation between the LCP status at term and both indicators of the LCP status at birth was tested, correcting for diet and follow-up. To guard against spurious correlations, we present separate P-values for the two LCP-indicators only when the F-test was significant.

\subsection{Results}

\subsubsection{Relation between LCP status at birth and gestational age at birth}

In table 7.2., mean values for the fatty acids studied $(\%(\mathrm{wV} / \mathrm{wt})$ and total amounts of PLassociated fatty acids) are listed. Eight infants had a birth weight below the 2.3 rd percentile of the Amsterdam growth charts [27]. These small-for-GA infants were not included in the analyses of the relations between LCP status, GA and anthropometric measurements at birth. From six infants of the remaining 44 infants, no umbilical cord sample was available. From the cords of five other infants, no acceptable blood sample could be obtained.

In cord plasma PLS, significant positive relations were found between GA at birth and the relative levels of $22: 6 n-3$, the sum of all $n-3$ LCPS, and the sum of all LCPS $(\mathbb{P}<0.01)$. In the arterial cord vessel walls, significant positive correlations were observed between GA at birth and relative levels of $20: 4 n-6$, the sum of all $n-6$ LCPS, the sum of all LCPS (P $<0.001$ for all), and 22:6n-3 $(P<0.05)$. No significant relations were found between GA and plasma or cord artery wall levels of 20:3n-6 or 20:5n-3, nor between GA and absolute. LCP levels in plasma or umbilical artery walls, nor between GA and LCP levels in RBC PLS.

\subsubsection{Relation between LCP status at birth and prenatal growth}

No significant correlations were observed for any of the anthropometric parameters with the LCP status measured in cord plasma or RBC PLS. The relations of LCP levels in the umbilical artery wall with birth weight are based on 38 infants, with HC on 31 infants, and with length on 29 infants, due to missing values for the latter two growth measures. All significant correlations between anthropometric measurements and LCP levels in umbilical artery wall PLs could at least partly be attributed to the significant positive correlation between the anthropometric measurement and GA at birth $(\mathrm{P}<0.0005)$.

After correction for GA at birth, only absolute and relative 22:6n-3 levels remained significantly related to birth weight ( $\mathrm{P}=0.03$ for both). Absolute levels of 20:4n-6, the sum of all $n-6$ LCPS ( $\mathrm{P}=0.05$ for both), the sum of all LCPS ( $\mathrm{P}=0.03)$ ) and 22:6n-3 ( $\mathrm{P}=0.01)$, and the relative level of $22: 6 n-3 \quad(\mathrm{P}=0.05)$ remained significantly related to $\mathrm{HC}$ at birth. The absolute level of 22:6n-3 remained significantly related to length at birth $(\mathrm{P}=0.02)$. Cord 
Table 7.2. Fatty acid composition ( $\left(\mathcal{E}(w / w t)^{d}\right.$, mean $\pm S D$ ) of phospholipids of umbilical artery vessel walls and of plasma and red blood cells (RBCs) at birth and at term postconceptional age (37-42 weeks gestational age).

\begin{tabular}{|c|c|c|c|c|c|}
\hline fatty acid & $\begin{array}{l}\text { umbilical artery } \\
(n=38)\end{array}$ & $\begin{array}{l}\text { plasma } \\
(n=39)\end{array}$ & $\begin{array}{l}\text { plasma }_{\text {at ierm }} \\
(\mathrm{n}=27)\end{array}$ & $\begin{array}{l}\mathrm{RBCs}_{\text {at }} \text { wirth } \\
(\mathrm{n}=39)\end{array}$ & $\begin{array}{l}\mathrm{RBCs}_{\text {at }} \text { term } \\
(\mathrm{n}=28)\end{array}$ \\
\hline $20: 3 n-6$ & $0.89 \pm 0.26$ & $3.99 \pm 0.88$ & $2.81 \pm 0.70$ & $1.68 \pm 0.54$ & $1.22 \pm 0.47$ \\
\hline $20: 4 n-6$ & $11.1 \pm 2.2$ & $17.0 \pm 2.0$ & $7.7 \pm 1.7$ & $11.7 \pm 4.4$ & $7.3 \pm 2.9$ \\
\hline$\Sigma n-6 L \mathrm{LP}^{b}$ & $17.8 \pm 3.3$ & $22.1 \pm 1.8$ & $11.4 \pm 2.0$ & $16.2 \pm 6.0$ & $10.6 \pm 4.2$ \\
\hline $20: 5 n-3^{6}$ & & $0.27 \pm 0.16$ & $0.17 \pm 0.11$ & $0.12 \pm 0.10$ & $0.10 \pm 0.09$ \\
\hline $22: 6 n-3$ & $4.20 \pm 0.97$ & $3.84 \pm 0.88$ & $1.85 \pm 0.79$ & $2.71 \pm 1.39$ & $1.28 \pm 0.77$ \\
\hline$\sum n-3 L C P^{b . r}$ & & $4.42 \pm 0.99$ & $2.39 \pm 1.03$ & $3.19 \pm 1.65$ & $1.85 \pm 1.05$ \\
\hline$\sum n-3+n-6 \mathrm{LCP}$ & $22.0 \pm 3.9$ & $26.5 \pm 2.3$ & $13.8 \pm 2.9$ & $19.4 \pm 7.5$ & $12.5 \pm 5.1$ \\
\hline total ${ }^{a}$ & $15533 \pm 4479$ & $660 \pm 150$ & $1060 \pm 175$ & $1027 \pm 267$ & $925 \pm 263$ \\
\hline
\end{tabular}

"Total amount of phospholipid (PL.)-associated fatty acids expressed as mg/kg dry weight for umbilical artery vessel walls and as $\mathrm{mg} / \mathrm{l}$ for plasma and for RBC suspension. Fatty acid concentrations can be calculated from the relative fatty acid levels and the total amounts of PL-associated fatty acids.

${ }^{b} n-6 \mathrm{LCP}=n-6$ long-chain polyunsaturated fatty acids $(20: 3 n-6,20: 4 n-6,22: 4 n-6$ and $22: 5 n-6), n-3 \mathrm{LCP}=n-3$ long-chain polyunsaturated fatty acids $(20: 4 n-3,20: 5 n-3,22: 5 n-3$ and 22:6n-3).

No $n-3$ fatiy acids other than docosahexaenoic acid $(22: 6 n-3)$ were detectable in the vessel walls of the umbilical artery.

artery wall levels of 20:3n-6 were not significantly related to any of the prenatal growth parameters.

\subsubsection{Relation between LCP status at birth and at term}

From three of the 28 infants followed until the term period, no cord blood sample was available and from 2 infants, the umbilical vessel wall sample was missing. As a result, 23 complete sets of data were available for the regression analyses concerning RBCs (Table 7.3.). From one infant, the plasma sample collected at term was lost during fatty acid analysis, so for the regression analyses of the plasma data, 22 complete sets were used.

The postnatal diet was the only explanatory variable for absolute $(\mathrm{P}=0.004)$ and relative $(\mathrm{P}=0.0004)$ plasma levels of 22:6n-3 and relative plasma levels of 20:4n-6 ( $\mathrm{P}=0.02)$ at term postconceptional age, with lower postnatal levels in the infants raised on formula than in those fed their own mother's milk. The absolute 20:4n-6 level in plasma PLs at birth was the only explanatory variable (positive correlation, $\mathrm{P}=0.02$ ) for the absolute 20:4n-6 level at term (figure 7.2.A.).

Absolute $(P=0.0003)$ and relative $(P<0.0001) 22: 6 n-3$ levels and the absolute 20:4n-6 level $(\mathrm{P}=0.02)$ in the umbilical artery wall were positively related to the corresponding LCP levels in RBC PLS at term (figure 7.2.B.). No significant explanatory variables were found for the relative level of $20: 4 n-6$ in RBCs in the term period. 
Table 7.3. Explanatory variables for the $22: 6 n-3$ and $20: 4 n-6$ status in the term period (37-42 wks gestational age), resulting from regression analysis ${ }^{a}$ performed in 22 subjects for plasma and in 23 subjects for red blood cells.

\begin{tabular}{llllc}
\hline Dependent variable (in term period) & $\mathrm{P}_{\mathrm{F} \text {-test }}{ }^{a}$ & explanatory variable & $\mathrm{P}_{\text {T-test }}{ }^{a}$ \\
\hline plasma & $22: 6 n-3, \mathrm{mg} / \mathrm{l}$ & 0.18 & enteral diet $^{b}$ & 0.004 \\
phospholipids & $22: 6 n-3, \%(\mathrm{wt} / \mathrm{wt})$ & 0.23 & enteral diet $^{b}$ & 0.0004 \\
& $20: 4 n-6, \mathrm{mg} / \mathrm{l}$ & 0.04 & $20: 4 n-6$ in umb. plasma & 0.02 \\
& $20: 4 n-6, \%(\mathrm{w} / \mathrm{wt})$ & 0.57 & enteral diet ${ }^{b}$ & 0.02 \\
red blood cell & $22: 6 n-3, \mathrm{mg} / 1$ & 0.0005 & $22: 6 n-3$ in umb. art. wall & 0.0003 \\
phospholipids & $22: 6 n-3, \%(\mathrm{w} / \mathrm{wt})$ & $<0.0001$ & $22: 6 n-3$ in umb. art. wall & $<0.0001$ \\
& $20: 4 n-6, \mathrm{mg} / \mathrm{l}$ & 0.05 & $20: 4 n-6$ in umb. art. wall & 0.02 \\
& $20: 4 n-6, \%(\mathrm{wt} / \mathrm{wt})$ & 0.21 & & - \\
\hline
\end{tabular}

aDependent variables: $22: 6 n-3$ or $20: 4 n-6$ level in the term period; explanatory variables: $22: 6 n-3$ or $20: 4 n-6$ levels at birth in umbilical (umb.) cord blood and in the umbilical artery (art.) wall, type of postnatal diet (human milk or formula) and length of period between birth and term (days), $\mathrm{P}_{\mathrm{F}-\text { test }}$ : significance level for the relation between postnatal long-chain polyunsaturated fatty acid (LCP) level and both indicators of the LCP status at birth (LCP levels in cord blood and in the umbilical artery vessel wall), corrected for enteral diet and length of follow-up period. $\mathrm{P}_{\text {T-test }}$ significance level for the separate explanatory variable, which results from calculating the entire regression equation.

bHigher fatty acid values in the human milk fed infants $(n=10)$ than in the formula fed infants $(n=12)$.

\subsection{Discussion}

One of the objectives of this study was to enhance the present knowledge of the relations between the LCP status at birth, GA at birth, and anthropometric measurements. GA was positively correlated with relative $n-3 \mathrm{LCP}$ amounts in cord plasma PLS and with relative $n-6$ and $n-3 \mathrm{LCP}$ amounts in the umbilical artery walls. We consider the higher

$n-6$ and $n-3$ levels observed with advancing GA an indication of an adequate response to the increasing demand for $n-6$ and $n-3$ LCPs, necessary for fetal brain and body growth, in the third trimester of pregnancy.

Increasing plasma $n-3$ levels with increasing gestational age have also been observed by others $[19,28,29$; Chapter 3]. Plasma $n-6$ levels have been reported to increase [28] or to decrease [29; Chapter 3] with advancing GA, or, as in this study, no significant relation was observed $[18,19]$. Fatty acid levels in plasma PLs are known to be affected by relatively short-term (dietary) influences. Therefore, we also studied umbilical artery walls, because their LCP composition can be looked upon as a long-term reflection of the fetal LCP status $[24,25]$. They are regarded as such because human umbilical vessels have no vasa vasorum, and human tissue cannot synthesize efas, so their walls have no other way to obtain EFAS than from the blood flowing through them. As a consequence, the LCP composition of the umbilical artery walls represents the EFA and LCP content of the return flow from the fetus 

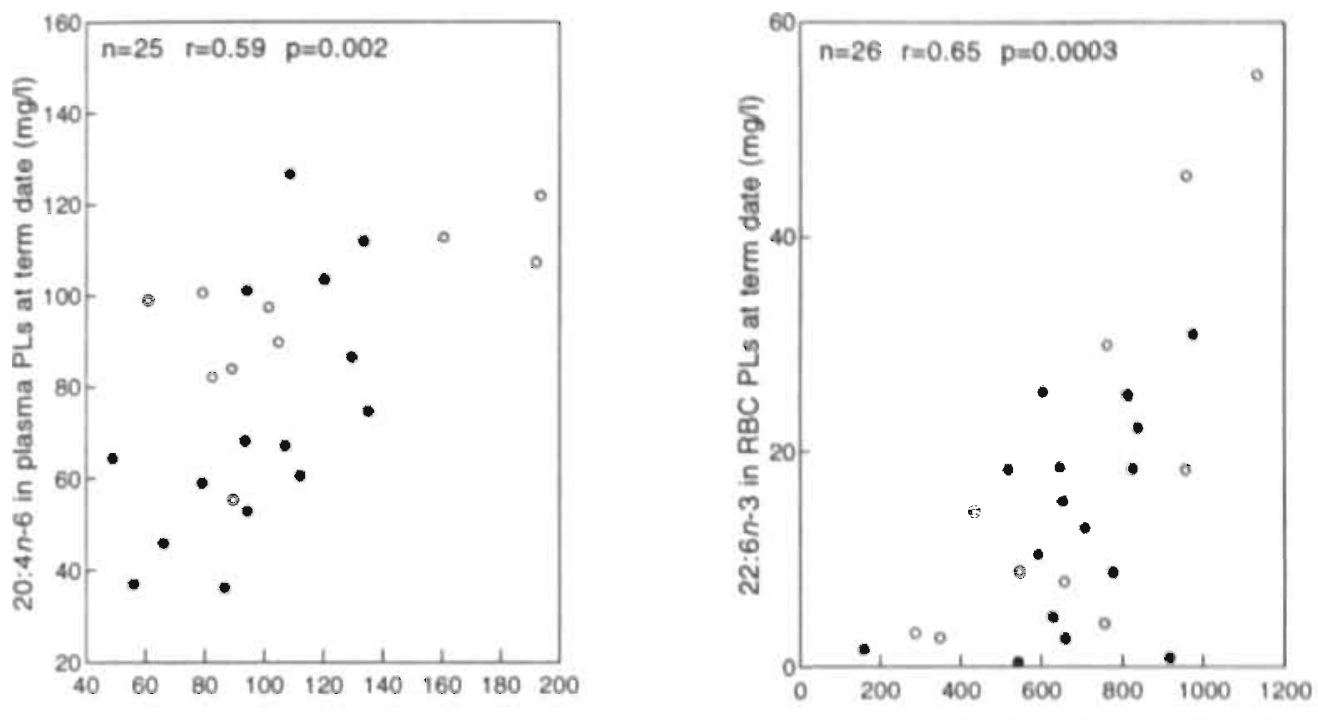

A

20:4n-6 in umbilical plasma PLs (mg/)!

- iormila o human milk
B

22:6n-3 in umbilical artery wall ( $m g / k g$ dry w1)

- formula $\circ$ human milk

Figure 7.2.: A. Influence of the arachidonic acid (20:4n-6) status at birth, measured in umbilical plasma phospholipids (PLS), on the absolute 20:4n-6 status in plasma PLS in the term period (at term date; $37-42$ wks gestational age). B. Influence of the docosahexaenoic acid $(22: 6 n-3)$ status at birth, measured in the walls of umbilical arteries, on the absolute 22:6n-3 status in red blood cell (RBC) PLs in the term period.

The scatterplots contain all available information, also that of the infants of whom incomplete data sets were obtained. Pearson correlation coefficients and significance levels result from linear regression between the two variables given.

to its mother and, thereby, indicates the lowest estimate of the fetal LCP status.

After correction for GA at birth, anthropometric measurements at birth were significantly related to LCP levels in the umbilical artery wall only. Because LCP levels in cord plasma and RBC PLS are considered to be relatively short-term indicators of the fetal LCP status, their correlation with measures of a long-term process like fetal growth, can be expected to be less distinct. 22:6n-3 levels in the arterial cord vessel walls were significantly related to weight, HC, as well as length at birth, and absolute $n-6$ LCP levels correlated with HC. Others have observed a positive relation of $n-3$ as well as $n-6$ LCPS with birth weight and HC, both in premature [19] and term [24,30] newborn infants. Koletzko and Braun [18] reported a positive relation between birth weight and relative levels of 20:4n-6 and the sum of all $n-6$ LCPS in plasma triglycerides of newborn preterm infants. No such relation was 
observed for $n-3$ LCPS, so they concluded that LCPS of the $n-6$ series specifically seem to be associated with tissue growth in utero. However, the correlations observed in the abovementioned studies were not always corrected for GA. In our population, significant correlations for percentage levels of 20:4n-6 and the sum of all $n-6$ LCPS with birth weight and with $\mathrm{HC}$ were completely attributable to GA at birth.

In the current study, we observed a striking relation between prenatal growth and 22:6n3 status; this fatty acid was significantly related to all three anthropometric measures, independent of the GA at which the infant was born. $22: 6 n-3$ has a highly specific distribution in the human body, being present in high concentrations in brain, retina, spermatozoa and mitochondria [31]. Perhaps an explanation for the consistent relation between 22:6n-3 status and prenatal growth may be sought in the high $22: 6 n-3$ concentration in mitochondrial membrane pls and its potential influence on mitochondrial metabolic functions [32].

We also demonstrated that the LCP status at term is determined, not only by the postnatal diet, but also by the LCP status at birth. The observed relations did not change when the data of infants who were SGA at birth were not included in the statistical analysis. The 22:6n-3 and 20:4n-6 levels in the walls of the umbilical arteries of preterm infants were positively related to the $22: 6 n-3$ and $20: 4 n-6$ content of RBC PLs collected at the time when these infants were expected to be born. Recent studies in preterm populations, have demonstrated the importance of both the $n-6$ and the n-3 LCP status for several functional [33-36] and anthropometric measures $[20,37]$. These studies pointed out the importance of an adequate LCP content of the early enteral diet of premature infants. However, our observation that higher LCP levels at birth result in higher postnatal levels stresses the significance of an appropriate prenatal LCP supply, because this is a major determinant of the LCP status at birth. The only potential way to achieve a change in this prenatal LCP supply is through an adaptation of the fatty acid content of the maternal diet during pregnancy, e.g., through an enhanced maternal EFA intake. The results of an earlier study support the feasibility of such an intervention [38].

Besides the observed relation between the LCP status at birth and LCP levels at term postconceptional age, the type of postnatal diet was demonstrated to be the major determinant of postnatal LCP levels in plasma PLs, indicating that conventional artificial formulas (containing no $n-6$ and $n-3$ LCPs) are unable to maintain the postnatal LCP status of preterm infanis at levels that can be obtained when feeding with preterm human milk. Our observation that the type of oral nutrition received by an infant influences the postnatal LCP status when measured in plasma PLs, but not when measured in RBC PLS, is in agreement with the findings of recent studies $[8,16]$.

We conclude (figure 7.3.) that in preterm infants, there are significant relations between the LCP status at birth, GA at birth and indicators of prenatal growth. Moreover, both the postnatal dietary LCP supply and the prenatal LCP supply, which is reflected in the LCP status at birth, were found to affect postnatal LCP levels of preterm infants. Considering the importance of LCPS for normal brain and retinal function, the latter observation may warrant further studies of the effects of EFA-enriched maternal diets during pregnancy on the neonatal LCP status at birth. 


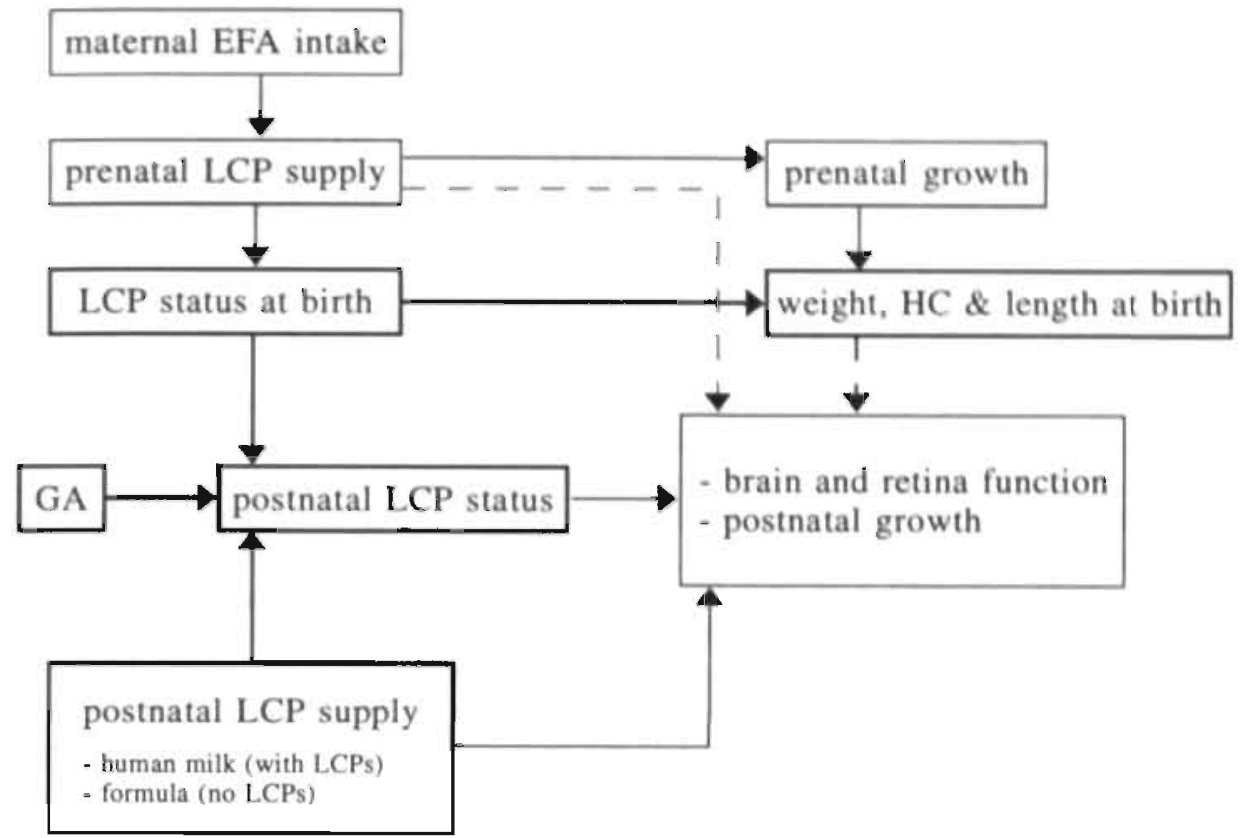

Figure 7.3: Relations between prenatal long-chain polyunsaturated fatty acid (LCP) supply and prenatal growth and between pre- and postnatal LCP supplies on the one hand, and postnatal LCP values on the other hand ( $\mathrm{EFA}=$ essential fatty acid, $\mathrm{GA}=$ gestational age, $\mathrm{HC}=$ head circumference). Bold type artows and boxes indicate relations observed in the current: study.

\subsection{Acknowledgements}

The authors express their appreciation for the skilled assistance obtained from the Analytical Biochemical Laboratory in Assen, The Netherlands (fatty acid analyses of blood samples) and Mrs. M. M. G. Simonis (fatty acid analyses of umbilical artery wall samples).

\subsection{References}

1. Svennerholm L. Distribution and fatty acid composition of phosphoglycerides in normal human brain. J Lipid Res 1968;9:570-9.

2. Crawford MA, Casperd NM, Sinclair AJ. The long chain metabolites of linoleic and linolenic acids in liver and brain in herbivores and carnivores. Comp Biochem Physiol 1976;54B:395-401.

3. Sastry PS. Lipids of nervous tissue: composition and metabolism. Prog Lipid Res 1985:24:69. 176. 
4. Fliesler SJ, Anderson RE. Chemistry and metabolism of lipids in the vertebrate retina. Prog Lipid Res 1983;22:79-131.

5. Carlson SE, Rhodes PG, Ferguson MG. Docosahexaenoic acid status of preterm infants at birth and following feeding with human milk or formula. Am J Clin Nutr 1986;44:798-804.

6. Pita ML, Fernández MR, De-Lucchi $C$, et al. Changes in the fatty acids pattern of red blood cell phospholipids induced by type of milk, dietary nucleotide supplementation, and postnatal age in preterm infants. J Pediatr Gastroenterol Nutr 1988;5:740-7.

7. Koletzko B, Schmidt E, Bremer HJ, Haug M, Harzer G. Effects of dietary long chain polyunsaturated fatty acids on the essential fatty acid status of premature infants. Eur J Pediatr 1989;148:669-75.

8. Clandinin MT, Parrott. A, Van Aerde JE, Hervada AR, Lien E. Feeding preterm infants a formula containing $C_{20}$ and $C_{22}$ fatty acids simulates plasma phospholipid fatty acid composition of infants fed human milk. Early Hum Dev 1992;31:41-51.

9. Foreman-v Drongelen MMHP, Houwelingen AC v, Kester ADM, et al. Long-chain polyene status of preterm infants with regard to the fatty acid composition of their diet: comparison between absolute and relative fatty acid levels in plasma and erythrocyte phospholipids. $\mathrm{Br}$ J Nutr 1995; 73:405-22.

10. Jensen RG, Hagerty MM, McMahon KE. Lipids of human milk and infant formulas: a review. Am J Clin Nutr 1978;31:990-1016.

11. Lammi-Keefe CJ, Jensen GJ. Lipids in human milk: a review. 2: Composition and fat-soluble vitamins. J Pediatr Gastroenterol Nutr 1984;3:172-98.

12. Jensen RG, Ferris AM, Lammi-Keefe CJ. Lipids in human milk and infant formulas. Ann Rev Nutr 1992;12:417-41.

13. Clandinin MT, Chappell JE, Leong S, Heim T, Swyer PR, Chance GW. Extrauterine fatty acid accretion in infant brain: implications for fatty acid requirements. Early Hum Dev 1980;4:131-8.

14. Chambaz J, Ravel D, Manier M-C. Pepin D, Mulliez N, Bereziat. G. Essential fatty acid interconversion in the human fetal liver. Biol Neonate 1985;47:136-40.

15. Carlson SE, Rhodes PG, Rao VS, Goldgar DE. Effect of fish-oil supplementation on the n-3 fatty acid content of red blood cell membranes in preterm infants. Pediatr Res 1987:21:507-10.

16. Carlson SE, Cooke RJ, Rhodes PG, Peeples JM, Werkman SH. Tolley EA. Long-term feeding of formulas high in linolenic acid and marine oil to very low birth weight infants: phospholipid fatty acids. Pediati Res 1991;30:404-12.

17. Carison SE, Cooke RJ, Rhodes PG, Peeples JM, Werkman SH. Effect of vegetable and marine oils in preterm infant formulas on blood arachidonic and docosahexaenoic acids. I Pediatr 1992;120:159-67.

18. Koletzko B, Braun M. Arachidonic acid and early human growth: is there a relation? Ann Nutr Metab 1991:35:128-31.

19. Leaf AA. Leighfield MJ, Costeloe KL. Crawford MA. Long chain polyunsaturated fatty acids and fetal growth. Early Hum Dev 1992:30:183-91.

20. Carlson SE, Werkman SH, Peeples JM, Cooke RJ, Tolley EA. Arachidonic acid status correlates with first year growth in preterm infants. Proc Natl Ac Sci USA 1993:90:1073-7.

21. Leaf AA, Leighfield MJ, Ghebremeskel K, Costeloe KL, Crawford MA. Polyunsaturated fatty acids in plasma choline phosphoglycerides of preterm infants (abstract). Third International Congress on Essential Fatty Acids and Eicosanoids, Adelaide, Australia 1992:77.

22. Hornstra G. Essential fatty acids, pregnancy and pregnancy complications: a round table discussion. In: Sinclair A. Gibson R, eds. Essential Fatty Acids and Eicosanoids: Invited papers from the Third International Congress. Champaign, Illinois: American Oil Chemist's Society. 1993:177-82. 
23. Carison SE, Carver JD, House SA. High fat diets varying in ratios of polyunsaturated to saturated fatty acid and linoleic and linolenic acid: a comparison of rat neural and red cell membrane phospholipids. J Nutr 1986;116:718-25.

24. Crawford MA, Doyle W, Drury P. Lennon A, Costleloe K, Leighfield M. n-6 and n-3 fatty acids during early human development. J Int Med 1989;225:159-69S1.

25. Hornstra G, Houwelingen AC v, Simonis M, Gerrard JM. Fatty acid composition of umbilical arteries and veins: possible implications for the fetal EFA-status. Lipids 1989;24:511-7.

26. Bligh EG, Dyer WJ. A rapid method for total lipid extraction and purification. Can J Biochem Physiol 1959;37:911-7.

27. Kloosterman GJ. On intrauterine growth, the significance of prenatal care. Int J Gynaecol Obstet 1970;8:895-912.

28. Friedman Z, Danon A, Lamberth EL, Mann WJ. Cord blood fatty acid composition in infants and in their mothers during the third trimester. J Pediatr 1978;92:461-6.

29. Houwelingen AC v, Foreman-v Drongelen MMHP, Al MDM, Hornstra G, Nicolini U. Fetal. essential fatty acid status during gestation (abstract). Am J Clin. Nutr 1993;57:815S.

30. Felton CV, Chang TC, Crook D, Marsh M, Robson SC, Spencer JAD. Umbilical vessel wall fatty acids after normal and retarded fetal growth. Arch Disease Child 1994;70:F36-9.

31. Salem N, Kim H-Y, Yergey JA. Docosahexaenoic acid: membrane function and metabolism. in: Simopoulos AP, Kifer RR, Martin RE, eds. Health Effects of Polyunsaturated Fatty Acids in Seafood. Orlando: Academic Press 1986:263-317.

32. Houtsmuller UMT. Specific biological effects of polyunsaturated fatty acids. In: Vergroesen AJ, ed. The Role of Fats in Human Nutrition. London: Academic Press, 1975:331-51.

33. Uauy RD, Birch DG, Birch EE, Tyson JE, Hoffman DR. Effect of dietary omega- 3 fatty acids on retinal function of very-low-birth-weight neonates. Pediatr Res 1990;28:485-92.

34. Carison SE, Werkman SH, Rhodes PG, Tolley EA, Visual-acuity development in healthy preterm infants: effect of marine-oil supplementation. Am J Clin Nutr 1993;58:35-42.

35. Birch E, Birch D, Hoffman D, Hale L, Everett M. Uauy R. Breast-feeding and optimal visual development. J Pediatr Ophthaimol Strabismus 1993;30:33-8.

36. Bjerve KS, Brubakk AM, Fougner KJ, Johnsen H, Midthjell K. Torstein V. Omega-3 fatty acids: essential fatty acids with important biological effects, and serum phospholipid fatty acids as markers of dietary omega-3 fatty acid intake. Am 」 Clin Nutr 1993;57:801-6S.

37. Carison SE, Cooke RJ. Werkman SH, Tolley EA. First year growth of preterm infants fed standard compared to marine oil n-3 supplemented formula. Lipids 1992:27:901-7.

38. Houwelingen AC v, Hornstra G, Simonis M, et al. Essential fatty acid composition of umbilical arteries and veins after fish oil supplementation during pregnancy. In: Drevon CA, Baksaas I, Krokan HE, eds. Omega-3 Fatty Acids: Metabolism \& Biological Effects. Basel, Switzerland: Birkhauser, 1993:125-9. 



\section{Influence of feeding artificial formulas containing docosa- hexaenoic and arachidonic acids on the postnatal long-chain polyunsaturated fatty acid status of healthy preterm infants}

Magritha M.H.P. Foreman-van Drongelen', Adriana C. v. Houwelingen', Arnold D.M. Kester ${ }^{2}$, Carlos E. Blanco ${ }^{3}$, Tom H.M. Hasaart ${ }^{4}$ and Gerard Hornstra!'

${ }^{1,2}$ Departments of 'Human Biology and ${ }^{2}$ Methodology and Statistics, University of Limburg, Maastricht, The Netherlands

${ }^{3,4}$ Departments of ${ }^{3}$ Neonatology and ${ }^{4}$ Obstetrics and Gynaecology, University Hospital Maastricht, The Netherlands

British Journal of Nutrition, in press

\subsection{Abstract}

In view of the importance of long-chain polyunsaturated fatty acids LCPS for growth and development of fetal and infant neural tissue, the influence of the dietary $n-3$ and $n-6$ LCP intake on the LCP status of 43 preterm infants (birth weight $<1800 \mathrm{~g}$ ) was studied. Thirtyone formula-fed infants were randomly assigned to receive a conventional formula, lacking LCPS, $(n=16)$, or an $22: 6 n-3(0.3$ wt \%) and $20: 4 n-6(0.6$ wt $\%)$ enriched formula $(n=15) ; 12$ infants received their own mother's breast milk. Fatty acid compositions of plasma and red blood cell (RBC) phospholipids (PLs) were determined in umbilical venous blood, in weekiy postnatal samples until the 35 th day of life and, for the formula-fed infants, at three months of corrected age. Both in plasma $(\mathrm{P}<0.001)$ and $\mathrm{RBC}(\mathrm{P}<0.01)$ PLs, the changes with time until day 35 for $22: 6 n-3$ and $20: 4 n-6$ in the two groups of formula-fed infants were significantly different, with higher values, comparable to those of human milk-fed infants, in the LCP-enriched formula group. At three months of corrected age, differences between the two formula-fed groups were even more pronounced. In conclusion, adding 22:6n-3 and 20:4n-6 to artificial formulas in balanced ratios, i.e. in amounts similar to those found in preterm human milk, raises both the $22: 6 n-3$ and $20: 4 n-6$ status of formula-fed preterm infants to values found for human milk-fed preterm infants. Additional studies are necessary to 
evaluate the potentially favourable effects of this combined addition on the neurodevelopmental outcome of preterm infants.

\subsection{Introduction}

The LCPS', docosahexaenoic acid (cervonic acid, 22:6n-3) and arachidonic acid (20:4n6) in particular, are the predominant structural fatty acids in the human brain [1-3] and retina [4]. These LCPS accumulate rapidly in fetal and infant neural tissue during the periods of most rapid growth and development, that is during the last months of gestation and the first months of postnatal life [5-9].

Unlike term infants, preterm infants cannot benefit from the maternal and placental LCP supply during the last trimester of pregnancy to cover the demands associated with this LCP accretion. Instead, they are dependent on their own dietary supply through either human milk, which contains small but significant amounts of 22:6n-3, 20:4n-6 and other LCPs, or through commercially available artificial formulas, the majority of which does not contain any but trace amounts of LCPS [10-12]. A substantial number of studies in preterm populations have since demonstrated that these conventional formulas, even when they do contain substantial amounts of the parent essential fatty acids (EFAs) linoleic acid $(18: 2 n-6)$ and $\alpha$ linolenic acid (18:3n-3), are unable to maintain postnatal $22: 6 n-3$ and $20: 4 n-6$ levels in plasma and RBC lipids at levels observed after feeding human milk [13-17; Chapter 6]. Probably, the desaturase capacity of preterm newborns is too limited to adequately cover the demands for $n-3$ and n-6 LCPs solely through metabolic conversion of the two parent fatty acids $[18,19]$. In addition, preterm newborn infants have very limited fatty acid stores $[18,20]$.

These observations have prompted an increasing number attempts, with varying degrees of success to reduce the differences between the biochemical LCP status of human milk-fed and formula-fed infants by adding LCPs to the diets of the latter [15,16,21-25]. However, increasing only the dietary $n-3$ LCP intake, through the addition of marine oils, resulted not only in the desired enhancement of 22:6n-3 levels, but also in decreased 20:4n-6 levels $[23,24]$, and has been reported to be associated with diminished first-year growth rates $[26,27]$. Effects on LCP status of formulas containing both $n-3$ and $n-6$ LCPS have also been reported $[15,16,25]$, but the duration of supplementation in these studies was confined to a few weeks.

Therefore, we studied the effects of long-term feeding of artificial formulas, containing both $22: 6 n-3$ and 20:4n-6 in amounts present in human milk, in formula-fed preterm infants which were randomly assigned to receive either conventional artificial formulas or the LCPenriched formulas. The LCP patterns of both plasma and RBC PLS were studied until three months after the initially expected date of delivery. The PL-fraction was studied because PLS are structural lipids, which are the richest source of polyunsaturated fatty acids (PUFAs), including LCPS, and because changes in PUFA profile are most pronounced in PLS. [28].

${ }^{1}$ Polyunsaturated fatty acids with a chain length of 20 carbon atoms or more, and derived from the parent essential fatty acids linoleic acid $(18: 2 n-6)$ and $\alpha$-linolenic acid $(18: 3 n-3)$ through alternate desaturation and elongation. 
Values for 22:6n-3 and 20:4n-6 during the first 5 weeks of life of infants fed on the supplemented formulas were compared with those of a group of preterm infants raised on their own mother's breast milk.

\subsection{Subjects and methods}

\subsubsection{Experimental design}

\section{Patients}

The total study population comprised. 43 infants (birth weight 900-1795 g), who were born before the 37 th week of gestation, had a birth weight appropriate for gestational age (above the 2.3rd percentile of the Amsterdam growth charts. [29]), and were free from metabolic disease and major congenital malformations. Gestational age was confirmed by menstrual history and early ultrasound dating, and by Dubowitz score [30] if the former information was missing or doubtful. Only infants with a birth weight of $1800 \mathrm{~g}$ or less were included, because larger infants were likely to be discharged home before the intended minimum duration of the study (4 weeks). Immediately after delivery (day 0), approximately $3 \mathrm{ml}$ of umbilical venous blood was collected. Thereafter, the essential fatty acid status of the infants was monitored until discharge home or transfer to a non-participating hospital. For this purpose, a weekly sample of approximately $0.5 \mathrm{ml}$ of capillary or venous blood was collected in conjunction with a diagnostic puncture, which was part of the routine clinical monitoring at the neonatology ward. Because of the frequent oral feeds that are given to preterm infants (every 2-3 hours), blood samples could not be collected after fasting, but were taken between one and one and a half hour after a feed. For the formulafed infants, follow-up was extended after discharge to three months after the initially expected date of delivery (three months of corrected age), when a final blood sample was collected.

All infants were admitted to the neonatal care unit, where clinical care was provided by the attending neonatologists and resident physicians, according to current standards. Some infants received intravenous $\mathrm{RBC}$ and plasma infusions at different times during the treatment. Since these preparations contain significant amounts of $22: 6 n-3$ and 20:4n-6, the time of infusion and the amount administered were registered carefully. Furthermore, neonatall blood samples were always collected 24 hours or more after an infusion. The infants were discharged home when their weight reached $2400 \mathrm{~g}$.

The study was approved by the medical ethics committees of the participating hospitals, and written informed consent was obtained from one or both parents.

\section{Diets}

Infants were eligible for entering the study when they were able to tolerate enteral feedings and did no longer require respiratory support (continuous positive airway pressure or intubation and mechanical ventilation). If the mother did not wish to provide breast milk, her infant was introduced to enteral feeding with a premature infant formula. These infants were randomly assigned to receive either a commercially available, conventional artificial formula, containing no LCPS (table 8.1 , preterm C-AF), or an LCP-enriched version of this formula, containing $22: 6 n-3$ and $20: 4 n-6$ in balanced ratios $(1: 2)$ and in amounts approxi- 
Table 8.1. Fatty acid composition, \% (wt/wt), of total lipids of preterm human milk (HM) and of the conventional (C-AF) and LCP-enriched (LCP-AF) artificial formulas used ${ }^{a}$.

\begin{tabular}{|c|c|c|c|c|c|}
\hline \multirow{2}{*}{$\begin{array}{l}\text { Fatty acides } \\
\%(w t / w t)\end{array}$} & \multicolumn{2}{|c|}{ preterm formula } & \multicolumn{2}{|c|}{ term formula } & \multirow{2}{*}{$\begin{array}{l}\text { preterm HM } \\
\qquad(\mathrm{n}=6)\end{array}$} \\
\hline & C-AF & LCP-AF & C.-AF & LCP-AF & \\
\hline$\Sigma$ SAFA & 39.5 & 38.5 & 41.1 & 40.4 & $48.1(43.4-50.3)$ \\
\hline$\Sigma$ MUFA & 44.3 & 44.6 & 44.3 & 44.9 & $32.4(30.9-36.1)$ \\
\hline$\Sigma$ PUFA & 15.5 & 16.4 & 14.2 & 14.1 & $18.7(14.6-21.7)$ \\
\hline $18: 2 n-6$ & 14.3 & 14.3 & 12.8 & 12.0 & $14.7(11.3-18.1)$ \\
\hline $20: 3 n-6$ & ND & 0.06 & ND & 0.05 & $0.55(0.49-0.63)$ \\
\hline $20: 4 n-6$ & ND & 0.61 & ND & 0.54 & $0.52(0.43-0.64)$ \\
\hline$\sum n-6$ LCP & ND & 0.67 & ND & 0.59 & $1.26(1.04-1.48)$ \\
\hline $18: 3 n-3$ & 1.2 & 1.1 & 1.4 & 1.2 & $0.90(0.77-1.02)$ \\
\hline $20: 5 n-3$ & ND. & ND & ND & ND & $0.04(0.04-0.06)$ \\
\hline $22: 6 n-3$ & ND & 0.30 & ND & 0.30 & $0.26(0.22-0.42)$ \\
\hline$\sum n-3$ LCP & ND & 0.30 & ND & 0.30 & $0.57(0.48-0.80)$ \\
\hline
\end{tabular}

aFor artificial formulas, data are based on chemical analyses performed at the Nutricia Chemical and Physical Research Laboratory Zoetermeer, the Netherlands; for human milk, results are based on own analyses as described before [17] (median (interquartile range) of average content during the study period [day 0-35]).

${ }^{b}$ SAFA $=$ saturated fatty acids, MUFA $=$ sum of monounsaturated fatty acids, PUFA $=$ polyunsaturated fatty acids, $n-6$ LCP $=n-6$ long-chain PUFAs $(20: 3 n-6,20: 4 n-6,22: 4 n-6$, and 22:5n-6), $n-3$ LCP $=n-3$ long-chain PUFAs $(20: 4 n-3,20: 5 n-3,22: 5 n-3$ and $22: 6 n-3)$.

${ }^{\mathrm{C} D}=$ none detected (less than $0.1 \%$ (wt/wt) of total fatty acid methylesters).

mating those in humain milk (table 8.1, preterm LCP-AF). The sources of the LCPS were highly purified, so-called 'single-cell oils', which are produced by single-celled organisms, such as micro-alga and fungi. The LCPS were added to the formula during commercial processing. Appropriate precautions against oxidation were taken during processing and storage, including the addition of $3 \mathrm{mg} \alpha$-tocopherol per $100 \mathrm{ml}$ of LCP-enriched formula.

Doubly-blinded randomization was performed using a computerized randomization program, and resulted in 16 infants being fed on the conventional formula and 15 infants receiving the LCP-enriched formula. At a weight of $2000 \mathrm{~g}$, the conventional premature infant formula was replaced by a commercially available, conventional regular infant formula, again containing no LCPS (table 8.1., term C-AF), while the LCP-enriched preterm formula was replaced by an LCP-enriched, but otherwise identical term formula (table 8.1., term LCP-AF). After the participating infants were discharged from the hospital, their parents were provided amply and free of charge with these term formulas for use at home. The formulas were supplied as ready-to-use bottles of $60 \mathrm{ml}$ (preterm formulas) or 100 and 200 $\mathrm{ml}$ (term formulas). To ensure an optimal patient compliance during hospitalization, the 
volumes of formula given and the numbers of the bottles used were recorded carefully by the nursing personnel. At home, the parents were instructed to fill in a daily questionnaire on the volumes of study formula, as well as any additional foods, consumed by their infants. In addition, the parents were counselled regularly.

For comparison with the LCP-enriched formula fed infants, a further 12 infants, given (initially expressed) preterm human milk obtained from their own mothers (see table 8.1. for average fatty acid composition), were studied. In five of these 12 infants, a so-called Breast Milk Fortifier was added to the milk expressed by their mothers. This fat-free fortifier was introduced on the neonatology ward halfway through our study and served to bring the intake of protein, vitamins, and minerals of human milk-fed preterm infants in line with their needs for these nutrients. It enhanced the energy intake content of the human milk with $44 \mathrm{~kJ} / 100 \mathrm{ml}$. When the mother was unable to express enough milk, an appropriate formula (table 8.1., preterm C-AF) was supplied to cover the nutritional demand of her child. If the intake of artificial formula exceeded 25 percent ( $v o l / v o l)$ of the total enteral intake, the infant was no longer included in the human milk group.

Enteral feedings were administered through a nasal tube, until the infant was able to drink from a bottle or his or her mother's breast. Until the infants were on full enteral feeding, they received parenteral nutrition, containing the appropriate amounts of carbohy= drates $(210 \mathrm{~kJ} / \mathrm{kg} / \mathrm{d})$, amino acids $(50 \mathrm{~kJ} / \mathrm{kg} / \mathrm{d})$, vitamins, and minerals. In addition, up to 95 $\mathrm{kJ} / \mathrm{kg} / \mathrm{d}$ of intravenous lipids (Intralipid ${ }^{\star} 10 \%$ and $20 \%$, Vitalipid ${ }^{\star}$ ) were given as a source of fat. Since these preparations proved to contain up to 0.2 and 0.3 percent ( $w t / w t)$ of 22:6n-3 and 20:4n-6 respectively (M.M.H.P. Foreman-v Drongelen, unpublished data), the amounts given were registered.

\section{Laboratory analysis}

Blood samples were collected in EDTA-containing tubes to prevent coagulation. Plasma and RBC samples were prepared and the fatty acid composition of their PLs analyzed as described previously [17; Chapter 6], with the modifications that the extraction of total lipids from RBCs was done within one week after blood sampling, and according to the method of Bligh and Dyer [31]. At the start of the analysis, approximately $31.0 \mu \mathrm{g}$ of 1,2dinonadecanoyl phosphatidylcholine [PC- $\left.(19: 0)_{2}\right]$ was added to every sample as an internal standard to quantify fatty acid amounts present in the PL fraction of the plasma and RBCs. Absolute fatty acid amounts are expressed as mg/l plasma or RBC suspension, relative fatty acid levels as \% (wt/wt) of total fatty acid methyl esters.

In total, 39 fatty acids were identified on the basis of a standard reference mixture containing most of the fatty acid methyl esters of interest. Since this study focuses on the $22: 6 n-3$ and 20:4n-6 status, only the following additional relevant fatty acids and fatty acid combinations are reported: 18:2n-6, dihomo- $\gamma$-linolenic acid $(20: 3 n-6), 18: 3 n-3$, eicosapentaenoic acid (20:5n-3), $\Sigma$ SAFA (sum of all saturated fatty acids), $\Sigma$ MUFA (sum of all monounsaturated fatty acids), $\Sigma$ PUFA (sum of all polyunsaturated fatty acids) , $\Sigma \boldsymbol{n}$-9 PUFA (sum of all PUFAs of the $n-9$ series), $\Sigma n-6$ LCP (sum of the LCPS of the $n-6$ series), and $\Sigma$ $n-3$ LCP (sum of the LCPS of the $n-3$ series). 
In addition, two indices were calculated to describe the functional $22: 6 n-3$ status. The cervonic acid deficiency index (CADI), defined as the ratio of $22: 5 n-6$ to its immediate precursor 22:4n-6, was used because a shortage of 22:6n-3 (cervonic acid) is accompanied by an increased conversion of $22: 4 n-6$ to $22: 5 n-6$, resulting in higher CADI values [32,33]. The cervonic acid sufficiency index (CASI), defined as the ratio of $22: 6 n-3$ to $22: 5 n-6$, was calculated based on the same metabolic principle, leading to a decreased CASI value in case of an 22:6n-3 shortage [24].

\section{Data analysis}

Study size calculations were based on the results of one of our previous studies [17; Chapter 6] using the exact calculations provided by Systat's Design program [34]. Assuming an $\alpha$ of 0.05 two-sided, a sample size of 15 infants per formula group was calculated to be ample for demonstrating a significant inter-group difference in $22: 6 n-3$ status ( 4 infants per group resulted in a power of 0.96 ), while for $20: 4 n-6$ a power of 0.77 would be obtained.

Since, during the clinical follow-up, not ali blood samples could be collected at exactly the intended days, fatty acid values were estimated at days $7,14,21,28$ and 35 by linear interpolation between the actual days on which blood had been sampled. Blood samples were usually collected within two days of these reference days, and for the majority of infants, none or only one of the ideally required six samples was missing. Unless mentioned otherwise, all data are presented as median and the upper and lower limits of the interquartile range.

The two LCPs of primary interest, 22:6n-3 and 20:4n-6 were analyzed most extensively. Values measured at birth and weekly up to 5 weeks postnatal age were evaluated in a repeated-measures analysis-of-variance model $[35,36]$, with gestational age and its square as covariables. The model gives estimated mean LCP levels at the mean gestational age of 220 days for each group, at each of the observation times, with correction for missing data. In the same model, we tested the difference between the conventional and the LCP-enriched formula groups at 4 weeks and at 5 weeks of postnatal age. Within the repeated-measures analysis, $22: 6 n-3$ and 20:4n-6 values of the infants raised on LCP-enriched formulas were also compared to those of the human milk fed group. Since the postnatal LCP status has been shown to be related to the LCP status at birth [37], and assignment to the human milk or the LCP-enriched artificial formula groups was not obtained by randomization but resulted from maternal choice, we compared the changes from the initial values at 4 and 5 weeks in the LCP-enriched formula and human milk groups using $95 \%$ confidence intervals. Confidence intervals were used here instead of tests since demonstration of an unequal LCP status was not a study objective. The confidence intervals reveal how close the LCP-enriched formula group gets to its 'natural target': the human milk group. Model assumptions were checked visually in scatterplots, and apparent outliers were examined for their impact on the qualitative results. Values for $22: 6 n-3$ and $20: 4 n-6$ at three months of corrected postnatal age were analyzed using the two-tailed Mann-Whitney test. For all these primary analyses, P-values smaller than 0.05 were considered to reflect a significant difference. 
For the other fatty acids, two-tailed Mann-Whitney tests were used to compare values of the two formula-fed study groups at day 0 , at day 35 , and at 3 months of corrected age. For this relatively large number of supportive analyses, differences with a significance level of PS0.01 were regarded as significant.

The volumes of plasma, RBCs and intravenous lipids administered in the three groups and continuous clinical variables were compared using the two-tailed Mann-Whitney test. Discrete clinical variables were compared using the chi-square test. Bonferroni correction with a factor three for the number of groups compared was used, when applicable.

\subsection{Results}

\subsubsection{Study populations}

The most important clinical and nutritional characteristics of the study groups are shown in table 8.2. No relevant differences between the two formula-fed study groups were present for any of these features. The majority of the infants received their first enteral intake well within the first week of life and they were on full enteral feeding of $420-500 \mathrm{~kJ} / \mathrm{kg} / \mathrm{d}$ at, on average, the 12 th day of life. Both during the clinical and the out-patient follow-up periods, the two groups of formula-fed infants achieved similar and adequate weight gains on comparable enteral energy intakes, which were almost exclusively originating from the study formulas. Energy sources other than formula milk were introduced at the same pace in both groups during the third month of corrected age. They consisted of fruits, which are known to contain any but trace amounts of fat [38], and were consumed in limited amounts in addition to the regular formula feeds.

As a result of the entrance-restriction placed on birth weight $(<1800 \mathrm{~g})$, the majority of the participating infants completed the initially intended minimum follow-up of 28 postnatal days before discharge home. The one exception were the human milk fed infants, nearly half of whom were transferred to a non-participating hospital or received less than $75 \%$ (vol/vol) of human milk by the 4 th week of life. However, because for a sufficient number of infants information on blood LCP status was even available until the 35th day of life, the statistical evaluation of the clinical period could reliably be extended to this postnatal age. Nearly all formula-fed infants continued to participate in the study after discharge home; one infant in each group was discharged before the required term study formulas were available, one infant fed on the conventional formulas turned out to have been fed on a non-study term formula from the second month of corrected age onward.

\subsubsection{Plasma phospholipids}

From one infant in the conventional artificial formula group, 3 infants in the LCPenriched formula group, and one child in the human milk group, no umbilical blood sample was. available.

Different patterns of postnatal changes of $22: 6 n-3$ and $20: 4 n-6$ were obtained when the fatty acid values were expressed as $\mathrm{mg} / \mathrm{l}$ plasma or as percentage (w/wt) of total fatty acid methyl esters (figure 8.1.). In the conventional formula fed group, concentrations (mg/l) of these major LCPS progressively decreased from $7(22: 6 n-3)$ or $0(20: 4 n-6)$ days of postnatal 
Tahle 8.2. Clinical and nutritional characteristics of study groups ${ }^{a t}$.

\begin{tabular}{|c|c|c|c|}
\hline & $\begin{array}{l}\text { conventional formula } \\
(n=16)\end{array}$ & $\begin{array}{l}\text { LCP-enriched formula } \\
(n=15)\end{array}$ & $\begin{array}{l}\text { human milk } \\
(\mathrm{n}=12)\end{array}$ \\
\hline maternal age $(y)$ & $29.5(28.0-32.0)$ & $26.0(23.0-32.0)$ & $27.5(22.0-28.0)$ \\
\hline primipara $^{b}$ & $8(50.0 \%)$ & $8(53.3 \%)$ & $9(75.0 \%)$ \\
\hline gestational age (weeks.days) & $31.5(28.6-34.0)$ & $30.5(28.4-32.4)$ & $29.3(28.2-33.6)$ \\
\hline $\mathrm{pH}$ of arterial cord blood & $7.22(7.17-7.36)$ & $7.18(7.16-7.26)$ & $7.25(7.23-7.27)$ \\
\hline birth weight $(\mathrm{g})$ & $1545(1233-1700)$ & $1532(1050-1740)$ & $1225(988-1.490)$ \\
\hline weight gain day $0-35(\mathrm{~g} / \mathrm{kg} /$ day $)$ & $17.1(15.0-20.8)$ & $14.4(12.3-17.8)$ & $11.6(8.3-14.9)^{g}$ \\
\hline IV lipids (kJ/kg/day) & $11.3(4.1-22.3)$ & $13.8(6.9-18.9)$ & $18.9(10.8-29.4)$ \\
\hline IV plasma $(\mathrm{ml})^{d}$ & $4.9(8.0)$ & $9.7(10.1)$ & $9.2(13.1)$ \\
\hline IV $\operatorname{RBCs}^{c}(\mathrm{ml})^{d}$ & $9.7(16.5)$ & $8.6(13.2)$ & $22.6(26.3)$ \\
\hline $\begin{array}{l}\text { total enteral intake day } 0-35 \\
(\mathrm{~kJ} / \mathrm{kg} / \mathrm{day})\end{array}$ & $377(345-488)$ & $362(321-415)$ & $321(267-353)$ \\
\hline $\begin{array}{l}\text { intake of experimental formula } \\
\text { day } 0-35(\mathrm{~kJ} / \mathrm{kg} / \text { day })\end{array}$ & $364(324-459)$ & $357(311-404)$ & - \\
\hline $\begin{array}{l}\text { intake of experimental formula } \\
\text { day } 0-35(\%(\mathrm{vol} / \mathrm{vol}) \text { of total } \\
\text { enteral intake) }\end{array}$ & $98.8(93.9-99.8)$ & $97.5(95.8-99.7)$ & - \\
\hline age at first enteral intake (days) & $1.0(0.0-3.0)$ & $2.0(0.8-4.3)$ & $5.0(3.0-7.0)^{\prime}$ \\
\hline $\begin{array}{l}\text { age at first intake of experimen- } \\
\text { tal formula (days) }\end{array}$ & $4.5(4.0-6.8)$ & $7.0(4.0-9.0)$ & - \\
\hline age at full enteral intake (days) & $10.0(6.3-16.5)$ & $12.0(8.0-17.0)$ & $13.5(10.3-18.3)$ \\
\hline vent. support (days)" & $0.5(0.0-4.0)$ & $5.0(0.0-8.0)$ & $3.0(0.3-13.3)$ \\
\hline vent, support $>24 \mathrm{~h}^{b, e}$ & $5(31.3 \%)$ & $10(66.7 \%)$ & $8(66.7 \%)$ \\
\hline $\mathrm{BPD}^{b, c}$ & $1(6.3 \%)$ & $1(6.7 \%)$ & $0(0.0 \%)$ \\
\hline $\operatorname{sepsis}^{b}$ & $2(12.5 \%)$ & $3(20.0 \%)$ & $4(33.3 \%)$ \\
\hline $\mathrm{IVH}^{\mathrm{b}, \mathrm{s}}$ & $0(0.0 \%)$ & $0(0.0 \%)$ & $3(25.0 \%)$ \\
\hline $\begin{array}{l}\text { weight gain } 0-3 \text { months of } \\
\text { corrected age }(\mathrm{g} / \mathrm{kg} / \text { day })\end{array}$ & $9.7(8.4-11.7)$ & $10.7(9.3-11.2)$ & - \\
\hline $\begin{array}{l}\text { intake of experimental formula } \\
0-3 \text { months of corrected age } \\
(\mathrm{kJ} / \mathrm{kg} / \mathrm{day})\end{array}$ & $495(473-542)$ & $479(447-486)$ & - \\
\hline
\end{tabular}

\footnotetext{
${ }^{a}$ Median (interquartile range) except for ${ }^{b}$ number of subjects and ${ }^{d}$ mean \pm standard deviation.

'TV=intravenous, RBCs=red blood cells, BPD=bronchopulmonary dysplasia, IVH=intraventricular haemorrhage 'ventilatory support included mechaniçal ventilation and continuous poșitive airway pressure.

Statistically significant differences were found only between conventional formula group and human milk group (two-tailed Mann-Whitney U test with Bonferroni correction factor 3 for number of groups compared when applicable): ${ }^{f} \mathrm{P}<0.02,{ }^{8} \mathrm{P}<0.005$
} 
$\mathrm{mg} / 1$
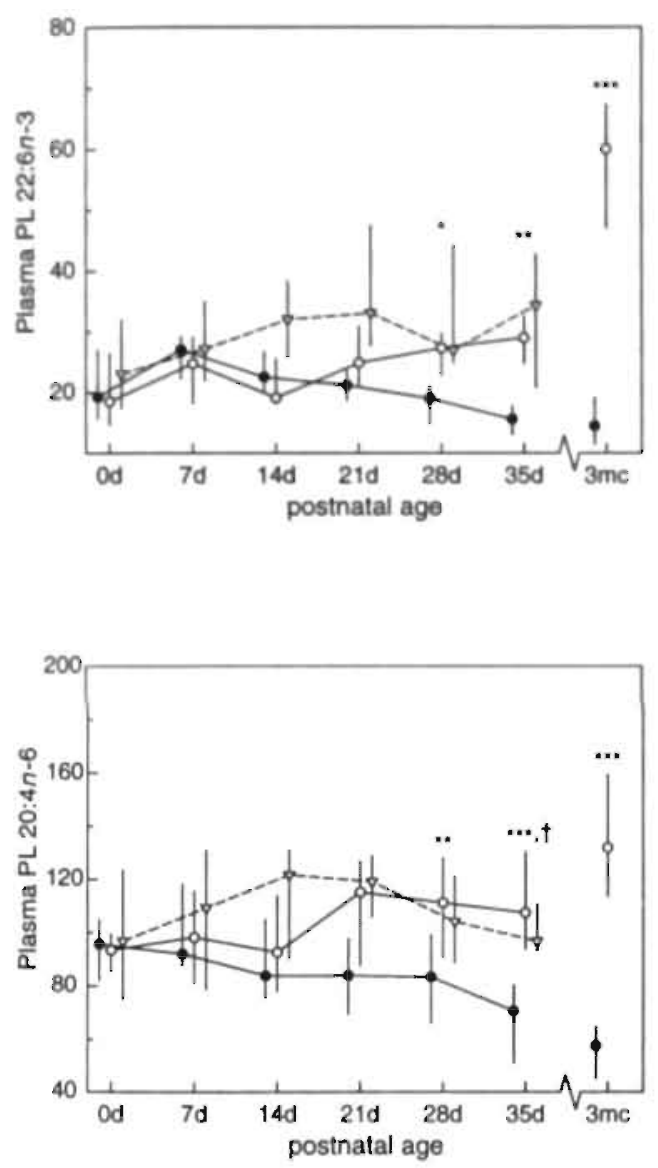

$\%(w t / w t)$
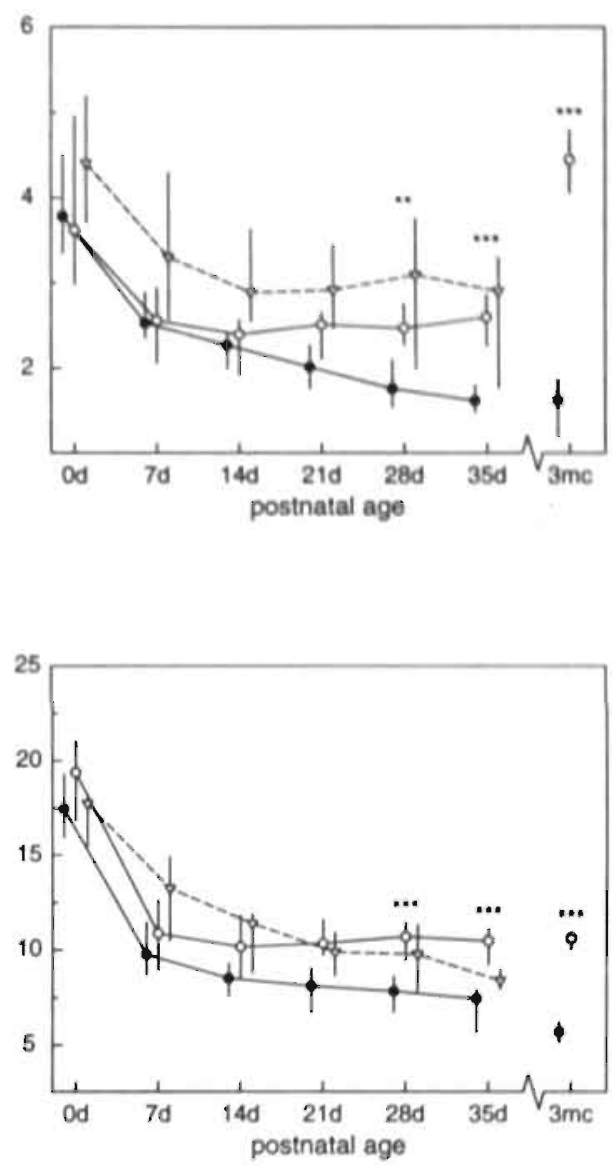

Figure 8.1.: $22: 6 n-3$ and $20: 4 n-6$ values in plasma phospholipids (PL). Median and interquartile range expressed as $\mathrm{mg} / \mathrm{l}$ (left) and as \% (wt/wt) of total fatty acid methyl esters (right). Number of infants, respectively, in conventional (- - ) and long-chain polyunsaturated fatty acid (LCP)-enriched (-O-) artificial formula groups and in human milk group $(-\nabla-)$ at day $0 ; 15 / 12 / 9$; day $7: 16 / 13 / 12$; day 14 : 16/14/12; day 21: 14/14/9; day 28: $12 / 13 / 7$; day $35: 9 / 12 / 7 ; 3$ months corrected age ( $3 \mathrm{mc}): 14 / 14$.

Statistical difference between conventional and LCP-enriched artificial formula groups (repeated measures analysis, except for 3 months of corrected age: Mann Whitney $U$ test):

"P<0.01, "P<0.001, " P $\mathrm{P}<0.0001$.

Difference between LCP-enriched artificial formula group and human milk group (changes from the values at day 0 ):

${ }^{\dagger} 0$ outside $95 \%$ confidence interval. 
age onwards. In the group of infants fed on an LCP-enriched formula, these LCPS again increased after the 14th day of life. This resulted in significantly higher postnatal concentrations in the latter study group (22:6n-3: day 28 : $\mathrm{P}<0.01$, day 35 : $\mathrm{P}<0.001 ; 20: 4 n-6$ : day 28 : $\mathrm{P}<0.001$, day 35: $\mathrm{P}<0.0001)$. At 3 months of corrected age average absolute $22: 6 n-3$ and 20:4n-6 amounts, respectively, were more than 3 and 2 times higher in the LCP-enriched formula group than in the conventional formula group ( $\mathrm{P}<0.0001$ for both). Relative 22:6n3 and 20:4n-6 levels decreased to almost half the values at birth during the first week of life in both study groups. They continued to decrease in the conventional formula group, while they stabilized in the infants fed on an LCP-enriched formula, again resulting in significantly higher levels in the latter population $(22: 6 n-3$; day $28: \mathrm{P}<0.001$ and 35 : $\mathrm{P}<$ $0.0001 ; 20: 4 n-6$; days 28 and $35: \mathrm{P}<0.0001$ ). At 3 months of corrected age the magnitudes of inter-group differences for relative $22: 6 n-3$ and $20: 4 n-6$ levels were similar to those for absolute amounts and also highly significant ( $\mathrm{P}<0.0001$ for both). At 28 to 35 days of postnatal age, the 22:6n-3 and 20:4n-6 status of infants fed on an LCP-enriched formula was at least comparable to that of preterm infants fed on their own mother's human milk (see table 8.3. for accompanying $95 \%$ confidence intervals).

Table 8.3. 95\% Confidence intervals for differences between LCP-enriched artificial formula (LCP-AF) group and human milk (HM) group:

\begin{tabular}{|c|c|c|c|}
\hline & fatty acid & day $28-0_{\text {LOP.MF }}-$ day $28-0_{\text {Hм }}$ & day $35-0_{\text {LCP AF }}-$ day $35-0_{\text {HM }}$ \\
\hline \multicolumn{4}{|c|}{ plasma phospholipids } \\
\hline \multirow[t]{2}{*}{$\mathrm{mg} / \mathrm{l}$} & $22: 6 n-3$ & {$[-8.1,3.7]$} & {$[-3.9,6.9]$} \\
\hline & $20: 4 n-6$ & {$[-2.9,34.3]$} & {$[3.5,41.8]$} \\
\hline \multirow[t]{2}{*}{$\%(w / w t)$} & $22: 6 n-3$ & {$[-1.0,0.8]$} & {$[-0.6,1.1]$} \\
\hline & $20: 4 n-6$ & {$[-2.8,0.8]$} & {$[-2,12,1.36]$} \\
\hline \multicolumn{4}{|c|}{ red blood cell phospholipids } \\
\hline \multirow[t]{2}{*}{$\mathrm{mg} / \mathrm{l}$} & $22: 6 n-3$ & {$[-9.59,4.8]$} & {$[-18.2,-1.1]$} \\
\hline & $20: 4 n-6$ & {$[-30.5,31.6]$} & {$[-67.5,6.1]$} \\
\hline \multirow[t]{2}{*}{$\%(w 1 / w t)$} & $22: 6 n-3$ & {$[-0.54,0.04]$} & {$[-0.51,0.19]$} \\
\hline & $20: 4 n-6$ & {$[-1.1,1.2]$} & {$[-0.91,1.3]$} \\
\hline
\end{tabular}


Significant inter-group differences were also observed for the other fatty acids reported (see tables 8.4. and 8.5. for absolute and relative amounts, respectively). The absolute amount of the sums of the $n-6$ LCPS ( $\Sigma n-6$ LCP) and of the $n-3$ LCPS $\left(\sum n-3\right.$ LCP) remained similar between day 0 and day 35 in the conventional formula group, whereas their concentrations increased in the LCP-enriched formula group, resulting in significantly higher concentrations in the latter ( $\Sigma$ n-6 LCP: P $<0.001, \Sigma n-3$ LCP: P 50.0001$)$. The relative levels of $\Sigma n-6$ LCP and $\Sigma n-3$ LCP declined in both formula-fed study populations, but this led to significantly lower levels in the conventional formula group (P $\leq 0.001$ for both). At three months of corrected postnatal age, inter-group differences were even more pronounced, both for absolute and relative $\Sigma n-6$ LCP and $\Sigma n-3$ LCP values ( $\mathrm{P}<0.0001$ for all). The relative levels of $20: 3 n-6$ and 20:5n-3, next to 20:4n-6 precursors of prostaglandins and other eicosanoids, were significantly lower in the infants fed formulas enriched with $22: 6 n-3$ and 20:4n-6 until three months of corrected age (day $35: 20: 3 n-6: \mathrm{P}<0.01 ; 3$ months: 20:3n-6: PS0.0001, 20:5n-3: P<0.01). The percentage levels of the parent EFAs, $18: 2 n-6$ and 18:3n-3, were also significantly lower in the LCP-enriched formula-fed infants (day $35: 18: 2 n-6$ : $\mathrm{P}<0.01 ; 3$ months: 18:2n-6: $\mathrm{P}<0.0001,18: 3 n-3: \mathrm{P}<0.001$ ).

The inter-group differences found for the $22: 6 n-3$ status were also reflected by the two indices representing the functional $22: 6 n-3$ status. Both at 35 days postnatal age and at three months corrected age, CADI values were significantly lower $(\mathrm{P}<0.001$ and $\mathrm{P}<0.0001)$ and CASI values significantly higher (P $\leq 0.0001)$ in the group raised on LCP-enriched formulas.

\subsubsection{Red blood cell phospholipids}

Two RBC samples, both in the study group fed on the conventional formula, one at day 28 and one at day 35 , were lost during fatty acid analysis.

Both absolute amounts and relative levels of $22: 6 n-3$ and 20:4n-6 in RBC PLs decreased after birth (figure 8.2.). The postnatal patterns of change for absolute amounts of $22: 6 n-3$ and. 20:4n-6 in the group fed on a conventional formula during the first 5 weeks of life were not significantly different from those in the LCP-enriched formula group. However, at three months of corrected age, the $22: 6 n-3$ concentration was significantly higher $(\mathrm{P}<0.00 \mathrm{I})$ in the RBC PLS of the infants that had received LCP-enriched formulas.

Between birth and the 35th day of life, relative levels of both 22:6n-3 (days 28 and 35 : $\mathrm{P}<0.01$ ) and 20:4n-6 (day 28: $\mathrm{P}<0.001$; day 35: $\mathrm{P}<0.000 \mathrm{I}$ ) declined significantly less in the LCP-enriched formula group than in the conventional formula group. At the third month of corrected postnatal age, these differences were even more pronounced ( $\mathrm{P}<0.0001$ for both). Relative 22:6n-3 and 20:4n-6 levels in LCP-enriched formula fed infants were comparable to. those of preterm infants raised. on human milk (table 8.3.).

Concentrations and relative levels of the other fatty acids studied are given in tables 8.6. and 8.7., respectively. At three months of corrected age, values for $\Sigma n-6 . L C P$ (\% (wt/wt): $\mathrm{P}<0.001)$ and $\Sigma n-3$ LCP (mg/l: $\mathrm{P}<0.01 ; \%$ (w/ wt) total fatty acids: $\mathrm{P}<0.0001)$ were significantly higher in the infants raised on the LCP-enriched formulas than in the infants given the conventional formulas. At the same time, values for the parent EFAs 18:2n-6 (mg/l: PS0.01; $\%(\mathrm{wt} / \mathrm{wt}): \mathrm{P}<0.0001)$ and 18:3n-3 (mg/1: $\mathrm{P}<0.001 ; \%$ (wt/wt): $\mathrm{P} \leq 0.001)$ and for 20:3n-6 
Table 8.4. Fatty acid composition of plasma phospholipids (absolute values for conventional artificial formula (C-AF), LCP-enriched artificial formula (LCP-AF) and human milk (HM) groups).

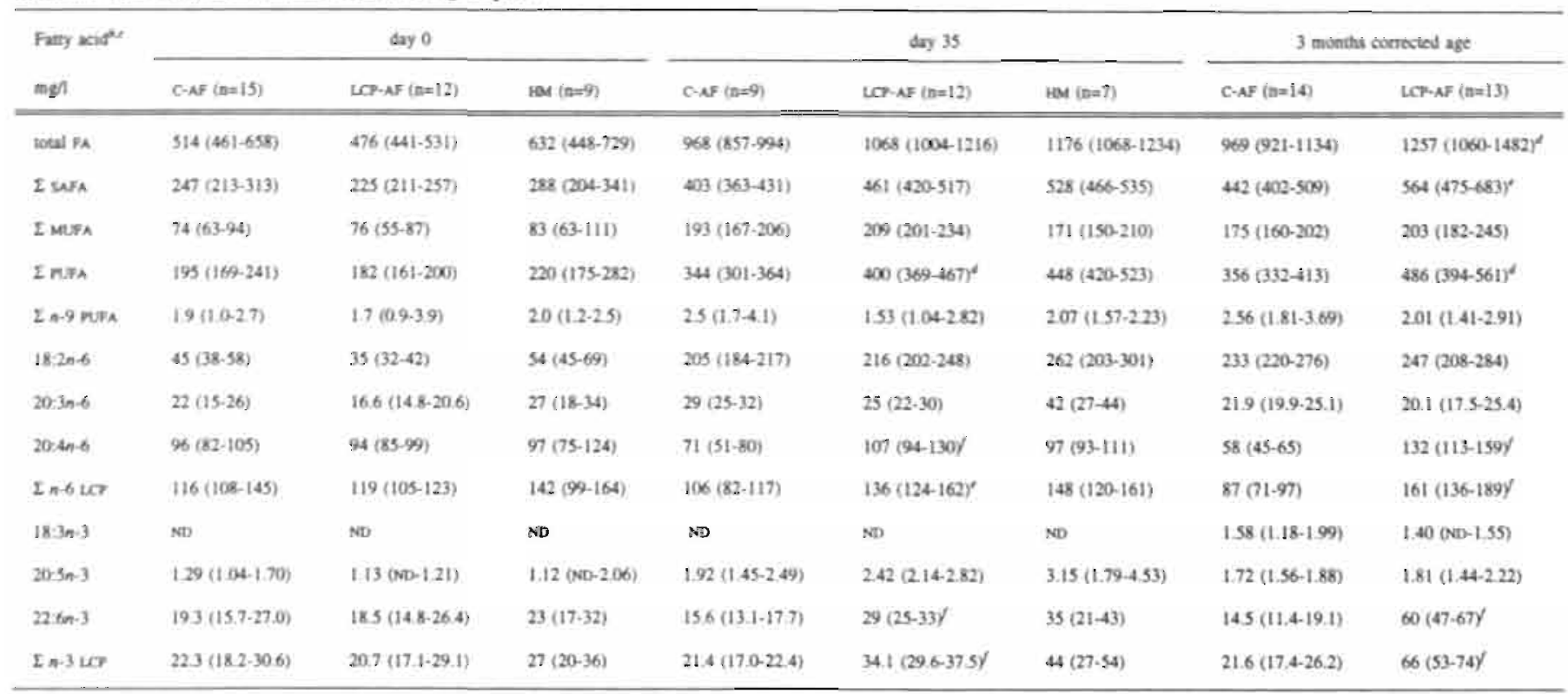

a.r As in table 8.1.

Statistical difference between control and LCP-enriched formula groups (two-tailed Mann-Whitney $U$ test, except for 22:6n-3 and 20:4n-6, day 35: repeated-measures analysis):

${ }^{d} \mathrm{P}<0.01,{ }^{\mathrm{P}} \mathrm{P} \leq 0.001,{ }^{\prime} \mathrm{P} \leq 0.0001$. 
Table 8.5. Fatty acid composition of plasma phospholipids (relative values for conventional artificial formula (C-AF), LCP-enriched artificial formula (LCP,AF) and human milk (HM) groups) ${ }^{a}$.

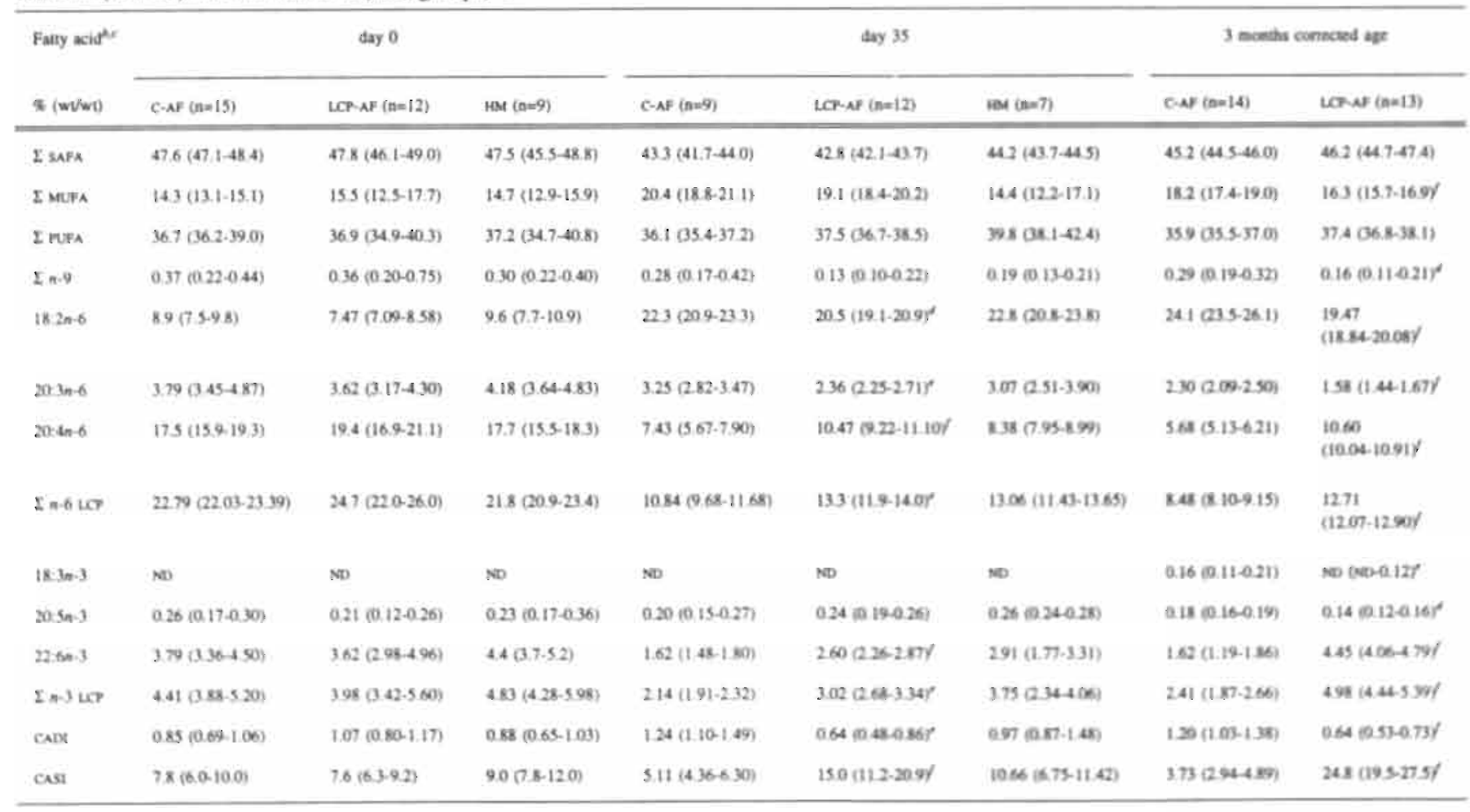

- As in table 8.1, in addition: $\mathrm{CADI}=$ cervonic acid $(22: 6 n-3)$ deficiency index $(22 \cdot 5 n-6 / 22: 4 n-6)$, CASl= cervonic acid sufficiency index $(22: 6 n-$ $3 / 22 \cdot 5 n-6)$

${ }^{H}$ As in table 8.4. 


\section{$\mathrm{mg} / \mathrm{l}$}
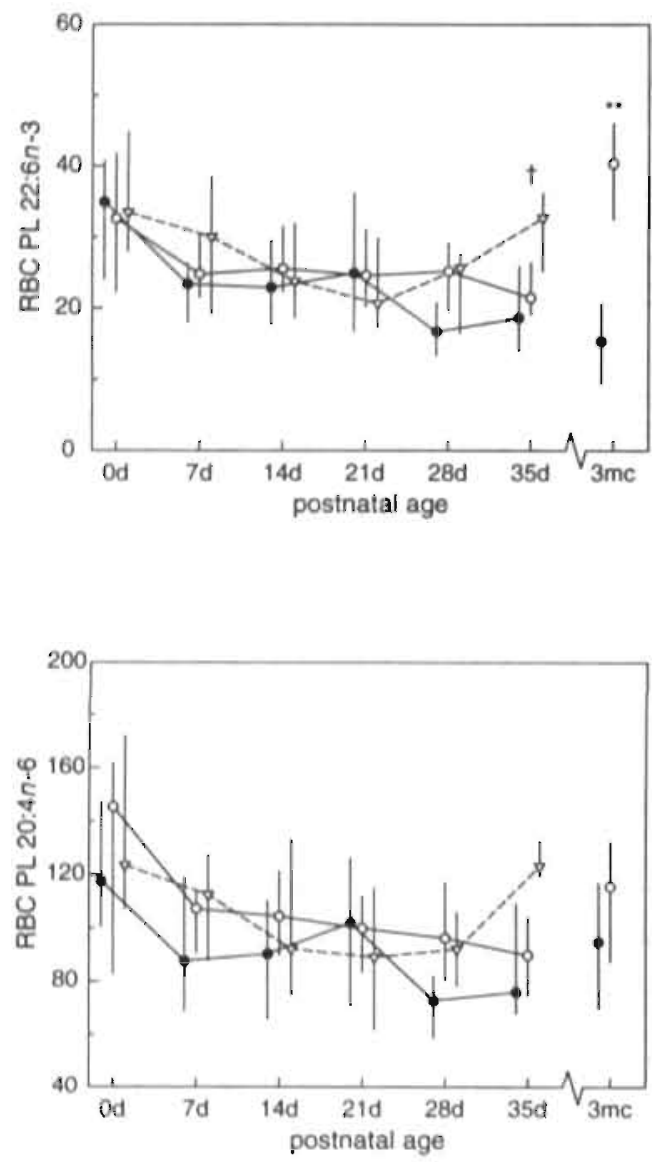

$\%(w t / w t)$
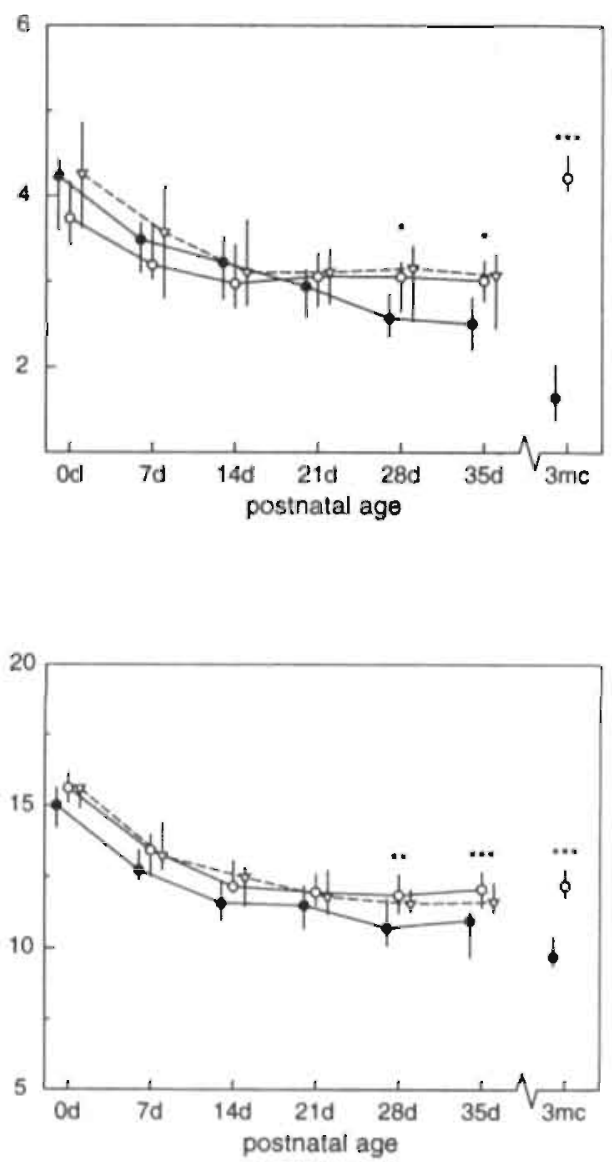

Figure 8.2.: 22:6n-3 and 20:4n-6 values in red blood cell (RBC) phospholipids (PL). Median and interquartile range expressed as $\mathrm{mg} / \mathrm{l}$ (left) and as \% (wt/wt) of total fatty acid methyl esters (right).

Number of infants, respectively, in conventional (- - ) and long-chain polyunsaturated fatty acid (LCP). enriched $(-\mathrm{O} \rightarrow$ ) artificial formula groups and in human milk group $(-\nabla-)$ at day $0: 15 / 12 / 9 ;$ day 7 : 16/13/12; day 14: 16/14/12; day 21: 14/14/9; day 28: $11 / 13 / 7$; day $35: 8 / 12 / 7 ; 3$ months corrected age (3mc): $14 / 14$.

Statistical difference between conventional and LCP-enriched artificial formula groups (repeated measures analysis, except for 3 months of corrected age: Mann Whitney $\mathrm{U}$ test):

"P<0.01, "P<0.001, "'P $<0.0001$.

Difference between LCP-enriched artificial formula group and human milk group (changes rrom the values at day 0 ):

${ }^{+} 0$ outside $95 \%$ confidence interval. 
Table 8.6. Fatty acid composition of red blood cell phospholipids (absolute values for conventional artificial formula (c-af), LCP-enriched artificial formula (LCP-AF) and human milk. (HM) groups) ${ }^{a}$.

\begin{tabular}{|c|c|c|c|c|c|c|c|c|}
\hline \multirow{2}{*}{$\begin{array}{l}\text { Fatty aciofer } \\
\operatorname{mel}\end{array}$} & \multicolumn{3}{|c|}{ day 0} & \multicolumn{3}{|c|}{ day 35} & \multicolumn{2}{|c|}{3 monitus corrocied ayt } \\
\hline & C.AY (n=15) & Ler.AF $(n=12)$ & нам $(n=9)$ & $C \cdot A F(n=8)$ & LoP $N y(n-12)$ & $\operatorname{man}(n=7)$ & $\cos (\operatorname{sen} 14)$ & 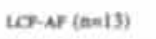 \\
\hline total $\mathrm{RA}$ & $830(668-989)$ & 901 (595-1008) & $832(728-1113)$ & $735(624-980)$ & $714(665-572)$ & $1068(1029-1095)$ & $945(713-1178$ & $957 .(744-1069)$ \\
\hline E WFA & $405(340-156)$ & $429(301-482)$ & $393(353-540)$ & $322(266-419)$ & $313(290-389)$ & $496(467-502)$ & 415 (922-519) & $433(347-423)$ \\
\hline E MUFA & $150(124-195)$ & $175(105-201)$ & $166(122-213)$ & $180(164-232)$ & $171(157-227)$ & $200(144-215)$ & $227(179.279)$ & $231(171-267)$ \\
\hline$\sum_{n-9}$ mirs & $75(5.4 .90)$ & $8.0(4.2 .0 .8)$ & $7.0(5.4 \cdot 11.3)$ & $3.30(2.60-4.70)$ & $3.29(2.57-3.70)$ & $3.55(2.76-4.20)$ & $4.140 .26 .5 \mathrm{~mm}$ & $1.90(1.13 .2 .128$ \\
\hline $15.2 n-6$ & $35(26-45)$ & $35(24-43)$ & $395(34.8-47.8)$ & $76(60-98)$ & $65(59.7 y)$ & $111(107.139)$ & $104(72: 130$ & $002(56.9 .4 .5)^{6}$ \\
\hline $20-\ln 6$ & $15.6(127.19 .2)$. & $15.9(10.9 .18 .1)$ & $17.4(14.7 .22 .4)$ & $130(11.9-17.6)$. & $110(100.12 .6)$ & $203(137.223)$ & $13.6(10.8-16.7)$ & $1.2160 .103 \%$ \\
\hline $20 \cdot \ln 6$ & $118(100-147)$ & $145(83-162)$ & $124(107-172)$ & $76(68 \cdot 109)$ & $90(75-104)$ & $123(130-13)$ & es $(70-117)$ & $116(08.132)$ \\
\hline E. .6 Ler & 169 (138-211) & $200(114-219)$ & 175 (152-242) & $112(100-160)$ & $123(104-143)$ & $17 k(164-191)$ & $144(105-17 n)$ & $155(114-177)$ \\
\hline $20 \cdot 5 \ln 3$ & $0.92(\mathrm{No}-1.90)$ & $(000(000-1 \times 3)$ & $1.17(\mathrm{Nob}-2.36)$ & 114 cort- 2780 & $(13$ asb- $(.73)$ & 3.16025 .372 & $153(00-215)$ & $101000-(41)$ \\
\hline 22 iton-3 3 & $49(241-40.7)$ & $33(22-42)$ & $335(28.0449)$ & $186(141.25 .8)$ & $21.5(19,265)$ & 327025.2 .33 & $15.40 .5 .20 .6)$ & $40.402 .45 .8 r^{\circ}$ \\
\hline$\sum n 3$ LCT & $400(23.2 .46 .5)$ & $40(25-48)$ & $37.6318 .541)$ & $26.2(200.398)$ & $27.6(25.1 \cdot 34.1)$ & $48:( \pm 0.51 .3)$ & $26.5(19.0349)$ & 470 G7.5.4. Wr \\
\hline
\end{tabular}

as in table 8.4 
Table 8.7. Fatty acid composition of red blood cell phosp
formula (LCP-AF) groups) and human milk (HM) groups)".

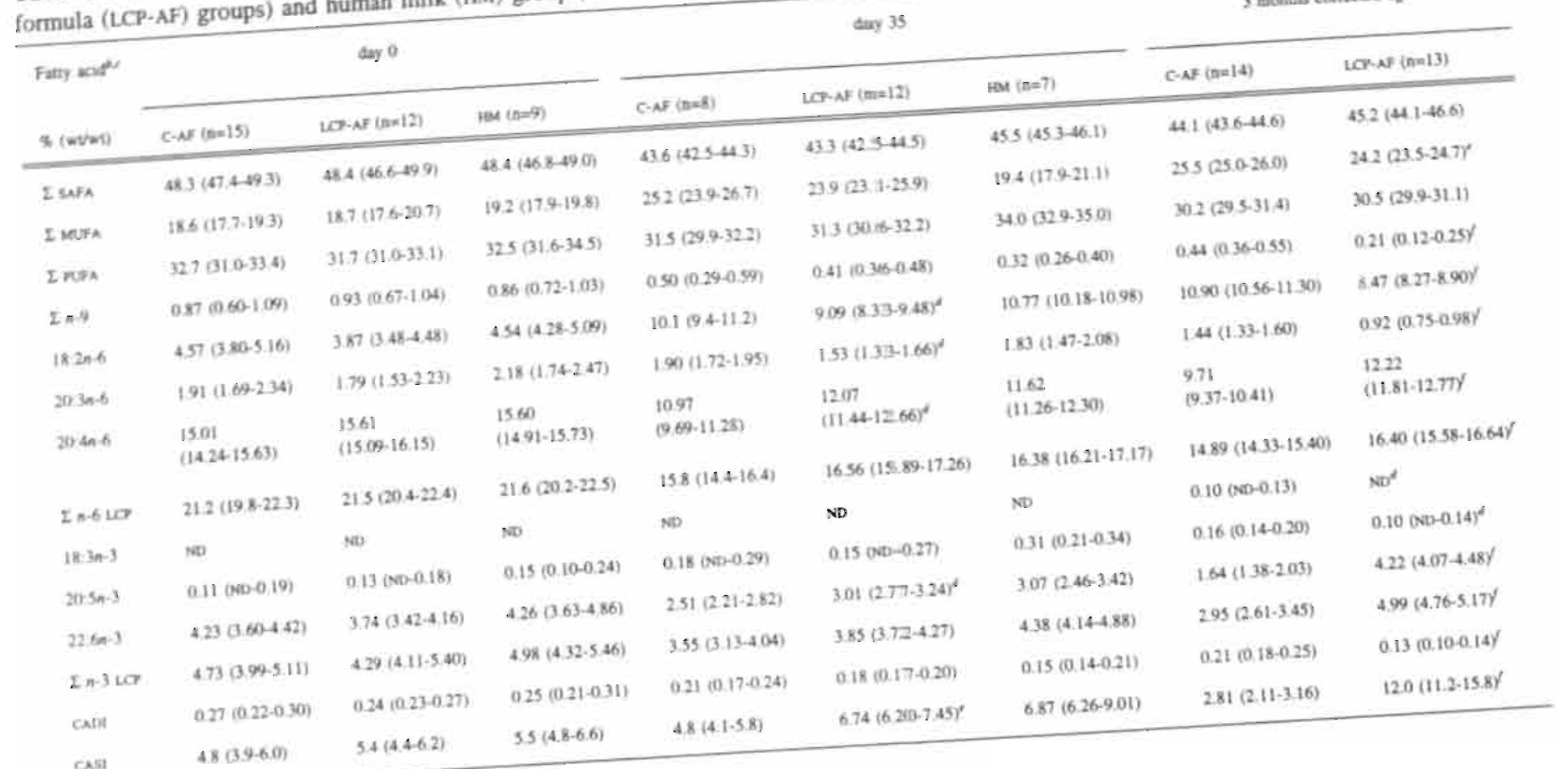

af As in table 8.5. 
2(mg/l: $\mathrm{P}<0.001 ; \%$ (wt/wt): $\mathrm{P}<0.0001$ ) and 20:5n-3 (\% (wt/wt): $\mathrm{P}<0.01$ ) were significantly lower in the LCP-enriched formula group.

The two indices calculated confirmed the observed inter-group differences in 22:6n-3 status, with lower values for the CADI $(3$ months: $\mathrm{P}<0.0001)$ and higher values for the CASI (day 35: P $\leq 0.001 ; 3$ months: $\mathrm{P} \leq 0.0001$ ) in the RBC PLs of infants receiving LCP-enriched formulas.

\subsection{Discussion}

The present study is, to our knowledge, the first to report on the effects of long-term feeding of artificial formulas enriched with both $22: 6 n-3$ and $20: 4 n-6$. Its results show that adding these two major LCPs to formulas in balanced ratios, i.e. amounts comparable to those found in preterm human milk, successfully raises both the $22: 6 n-3$ and 20:4n-6 status of preterm formula-fed infants to values found in plasma and RBC PLs of preterm infants fed on human milk. Inter-group differences in the 22:6n-3 status were also reflected by the two indices of the functional 22:6n-3 status, with lower CADI values and higher CASI values. in the infants raised on LCP-enriched formulas.

Results of three studies that evaluated the effects of short-term feeding of an $n-3$ and $n$ 6 LCP-enriched formula on the LCP status of preterm infants are available for comparison. In 1989, Koletzko and co-workers [15] reported that 17 days (day 4-21) of feeding an artificial formula containing 22:6n-3 and 20:4n-6 in levels half those present in human milk, resulted. in plasma lipid LCP levels that were higher than those of infants fed a conventional formula, but were still substantially lower than those of infants raised on human milk. In a more recent study by Clandinin and colleagues [16], preterm infants fed for four weeks (1-5 weeks) on an artificial formula which contained all $n-3$ and $n-6$ LCPs within the range characteristic of human milk, had plasma PL-associated LCP concentrations similar to those of infants fed human milk. LCP levels in RBC PC and phosphatidylethanolamine (PE) were also. evaluated, but reported not to be affected by dietary LCP supply. Preliminary results from a study by Carnielli and co-workers [25], in which the LCP-enriched formula contained 0.60 $\%$ (wt/wt) of $22: 6 n-3$ and $0.75 \%$ (wt/wt) of 20:4n-6 (comparable to levels in human colostrum), also indicated similar plasma PL LCP levels in LCP-enriched formula and human milk-fed infants at four weeks of age.

Enhancing the dietary intake of the parent EFA of the n-3 series, 18:3n-3, has been suggested to be equally effective in increasing the $n-3$ LCP status as adding $n-3$ LCPS. to formulas. This view was based on the results of two short-term (4 to 5 weeks) feeding trials, in which RBC 22:6n-3 levels of preterm infants consuming formulas containing > $2.0 \%$ of total fatty acids of $18: 3 n-3$ were reported not to differ from those of infants fed on human milk $[39,40]$. However, longer-term studies have quite clearly demonstrated that even higher intakes of $18: 3 n-3$ (up to $4.8 \%$ (wt/wt) of total fatty acids, with a ratio of 18:2n-6 to $18: 3 n-3$ as low as 6.4), cannot prevent n-3 LCP declines in formula-fed preterm infants $[23,24]$. The artificial formulas used in the present study were designed to contain the parent EFAs in amounts present in human milk, resulting in a maximum $18: 2 n-6 / 18: 3 n-3$ ratio of 13.0 . 
Three months after the initially expected date of delivery, both the $22: 6 n-3$ and $20: 4 n-6$ status were considerably higher in the plasma and RBC PLS of infants that had been fed on artificial formulas enriched with these LCPS than in those that had received conventionall formulas. Unfortunately at this age, the values of the LCP-enriched formula group could not be compared to those of the preterm infants fed on human milk, since the far majority of these infants had to be excluded from further follow-up due to the limited amounts of human milk they actually received. However, the plasma levels of 22:6n-3 and 20:4n-6 in our LCP-enriched formula group were similar to, and RBC levels somewhat lower than those recently reported by Luukkainen and co-workers [41] for 10 preterm infants which were fully breast-fed until 6 months postnatal age. This strongly suggests that the 22:6n-3 and 20:4n-6 levels measured in the infants fed on LCP-enriched formulas are within their physiological ranges. Carlson and co-workers [23], at approximately 3 months corrected age, observed 22:6n-3 values in plasma and RBC PC and PE of preterm infants fed on $n-3$ LCPenriched formulas which were only twice as high as those in infants fed conventional formulas. The ratios of $18: 2 n-6$ to $18: 3 n-3$ present in these conventional formulas, however, were smaller (6.4-6.9 compared to 9.1-11.9), and the 18:3n-3 contents higher (3.0-4.8 compared to $1.2-1.4 \%$ (wt/wt) of total fatty acids) than those in ours, which may account for the somewhat smaller inter-group differences than in the present study.

After 28 to 35 days of life, the $22: 6 n-3$ and $20: 4 n-6$ status of the infants fed on a preterm formula containing these LCPs in amounts typical for human milk was indeed comparable to that of infants receiving actual human milk. However during the study period, the total enteral intake of the human milk-fed population, on average, consisted for only $89.3 \%$ ( $\mathrm{vol} / \mathrm{vol})$ of human milk, while the LCP-enriched formula group consumed almost exclusively their particular study formula. This apparently higher efficiency of human milk in maintaining certain LCP levels, when compared to the LCP-enriched artificial formula, is possibly related to the presence of human milk bile salt-stimulated lipase, which is not only known to be of major importance for overall triglyceride digestion [42], but may also play a particular role in the release of LCPs during this process $[43,44]$.

In the present study, a diet-induced decrease of 20:4n-6, which was reported after supplying only additional $n-3$ LCPS [23,24], was not observed. Preliminary data by Carlson and co-workers [45] indit ated that reducing the amount of 20:5n-3 added to the formula (0.06 in stead of $0.3 \%$ (wt/wt) of total fatty acids) prevents this lowering of the 20:4n-6 status. However, considering the presence of high levels of 20:4n-6 in neural tissue and the potential influence of this $n-6 \mathrm{LCP}$ on postnatal growth [26,27], raising the 20:4n-6 status of formula-fed preterm infants to that of infants receiving human milk may be preferable. To achieve this, adding preformed 20:4n-6 to the formulas appears to be necessary.

The use of an LCP-enriched formula not only resulted in higher 22:6n-3 and 20:4n-6 values, but also in significantly lower blood levels of $18: 2 n-6$ in the supplemented formula group, when compared to the infants fed the conventional formulas. This relatively shortterm effect was also found in other LCP-supplementation studies [16,25]. The decreased 18:2n-6 values may reflect a competition between this parent EFA and the supplemented $n-3$ and $n-6$ LCPS for incorporation into blood PLS. 
Effects of enhancing the LCP content of artificial formulas were not only detected in plasma, but also in RBC PLs. The assumption that changes observed in the fatty acid profile of the RBC membrane reflect changes occurring in the fatty acid composition of the brain $[33,46]$, has been subject of debate [47]. However for 22:6n-3, recent studies demonstrated that breast-fed infants have significantly higher levels of this major $n-3$ LCP in their cerebral cortex lipids than formula-fed infants $[9,48,49]$, and that these levels are significantly related to those in RBCS [9]. The findings of these studies are supplemented by those of the increasing number of studies that report significant influences of the dietary LCP supply, and the resultant LCP status, on several parameters of brain and visual function [40,50-53]. However, all of these studies have focused solely on the dietary intake of $n-3$ LCPs. Further studies in preterm infants are needed to evaluate the potential functional consequences of enhancing the dietary 20:4n-6 intake, other than achieving better growth.

In conclusion, adding $22: 6 n-3$ and $20: 4 n-6$ to artificial formulas in balanced ratios and in amounts similar to those found in preterm human milk, raises both the $22: 6 n-3$ and 20:4n-6 status of formula-fed preterm infants to values reported for human milk-fed preterm infants. Additional studies are necessary to evaluate the potentially favourable effects of feeding formulas enriched with both $n-3$ and $n-6$. LCPs on the neurodevelopmental outcome of preterm infants.

\subsection{Acknowledgements}

The authors gratefully acknowledge the financial support from Nutricia, Zoetermeer, The Netherlands and the skilled assistance obtained from Mrs. H. Aydeniz (preparation of plasma and RBC samples) and the Analytical Biochemical Laboratory in Assen, The Netherlands (fatty acid analysis of blood samples). They also wish to express their appreciation for the help obtained from Mrs. M.-J. Slangen, children's laboratory of the University Hospital Maastricht (neonatal blood sampling), the staff and nursing personnel of the departments of Neonatology of the Uiniversity Hospital Maastricht, the Saint Joseph Hospital in Kerkrade and the De Wever Hospital in Heerlen, The Netherlands (practical assistance) and Miss E.

E. Zeijdner (practical assistance).

\subsection{References}

1. Svennerholm L. Distribution and fatty acid composition of phosphoglycerides in normal human brain. J Lipid Res 1968;9:570-9.

2. Martinez M, Conde $\mathrm{C}$ and Ballabriga A. Some chemical aspects of human brain development. İI. Phosphoglyceride fatty acids. Pediatr Res 1974;74:93-102.

3. Sastry PS. Lipids of nervous tissue: composition and metabolism. Progress Lipid Res 1985;24:69176.

4. Fliesler SJ and Anderson RE. Chemistry and metabolism of lipids in the vertebrate retina. Progress Lipid Res 1983:22:79-131.

5. Clandinin MT, Chappell JE, Leong S, Heim T, Swyer PR, Chance GW. Intrauterine fatty acid accretion rates, in human brain: implications for fatty acid requirements. Early Hum Dev 1980; 4:121-9.

6. Clandinin MT, Chappell JE, Leong S, Heim T, Swyer PR, Chance GW. Extrauterine fatty acid accretion in infant brain: implications for fatty acid requirements. Early Hum Dev 1980;4:131-8. 
7. Martinez M, Ballabriga A, Gil-Gibernou JJ. Lipids of the developing human retina: 1 . Total fatty acids, plasmalogens, and fatty acid composition of ethanolamine and choline phosphoglycerides. J Neurosci Res. 1988;20:484-90.

8. Martinez M. Tissue concentration of polyunsaturated fatty acids during early human development. J Pediatr 1992;120:\$129-38.

9. Makrides M, Neumann MA, Byard RW, Simmer K, Gibson RA. Fatty acid composition of brain, retina, and erythrocytes in breast- and formula-fed infants. Am J Clin Nutr 1994;60:189-94.

10. Jensen RG, Hagerty MM, McMahon KE. Lipids of human milk and infant formulas: a review. Am J Clin Nutr 1978;31:990-1016.

11. Lammi-Keefe CJ, Jensen RG. Lipids in human milk: a review. 2: Composition and fat-soluble vitamins. J Pediatr Gastroenterol Nutr 1984;3:172-98.

12. Jensen RG, Ferris AM, Lammi-Keefe CJ. Lipids in human milk and infant formulas. Annual Rev Nutr 1992:12:417-41.

13. Carlson SE, Rhodes PG, Ferguson MG. Docosahexaenoic acid status of preterm infants at birth and following feeding with human milk or formula. Am J Clin Nutr 1986;44:798-804.

14. Pita ML, Fernández MR, De-Lucchi C, Medina A, Martínez-Valverde A, Uauy R, Gil A. Changes in the fatty acids pattern of red blood cell phospholipids induced by type of milk, dietary nucleotide supplementation, and postnatal age in preterm infants. J Pediatr Gastroenterol Nutr 1988;7:740-7.

15. Koletzko B, Schmidt E, Bremer HJ, Haug M, Harzer G. Effects of dietary long-chain polyunsaturated fatty acids on the essential fatty acid status of premature infants. Eur $\mathbf{J}$ Pediatr 1989:148:669-75.

16. Clandinin MT, Parrott A, Van Aerde JE, Hervada AR, Lien E. Feeding preterm infants a formula containing $\mathrm{C}_{20}$ and $\mathrm{C}_{22}$ fatty acids simulates plasma phospholipid fatty acid composition of infants fed human milk. Early Hum Dev 1992:31:41-51.

17. Foreman-v Drongelen MMHP, Houwelingen AC $v_{\text {w }}$ Kester ADM, de Jong AEP, Blanco CE, Hasaart THM, Hornstra G. Long-chain polyene status of preterm infants with regard to the fatty acid composition of their diet: comparison between absolute and relative fatty acid levels in plasma and erythrocyte phospholipids. Br J Nutr 1995;73:405-22.

18. Clandinin MT, Chappell JE, Heim T, Swyer PR, Chance GW. Fatty acid accretion in fetal and neonatal liver: implications for fatty acid requirements. Early Hum Dev 1981;5:7-14.

19. Chambaz J, Ravel D, Manier M-C, Pepin D. Mulliez N, Bereziat G. Essential fatty acid interconversion in the human fetal liver. Biol Neonate 1985;47:136-140.

20. Clandinin MT, Chappell JE, Heim T, Swyer PR. Chance GW. Fatty acid utilization in perinatal de novo synthesis of tissues. Ear!y Hum Dev 1981;5:355-66.

21. Carlson SE, Rhodes PG, Rao VS, Goldgar DE. Effect of fish-oil supplementation on the n-3 fatty acid content of red blood celi membranes in preterm infants. Pediatr Res 1987;21:507-10.

22. Liu C-CF, Carison SE, Rhodes PG. Rao VS, Meydrech EF, Increase in plasma phospholipid docosahexaenoic and eicosapentaenoic acids as a reflection of their intake and mode of administration. Pediatr Res 1987:22:292-6.

23. Carlson SE, Cooke RJ, Rhodes PG, Peeples JM, Werkman SH, Tolley EA. Long-term feeding of formulas high in linolenic acid and marine oil to very low birth weight infants: phospholipid fatty acids. Pediatr Res 1991;30:404-12.

24. Hoffman DR, Uauy R. Essentiality of dietary $\omega 3$ fatty acids for premature infants: plasma and red blood cell, fatty acid composition. Lipids. 1992;27:886-95.

25. Carnielli VP, Pederzini F, Luijendijk IHT, Bomaars WEM, Boerlage A, Degenhart, HJ, Pedrotti D, Sauer, PJJ. Long-chain polyunsaturated fatty acids (LCP) in low birth weight formula at levels found in human colostrum. Pediatr Res 1994;35:309A. 
26. Carlson SE, Cooke RJ, Werkman SH, Tolley, EA. First year growth of preterm infants fed standard compared to marine oil n-3 supplemented formula. Lipids 1992;27:901-7.

27. Carlson SE, Werkman SH, Peeples JM, Cooke RJ. Tolley EA. Arachidonic acid status correlates with first year growth in preterm infants. Proc Natl Ac Sci USA 1993;90;1073-7.

28. Holman RT. Controll of polyunsaturated farty acids in tissue lipids. J Am Coll Nutr 1986:5:183. 211.

29. Kloosterman GJ. On intrauterine growth, the significance of prenatal care. International Journal of Gynaecol Obstet 1970;8:895-912.

30. Dubowitz LMS, Dubowitz V', Goldberg C. Clinical assessment of gestational age in the newborn infant. J Pediatr 1970;77:1-10.

31. Bligh EG, Dyer WJ. A rapid method for total lipid extraction and purification. Can J Biochem Physiol 1959:37:11-7.

32. Holman RT. The deficiency of essential fatty acids. In: Kunau W, Holman RT, eds. Polyunsaturated fatty acids. Champaign (IL): American Oil Chemist's Society, 1977;4:163-82.

33. Neuringer M, Connor WE, Lin DS, Barstad L, Luck S. Biochemical and functional effects of prenatal and postnatal w3 fatty acid deficiency on retina and brain in rhesus monkeys. Proc Natl Ac Sci USA 1986;83:4021-5.

34. Dallal GE. DESIGN: A supplementary Module for Systat and Sysgraph. Evanston, IL: SYSTAT Inc, 1988.

35. Jennrich RI, Schluchter MD. Unbalanced repeated-measures models with structured covariance matrices. Biometrics 1986;42:805-20.

36. Dixon WJ, chief ed. BMDP statistical software manual: to accompany the 7.0 software release. Berkeley: University of California Press, 1992;2:13!1-52.

37. Foreman-v Drongelen MMHP, Houwelingen AC v, Kester ADM, Hasaart THM, Blanco CE, Hornstra G. Long-chain polyunsaturated fatty acids in preterm infants: status at birth and its influence on postnatal levels. J Pediatr 1995;126:611-8.

38. NEVO Foundation. Dutch food composition table 1993. The Hague, The Netherlands: Voorlichtingsbureau voor de Voeding, 1993 (in Dutch).

39. Innis SM, Foote KD, MacKinnon MJ, King DJ. Plasma and red cell fatty acids of low birthweight infants fed their mothers expressed breast milk or preterm infant formula. Am J Clin Nutr 1990:51:994-1000.

40. Uauy RD, Birch DG, Birch EE, Tyson JE and Hoffman DR. Effect of dietary omega-3 fatty aciids on retinal function of very-low-birth-weight neonates. Pediatr Res 1990;28:485-92.

41. Luukkainen P, Salo MK, Janas M, Nikkari, T, Fatty acid composition of plasma and red blood cell phospholipids in preterm infants from 2 weeks to 6 months postpartum. J Pediatr Gastroenterol Nuti 1995;20:310-5.

42. Hernell O, Blåckberg L. Digestion and absorption of human milk lipids. In: Dulbecco R, ed. Encyclopedia of human biology. New York: Academic Press, 1991;3:47-56.

43. Hernell O, Blåckberg L, Chen Q. Sternby B, Nilsson Å. Does, the bile salt-stimulated lipase of human milk have a role in the use of the milk long-chain polyunsaturated fatty acids? J Gastroenterol Nutr 1993;16:426-31.

44. Chen Q, Bläckberg L. Nilsson A., Sternby B, Hernell O. Digestion of triacylglycerols containing long-chain polyenoic fatty acids in vitro by colipase-dependent pancreatic lipase and human milk bile salt-stimulated lipase. Biochim Biophys Acta 1994;1210:239-43.

45. Carlson SE, Peeples JM, Cooke RJ. Werkman SH. Effects of docosahexaenoate (DHA, 22.6n-3) supplementation of preterm (PT) infants on arachidonate (AA, 20:4n-6) and DHA status. Pediatr Res 1992;31:286A. 
46. Carlson SE, Carver JD, House SA. High fat diets varying in ratios, of polyunsaturated to saturated fatty acid and linoleic to linolenic acid: a comparison of rat neural and red cell membrane phospholipids. J Nutr 1986;116:718-25.

47. Innis SM. Plasma and red blood cell fatty acid values as indexes of essential fatty acids in the developing organs of infants fed with milk or formulas. J Pediatr 1992:120;78-86S.

48. Farquharson J, Cockburn F, Patrick WA, Jamieson EC, Logan RW. Infant cerebral cortex fatty acid composition and diet. Lancet 1992;340:810-3.

49. Neuringer $\mathbf{M}$. Cerebral' cortex docosahexaenoic acid is lower in formula-fed than in breast-fed infants. Nutr Rev 1993;51:238-41.

50. Uauy R. Are w-3 fatty acids required for normal eye and brain development in the human? $\mathrm{J}$ Pediatr Gastroenterol Nutr. 1990; 11:296-300.

51. Birch DG, Birch EE, Hoffman DR, Uauy R. Retinal development in very low birth weight infants fed diets differing in omega-3 fatty acids. Invest Ophthalmol Vis Sci 1992;33:2365-3276.

52. Birch EE, Birch DG, Hoffman DR, Uauy R. Dietary essential fatty acid supply and visual acuity development. Invest Ophthalmol Vis Sci 1992;33:3242-3253.

53. Carlson SE, Werkman SH, Rhodes PG and Tolley EA. Visual-acuity development in healthy preterm infants: effect of marine-oil supplementation. Am J Clin Nutr 1993;58:35-42. 


\section{General discussion}

The studies described in this thesis focused on long-chain polyunsaturated fatty acid (LCP) levels in preterm infants. One of the factors which has contributed significantly to the decreased mortality and morbidity of these vulnerable infants, is the increase in the knowledge of their particular nutritional needs for achieving optimal growth and development. These concern not only the supplies of fluid, amino acids, vitamins, minerals and energy, but also that of specific, essential fatty acids (EFAs), which are necessary for maintaining particular body functions.

The EFAS of main importance for preterm infants are probably not so much the parent EFAs, linoleic acid $(18: 2 n-6)$ and $\alpha$-linolenic acid $(18: 3 n-3)$, but rather their more desaturated and elongated derivatives (LCPS). The major LCP of the $n-3$ series, docosahexaenoic acid (also named cervonic acid, 22:6n-3), and that of the $n-6$ series, arachidonic acid (20:4n-6), are the most abundant polyunsaturated fatty acids (PUFAs) present in human brain [1-3] and retina [4]. These LCPS accumulate rapidly in neural tissue during the last trimester of gestation [5-7], a period associated with rapid cell division, formation of synapses and dendritic spines $[8,9]$, and development of the photoreceptor cells. In addition, 20:4n-6 is present in considerable amounts in membrane phospholipids (PLS) throughout the body, and, like dihomo- $\gamma$-linolenic acid $(20: 3 n-6)$ and eicosapentaenoic acid $(20: 5 n-3)$, is a precursor of prostaglandins and other eicosanoids that have important bioregulatory functions [10-13].

Unlike term infants, preterm infants undergo third trimester growth and development extrauterinely, and are deprived of the substantial accretion of fat, including $n-6$ and $n-3$ LCPS, during late pregnancy. Hence, the postnatal dietary EFA supply to preterm infants will potentially have to meet specific requirements, a topic which was addressed in Chapters 6 to 8 . Besides, it is of interest to know whether preterm birth is associated with a particular prenatal EFA supply and whether this prenatal supply has certain consequences for postnatal LCP levels in preterm infants. These subjects were studied in Chapters 2 to 4 , and 7.

\subsection{Main findings}

\subsubsection{Supply of long-chain polyunsaturated fatty acids during intrauterine life}

Information on the prenatal EFA supply and the resultant fetal EFA status is almost always gathered from EFA levels in materials (umbilical plasma, red blood cells (RBCs), or cord vessel walls) that were collected (shortly) after delivery [14-20]. The potential of the EFA profile of umbilical vessel walls as a tool for studying the EFA status during intrauterine life

'Polyunsaturated fatty acids with a chain. length of 20 carbon atoms or more, and derived from the parent essential fatty acids linoleic acid (18:2n-6) and $\alpha$-linolenic acid (18:3n-3) through alternate desaturation and elongation. 
has been discovered only recently. Since human umbilical vessels have no vasa vasorum, and human tissue cannot synthesize EFAs de novo, EFAs present in the umbilical vessel walls must have been derived from the blood flowing through them. When combined with the relatively slow turnover of vessel wall PLS, this renders the EFA composition of the umbilical vein wall PLs likely to be a longer-term representation of the EFA supply to the fetus [18]. Similarly, the EFA profile of the umbilical artery wall PLS can be considered a longer-term reflection of the EFA content of the return flow from the fetus to the mother. Although direct comparisons with the EFA profiles of other fetal tissues are yet to be performed, the EFA content of the umbilical artery wall is, therefore, regarded as an indication of the fetal EFA status [17,18]. Studies that evaluated the EFA. content of umbilical vessel walls of for the most part healthy, full-term infants, born after an uncomplicated pregnancy have raised doubts as to whether the prenatal supply of EFAs, including LCPS, adequately covers the fetal demands [17-19,21,22].

\section{Long-chain polyunsaturated fatty acid status of preterm infants at birth}

To extend on the observations in full-term infants, we reported, to our knowledge, the first extensive data on the EFA profiles of umbilical vessel walls of preterm infants in Chapter 2. When compared to cord vessel walls of term infants, the fatty acid profiles of preterm umbilical arteries and veins were characterized by a lower $n-6$ and $n-3$ LCP content and by higher values for indicators of a general EFA shortage, 20:3n-9, and the EFA deficiency index (EFADI, 20:3n-9/20:4n-6), and for those of an isolated 22:6n-3 shortage, Osbond acid (22:5n6) and the cervonic acid deficiency index [CADI, 22:5n-6/adrenic acid (22:4n-6)]. In other words, the biochemical EFA status of downstream preterm fetal tissue (indicated by the EFA profile of the umbilical artery walls) is substantially lower than that of the term fetus, but the EFA supply to the preterm fetus (reflected by the EFA contents of the umbilical vein wall) is lower as well.

In accordance with the differences observed between the mean fatty acid values in preterm and term cords, the EFA content of umbilical vessel walls of preterm infants was found to increase with advancing GA (Chapters 2 and 7), while values for EFA deficiency markers decreased (Chapter 2). Potential relations between LCP profile and G.A were also studied in the PL.s of plasma collected by fetal blood sampling during pregnancy (Chapter 3) or gathered from the umbilical cord shortly after delivery (Chapter 7). As in studies by others [16,23], $n-3$ LCP levels were consistently found io increase with increasing GA. Plasma $n-6$ levels decreased with advancing gestation when the blood was collected by fetal blood sampling, but in blood collected immediately after preterm birth no correlation with GA was found. In studies by others, the plasma $n-6$ LCP content at birth has been found to increase [16] with advancing GA, or, as in Chapter 7 , no significant relation was observed [23,24]. The inconsistent relation between $n-6$ LCP levels and GA could be explained the relatively short-term (dietary) influences which are known to affect fatty acid levels in plasma PLS, but which are less likely to influence the EFA profiles of umbilical vessel walls.

The increasing n-6 and $n-3$ values observed with advancing GA can be considered a reflection of an adequate response (increased supply) to the increasing fetal demand for $n-6$ and $n-3$ LCPs, necessary for brain and body growth, during the last trimester of pregnancy. At the same time, the decreasing values of EFA deficiency markers found in cord vessel walls with advancing GA might suggest an increasing adequacy of the EFA supply towards term. Olsen and co-workers [25] have argued that the increasing n-3 EFA levels seen with increas- 
ing pregnancy duration are the result of a higher maternal dietary $n-3$ intake, which leads to the prolonging of gestation through a down-regulation of the formation of dienoic prostaglandins involved in the triggering of parturition. They considered the results of their intervention study [26] as supportive of this hypothesis. However, in their recent prospective study of the influence of the maternal n-3 LCP intake during pregnancy on gestation length [27], no such influence was observed. Moreover, preliminary data reported by $\mathrm{Al}$ and co-workers [28] show that the maternal $n-3$ LCP status during pregnancies ending in preterm or term delivery and during prolonged pregnancy (GA $>42$ weeks) are not significantly different. Umbilical cord blood n-3 LCP values of the infants born from these pregnancies, were again higher for term than for preterm infants, with that of infants born after a prolonged pregnancy being even higher than that of term infants. In addition, as mentioned before, a significant positive correlation between plasma $n-3$ levels and GA was also observed in samples obtained through fetal blood sampling during pregnancy (Chapter 3). Furthermore, when comparing the EFA profiles of fetal and postnatal umbilical plasma PLS, the EFA status of the preterm newborn infant (postnatal umbilical plasma), if anything, is higher than that of the preterm fetus (fetal plasma) at similar GAs (Chapter 3). This latter observation may be regarded the most convincing argument in favour of the view that the lower EFA values of preterm infants are a reflection of a physiologically lower demand for EFAs, necessary for growth and development, that is associated with less advanced gestation.

\section{Long-chain polyunsaturated fatty acid status of infants born after a multiple pregnancy}

Since the human fetus must derive the necessary EFAs from the maternal circulation, the Iow EFA status reported for newborn infants in this thesis (Chapter 2) and by others [18,19. 21] could very well be caused by a limiting maternal EFA supply. To check the validity of this view, the EFA profiles of the umbilical cord vessel walls of infants born after a multiple or after a singleton pregnancy were compared (Chapter 4), assuming that the increased accretion of fetal and placental tissues and the resultant higher total EFA demand associated with a multiple pregnancy would result in an even lower infant EFA status.

Indeed, the EFA status of downstream fetal tissue during a multiple pregnancy appears to be substantially lower than that during a singleton pregnancy, as indicated by the lower levels of 18:2n-6 and of the major LCPS $20: 4 n-6$ and 22:6n-3, and the higher values for markers of a general EFA shortage (20:3n-9, its elongation produci dihomo-Mead acid (22:3n-9), and the EFADI) in the cord artery yessel walls of the former. The fatty acid pattern of the supplying umbilical vein of infants born after a multiple pregnancy, when compared to that of infants born after a singleton pregnancy was characterized by lower levels of 18:2n-6 and higher values for markers of a general EFA deficiency and a specific shortage of $22: 6 n-3(22: 5 n-6$, and the CADI). The one other study reporting EFA data of a limited number ( 3 twins) of infants born after a multiple pregnancy [29] observed a similar trend in umbilical plasma cholesterol esters and triglycerides.

These differences, observed between the EFA profiles of infants born after a singleton and after a multiple pregnancy do not only support the hypothesis that the maternal EFA supply to the fetus is limiting, but also indicate that the mother has difficulty coping with the EFA demands of the developing and growing multiple fetuses. During a singleton pregnancy, women would have to increase their daily dietary EFA intake by about $1.5 \%$ of energy intake to adequately cover the EFA demands of the fetus, which amount to about 400 and $50 \mathrm{mg} / \mathrm{kg}$ 
of body weight per day for $n-6$ and $n-3$ EFAs, respectively [30] as well as those of the accreting placental and maternal tissues [31]. This increase is roughly similar to that recommended to pregnant women by the Food and Nutrition Council [32] in the Netherlands "but no specific guidelines have been formulated in case of a multiple pregnancy. Moreover, results of a recent longitudinal study [20] of the maternal EFA status during and after an uneventful singleton pregnancy, indicated that these pregnant women had already drawn on their EFA stores to supply their fetuses with the necessary quantities of EFAS, $22: 6 n-3$ in particular.

All in all, the above-mentioned results warrant further studies of the need for supplying women who carry more than one infant with additional n-3 and n-6 EFAS and LCPS. An additional argument for extra supply is the fact that multiple pregnancies result in preterm delivery more often than singleton pregnancies do [33]. The combined effect of a lower EFA and LCP status due to preterm birth ([16], Chapter 2), and as a result of multiple pregnancy might seriously threaten the quality of the EFA and LCP status of preterm twins and triplets.

\section{Influence of prenatal long-chain polyunsaturated fatty acid supply on intrauterine growth}

The influence of the prenatal LCP supply on parameters of prenatal growth was studied by evaluating relations between anthropometric parameters at birth (weight, head circumference (HC), and length), and the LCP profiles of umbilical cord plasma (Chapter 7), RBC (Chapter 7), and vessel wall (Chapters 2 and 7) PLs. Because both the growth parameters and the fatty acid profiles are known to be related to GA at birth, correlations were corrected for this confounder by multiple regression analysis. Indeed, all significant correlations between fatty acid levels and growth parameters were significantly influenced by GA.

No significant correlations were observed for any of the anthropometric parameters with the LCP status measured in cord plasma or RBC PLS. Perhaps, the fact that LCP levels in umbilical plasma and RBC PLS are relatively short-term indicators of the fetal LCP status, renders their correlation with measures of a long-term process like fetal growth likely to be less distinct. The fatty acid composition of the PLS of walls of the supplying umbilical vein was also unrelated to any of the parameters of prenatal growth. This could indicate that varying amounts of the supplied LCPS are used as 'building bricks' for structural growth. In the arterial cord vessel walls, values for $n-6$ LCPS were found to be positively related to birth weight (Chapter 2), and HC at birth (Chapter 7), while 22:6n-3 quite consistently correlated positively with all three anthropometric parameters.

Others have also reported a positive relation of both $n-3$ and $n-6$ LCP levels at birth with weight and HC at birth, namely in preterm cord plasma [23] and in term cord blood [17] and umbilical vessel walls [17,34]. Koletzko and Braun [24], however, argued that LCPS of the $n$ 6 series are specifically related to tissue growth in utero, based on a positive relation between birth weight and relative levels of $20: 4 n-6$ and the sum of all n-6 LCPs they observed in plasma triglycerides of newborn preterm infants, and the absence of such a relation for $n-3$ LCPS. Crawford and co-workers [35] stressed the importance of the highly significant negative correlations they observed for the EFADI and the CADI measured in the umbilical artery wall with both weight and $\mathrm{MC}$ at birth. Also in contrast to the findings in Chapter 2. Felton and coworkers [34] reported significant positive correlations with growth of $n-6$ and $n-3$ fatty acid levels in both arterial and venous cord vessel walls. The most probable explanation for the discrepancies between our results and those of others, is that the correlations observed in the 
latter were not always corrected for GA. Correction for this main confounder proved to be of substantial influence on the relations observed in our study population: the significant correlations for percentage levels of 20:4n-6 and the sum of all $n-6$ LCPs with birth weight and with HC in Chapter 7 were completely attributable to GA at birth, while strong correlations between prenatal growth and deficiency indicators as well as venous fatty acid levels were completely attributable to GA at birth (Chapter 2).

In addition to the striking relation between prenatal growth and 22:6n-3 status that was observed in the studies of Chapters 2 and 7, the only significant difference observed between the EFA profiles of the lightest and heaviest infants of the sets of twins or triplets studied (Chapter 4), was the lower 22:6n-3 level in the umbilical vein wall of the lightest infants. In contrast to $20: 4 n-6$, which is present in considerable amounts in membrane PLs throughout the human body, 22:6n-3 has a highly specific distribution, being present in high concentrations in brain, retina, spermatozoa and mitochondria [36]. Consequently, the explanation for the seemingly important influence of $22: 6 n-3$ on prenatal growth must perhaps be sought in the high 22:6n-3 concentration in mitochondrial membrane PLs and its potential influence on mitochondrial metabolic functions [37]. In isolated liver mitochondria of EFA deficient rats, partial uncoupling of the oxidative phosphorylation has been observed [38]. This uncoupling will result in a decreased efficiency of the conservation of the energy available from the oxidation of dietary substrates.

\subsubsection{Postnatal long-chain polyunsaturated fatty acid status of preterm infants}

The two enteral dietary EFA sources available for newborn infants are human milk, which contains small but significant amounts of 22:6n-3, 20:4n-6 and other LCPs, or commercially available artificial formulas, the majority of which did not contain any but trace amounts of LCPS when the studies described in this thesis were initiated [39-41]. The presence of the parent EFAS 18:2n-6 and 18:3n-3 in these formulas will possibly not fully compensate for the absence of LCPS, considering the limited desaturase capacity of preterm newborns [42,43]. The findings that preterm infants have very limited fatty acid stores $[30,42,44]$ and are borm with a lower EFA status than infants carried to term ([16], Chapter 2) will potentially provide an additional challenge to their postnatal LCP status.

\section{Influence of postnatal long-chain polyunsaturated fatty acid supply}

Indeed, when the postnatal LCP status of preterm infants fed on conventional artificial formulas was compared with that of preterm infants raised on their own mother's milk during the first four weeks of life (Chapter 6), a number of significant differences were observed. After 21 to 28 days of postnatal life, absolute $(\mathrm{mg} / \mathrm{l})$ and relative (\% (wV/wt) of total fatty acid methyl esters) 22:6n-3 values and the absolute amount of 20:4n-6 had become substantially and significantly lower in the plasma PLS of the formula-fed infants. Effects on the 22:6n-3 status were supported by the changes in the sum of all $n-3$ LCPs and by a higher value for the marker of an isolated 22:6n-3 deficiency, the CADI, in the formula-fed infants. In RBC PLs, the postnatal decreases of $22: 6 n-3$ and $20: 4 n-6$ in the formula-fed preterm infants were approximately twice those in the human milk-fed group, but like in other recent shortterm studies $[45,46]$, these inter-group differences did not reach significance. The slower turnover rate of RBC PLS than of plasma PLS may have contributed to the less apparent nutritional effects on this tissue over a relatively short period of time. 
The results described in Chapter 6, as well as those of other studies [45-48], provided a strong indication that the conventional artificial formulas that contain the parent EFAs but lack their longer-chain derivatives, are unable to maintain the postnatal biochemical LCP status of preterm infants at levels that can be obtained when feeding with preterm human milk. Therefore, at long-term study (until three months of corrected age, that is three months after the initially expected date of delivery) on the consequences of feeding preterm infants on preterm formulas, containing both $22: 6 n-3$ and $20: 4 n-6$ in amounts typical for preterm human milk, was initiated (Chapter 8). The usefulness of this approach was supported by the results of the first short-term studies on the effects of increasing the dietary intake of preterm infants of $n-3$ LCPS $[47,49]$ or both $n-3$ and $n-6$ LCPS [48].

After four weeks of postnatal life, the plasma PL, 22:6n-3 and 20:4n-6 contents in preterm infants fed on the LCP-enriched preterm formula were significantly higher than those in infants which had received a conventional formula, and were comparable to those of preterm infants raised on their own mother's milk. These differences between the two formula-fed populations continued to increase, resulting in average $22: 6 n-3$ and $20: 4 n-6$ values that were up to four and two times higher, respectively, in the LCP-enriched formula group than in the conventional formula group at three months of corrected age. In RBC PLS, differences between the two formula-fed groups reach significance as early as after 28 days of life only for relative (weight \%) levels of 22:6n-3 and 20:4n-6. These were again higher, and comparable to those of human milk-fed infants, in the group raised on an LCP-enriched formula. Three months after the expected date of delivery, these inter-group differences were even more pronounced and also significant for the absolute (mg/l) 22:6n-3 amount. Both in plasma and RBC PLS, inter-group differences found for the 22:6n-3 status were also reflected by the two indices of the functional 22:6n-3 status: CADI values were significantly lower in the infants raised on LCP-enriched formulas, while values the cervonic acid sufficiency index. (CASI, $22: 6 n-3 / 22: 5 n-6)[50]$ were significantly higher.

The results of this study, supported by those of two short-lerm (up to four weeks) studies [46,48], show that feeding preterm infants with artificial formulas enriched with both $22: 6 n-3$ and 20:4n-6 in balanced ratios and in amounts approximating those found in preterm human milk, is a successful approach to raising both the $22: 6 n-3$ and $20: 4 n-6$ status of preterm formula-fed infants to values found in plasma and RBC PLS of preterm infants fed on human milk. A diet-induced decrease of $20: 4 n-6$, as reported after supplying only additional $n-3$ LCPS $[45,50]$, was not observed.

Another main finding of the studies described in Chapters 6 and 8 was that the changes with time after birth were strikingly different when fatty acid values were expressed as absolute amounts or concentrations (mg/l plasma) or as relative levels (\% (wt/wt) total fatty acid methyl esters). Details of these differences, as well as the advantages and disadvantages of each form of expression and the specific information they may yield, are discussed in the section on methodological considerations of this general discussion.

\section{Influence of prenatal long-chain polyunsaturated fatty acid supply}

All in all, the substantial influence of the postnatal LCP supply on the biochemical postnatal LCP status of preterm infants is quite well established. However, to what extent postnatal LCP levels are also affected by the intrauterine LCP supply has hardly been studied. Preliminary data by Leaf and co-workers [51] did reveal a positive correlation between plasma LCP 
levels at birth (reflecting the prenatal LCP status) and those at term postconceptional age (40 wks GA). The relation was reportedly independent of the type of postnatal diet, and as such was considered to indicate that the intrauterine experience of the fetus may set the pattern for postnatal LCP levels [52]. This observation may be of particular relevance, considering the widely divergent LCP levels with which infants are born ([16] Chapters 2, 4 and 6). Therefore, it gave rise to the study in Chapter 7, in which the nature of the relation between the LCP status at birth and that in the term period $(37-42$ wks GA) in a group of preterm infants was explored more extensively by studying LCP levels in plasma, RBCs, as well as umbilical artery walls.

In this study, the postnatal diet was the only significant determinant of absolute and relative plasma levels of 22:6n-3 and relative plasma levels of 20:4n-6 at term postconceptional age, with lower postnatal levels in the infants raised on formula than in those fed their own mother's milk. The absolute 20:4n-6 amount in plasma PLs at birth was the only explanatory variable (positive correlation) for the absolute 20:4n-6 amount at term. The 22:6n-3 and 20:4n-6 contents of the walls of the umbilical arteries of the preterm infants were positively related to the 22:6n-3 and 20:4n-6 contents of RBC PLS collected at the time when these infants were expected to be born. These results quite clearly demonstrate that the biochemical LCP status at term is determined, not only by the postnatal diet, but also by the LCP status at birth, with higher LCP levels at birth resulting in higher postnatal levels. This finding stresses the significance of an appropriate prenatal LCP supply (a major determinant of the LCP status at birth), particularly for infants who are born preterm, or after a multiple pregnancy, or both. Since the only potential way to achieve a change in this prenatal LCP supply is through an adaptation of the fatty acid content of the maternal diet during pregnancy, these results may warrant further studies of the effects of EFA-enriched maternal diets during pregnancy on the infant LCP status at birth. Such studies should also include an evaluation of the functional and clinical consequences of such an intervention, a subject which will be addressed more extensively later in this general discussion.

\subsection{Methodological considerations}

\subsubsection{Is Mead acid a deficiency indicator in umbilical vessel walls?}

When the infant EFA status at birth was studied in Chapters 2 (preterm compared with fill-term infants) and 4 (infants of multiple and of singleton pregnancies), EFA profiles of the umbilical vessel walls were focused on, for they are considered to give a longer-term reflection of intrauterine EFA levels than those of umbilical plasma or RBCs [17,18]. Apart from the EFA. content, values for EFA deficiency indicating fatty acids, such as 20:3n-9, were compared. However, these EFA deficiency indicating fatty acids are regarded as such based on biochemical reactions in adult material, which leaves room for debate about the applicability of these deficiency indicators to fetal cells and tissues.

In this respect, Sanders and Reddy [53] have postulated that the presence of 20:3n-9 in cord artery walls may not reflect an EFA deficiency, but rather a high activity of the conversion system (overactive $\Delta 6$-desaturase) in the arterial wall, resulting in the formation of 20:3n-9 even in the presence of adequate EFA levels. Yet, the information presently available on fetal fatty acid biochemistry indicates that the desaturase activity in fetal liver microsomes is low [43], and that in (fetal) placental tissue is low [54] or even not detectable [43,55]. In addition, the higher 20:3n-9 content of preterm than of full-term cord vessels (Chapter 2) 
would indicate a decreasing activity of the fatty acid desaturation system during progressing pregnancy. However, microsomal synthesis of LCPS was shown to increase with advancing GA in piglet liver and brain [56]. Moreover, in case of a highly active desaturase system, the conversion of oleic acid (18:1n-9) to 20:3n-9 would be accompanied by an even higher conversion of the preferred desaturase substrates $18: 2 n-6$ and 18:3n-3, leading to a positive relation between $n-9$ and $n-6$ or $n-3$ LCPS. Nevertheless, when relating cord levels of $20: 3 n-9$ to those of 20:4n-6 (the major $n-6$ LCP), significant negative correlations between these two fatty acids were observed both in our preterm and in our full-term study populations (Chapter 2). Finally, the higher 20:3n-9 content, combined with a lower EFA content, of cord arterial vessel walls of infants born after a multiple pregnancy, when compared to those born after a singleton pregnancy, support the validity of $20: 3 n-9$ as an indicator of EFA deficiency, rather than of desaturase activity.

Another explanation given for the high cord artery vessel wall levels of 20:3n-9 and other EFA deficiency indicating fatty acids is that these vessel walls serve as a dustbin for the infant to store unnecessary fatty acids. If this is the case, the 20:3n-9, 22:n-9, and 22:5n-6 contents of umbilica! vessel walls would be expected to increase with advancing GA. However, values of these fatty acids were found to be stable (umbilical artery walls) or to even decrease (umbilical vein wall) with increasing pregnancy duration (Chapter 2).

All in all, the information currently available from studies described in this thesis or from the literature does not refute the supposition that fatty acids that are established EFA deficiency indicators in adult tissues, can also be used as such in fetal or infants tissues. However, additional studies that provide more information on fetal and infant fatty acid biochemistry are necessary to indisputably establish whether this assumption is justified.

\subsubsection{Comparability of fatty acid profiles of venous and capillary plasma and red blood cell phospholipids}

In the studies of dietary influences on the LCP status of preterm infants in plasma and RBC PLs (Chapters 6 and 8), the necessary blood samples were collected in connection with dingnostic punctures. As a result, the longitudinal sample sets consisted of blood samples of venous or capillary origin in a random order. To ensure that such a set of blood samples would provide reliable information on dietary influences, the comparability of the fatty acid profiles of venous and capillary plasma and RBC PLS was studied, for ethical reasons, in eight healthy adult volunteers (Chapter 5).

Fatty acid profiles of venous and capillary plasma PLs were found to be comparable, which directly enabled an accurate evaluation of dietary influences in this substance, without imposing the burden of extra blood punctures on the participating infants. The comparability of the fatty acid profiles of venous and capillary RBC. PLS was good when lipids were extracted within one week after blood collection. However, when the RBCs were stored for four weeks at $-20{ }^{\circ} \mathrm{C}$, considerable differences were observed that resulted from substantial fatty acid losses in the capillary samples. These losses mainly concerned the PUFAs, the concentration of which decreased to some $10 \%$ of the initial value, and the highly unsaturated LCPS in particular.

This loss of PL-associated PUFAs from RBCs as a consequence of storage at temperatures below $0{ }^{\circ} \mathrm{C}$ has also been reported by others [57-59], with autoxidation of PUFAs as the obvious major cause, since the process of lipid peroxidation, both in the initiation and propa- 
gation stages, uses iron, which is largely present in haemoglobin, as a catalyst [60-64]. In Chapter 5, the multiple significant fatty acid losses were observed in the capillary, rather than in the venous RBC samples. This could be the result of more extensive loss of membrane integrity caused by the considerable manual pressure by which the blood is driven into a tube during a capillary blood collection. This RBC membrane damage may enhance RBC susceptibility for lipid peroxidation through the release of otherwise sequestered iron, which thus becomes available for the radical reactions involved in autoxidation [64]. Besides, the structural insulation that proteins give to autoxidisable lipids [65] as well as the protective structural organization of the lipids themselves [66] are disturbed.

In any event, to obtain reliable information on dietary influences on the fatty acid profile of RBCs attempts ought to be made to prevent the PUFA losses observed in this tissue. One potential strategy is storage of RBC suspensions at very low temperatures, e.g. at $-50^{\circ} \mathrm{C}$ or even $-80^{\circ} \mathrm{C}$, but this appeared only to delay and not to prevent lipid loss (unpublished observation). Another option is removing the oxidation-promoting haemoglobin from the RBC lipids by preparing red cell ghosts or lipid extracts from the RBCs within one week after blood sampling. If all steps of the analyses are to be simultaneous for a series of consecutive RBC samples, autoxidation may be prevented by handling and storing the RBC samples in the presence of an iron-binding chelating agent, preferably desferrioxamine [67], which has been demonstrated to effectively prevent or at least reduce lipid peroxidation in various in vitro and in vivo studies [67-70]. That desferrioxamine is also effective in preventing lipid loss from RBC samples stored for longer periods at temperatures below $0{ }^{\circ} \mathrm{C}$, as will be the case in many dietary studies, is illustrated by figure 9.1. It shows the preliminary results of a study initiated by that of Chapter 5 , in which $0.25 \mathrm{mg}$ of desferrioxamine per $\mathrm{ml} \mathrm{RBC}$ suspension was added to RBCs stored for up to 4 months, and clearly demonstrates the protective effect of this addition on lipid loss.

\subsubsection{Information obtained from absolute and relative fatty acid values}

In all but one of the studies presented in this thesis, the fatty acid content was expressed. as absolute amounts or concentrations ( $\mathrm{mg} / \mathrm{l}$ plasma or RBC suspension, or mg per $\mathrm{g}$ of dry weight tissue), next to or instead of relative levels (\% (wt/wt) total fatty acid methyl esters). The impression obtained from these absolute data was sometimes quite different from that obtained from relative values.

In Chapters 6 and 8, absolute LCP amounts in plasma PLS of preterm infants showed an initial increase during the first week of life, followed by a gradual decline (conventional formula) or stabilization (human milk or LCP-enriched formula) during the following weeks, while percentage values declined steadily from the first day of life onward. These different patterns resulted from a considerable increase in, the total amount of PL-associated fatty acids in plasma. In RBC PLS, the total amount of fatty acids present did not change markedly and, consequently, the postnatal changes in absolute and relative LCP values were more or less similar. In Chapter 5, absolute amounts of PUFAs, but also of saturated fatty acids (SAFAs) and monounsaturated fatty acids (MUFAs) were shown to decrease in capillary RBCs stored for four weeks. Due to a $50 \%$ reduction of the total amount of PL-associated fatty acids, which was mainly caused by the decrease in PUFAs, relative levels of SAFA and MUFA were increased in stead of decreased. This would suggest a shift in the fatty acid profile of the RBCs, rather than a loss of all types of fatty acids, which is what really happened. So when pool 


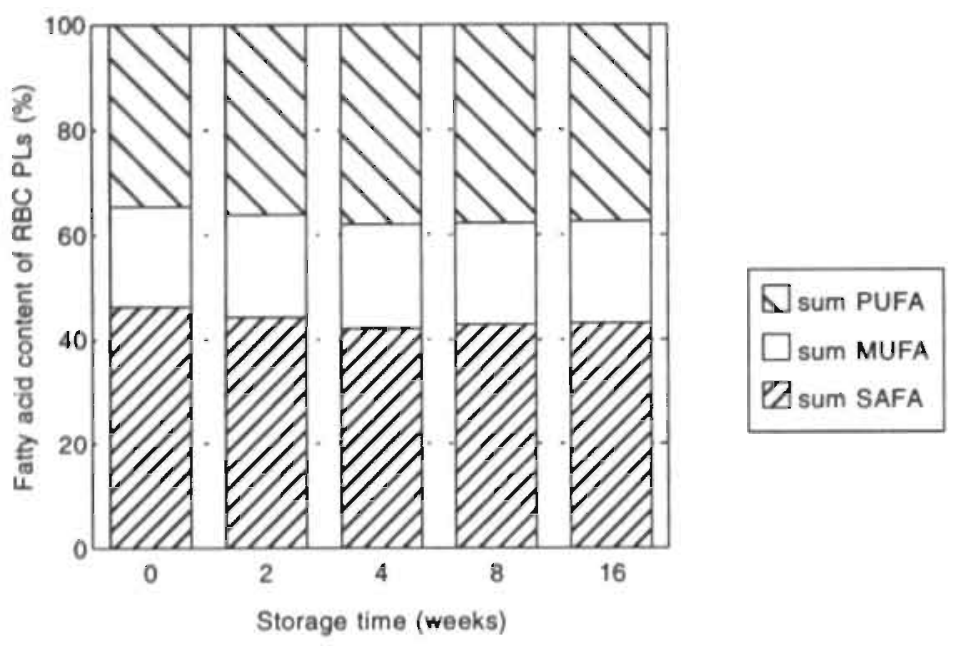

Flgure 9.1. Protection against lipid loss from the phospholipid (PL) fraction of stored capillary red blood cells (RBCs) by the addition of $0.25 \mathrm{mg}$ desferrioxamine per ml RBC suspension.

Storage time= time between biood collection and extraction of total lipids; SAFA= saturated fatty acids; MUFA $=$ monounsaturated fatty acids, PUFA = polyunsaturated fatty acids.

sizes change markedly over time, or when pools sizes are different, as is the case in comparisons between maternal and fetal blood (Chapter 3, [52]), absolute fatty acid data provide information, that is at least additional to, but sometimes even more adequate than that obtained from relative values. Absolute LCP amounts also seem to correlate better with parameters of prenatal growth, than relative levels (Chapters 2 and 7).

The particular importance of relative fatty acid levels is evident, when considering that, with fatty acid reactions occurring in a lipid environment, it is the amount of a given fatty acid relative to that of the others that determines the rate of these reactions. Besides, the measurement error of the malytical procedure is usually smaller when calculating relative values, as is illustrated by the inter-group differences for RBC LCP levels in Chapter 8, which reached significance for relative data earlier than for absolute data.

So, ideally, both absolute and relative fatty acid data should be reported. However, when comparing absolute amounts of PL-associated LCP levels in plasma reported in Chapters 6 and 8 to those reported by others $[45,46,71,72]$, considerable differences (up to a factor ten) are observed, even when relative levels are comparable. Although these discrepancies may be caused by varying study designs and population characteristics, they could also result from methodological differences. For example, the addition of the internal standard (the amount of which absoluie amounts of the other fatty acids are based on) not at the start of the fatty acid analysis (lipid exiraction) but at some point in time thereafter, will result in artefactually lower absolute values for the fatty acids present, because fatty acid losses during the preceding steps of the analysis are not accounted for. On the other hand, an overestimation of actual fatty acid amounts could be the result when the lipid fraction studied (e.g PLs) is not 
separated to near homogeneity, but contaminated with other fractions (e.g. triglycerides and cholesteryl esters). All in all, analytic procedures need to be standardized to enable a better comparability of absolute data from various research groups.

\subsubsection{Blood LCP status as a reflection of neural tissue LCP status?}

When studying the effects of the LCP supply on the fetal or infant $22: 6 n-3$ and 20:4n-6 status, the actual tissue of interest is neural tissue, especially that of the brain and retina. Blood LCP levels have been adopted as an alternative to the direct measurement of the LCP composition of these target organs in living human infants. In this respect, changes in plasma fatty acid levels are regarded to reflect the dietary LCP supply, while those in RBC membrane were considered to reflect changes occurring in the fatty acid composition of the brain. Until recently, this latter assumption was based on direct correlations of brain and RBC lipid fatty acid distribution found in animal studies in rats [73] and rhesus monkeys [74], and its validity has been subject of debate [75]. However, recent studies demonstrated that breast-fed infants have significantly higher levels of $22: 6 n-3$ in their cerebral cortex lipids than formula-fed infants [76-78], and that 22:6n-3 levels in RBC and cortex are even significantly related [78]. The findings of these studies are supplemented by those of the increasing number of studies that report significant influences of the dietary $n-3$ LCP supply, and the resultant $n-3$ LCP status measured in blood lipids, on several parameters of brain and visual function [79-82]. which will be considered in more detail later in this discussion.

\subsection{Supplementation of essential fatty acids, the longer-chain deriva- tives in particular, during pre- and postnatal life}

The majority of the studies described in this thesis evaluated the LCP status of especially preterm infants, and to what extent this is influenced by the pre- and postnatal EFA supplies under the prevailing dietary conditions for pregnant women (Chapters 2 to 4 , and 7), and for newborn infants (Chapters 6 and 7), respectively. The results from these studies, combined with those of studies by others, indicate that the EFA supplies resulting from the current diets do not lead to an optimal fetal and infant LCP status, and that supplementation of $n-6$ and $n-3$ LCPS to both the maternal and the infant diets may be beneficial.

\subsubsection{Supplementation during prenatal life}

The results in Chapter 2 showed that the EFA status at birth of preterm infants is significantly lower than that of infants carried to term. In addition, the EFA status at birth of infants born after a multiple pregnancy is significantly lower than that of infants born after a singleton pregnancy of equal duration (Chapter 4). The results of the study described in Chapter 3 indicated that this impression of the fetal EFA status given by the EFA profile of material collected shortly after delivery is fairly reliable, since it is reasonably consistent with that given more directly by fetal blood.

As stated earlier, the lower preterm EFA values probably are a reflection of a physiologically lower demand for LCPS, necessary for brain. and body growth and development, of the preterm fetus when compared to the term fetus. Yet, this lower LCP status at birth will result in a lower postnatal LCP status (Chapter 7). Preterm infants are: born during the period of most rapid brain growth, which is associated with a high demand for EFAs and the LCPs in 
particular. As a result, these infants are deprived too early from their intrauterine source of LCPS, which, based on the results in Chapter 7, may be more adequate than the dietary extrauterine supply. First, however, it is of interest to discuss why the EFA status of healthy, term infants, born after an uneventful pregnancy, which is widely considered to represent the 'normal' situation, may not be an optimal one. As mentioned earlier in this chapter, this discussion was initiated by the discovery of relatively high $20: 3 n-9$ levels in the umbilical (artery) vessel walls of these infants, and the information currently available indicates that, this and other established EFA deficiency indicators in adult tissues, can also be used as such. in fetal or infant tissues.

A number of years ago, a study on the composition of the diet of our paleolithic ancestors and its potential effects on current diet-related health problems was published [83]. It describes how alterations in the human genetic constitution have been relatively small over the last. 40,000 years, while the dietary patterns have changed substantially in the last millennia as a result of the many developments in food production and processing. The transition from at hunter-gatherer society to an agricultural society, was associated with an increased intake of SAFAs through the currently high consumption of edible fats and diary products. [84], which were lacking from the paleolithic diet, and a reduced dietary intake of $n-6$ and n-3 LCPS, which are present in larger amounts in wild animals than in domestic livestock $[83,85]$. Indeed, the major EFA present in the diet of pregnant women participating in a study [86] that. was conducted in the same period, region, and hospitals as the studies reported in this thesis, was 18:2n-6 (> $80 \%$ of the total PUFA intake). To obtain information on the intake of other EFAs, duplicate food portions were collected by a subset of 48 women during four days in the second trimester of pregnancy. Fatty acid analysis of these food portions revealed that the mean daily intakes of the major LCPS $20: 4 n-6$ and $22: 6 n-3$ were 0.13 and $0.01 \%$ of the total daily fatty acid intake, respectively (R.P. Mensink, unpublished data). These preliminary results are in agreement with the combined 20:4n-6 and 22:6n-3 intake of less than one percent of the total dietary fat intake, which was reported for British pregnant women [17]. Thus, it is conceivable that the combination of a developing human body and brain, which are genetically still adjusted to a relatively high PUFA and LCP supply, and a maternal diet. which has meanwhile evolved to contain less of these fatty acids, leads to a relative EFA. deficiency, accompanied by the presence of EFA-deficiency indicators, during apparently normal pregnancies.

Based on the data discussed above, an increase of the prenatal supply of EFAs, and LCPS in particular, may have potential beneficial effects on the fetal and (newborn) infant LCP status. Of course, the only way to achieve this is through a maternal dietary intervention. The highly significant positive correlations observed at delivery between EFA values in umbilical and maternal venous plasma PLS $[19,20]$ support the potential effectiveness of such an intervention. Moreover, the intake of increased amounts of $18: 2 n-6$ [87] and n-3 LCPS [88,89] was reported to result in a, respectively, higher $n-6$ and $n-3$ LCP status of the newborn infant. However, the increase in LCP levels of the $n-6$ series was accompanied by a decrease in $n-3$ LCPS [87] and vice versa [89]. Since both $n-6$ and $n-3$ are of importance for proper body function, growth, and development (which will be discussed in more detail later in this section), these additional decreases should be considered undesirable. Consequently, EFAs of both series should be supplemented in balanced ratios. Yet, controlled clinical intervention 
studies are indispensable to the determination of the optimal ratio and content of $n-6$ and n-3 EFAs in the maternal diet during or even before pregnancy.

\subsubsection{Supplementation during postnatal life}

Clearly, conventional artificial formulas, which lack LCPS, are unable to maintain the postnatal LCP status of preterm infants at levels obtained after feeding on preterm human milk ([45-48], Chapter 6). Consequently, to establish at least comparable 22:6n-3 and 20:4n-6 blood levels in formula and human milk-fed preterm infants, alterations to the EFA composition of the formulas are in order. A number of strategies are available to achieve this goal.

Many of the conventional artificial formulas do not only lack LCPs, but also contain levels of 18:2n-6 that are extremely high when compared to those of the other parent EFA 18:3n-3, with the ratio of $18: 2 n-6$ to $18: 3 n-3$ reaching $50: 1$ (Chapter 6). Basically, the substrate affinity of $\Delta 6$-desaturase, which is the limiting enzyme for the rate of synthesis of LCPs from their parent EFAS [90] is higher for 18:3n-3 than for 18:2n-6 [91]. However in these formulas, the 18:2n-6 content is that much higher than the 18:3n-3 content, that the former displaces the latter from the enzyme sites, which results in a decreased $n-3$ LCP synthesis. Therefore, some researchers have tried to increase the $n-3$ LCP status of preterm infants by enhancing the dietary intake of $18: 3 n-3$ in short-term (4 to 5 wks) feeding trials $[79,92]$. In these studies, RBC 22:6n-3 levels of preterm infants consuming formulas containing $>2.0 \%$ of total fatty acids as 18:3n-3 were apparently similar to those of infants fed on human milk. Nevertheless, longer-term studies demonstrated quite clearly that even higher intakes of 18:3n-3 (up to $4.8 \%$ of total fatty acids, with a ratio of $18: 2 n-6$ to $18: 3 n-3$ as low as 6.4 ), cannot prevent $n-3$ LCP declines in formula-fed preterm infants $[45,50]$, indicating that the biosynthesis of $n-3$ LCPS cannot meet the $n-3$ LCP demand.

Another approach used is the addition of marine oils to the diet of preterm infants, which increases only their $n-3$ LCP intake $[45,47,49,50]$. However, besides the desired enhancement of 22:6n-3 levels, this type of intervention also resulted in decreased 20:4n-6 levels [45,50]. Reducing the amount of $20: 5 n-3$ added to the formula e.g. from $0.3 \%$ to $0.06 \%$ of total fatty acids, may prevent this diet-induced lowering of the 20:4n-6 status [93]. Yet, in view of the presence of high levels of 20:4n-6 in neural tissue and the influence of this $n-6$ LCP on postnatal growth [94], raising the 20:4n-6 status of formula-fed preterm infants to that of infants receiving human milk may be preferable.

The third possible strategy is the addition of both n-6 and n-3 LCPs to the preterm infant formulas, as was done in the long-term study described in Chapter 8. In accordance with the findings of two short-term studies. [46,48], this approach successfully raised both the 22:6n-3 and 20:4n-6 status. Three months after the initially expected date of delivery, the LCP status of the LCP-formula group could not be compared to that of preterm infants raised on their own mother's milk, as most of these did not receive enough human milk any more by that time. However, the considerably higher values for $22: 6 n-3$ and $20: 4 n-6$ in the LCP-enriched formula group, when compared to infants fed on conventional formulas, appear to be within their physiological ranges, since they were similar to (plasma) or somewhat lower than (RBCs) those recently reported by Luukkainen and co-workers [95] for 10 preterm infants which were fully breast-fed until' 6 months postnatall age. In addition, in two long-term studies in which 
only $n-3$ LCPS were supplemented [45,50], differences between the $22: 6 n-3$ status of the two formula-fed study groups similar to those in Chapter 8 were reported.

However, levels of two other important LCPS which were not added, 20:3n-6 and 20:5n-3, were significantly lower in the supplemented formula group than in the infants fed the conventional formulas, even at 35 days postnatal age. At the same time, 20:3n-6 and 20:5n-3 values in infants receiving human milk, were at least comparable, but usually higher than those in the conventional formula group. Clandinin and co-workers [46], who studied an LCPenriched formula containing all LCPS at levels typical for human milk, did not observe a decreased 20:5n-3 concentration (20:3n-6 was not reported separately) in the infants receiving this formula. In view of the potentially important physiological function, particularly of $20: 3 n-6$, as a precursor of prostaglandins and other eicosanoids, studies of further 'finetuning' of the LCP content of LCP-enriched artificial formulas may be in order, for example by copying the entire LCP profile of preterm human milk. However, whether human milk is able to maintain an optimal LCP status in preterm infants, during a period of (brain) growth and development that actually ought to have been spent in utero, is open to debate. In Chapters 6 and 8 , relative 22:6n-3 and 20:4n-6 levels decreased significantly after birth, which resulted in values sometimes well below those measured in cord blood of infants born after normal full-term pregnancy [19], also in human milk-fed infants.

\subsubsection{Influence of long-chain polyunsaturated fatty acid status on functional and anthropometric parameters}

Initially, studies of the effects of various dietary L.CP supplies on preterm human infants had biochemical end-points, usually blood LCP levels that were used as a reflection of the LCP status elsewhere in the body, particularly in the neural target organs. Faced with significant differences in infant LCP status resulting from the various diets, researchers then sought to evaluate the influence of the differences in LCP supply and status on infant development by adding clinical and functional outcomes to the biochemical data.

\section{Visual function}

So far, functional studies in preterm infants have focused on the influence of the supply of $n-3$ EFAs, and have mainly and most thoroughly evaluated dietary effects on early visual function [79-82]. This preference for studying the visual system can be considered logical for a number of reasons. Firstly, within the human body, amounts of the major $n-3$ LCP. 22:6n-3. are particularly high in the retina $(60 \%$ of total fatty acids in photoreceptor outer segment membranes [96]) and the brain (grey matter of the cerebral cortex). Secondly, the retina, particularly the fovea, and the primary visual cortex of the cerebrum are relatively immature at birth, and undergo substantial development, including active synaptogenesis, thereafter [97100): this renders these tissues and their function particularly vulnerable to nutritional manipulation, especially in preterm infants. Thirdly, effects of the dietary $n-3$ EFA supply on visual function had already been demonstrated in several animal studies [101-105].

The two measures of visual function used in preterm human infants are the electroretinogram (ERG) and visual acuity. The ERG is an electrophysiologic response of the retina to light, and provides a non-invasive measure of retinal function. The a-wave of the ERG provides information on photoreceptor function [106], while the b-wave originates from the inner retinal neurons that are activated by the input from the photoreceptors. Responses generated 
by the rods (photoreceptors responsible for night vision) can be differentiated from those arising from the cones (daylight and colour vision, and high visual acuity). Performance on ERG is quantified by a number of parameters that are either measured directly or calculated. Those of most relevance are the threshold (the minimum intensity to elicit a small criterion amplitude), the implicit time, or peak latency (the time from the eliciting brief flash of light to the response peak), $\mathrm{V}_{\max }$ (the maximum amplitude), and $\mathrm{K}$, or sensitivity (the intensity that elicits a response half the amplitude of $\mathrm{V}_{\max }$. The latter two parameters are determined using the so-called Naka-Rushton method [107].

The amount of n-3 LCPS present in the enteral diet, was demonstrated to significantly influence ERG measures of retinal function in healthy preterm infants by Birch, Uauy, and coworkers $[79,80]$. Up to 71 formula-fed infants were randomly allocated to receive either a corn oil-based artificial formula (low in all n-3 fatty acids), a soy oil-based formula (containing a relatively high level $(2.7 \%)$ of the parent $n-3$ EFA, $18: 3 n-3$, but no $n-3$ LCPs), or a soy and marine oil-based formula (containing $0.35 \%$ of total fatty acids as $22: 6 n-3$, and $0.65 \%$ as $20: 5 n-3$ ). Of these and of 10 human milk-fed infants, full-field ERGs were obtained. at 36 and 57 weeks after conception. In addition, 10 infants born at 35 weeks after conception were tested at one week of age; these intrauterine nurtured infants, and those raised on human milk, were considered to provide 'gold standards' for preterm retinal development. At 36 weeks after conception, infants raised on the $n-3$ fatty acid-lacking com oil-based artificial formula had significantly lower plasma and RBC 22:6n-3 levels, a higher rod b-wave threshold, and a lower maximum amplitude $\left(\mathrm{V}_{\max }\right)$ and sensitivity $(\mathrm{K})$ of the rod ERG b-wave than those receiving preformed dietary $n-3$ LCP from the soy and marine oil-based formula, human milk, or intrauterine nutrition. Infants fed on the soy oil-based formula had intermediate thresholds that were significantly higher than those of infants receiving intrauterine nutrition. Similar differences among groups in a-wave amplitude suggested that dietary effects on the rod b-wave originated primarily at the photoreceptor level. The ERG parameters were also significantly related to plasima and RBC $n-3$ LCP levels, with higher values for blood n-3 LCPS being associated with better ERG performances [79]. At 57 weeks after conception, the abovementioned inter-group differences were no longer present [80]. The authors considered these results to be consistent with delayed rod development rather than permanent rod damage. Cone-ERGs were similar for all study groups both at 36 and 57 weeks postconception, possibly as a result. of the earlier morphological and functional maturation of extrafoveal cones, when compared to rods [108], which renders them less susceptible to dietary manipulation. Yet, at 57 weeks postconception, a delay in retinal development was seen in infants fed the corn oil-based formula, in that they had significantly prolonged implicit times of the so-called 'oscillatory potentials' [80]. These are generated by circuits in the inner retina and presumably reflect ganglion cell-amacrine cell interactions [109].

While an ERG provides valuable information on retinal physiology, it does not actually indicate how well an infant can see, for vision is a process which is affected not only by the activity of the retina, but also by that of the central visual system. The quality of vision is usually evaluated by measuring visual acuity, which indicates the maximum spatial resolution of the visual system. In young preterm infants, resolution acuity, and how this is influenced by the dietary $n-3$ EFA supply, have recently been evaluated by the forced-choice preferential looking method [81], the Teller acuity card procedure [82], and by measuring cortical visual evoked potentials (VEPS) [81]. The preferential looking method and the acuity card procedure 
are both behavioral measures of grating acuity, which is a form of resolution acuity that indicates the finest stripes that can be discriminated from a homogeneous grey stimulus. They are both based on an infants' inherent visual preference for a patterned rather than a homogeneous surface, with the acuity card procedure being a concise, less time-consurning version of the preferential looking method [110,111]. Results of both methods, correspond well with one another $[111,112]$. With VEPS, the infant gazes at grating or checkerboard pattems on a video display in which the light elements change to dark, and vice versa. The VEPS monitor the responses from neurons in the primary visual cortex to each change. The acuity threshold is estimated by extrapolating the linear relationship between response amplitude and the size of the stripes or squares to zero amplitude. Compared with preferential looking acuity, VEP acuity develops more rapidly [111-113]. This is probably related partly to differences in stimuli and ways of threshold determination used, and partly to slower maturation of neural systems involved in levels of visual processing beyond the primary visual cortex or in the behavioral response, which both also determine preferential looking acuity.

Birch and co-workers [81] reported on the influence of the dietary $n-3$ fatty acid supply on both VEP and preferential looking visual acuity development of preterm infants (GA at birth: 29-35 weeks). Among 73 formula-fed healthy preterm infants which were randomly assigned to one of three dietary groups (identical to those in the studies of Birch, Uauy, and colleagues on retinal function), they found that preterm infants raised on a com oil-based artificial formula had significantly poorer VEP and preferential looking acuities at 36 (VEP done) and 57 weeks (both done) after conception than infants fed a soy and marine oil-based formula. Infants that received a soy oil-based formula had intermediate values for the measures of visual acuity, with their mean VEP acuity at 57 weeks postconceptional age being significantly poorer than that of the soy/marine oil group. Additionally and interestingly, only the acuities of the soy/marine oil group were comparable to those of the two (non-randomized) groups that were considered to represent 'gold standards' for visual acuity development in preterm infants, namely preterm infants raised on human milk, and infants born and tested 35-36, weeks after conception. Results for acuity measures also correlated significantly with the $22: 6 n-3$ status, evaluated through the ratio of $22: 6 n-3$ to $22: 5 n-6$ (CASI), with higher CASI values being associated with better visual acuity. Comparisons with VEP and preferential looking acuities of full-term infants suggested that physical maturation (represented by postcenceptional age at measurement) rather than visual experience (indicated by postnatal age) is the major determinant of acuity development.

Carlson and colleagues [82] studied the effects of marine-oil supplementation $(0.2 \%$ $22: 6 n-3,0.3 \% 2: 0: 5 n-3)$ until 9 months postterm on visual acuity in 67 healthy preterm infants. They used the Teller acuity card procedure to measure visual acuity at term date and $2,4,6.5,9$, and 12 months thereafter. Their findings were in accordance with those of Birch and co-workers, in that infants randomly assigned to receive a standard soy oil-based formula had significantly poorer resolution acuity than infants raised on a marine-oil supplemented (but otherwise similar) formula at 2 and 4 months after term, and tended to do so at term date. In addition, visual acuity was correlated positively with RBC phosphatidylethanolamine 22:6n-3 and postnatal age, and negatively with hours of supplementary oxygen received by the infants. When the $n-3$ formula was given until 2 months postterm, differences in early visual acuity were found until that time but not thereafter [114]. The decreased VEP and preferential looking acuities are consistent with the relative immaturity of oscillatory poten- 
tials reported for preterm infants fed an artificial formula lacking $n-3$. EFAs [80]. They may all reflect a relative 22:6n-3 shortage at an age when functional connections in the retina are developing rapidly.

Although inter-group differences in $n-3$ LCP status persisted, many of the apparently dietinduced variations in visual function appear to be temporary: effects on rod-ERG found at 36 weeks postconception were no longer detectable some 5 months thereafter, and infants that did and did not receive dietary $n-3$ LCPs had comparable preferential looking acuities at least at 6.5 months postterm and thereafter. Perhaps, the infants eventually manage to accumulate adequate amounts of $22: 6 n-3$ for undisturbed visual development from dietary 18:3n-3, e.g. through increasingly efficient mechanisms for delivery and sequestering of 22:6n-3 in rod outer segments [80]. On the other hand, dietary and body levels of $22: 6 n-3$ may continue to influence aspects of vision other than those studied so far. There is also evidence that alterations in the maturation during early infancy of a sensory process like vision may (almost irreversibly) affect later development: in primates, the development of the primary visual cortex was shown to be guided by normal retinal input during an early sensitive period [115].

\section{Cognitive function}

Other functional end-points of interest are cognitive and psychomotor development, and the resultant early behaviour. Similar to the primary visual cortex, the frontal and temporal cortex of the brain (association areas involved in higher cognitive processes such as learning and memory) are still relatively undeveloped at birth. Their eventual function is, therefore, prone to be affected by dietary manipulation. However, to what extent intellectual performance is actually influenced by levels of $22: 6 n-3,20: 4 n-6$, and other LCPs, is probably even more difficult to establish conclusively than for visual function, for a number of reasons. For one thing, substantial LCP levels are present in neural membranes throughout the brain, so. many neural systems and functions (sensory and motor systems, activity, motivation, altention, learning, memory) are potentially susceptible to dietary influences. Moreover, these systems and functions, which are all of importance for intellectual development, interact with one another in many complex ways. Consequently, conclusive evidence on the importance of LCPS for appropriate cognitive and psychomotor development is rather limited, if not almost lacking. So far, only Carlson and colleagues [114,116] have reported on studies of specific effects of n-3 LCP supplementation on these functional end-points. Up to 54 preterm infants. were fed either a conventional LCP-lacking formula (identical in studies 1 and 2) or a marineoil supplemented formula, which provided $0.2 \%$ of total fatty acids as $22: 6 n-3$, and $0.3 \%$ (study 1) or $0.06 \%$ (study 2) as $20: 5 n-3$. The functional outcomes measured at twelve months after the initial term date were the Bayley Scales of Mental and Psychomotor Development [117], and the Fagan Infantest.

The Bayley Mental Development Index (MDI) is aimed at measuring perception, memory, learning, problem. solving, abstract thinking, vocalization, and early verbal communication. The Bayley Psychomotor Development Index (PDI) is designed to assess gross motor abilities and hand and finger manipulation. In study 1, Bayley MDIs of both study populations were comparable, while the Bayley PDI tended $(\mathrm{P}<0.09)$ to be significantly lower in the marine-oil group. The latter observation was suggested to be associated with a negative effect of marineoil supplementation on linear growth [116]. However in study 2 [114], psychomotor development was similar in both populations, while the MDI was significantly $(\mathrm{P}<0.03)$ higher in the 
supplemented infants. These discrepancies between the results of both studies were considered to be an effect of an improvement in the nutritional status by a prolonged provision of nutrient-rich preterm study formulas. When interpreting results for Bayley Indices, it is important to realize that these give an overall reflection of performances in several sensory, motor, and cognitive domains, and that deficits in one particular domain may be masked by otherwise normal development.

The Fagan Infantest is a test of infant looking behaviour, which uses an infant's inherent tendency to look at novel stimuli (faces) as a means to assess visual recognition memory [118]. With this test, the infant's memory of the familiar faces is measured by his or her preference for novel ones. Novelty preference scores of the marine-oil supplemented infants of studies 1 and 2 were similar and, surprisingly, lower than those of the control groups ( $\mathrm{P}<0.02$, and $\mathrm{P}<0.075$, for studies 1 and 2 , respectively). $\mathrm{Yet}$, infants in the marine-oil group had more discrete looks to novel and familiar faces (study 1), and this number of discrete looks was positively correlated to values for Bayley MDI (study 2) [114]. In addition, supplemented infants had shorter visual fixation, or look duration, when tested at 6, 9, and 12 months after the initial term date [119].

\section{Growth}

Researchers have also evaluated the influence of the dietary LCP intake of preterm infants on anthropometric parameters. Associations between the intrauterine LCP supply and prenatal growth $([17,23,24,34,35]$, Chapters 2 and 7$)$ have been addressed in an earlier subsection of this general discussion. With respect to postnatal growth achievements, the intake of $n-3$ LCP containing formula was found to be associated with poorer first year growth (concerning weight, length, as well as HC) in preterm infants [120]. Furthermore, the 20:4n-6 status in plasma phosphatidylcholine was reported to be positively correlated with the above-mentioned measures of postnatal growth in preterm infants through 12 months corrected postnatal age, irrespective of the dietary $n-3$ LCP intake [94]. Therefore, attempts were made to prevent significant declines in $20: 4 n-6$ status by making two changes to the dietary regime of the preterm infants: the amount of $20: 5 n-3$ added to the marine-oil supplemented formula was reduced from $0.3 \%$ to $0.06 \%$ of total fatty acids, and the time-span during which this formula was given was reduced from until 9 to until 2 months after term date [93]. Preliminary data suggest that this approach did indeed result in comparable growth performances of infants receiving an $n-3$ LCP supplemented or a standard formula [114].

All of the above-mentioned studies of influences of the dietary LCP supply, and the resultant LCP status, on several parameters of brain and visual function have focused primarily on the dietary intake of n-3 LCPs. Both 22:6n-3 and 20:4n-6 account for a substantial proportion (some $25 \%$ each) of the total fatty acids in the cerebral cortex. Consequently, potential beneficial effects on brain function of dietary $n-3$ LCP supplementation, might well be undone by the associated decrease in 20:4n-6 status; a view supported by the different effects on Bayley MDi of two types of $n-3$ LCP suppletion discussed earlier [114]. Thanks to recent technological advances, artificial preterm formulas can be designed to meet both $n-3$ and $n-6$ LCP needs by using so-called 'single-cell oils'. These oils that are produced by single-celled organisms, such as microalgae and fungi, are highly purified and lack undesirable contamination with other LCPS. Further studies in preterm infants are needed to evaluate the 
potential functional and clinical consequences of these formulas, which simultaneously enhance the dietary $n-3$ and $n-6$ LCP intake.

\subsection{Perspectives for future research}

As described earlier in this discussion, further studies are in order to determine the optimal ratio and content of $n-6$ and $n-3$ EFAs in the diets of both pregnant women and preterm infants, and the optimal starting-points, durations, and types of possible adaptations in particular. On the one hand, these studies will have to be of a biochemical nature. This will include the use of stable isotope labelled fatty acids, which may clarify yet uncertain or unknown aspects of maternal, fetal, and infant EFA metabolism. On the other hand, the biochemical data will have to be supported by studies of the effects on functional parameters. Apart from extending the current knowledge of effects on visual function of preterm formulas supplemented with $n-3$ LCPS, with those of formulas providing both $n-3$ and $n-6$ LCPS, much attention and effort ought to go out to conclusively establishing pre- and postnatal dietary influences on higher mental function. These influences might not always be beneficial, as is indicated by preliminary results by Janowsky and co-workers [121], which suggest a possible negative effect of 22:6n-3 on language development in healthy term infants.

Guidelines for choosing methods appropriate for assessing cognitive development have been described in a recent brief review article by Neuringer and colleagues [122]. They are based on studies aimed at understanding the neural basis of specific cognitive functions and the effects of neurotoxins $[123,124]$. Since no single test can fit these guidelines, the preferred strategy is to perform a set of tests that provide useful comparisons and, in this way, can indicate dietary effects on specific aspects of cognition. Firstly, effects on a given cognitive function should be measured by several tests and their results should be consistent: convergent validity. Secondly, when testing other, unrelated abilities, no effects ought to be found: divergent validity. Thirdly, the tests chosen should have the power to predict later outcomes: predictive validity. Fourthly, tests should preferably be able to detect developmental delays as well as deviances from normal performances. Consequently, the normal course of development should be known, and performances on the tests should change qualitatively with age.

As mentioned earlier, Bayley scales do not meet most of these criteria, but a visual comparison test like the Fagan Infantest does. Other potentially suitable tests are [122]: the socalled 'AnotB, tasks' that measure short-term memory of infants [125] as well as their ability to inhibit preferred responses [126], which may possibly depend on a late developing frontal lobe system [127], and 'delayed-matching-to-sample', another way of measuring visual recognition memory. Valuable information may also be obtained from so-called 'infant habituation scores' [128], which indicate an infant's efficiency at processing and memorizing information. Unlike the development assessment scores from standard tests such as the Bayley scales, habituation scores obtained during the first year of life correlate reasonably well with later childhood intelligence scores [129]. Recently "early infant habituation was reported to be affected by the dietary LCP content in a randomised study in term infants [130].

With all of the functional research to be performed, aiming for a long-term follow-up is of great importance. As stated earlier, dietary effects during early infancy, which appear to be 
transient, may have important implications for later development. Moreover in higher, more complex functions, dietary effects may not emerge until these functions actually mature.

\subsection{References}

1. Svennerholm L. Distribution and fatty acid composition of phosphoglycerides in normal human brain. J Lipid Res 1968:9:570-9.

2. Martinez $\mathrm{M}$, Conde $\mathrm{C}$ and Ballabriga A. Some chemical aspects of human brain development. II. Phosphoglyceride fatty acids. Pediatr Res 1974;74:93-101.

3. Sastry PS. Lipids of nervous tissue: composition and metabolism. Progress Lipid Res 1985; 24:69-176.

4. Fliesler SJ and Anderson RE. Chemistry and metabolism of lipids in the vertebrate retina. Progress Lipid Res 1983;22:79-131.

5. Clandinin MTT, Chappeil JE, Leong S, Heim T, Swyer PR, Chance GW. Intrauterine fatty acid accretion rates in human brain: implications for fatty acid requirements. Early Hum Dev 1980:4:12i-9.

6. Martinez M, Ballabriga A, Gil-Gibernou JJ. Lipids of the developing human retina: I. Total fatty acids, plasmalogens, and fatty acid composition of ethanolamine and choline phosphoglycerides. J Neurosci Res 1988;20:484-90.

7. Martinez M. Tissue concentration of polyunsaturated fatty acids during early human development. J Pediatr 1992;120:SI29-38.

8. Martinez M, Ballabriga A. A chemical study on the development of the human forebrain and cerebellum during the brain "growth spurt" period. I. Gangliosides and plasmalogens. Brain Res 1978; 159:351-62.

9. Purpura DP. Morphogenesis of the visual cortex in the preterm infant. In: Brazier MAB, ed. Growth and development of the brain. New York: Raven Press, 1975:33-49.

10. Dusting GJ, Moncada S, Vane JR. Prostaglandins, their intermediates and precursors: cardiovascular actions and regulatory roles in normal and abnormal circulatory systems. Prog Cardiovasc. Diseases 1979;21:405-23.

11. Cassin S. Arachidonic metabolites and the pulmonary circulation of fetus and newborn. Prog Clin Biol Res; 135:227-50.

12. Friedman Z. Essential fatty acid consideration at birth in the premature neonate and the specific requirernent for preformed prostaglandin precursors in the infant. Prog Lipid Res 1986;25:35564.

13. Kitterman JA. Arachidonic acid metabolism and control of breathing in the fetus and newborn. Semin Perinatol 1987;11:43-52.

14. Berg. Hansen I, Friis-Hansen B, Clausen J. The fatty acid composition of umbilical cord serum, infant serum and maternal senum and its relation to the diet. Zeitschrift für Emăhrungswissensehaft 1969:9:352-63.

15. Olegård R, Svennerholm L. Fatty acid composition of plasma and red cell phosphoglycerides in full term infants and their mothers. Acta Pædiat Scand 1970;59:637-47.

16. Friedman Z, Danon A, Lamberth EL, Mann WJ. Cord blood fatty acid composition in infants and in their mothers during the third trimester. J Pediatr 1978;92:461-6.

17. Crawford MA, Doyle W, Drury P, Lennon A, Costleloe K, Leighfield M. N-6 and n-3 fatty acids during early human development. J Int Med 1989;225:159-69S1.

18. Hornsira G, Houwelingen AC v, Simonis M, Gerrard JM. Fatty acid composition of umbilical arteries and veins: possible implications for the fetal EFA-status. Lipids 1989;24:511-7. 
19. Al MDM, Hornstra G, van der Schouw YT, Bulstra-Ramakers MTEW, Huisjes HJ. Biochemical EFA status of mothers and their neonates after normal pregnancy. Early Hum Dev 1990;24 :239-48.

20. Al MDM, v Houwelingen AC, Kester ADM, Hasaart THM, de Jong AEP, Hornstra G. Maternal' essential fatty acid patterns during normal pregnancy and their relationship to the neonatal essential fatty acid status. Br J Nutr 1995a;74:55-68.

21. Ongari MA, Ritter JM, Orchard MA, Waddell KA, Blair IA, Lewis PJ. Correlation of prostacyclin synthesis by human umbilical artery with status of essential fatty acid. Am J Obstet Gynecol 1984;149:455-60.

22. Hornstra G, Al MDM, Gerrard JM, Simonis, MMG. Essential fatty acid status of neonates born to Inuit mothers: comparison with Caucasian neonates and effect of diet. Prostaglandins Leukotrienes Essential Fatty Acids 1992;45:125-30.

23. Leaf AA, Leighfield MJ, Costeloe KL, Crawford MA. Long-chain polyunsaturated fatty acids and fetal growth. Early Hum Dev 1992;30:183-91.

24. Koletzko B. Braun M. Arachidonic acid and early human growth: is there a relation? Ann Nutr Metab 1991;35:128-31.

25. Olsen SF, Hansen HS, Sørensen TIA, Jensen B, Secher NJ, Sommer S, Knudsen LB. Intake of marine fat, rich in ( $\mathrm{n}-3$ )-polyunsaturated fatty acids, may increase birth weight by prolonging gestation. Lancet 1986;ii:367-9.

26. Olsen SF, Dalby Sørensen J, Secher NJ, Hedegaard M, Brink Henriksen T, Hansen HS, Grant A. Randomised controlled trial of effect of fish-oil supplementation on pregnancy duration. Lancet 1992;339: 1003-7.

27. Olsen SF, Hansen HS, Secher NJ, Jensen B, Sandstrom B. Gestation length and birth weight in relation to intake of marine $n-3$ fatty acids. Br J Nutr 1995:73:397-404.

28. Al MDM, $\vee$ Houwelingen AC, Hornstra G. Essential fatty acids, pregnancy and pregnancy outcome (abstract). Workshop: Maternal fatty acid requirements during pregnancy and lactation. Fatty Acids and Lipids: From Cell Biology To Human Disease, 2nd International Congress of the ISSFAL International Society of Fatty Acids and Lipids, Bethesda, United States of America 1995.

29. Hoving EB, v Beusekom M, Nijeboer HJ, Muskiet FAJ. Gestational age dependency of essential fatty acids in cord plasma cholesterol esters and triglycerides. Pediatr Res 1994:35:461-9.

30. Clandinin MT, Cappell JE, Heim T, Swyei PR, Chance GW. Fatty acid utilization in perinatal de novo synthesis of tissues. Early Hum Dev 1981;5:355-66.

31. Crawford MA, Hassam AG, Stevens PA. Essential fatty acid requirements in pregnancy and lactation with special reference to brain development. Progr Lipid Res 1981;20:31-40.

32. Food and Nutrition Council. Guidelines for a healthy diet: recommendations drawn up by the committee on guidelines for a healthy diet. The Hague: Food and Nutrition Council, 1986.

33. Kloosterman GJ. De meerlingzwangerschap (Dutch). In: Kloosterman GJ, chief ed. De Voortplanting van de mens. Bussum, The Netherlands: Uitgeversmaatschappij Centen, 1983:21 1-9.

34. Felton CV. Chang TC, Crook D, Marsh M, Robson SC, Spencer JAD. Umbilical vessel wall fatty acids after normal and retarded fetal growth. Arch. Disease Child 1994;70:F36-F39.

35. Crawford MA, Costeloe K. Doyle W, Leighfield MJ, Lennon EA, Meadows N. Potential diagnostic value of the umbilical artery as a definition of neural fatty acid status of the fetus during its growth: the umbilical artery as a diagnostic tool. Biochem Soc Trans, 1990;18:761-6.

36. Salem N, Kim H=Y, Yergey JA. Docosahexaenoic acid: membrane function and metabolism. In: Simopoulos AP, Kifer RR, Martin RE, eds. Health Effects of Polyunsaturated Fatty Acids in Seafood. Orlando: Academic Press 1986:263-317. 
37. Houtsmuller UMT. Specific biological effects of polyunsaturated fatty acids. In: Vergroesen AJ, ed. The Role of Fats in Human Nutrition. London: Academic Press, 1975:331-51.

38. Klein PD, Johnson RM. Phosphorus metabolism in unsaturated fatty acid deficient rats. J Biol Chem 1954;211:103-10.

39. Jensen RG, Hagerty MM, McMahon KE. Lipids of human milk and infant formulas: a review. Am J Clin Nutr 1978;31:990-1016.

40. Lammi-Keefe CJ, Jensen RG. Lipids in human milk: a review. 2: Composition and fat-soluble vitamins. J Pediatr Gastroenterol Nutr 1984;3:172-98.

41. Jensen RG, Ferris AM, Lammi-Keefe CJ. Lipids in human milk and infant formulas. Annual Rev Nutr 1992;12:417-41.

42. Clandinin MT, Chappell JE, Heim T, Swyer PR, Chance GW. Fatty acid accretion in fetal and neonatal liver: implications for fatty acid requirements. Early Hum Dev 1981;5:7-14.

43. Chambaz J, Ravel D, Manier M-C, Pepin D, Mulliez, N, Bereziat G. Essential fatty acid interconversion in the human fetal liver. Biol Neonate 1985;47:136-140.

44. Friedman Z. Essential fatty acids revisited. Am J Dis Child 1980;134:397-408.

45. Carlson SE, Cooke RJ, Rhodes PG, Peeples JM, Werkman SH, Tolley EA. Long-term feeding of formulas high in linolenic acid and marine oil to very low birth weight infants: phospholipid fatty acids. Pediatr Res 1991;30:404-12.

46. Clandinin MT, Parrott A, Van Aerde JE, Hervada AR, Lien E. Feeding preterm infants a formula containing $\mathrm{C}_{20}$ and $\mathrm{C}_{22}$ fatty acids simulates plasma phospholipid fatty acid composition of infants fed human milk. Early Hum Dev 1992;31:41-51.

47. Carlson SE, Rhodes PG, Rao VS, Goldgar DE. Effect of fish-oil supplementation on the n-3 fatty acid content of red blood cell membranes in preterm infants. Pediatr Res 1987;21:507-10.

48. Koletzko B, Schmidt E, Bremer HJ, Haug M, Harzer G. Effects of dietary long-chain polyunsaturated fatty acids on the essential fatty acid status of premature infants. Eur J Pediatr 1989;148:669-75.

49. Liu C-CF, Carlson SE, Rhodes PG, Rao VS, Meydrech EF. Increase in plasma phospholipid docosahexaenoic and eicosapentaenoic acids as a reflection of their intake and mode of administration. Pediatr Res 1987;22:292-6.

50. Hoffman DR, Uauy R. Essentiality of dietary $\omega 3$ fatty acids for premature infants: plasma and red blood cell fatty acid composition. Lipids 1992;27:886-95.

51. Leaf AA, Leighfield MJ, Ghebremeskel K. Costeloe KL, Crawford MA. Polyunsaturated fatty acids in plasma choline phosphoglycerides of preterm infants (abstract). Third International Congress on Essential Fatty Acids and Eicosanoids, Adelaide, Australia 1992:7.

52. Hornstra G. Essential fatty acids, pregnancy and pregnancy complications: a round table discussion. In: Sinclair A, Gibson R, eds. Essentiall Fatty Acids and Eicosanoids: Invited papers from the Third International Congress. Champaign, Illinois: American Oil Chemist's Society, 1993:177-82.

53. Sanders TAB, Reddy, $S$. The influence of a vegetarian diet on the fatty acid composition of human milk and the essential fatty acid status of the infant. J Pediatr 1992;120:71S-77S.

54. Zimmerman T. Winkler L, Moller U, Schubert H, Goetze E. Synthesis of arachidonic acid in the human placenta. Biol Neonate 1979;35:209-12.

55. Booth C, Elphick MC, Hendrickse W. Hull D. Investigation of $\left[{ }^{14} \mathrm{C}\right]$ linoleic acid conversion into $\left[{ }^{14} \mathrm{C}\right]$ arachidonic acid and placental transfer of linoleic and palmitic acids across the perfused human placenta. J Dev Physiol 1981;3:177-189.

56. Clandinin, MT, Wong C, Hacker, RR. Synthesis of chain-desaturation products of linoleic acid by liver and brain microsomes during development of the pig. Biochem J 1985;226:305-9. 
57. Dodge JT, Philips GB. Autoxidation as a cause of altered lipid distribution in extracts from human red cells. J Lipid Res 1966;7:387-95.

58. Ways PO. Degradation of glycerophosphatides during storage of saline-washed, saline-suspended red cells at $-20^{\circ} \mathrm{C}$. J Lipid Res 1967;8:518-21.

59. Glatz JFC, Soffers AEMF, Katan MB. Fatty acid composition of serum cholesteryl esters and erythrocyte membranes as indicators of linoleic acid intake in man. Am J Clin Nutr 1989; 49:269-76.

60. Halliwell B. Superoxide-dependent formation of hydroxyl radicals in the presence of iron-salts. FEBS Lett 1978;96:238-43,

61. Aust SD, Morehouse LA. Thomas CE. Role of metals in oxygen radical reactions. J Free Radical Biol Med 1985;1:3-25.

62. Halliwell B, Gutteridge JMC. Oxygen free radicals and iron in relation to biology and medicine: Some problems and concepts. Arch Biochem Biophys 1986;246:501-14.

63. Chiu D, Kuypers F, Lubin B. Lipid peroxidation in human red cells. Semin Hematol 1989; 26:257-76.

64. Gutteridge JMC. Iron and oxygen: a biologically damaging mixture. Acta Padiatr Scand Suppl 1989:361:78-85.

65. Stocks J, Kemp M, Dormandy TL. Increased susceptibility of red-blood-cell lipids to autoxidation in hæmolytic states. Lancet 1971;i:266-9.

66. Halliwell B, Gutteridge JMC. Free Radicals in Biology and Medicine, 2nd edition. Oxford: Clarendon Press 1989:234-6.

67. Gutteridge JMC, Richmond R, Halliwell B. Inhibition of the iron-catalysed formation of hydroxyl radicals from superoxide and of lipid peroxidation by desferrioxamine. Biochem J 1979;184:469-72.

68. Fuller BJ, Lunec J, Healing G, Simpkin S, Green CJ. Reduction of susceptibility to lipid peroxidation by desferrioxamine in rabbit kidneys subjected to 24 -hour cold ischemia and reperfusion. Transplantation 1987;43:604-6.

69. Menasché P, Antebi H, Alcindor L-G, Teiger E, Perez G, Giudicelli Y, Nordmann R, Piwnica A. Iron chelation by deferoxamine inhibits lipid peroxidation during cardiopulmonary bypass in humans. Circulation 1990;82:SIV390-6.

70. Knight JA, Voorhees RP, Martin L. The effect of metal chelators on lipid peroxidation in stored erythrocytes. Ann Clin Lab Sci 1992;22:207-13.

71. Carlson SE, Cooke. RJ, Rhodes PG, Peeples JM. Werkman SH. Effect of vegetable and marine oils in preterm infant formulas on blood arachidonic and docosahexacnoic acids. J Pediatr 1992;120:159-67.

72. Foote KD, MacKinnon MJ, Innis SM. Effect of early introduction of formula ys fat-free parenteral nutrition on essential fatty acid status of preterm infants. Am J Clin Nutr 1991;54:93. 7.

73. Carlson SE, Carver JD, House SA. High fat diets varying in ratios of polyunsaturated to saturated fatty acid and linoleic to linolenic acid: a comparison of rat neural and red cell membrane phospholipids. J Nutr 1986:116:718-25.

74. Neuringer. M, Connor WE, Lin DS, Barstad L, Luck S. Biochemical and functional effects of prenatal and postnatal w3 fatty acid deficiency on retina and brain in rhesus monkeys. Proc Natl Ac Sci USA 1986;83:4021-5.

75. Innis SM. Plasma and red blood cell fatty acid values as indexes of essential fatty acids in the developing organs of infants fed with milk or formulas. I Pediatr 1992:120;78-86S.

76. Farquharson J, Cockburn F, Patrick WA, Jamieson EC, Logan RW. Infant cerebral cortex fatty acid composition and diet. Lancet 1992;340:810-3. 
77. Neuringer M. Cerebral cortex docosahexaenoic acid is lower in formula-fed than in breast-fed infants. Nutr Rev 1993;51:238-41.

78. Makrides M, Neumann MA, Byard RW, Simmer K, Gibson RA. Fatty acid composition of brain, retina, and erythrocytes in breast- and formula-fed infants. Am J Clin Nutr 1994;60:18994.

79. Uauy RD, Birch DG, Birch EE, Tyson JE and Hoffman DR. Effect of dietary omega-3 fatty acids on retinal function of very-low-birth-weight neonates. Pediatr Res 1990;28:485-92.

80. Birch DG, Birch EE, Hoffman DR, Uauy R. Retinal development in very low birth weight infants fed diets differing in omega-3 fatty acids. Invest Ophthalmol Vis Sci 1992;33:23653276.

81. Birch EE, Birch DG, Hoffman DR, Uauy R. Dietary essential fatty acid supply and visual acuity development. Invest Ophthalmol Vis Sci 1992;33:3242-3253.

82. Carlson SE, Werkman SH, Rhodes PG and. Tolley EA. Visual-acuity development in healthy preterm infants: effect of marine-oil supplementation. Am 』 Clin Nutr 1993;58:35-42.

83. Eaton SB, Konner M. Paleolithic nutrition. A consideration of its nature and current implications. N Eng J Med 1985;312:283-9.

84. Badart-Smook JMT, AI MDM, v Houwelingen AC, Hornstra G. Essentiali fatty acid intake during and contribution of various products (abstract). Fatty acids and lipids from cell biology to human disease, Ist international congress ISSFAL, Lugano June 30-July 3 1993:100.

85. Crawford MA, Doyle W, Drury P, Ghebremeskel K, Harbige L, Leyton J, Williams G. The food chain for n-6 and n-3 fatty acids with special reference to animal products. In: Galli C, Simopoulos AP, eds. Dietary $\omega 3_{i}$ and $\omega 6$ fatty acids. Biological effects and nutritional essentiality. New York and London: Plenum Press 1989:5-19.

86. Al MDM. Nutrient intake of women during normal pregnancy with special emphasis on fat intake. In: Essential fatty acids, pregnancy, and pregnancy outcome: relationship between mother and child. PhD Thesis, University of Limburg, Maastricht, The Netherlands, 1994:3746.

87. Al MDM, v Houwelingen AC, Badart-Smook. A, Hornstra G. Some aspects of neonatal essential fatty acid status are altered by linoleic acid supplementation of women during pregnancy. J Nutr 1995;125:2822-30.

88. Connor WE, Lowensohn R, Hatcher L. Enhanced $\omega 3$ fatty acid levels in the newborn infant by maternal $\omega 3$ fatty acid supplementation (abstract). Symposium C: Fatty acids and brain function. Fatty Acids and Lipids: From Cell Biology To Human Disease, 2nd International Congress of the ISSFAL International Society of Fatty Acids and Lipids, Bethesda, United States of America 1995 .

89. Houwelingen AC v, Dalby Sørensen J. Hornstra G, Simonis MMG, Boris J, Olsen SF, Secher NJ. Essential fatty acid status in neonates after fish-oil supplementation during late pregnancy. Bi J Nuti 1995; 74:723-31.

90. Brenner RR. Regulatory function of 46 -desaturase, key enzyme of polyunsaturated fatty acid synthesis. Adv Exp Med Biol 1977;83:85-101.

91. Holman RT. Nutritional and metabolic interrelationships between fatty acids. Fed Proc 1964; 23:1062-7.

92. Innis SM, Foote KD, MacKinnon MJ, King. DJ. Plasma and red cell fatty acids of low birthweight infants fed their mothers expressed breast milk or preterm infant formula. Am J Clin Nutr 1990;51:994-1000.

93. Carlson SE, Peeples JM, Cooke RJ, Werkman SH. Effects of docosahexaenoate (DHA, 22:6n-3) supplementation of preterm (PT) infants on arachidonate (AA, 20:4n-6) and DHA status. Pediatr Res 1992;31:286A. 
94. Carlson SE, Werkman SH, Peeples JM, Cooke RJ. Tolley EA. Arachidonic acid status correlates with first year growth in preterm infants. Proc Natl Ac Sci USA 1993:90:1073-7.

95. Luukkainen P. Salo MK, Janas M, Nikkari. T. Fatty acid composition of plasma and red blood cell phospholipids in preterm infants from 2 weeks to 6 months postpartum. J Pediatr Gastroenterol Nutr 1995;20:310-5.

96. Anderson RE, Benolken RM, Dudley PA, Landis DJ, Wheeler TG, Proceedings: polyunsaturated fatty acids of photoreceptor membranes. Exp Eye Res 1974;18:205-13.

97. Garey L. Structural development of the visual system of man. Hum Neurobiol 1984:3:75-80.

98. Kretzer FL, Hittner HM. Initiating events in the development of retinopathy of prematurity. In: Silverman WA, Flynn JT, eds. Retinopathy of Prematurity. Cambridge: Blackwell Scientific 1985:121-152.

99. Yuodelis C, Hendricksoni A. A qualitative and quantitative analysis of the human fovea during development. Vision Res 1986;26:847-55.

100. Huttenlocher PR, deCourten Ch. The development of synapses in the striae cortex of man. Human Neurobiol 1987;6:1-9.

101. Benolken RM, Anderson RE, Wheeler TG. Membrane fatty acids associated with the electrical response in visual excitation. Science 1973;182:1253-4.

102. Neuringer M, Connor WE, Van Petten C, Barstad L. Dietary omega-3 fatty acid deficiency and visual loss in infant rhesus monkeys. J Clin Invest 1984;73:272-6.

103. Neuringer M, Connor WE, Lin DS, Barstad L, Luck S. Biochemical and functional effects of prenatal and postnatal $w 3$ fatty acid deficiency on retina and brain in rhesus monkeys. Proc Natl Ac Sci USA 1986:83:4021-5.

104. Watanabe I, Kato M, Aonuma H, Hashimoto A, Naito Y, Moriuchi A, Okuyama H. Effect of dietary alpha-linolenate/linoleate balance on the lipid composition and electroretinographic responses in rats. Adv Biosci 1987;62:563-70.

105. Bourre J-M, Francois M, Youyou A, Dumont O, Piciotti M, Pascal G, Durand G. The effects of dietary $\alpha$-linolenic acid on the composition of nerve membranes, enzymatic activity, amplitude of electrophysiological parameters, resistance to poisons and performance of learning tasks in rats. J Nutr 1989;119:1880-92.

106. Hood DC, Birch DG. The a-wave of the human electroretinogram and rod receptor function. Invest Ophthalmol Vis Sci 31 1990;31:2070-81.

107. Naka KI, Rushton WAH. S-potentials from colour units in the retina of fish (cyprinidac), J Physiol (Lond) 1966;185:536-55.

108. Birch EE, Birch DG, Petrig B, Uauy R. Retinal and cortical function of infants at 36 and 57 weeks post-conception. Clin Vis Sci 1990;5:363-73.

109. Ogden TE. The oscillatory waves of the primate electroretinogram. Vis Res 1973:13:1059-74.

110. McDonald M, Dobson V. Sebris SL, Baitch L, Varner D, Teller DY. The acuity card procedure: a rapid test of infant acuity. Invest Ophthalmol Vis Sci 1985;26:1158-62.

111. Teller DY, McDonald MA, Preston K, Sebris SL. Dobson V. Assessment of visual acuity in infants and children: the acuity card procedure. Dev Med Child Neurol 1986;28:779-89.

112. Hamer RD, Mauer DL. The development of spatial vision. In: Albert DM, Jakobiec FA, eds. Principlesi and practice of ophthalmology: Basic Science. Philadelphia: WB Saunders 1994:578. 607.

113. Norcia AM. Tyler CW. Spatial frequency sweep VEP: visual acuity during the first year of life. Vision Res 1985;25:1399-408.

114. Carlson SE, Werkman SH, Peeples JM, Wilson WM III. Growth and development of premature infants in relation to $\omega 3$ and $\omega 6$ fatty acid status. In: Galli C, Simopoulos AP. Tremoli (eds). Fatty Acids and Lipids: Biological Aspects. Basel: Karger World Rev Nutr Diet 1994;75:63-9. 
115. Neuringer $M$. The relationship of fatty acid composition to function in the retina and visual system. In: Dobbing J, ed. lipids, learning and the brain. 103rd Ross conference. Columbus. OH: Ross Laboratories 1993:134-58.

116. Carlson SE, Werkman SH, Peeples JM, Cooke RJ, Tolley EA, Wilson WM III. Growth and development of very low-birthweight infants in relation to n-3 and n-6 essential fatty acid status. In: Sinclair A, Gibson R (eds). Essential Fatty Acids and Eicosanoids: Invited papers from the Third. International Congress. Champaign, Illinois: American Oil Chemist's Society, 1993:192-6.

117. Anastasi A. Psychological Testing, 6th edn. New York: Macmillan Publishing Co. 1988:275-7.

118. Fagan JF III, Singer LT, Montie JE, Shepard PA. Selective screening device for the early detection of normal or delayedl cognitive development in infants at risk for later mental retardation. Pediatr 1986;78:1021-6.

119. Carlson SE, Werkman SH. Preterm infants fed formula with compared to without docosahexaenoic acid (DHA) have shorter look duration ten months after DHA is discontinued. Pediatr Res 1995:37:14A.

120. Carlson SE, Cooke RJ, Werkman SH, Tolley, EA. First year growth of preterm infants fed standard compared to marine oil n-3 supplemented formula. Lipids 1992;27:901-7.

121. Janowski JS, Scott DT, Wheeler RE, Auestad N. Fatty acids affect early language development. Pediatr Res 1995;37:310A.

122. Neuringer $M$, Reisbick S, Janowsky J. The role of $n-3$ fatty acids in visuali and cognitive development: current evidence and methods of assessment. J Pediatr 1994;125:S39-47.

123. Stanton ME, Spear LP. Workshop on the qualitative and quantitative comparability of human and animal developmental neurotoxicity. Work Group I report: comparability of measures of developmental neurotoxicity in humans and laboratory animals. Neurotoxicol Teratol 1990;12: 261-7.

124. Diamond A. Guidelines for the study of brain-behavior relationships during development. In: Levin HS, Eisenberg HM, Benton AL, eds. Frontal Lobe function and dysfunction. New York: Oxford University Press, 1991:339-78.

125. Piaget J: Cook, M, trans. The construction of reality in the child. New York: Basic Books Inc., 1954.

126. Diamond A. Developmental time course in human infants and infant monkeys, and the neural bases of, inhibitory control in reaching. Ann N Y Acad Sci 1990;608:637-69.

127. Diamond A, Goldman-Rakic PS. Comparison of hurnan infants and rhesus monkeys on Piaget's AB task: evidence for dependence on dorsolateral prefrontal cortex. Exp Brain Res 1989;74:2440.

128. Horowitz FD, Paden LY, Bhana K, Self PA. An infant control procedure for the study of infant visual fixations. Develop Psych 1972;7:90-5.

129. Rose DH, Slater A, Perry H. Prediction of childhood intelligence from habituation in early infancy. Intelligence 1986;10:251-63.

130. Forsyth JS, Dimodugno MK. Willatts PW. LCP and cognitive function in the first months of life (abstract). Infant Nutrition in the prevention of chronic pathology, III International Symposium, Alicante, Spain, 1995:39. 


\section{Summary}

The long-chain polyunsaturated fatty acids (LCPs: essential fatty acids (EFAs) with 20 or more carbon atoms and at least 3 double bonds) docosahexaenoic acid (cervonic acid, $22: 6 n-3)$ and arachidonic acid (20:4n-6) are the predominant structural fatty acids in the human brain and retina. An adequate supply of these LCPs during the period of their most rapid accumulation (the last months of gestation and the first months of postnatal life) is believed to be of major importance for appropriate growth and development of these organs. In addition, 20:4n-6, dihomo- $\gamma$-linolenic acid (20:3n-6) and eicosapentaenoic acid $(20: 5 n-3)$ are precursors of prostaglandins and other eicosanoids, which have important bioregulatory functions. Preterm infants undergo 3rd trimester growth and development extrauterinely and are deprived of the substantial accretion of fat, including $n-6$ and $n-3$ LCPs, during late pregnancy. The studies described in this thesis were designed to extend the existing knowledge on the biochemical LCP status of preterm infants and on how this status is influenced by the supply of EFAs, and LCPS in particular, during intrauterine and early postnatal life. In addition, some methodological aspects were considered.

First, the EFA status at birth of 43 preterm infants was compared with that of 43 infants carried to term (Chapter 2). To obtain an indication of the fetal EFA status over a longer period of time, the EFA composition of umbilical vessel wall phospholipids (PLs) was studied. Generally, n-6 and n-3 LCP levels were lower, while levels of EFA deficiency markers, such as Mead acid (20:3n-9), the EFA deficiency index (20:3n-9/20:4n-6), Osbond acid $(22: 5 n-6)$, and the cervonic acid deficiency index. (CADI: $22: 5 n-6 / 22: 4 n-6$ ), were higher in preterm cords. This lower biochemical EFA status of the preterm fetus was reflected by fatty acid values in both the draining arteries and the supplying vein. Yet, $n-6$ and n-3 EFA levels in preterm cords correlated significantly and positively with gestational age (GA) at birth. which indicates that the lower preterm EFA values could merely be a reflection of a physiologically lower demand for EFAs, necessary for growth and development, of the preterm. fetus. The negative correlations found between GA and values for EFA deficiency markers suggest an increasing adequacy of the EFA supply towards term. For the preterm infants, arterial LCP levels were also found to be related to prenatal growth: significant, positive correlations between umbilical cord $n-6$ and $n-3$ LCP levels and birth weight, and between 22:6n-3 and length at birth were supported by a number of positive relations between $n-6$ and n-3 LCP levels and head circumference (HC), or length, which tended to be significant. All correlations were corrected for the confounding effect of GA at birth.

As in Chapter 2, studies on the fetal EFA or LCP status are usually based on materials collected (shortly) after delivery (umbilical plasma, red blood cells (RBCs), or cord vessel walls), but whether the EFA profile at birth accurately reflects fetal EFA values is actually unknown. To obtain some insight into this, the EFA profiles of fetal plasma samples obtained by transabdominal puncture during pregnancy $(n=86, G A: 18-39$ weeks) were studied (Chapter 3). The fetal plasma EFA profile was found to change with increasing pregnancy duration in a fatty acid specific way: the linoleic acid (18:2n-6) level increased slightly, values for 20:4n-6 decreased, while those for 22:6n-3 increased. The overall EFA status increased with advancing GA, which is in agreement with the observations in. Chapter 2. However, increasing values for the markers of a specific $22: 6 n-3$ shortage $(22: 5 n-6$ and 
CADI) and the decreasing value for the cervonic acid sufficiency index (CASI: 22:6n-3/22:5n6) indicated that the functional $22: 6 n-3$ status declined. This may suggest that the increased availability of $22: 6 n-3$ (fetal plasma 22:6n-3 values increased) is still insufficient to cover the high fetal 22:6n-3 demand associated with rapid (neural) tissue growth and development during late gestation. Compared with plasma samples $(n=51)$, that were collected from the umbilical cord immediately after birth at similar GAs (28-39 weeks), EFA levels in the fetal samples were alike or slightly lower (18:2n-6, $\Sigma n-6$ EFAs). This observation supports the assumption that the relatively low EFA status of preterm infants at birth (Chapter 2) is developmentally related. Besides, it indicates that the plasma EFA status measured after delivery is a reasonably adequate reflection of the actual fetal plasma EFA status.

Although higher than that of preterm newborns (Chapter 2), the EFA status of term infants born after an uneventful, singleton pregnancy may still be considered marginal because of the high 20:3n-9 levels that are present in their umbilical artery vessel walls. If this low EFA status is caused by a limiting maternal EFA supply, the higher total fetal EFA demand associated with a multiple pregnancy would result in an even lower infant EFA status. Hence, we compared the EFA status at birth of 30 pairs of twins, 7 sets of triplets, and I set of quintuplets with that of 94 infants ( 51 preterm, 43 term) born after a singleton pregnancy (Chapter 4). Again, PL-associated EFA profiles of the umbilical vessel walls were studied. At similar GAs, arterial and venous levels of $n-6$ and $n-3$ EFAs were generally lower, while those of EFA=deficiency indicating $n-9$ polyunsaturated fatty acids (PUFAS) were significantly higher for infants born after a multiple pregnancy. The EFA profiles of twins and triplets were comparable, but the average EFA status of the set of quintuplets was lower than that of iwins and iriplets. All in all, the observation of a lower EFA status of infants born after a multiple pregnancy supports the view that the maternal EFA supply to the fetus is limiting. Considering the importance of particularly LCPs for proper growth (Chapter 2) and development, this finding warrants further studies of the adequacy of the maternal EFA intake during pregnancy in general. Moreover, multiple pregnancy is a major cause of preterm delivery which is also associated with a lower EFA status. Considering the added effect of a lower EFA and LCP status as a result of multiple pregnancy, the adequacy of the EFA and LCP status of preierm twins and triplets may be a subject of particular concern.

Effects of the pre- and postnatal LCP supplies on the postnatal LCP status of preterm infants were studied in plasma and RBC PLs of blood samples collected at regular intervals after birth (Chapters 6 to 8 ). To reduce the burden placed on the participating infants, the required blood samples were to be collected in conjunction with venous or capillary diagnostic punctures. The comparability of the fatty acid profiles of plasma and of RBC PLS isolated from both types of blood is described in Chapter 5. In addition, the effects of storage at $-20{ }^{\circ} \mathrm{C}$ for a maximum of 4 weeks were evaluated, since all blood samples of a preterm infant were to be analyzed simultaneously to ensure uniformity of analytic conditions. For ethical reasons, this study was not performed in young infants but in 8 healthy adult volunteers. Plasma fatty acid profiles from venous and capillary blood were comparable and not affected by up to 4 weeks of storage. RBC fatty acid concentrations from venous and capillary blood were comparable after up to 1 week of storage before lipid extraction. However after 4 weeks of storage, the total amount of PL-associated fatty acids in capillary RBCs, was decreased to half the initial value. This decline was mainly caused by 
a decrease of almost $90 \%$ in the concentration of PUFAs and was not observed in venous RBCs. Consequently, highly significant differences developed between the fatty acid profiles of venous and capillary RBCs. Loss of membrane structural integrity may have added to the higher susceptibility to lipid loss of RBCs collected by capillary puncture. The iron-induced oxidation of PUFAs can possibly be prevented by preparing RBC ghosts or lipid extracts from the capillary RBCs within 1 week after blood sampling, or by adding an iron-chelating agent, preferably desferrioxamine, during handling and storage of the RBCs.

Preterm infants are dependent on their own dietary EFA supply to handle the demands associated with the rapid brain and body growth which normally takes place during the last trimester of pregnancy. The two enteral dietary EFA sources available to newborn infants are human milk, which contains small but significant amounts of 22:6n-3,20:4n-6 and other LCPS, or commercially available artificial formulas, which did not contain LCPs when the studies described in this thesis were initiated. Considering the facts that preterm infants have very limited fatty acid stores and are born with a lower LCP status than infants carried to term (Chapter 2), feeding preterm newborns on an artificial formula will potentially threaten their postnatal LCP status. Indeed, when the LCP' status of 12 human milk-fed preterm infants (birth weight $<1800 \mathrm{~g}$ ) was compared with that of 27 formula-fed infants during the first 4 weeks of life (Chapter 6), a number of significant differences were observed. After 21 to 28 days, absolute (mg/l) and relative ( $\%$ (wt/wt) of total fatty acids) $22: 6 n-3$ values and the absolute 20:4n-6 amount had become substantially lower in the plasma PLs of the formula-fed infants. Effects on the 22:6n-3 status were supported by the a higher value for the CADI in the formula group. In RBC PLS, the postnatal decreases of 22:6n-3 and 20:4n-6 in the formula group were approximately twice those in the human milk-fed group, but these differences did not reach significance. The slower turnover rate of RBC PLS than of plasma. PLs may have contributed to the less distinct nutritional effects on these cells over a relatively short period of time. Apparently, the presence of the parent EFAs $18: 2 n-6$ and $\alpha$-linolenic acid $(18: 3 n-3)$ in the formulas was unable to fully compensate for the absence of LCPS, which may be related to the limited desaturase capacity of preterm newborns. Therefore, for formula-fed infants to achieve postnatal plasma LCP values at least similar to those found in infants fed on human milk, both $n-3$ and $n-6$ LCPs should be added to preterm infant formulas. Another main finding of this study (and that of Chapter 8) was that, in plasma PLs, the changes with time after birth were markedly different when fatty acid values were expressed as absolute or as relative values, which illustrates the additional importance of measuring absolute fatty acid amounts. However, analytical procedures need to be standardized to enable effective comparison of results from various research groups.

After having found a substantial effect of the postnatal LCP supply on the biochemical postnatal LCP status of preterm infants (Chapter 6), the influence of the intrauterine LCP supply on postnatal LCP values was assessed in 28 preterm infants (average GA at birth: 32 weeks; Chapter 7). Such an influence could be of importance, considering the widely divergent LCP levels with which infants are born (Chapters 2, 4 and 6). The LCP status at birth (measured in the umbilical artery wall PLs, and in umbilical plasma or RBC PLs) which results from the prenatal LCP supply, and the postnatal diet (human milk or conventional artificial formula), representing the postnatal LCP supply, were related to the LCP status measured in plasma or RBC PLS collected from the preterm infants in the period during 
which they were actually due to be born (37-42 weeks GA). Indeed, the biochemical LCP status some 2 months after preterm birth was determined not only by the postnatal diet, but also by the LCP status at birth: a higher plasma 20:4n-6 concentration at birth resulted in a higher plasma 20:4n-6 concentration 'at term', and higher 22:6n-3 and 20:4n-6 values in the walls of the umbilical arteries lead to higher postnatal RBC 22:6n-3 and 20:4n-6 contents. These findings stress the significance of an appropriate prenatal LCP supply (a major determinant of the LCP status at birth), particularly for infants who are born preterm, or after a multiple pregnancy, or both. Since this prenatal LCP supply can only be changed by adapting the maternal fatty acid intake, these results warrant further studies of the effects of EFA-enriched maternal diets during pregnancy on the infant LCP status at birth. Besides in the study of Chapter 7, the exploration of the relations among EFA status, GA, and growth parameters at birth (Chapter 2) was extended by also studying LCP levels in umbilical plasma and RBC PLs. However, after correction for GA at birth, significant relations were only observed between anthropometric measurements at birth (weight, HC, and length) and LCP levels in the umbilical artery wall. Perhaps the fact that LCP levels in umbilical plasma and RBC PLs are relatively short-term indicators of the fetal LCP status, renders their correlation with measures of a long-term process like fetal growth likely to be less distinct.

The results of a randomized controlled intervention study of the effects on the LCP status of supplying formula-fed preterm infants (birth weight $<1800 \mathrm{~g}$ ) with an artificial formula containing both $22: 6 n-3(0.3 \%)$ and $20: 4 n-6(0.6 \%)$ in levels present in human milk were described in Chapter 8. Blood LCP levels of 15 infants fed on the LCP-enriched study formula were compared with those of 16 infants receiving a conventional formula (lacking LCPS), and with those of 12 preterm infants raised on human milk. Weekly postnatal blood samples were collected until the 35th day of life and, for the formula-fed infants, at 3 months after their initial term date ( 3 months of corrected age). After 4 weeks of postnatal life, the plasma and RBC PL 22:6n-3 and 20:4n-6 levels in preterm infants fed on the LCPenriched preterm formula were significantly higher than those in infants which had received a conventional formula, and were comparable to those of preterm infants raised on their own mother's milk. The differences between the two formula groups continued to increase, resulting in average plasma $22: 6 n-3$ and 20:4n-6 values that were up to 4 and 2 times higher, respectively, in the LCP-enriched formula group at 3 months of corrected age. Both in plasma and RBC PLS, inter-group differences found for the $22: 6 n-3$ status were also reflecied by the two indices of the functional $22: 6 n-3$ status: CADI values were significantly lower in the infants fed on LCP-enriched formulas, while CASI values were higher. The results of this relatively long-term study show that feeding preterm infants on artificial formulas enriched with both 22:6n-3 and 20:4n-6 in balanced ratios, i.e. in amounts found in preterm human milk, is a successful approach to raising both the $22: 6 n-3$ and $20: 4 n-6$ status of preterm formula-fed infants to values found in blood PLs of preterm infants fed on human milk. Additional studies are necessary to evaluate the potentially favourable effects of this combined addition on the (neuro)developmental outcome of preterm infants.

In Chapter 9, the major findings of the above-mentioned studies and their implications for current views and future research are discussed. In particular, the purpose of supplementing the maternal, fetal and infant diet with $n-6$ and n-3 EFAs, and the importance of adding clinical and functional outcomes to the biochemical data are considered. 


\section{Samenvatting}

Het centrale zenuwstelsel (CZS) van de mens is rijk aan zogenaamde langketenige meervoudig onverzadigde vetzuren ('long-chain polyunsaturated fatty acids*', LCPs). Dit zijn voor het lichaam essentiële vetzuren ('essential fatty acids', EFAs) met een ketenlengte van 20 koolstofatomen of meer en tenminste 3 onverzadigde bindingen. De belangrijkste bouwstenen van de celmembranen van het czs zijn de LCPs docosahexaeenzuur (cervonzuur, 22:6n-3) en arachidonzuur (20:4n-6). Met name tijdens de laatste maanden van de zwangerschap en de eerste maanden na de geboorte neemt het czs zeer snel in omvang toe, en een toereikende aanvoer van 22:6n-3 en 20:4n-6 in die periode wordt geacht van groot belang te zijn voor een ongestoorde groei en ontwikkeling van dit orgaan. Daarnaast dienen 20:4n-6, dihomo- $\gamma$-linoleenzuur (20:3n-6) en cicosapentaeenzuur (20:5n-3) als substraat voor de vorming van prostaglandines en andere eicosanoiden, die belangrijke regulerende taken hebben. Te vroeggeboren kinderen maken de bij het laatste trimester van de zwangerschap horende groei en ontwikkeling buiten de baarmoeder door; zij zijn derhalve verstoken van de belangrijke opslag van vetten, waaronder $n-6$ en $n-3$ LCPs, die normaal aan het einde van de zwangerschap plaatsvindt. Het in dit proefschrift beschreven onderzoek had tot doel de reeds aanwezige kennis van de biochemische LCP status van premature zuigelingen uit te breiden dan wel te verdiepen. Hierbij werd met name bestudeerd hoe deze status wordt beïnvloed door de voorziening van EFAs, en met name van LCPs, tijdens het intra-uteriene en vroeg-postnatale leven. Ook werden een aantal methodologische aspecten onderzocht.

Ten eerste werd de EFA status bij de geboorte van 43 premature zuigelingen vergeleken met die van eenzelfde aantal voldragen kinderen (Hoofdstuk 2). Hierbij werd de EFA samenstelling van de fosfolipiden (FLS) in de navelstrengvaatwanden beoordeeld, omdat die een indruk geeft van de foetale EFA status over een langere termijn. Over het algemeen waren de gehaltes aan EFAs van de $n-6$ en $n-3$ families lager en de gehaltes aan EFA deficiëntie-indicatoren [waaronder Meadzuur (20:3n-9), de EFA deficiëntie index (20:3n-9/20:4n6), Osbondzuur (22:5n-6), en de cervonzuur deficiëntie index (CADI: 22:5n-6/22:4n-6)] hoger in de navelstrengen van premature kinderen. Deze lagere biochemische EFA status van de premature foetus werd weerspiegeld in de vetzuurgehaltes van zowel de afvoerende navelstrengarteriën als de aanvoerende -vene. De gehaltes aan n-6 en n-3 EFAs bleken echter positief gecorreleerd te zijn met de zwangerschapsduur ten tijde van de geboorte. Dit zou erop kunnen duiden dat de lagere EFA waarden zoals gemeten bij het te vroeggeboren kind slechts een afspiegeling zijn van een fysiologisch lagere behoefte aan EFAs van de premature foetus, wiens CZS en lichaam zich nog in een relatief vroege fase van groei en ontwikkeling bevinden. De negatieve correlaties die werden gevonden tussen de zwangerschapsduur en de gehaltes aan EFA deficiëntie-indicatoren geven aan dat, naarmate de zwangerschap vordert, de EFA aanvoer steeds beter in de aanwezige behoefte voorziet. Arteriële LCP gehaltes van premature pasgeborenen bleken ook nauw samen te hangen met de foetale groei: significante, positieve correlaties werden gevonden tussen $n-6$ en $n-3$ LCP waardon en het geboortegewicht, en tussen 22:6n-3 en de geboortelengte. Daarnaast werden een aantal nagenoeg significante, positieve correlaties gevonden tussen n-6 en n-3 LCP gehaltes enerzijds en schedelomtrek en lengte bij de geboorte anderzijds. Al deze correlaties werden gecorrigeerd voor de invloed van de zwangerschapsduur bij de geboorte. 
Zoals ook in Hoofdstuk 2, wordt bij onderzoek naar de foetale EFA of LCP status doorgaans gebruik gemaakt van materialen die (kort) na de geboorte worden verzameld (navelstrengplasma, -erytrocyten ('red blood cells', RBCs), of -vaatwanden). Het is echter onbekend of de EFA samenstelling bij de geboorte een juiste afspiegeling is van foetale EFA gehaltes. Om hier enig inzicht in te krijgen, werd de. EFA samenstelling van plasma uit foetaal bloed dat via een transabdominale punctie tijdens de zwangerschap werd afgenomen ( $n=86$, zwangerschapsduur: 18-39 weken) bestudeerd (Hoofdstuk 3). Naarmate de zwangerschap vorderde, veranderden de gehaltes van de diverse EFAs in foetale plasma FLs op verschillende manieren: linolzuur (18:2n-6) vertoonde een geringe stijging, het 20:4n-6 gehalte nam af, dat van 22:6n-3 nam toe. De algehele EFA status steeg bij een toenemende zwangerschapsduur, hetgeen overeenkomt met de bevindingen in Hoofdstuk 2. De stijgende waarden voor de indicatoren van een specifiek tekort aan 22:6n-3 (22:5n-6, CADI) en de daling van de waarde voor de cervonzuur 'sufficiëntie' index (CASI: 22:6n-3/22:5n-6) duidden echter op een vermindering van de functionele 22:6n-3 status. Wellicht is de verhoogde beschikbaarheid van $22: 6 n-3$ (foetale $22: 6 n-3$ plasmawaarden stegen met toenemende zwangerschapsduur) nog steeds onvoldoende om te voorzien in de, door de snelle weefselgroei en -ontwikkeling, grote foetale behoefte aan dit vetzuur tijdens de laatste maanden van de zwangerschap. Wanneer de foetale plasmamonsters werden vergeleken met plasmamonsters uit bloed dat, bij de geboorte uit de navelstreng was afgenomen ( $\mathrm{n}=51$, zwangerschapsduur: 28-39 weken), bleek dat, op hetzelfde moment in de zwangerschap, de EFA gehaltes in het foetale plasma hetzelfde of enigszins lager (18:2n-6, $\Sigma n-6$ EFAs) waren. Deze bevinding ondersteunt onze veronderstelling dat de relatief lage EFA status van premature pasgeborenen (Hoofdstuk 2) een fysiologisch verschijnsel is dat samenhangt met hun vroegere ontwikkelingsfase. Daarnaast blijkt hieruit dat de EFA status zoals gemeten in na de geboorte afgenomen navelstrengplasma cen redelijk betrouwbare weergave is van de EFA status in foetaal plasma.

Hoewel de EFA status van gezonde, voldragen kinderen hoger is dan die van te vroeggeboren zuigelingen (Hoofdstuk 2), zouden hun EFA waarden nog steeds als 'krap' beschouwd kunnen worden, met name vanwege de aanzienlijke 20:3n-9 gehaites (EFA deficiëntie-indicator) in de wanden van de navelstrengarteriën. Indien deze krappe EFA. gehaltes het gevolg zijn van een beperkende EFA voorziening door de moeder, dan zou de hogere gezamenlijke foetale EFA behoefte bij een meerlingzwangerschap tot nog lagere EFA waarden bij de kinderen moeten leiden. Of dit inderdaad het geval was, werd onderzocht (Hoofdstuk 4) door de EFA status bij de geboorte van 30 tweelingen, 7 drielingen, en 1 vijfling te vergelijken met die van 94 eenlingen ( 51 prematuur, 43 voldragen). Net zoals in Hoofdstuk 2, werd de EFA samenstelling van de FLs in de wanden van de navelstrengvaten beoordeeld. Bij eenzelfde zwangerschapsduur bevatten de navelstrengarteriën en -vene van meerlingen over het algemeen significant lagere EFA gehaltes en significant hogere waarden voor de op een EFA-deficiëntie wijzende $n-9$ meervoudig onverzadigde vetzuren ('polyunsaturated fatty acids', PUFAs). Twee- en drielingen hadden een vergelijkbare EFA status, mar de gemiddelde EFA status van de vijfling was beduidend lager dan die van de andere meerlingen. Alles in ogenschouw nemend, lijken deze bevindingen er inderdaad op te duiden dat een beperkende moederlijke EFA voorziening aan de zich ontwikkelende foetus een oorzaak voor de krappe EFA status van pasgeborenen is. Aangezien EFAs, en LCPS in het 
bijzonder, worden geacht van groot belang zijn voor een goede groei (Hoofdstuk 2) en ontwikkeling, geven deze resultaten aanleiding tot meer en uitgebreider onderzoek naar de kwaliteit van de moederlijke inneming van EFAs tijdens zwangerschap in het algemeen. Een meerlingzwangerschap resulteert bovendien vaker dan een eenlingzwangerschap in een premature geboorte, die ook gepaard gaat met een lagere EFA status (Hoofdstuk 2). De als het ware 'dubbel-verlaagde' EFA en LCP status van premature meerlingen verdient derhalve bijzondere aandacht.

De invloed van de pre- en postnatale LCP voorziening op de postnatale LCP status van premature zuigelingen (geboortegewicht $<1800 \mathrm{~g}$ ) werd bestudeerd in de plasma en RBC FLs van bloedmonsters die na de geboorte wekelijks werden afgenomen (Hoofdstuk 6 tot en met 8 ). Om de participerende zuigelingen zo min mogelijk te belasten, werd de afname van de benodigde bloedmonsters steeds gecombineerd met veneuze, dan wel capillaire diagnostische puncties. In Hoofdstuk 5 wordt de vergelijkbaarheid van de vetzuursamenstelling van de FL-fractie van veneus en capillair plasma en van veneuze en capillaire RBCs beschreven. Hierbij werd ook de invloed van een bewaartijd van maximaal 4 weken bij $-20^{\circ} \mathrm{C}$ onderzocht, aangezien alle bloedmonsters van een premature proefpersoon tegelijk, en dus onder dezelfde omstandigheden, geanalyseerd dienden te worden. Om ethische redenen werd dit onderzoek niet gedaan bij (premature) zuigelingen, maar bij 8 gezonde volwassen vrijwilligers. De vetzuurprofielen van plasma van veneuze en capillaire origine bleken goed overeen te komen en niet te worden beïnvloed door een bewaarperiode van 4 weken. De vetzuurprofielen van RBCs afkomstig uit veneus en capillair bloed waren vergelijkbaar indien de vetextractie op de dag van bloedafname of 1 week daarna werd verricht. Echter, na 4 weken bewaren was de totale hoeveelheid vetzuren in capillaire RBCs gedaald tot de helft van de uitgangswaarde. Deze daling was grotendeels het gevolg van een vermindering van de absolute hoeveelheid PUFAs met $90 \%$, en werd niet waargenomen voor de RBCs van veneuze oorsprong. Dientengevolge ontstonden er aanzienlijke verschillen tussen de vetzuurprofielen van veneuze en capillaire RBCs. De grotere gevoeligheid voor vetzuurverliezen van RBCs die via een capillaire punctie zijn verkregen, zou hel gevolg kunnen zijn van een verstoring van de structurele integriteit van hun membranen door de bloedafname. De met ijzer als katalysator optredende oxydatie van PUFAs kan wellicht voorkomen worden door binnen 1 week na hun afname het hemoglobine uit de capillaire RBCs te verwijderen, dan wel door hun lipiden te extraheren, ò door een ijzer-chelator, liefst desferrioxamine, tijdens de bewerkings- en bewaarfase aan de RBCs toe te voegen.

Premature pasgeborenen zijn aangewezen op hun eigen voeding om te voorzien in de grote EFA-behoefte die het gevolg is van de snelle groei van het CZS, die normaal gesproken tijdens de laatste 3 maanden van het intra-uteriene leven plaatsvindt. De twee soorten enterale voeding die geschikt zijn voor zuigelingen zijn enerzijds moedermelk, die geringe. hoeveelheden 22:6n-3, 20:4n-6 en andere LCPS bevat, en anderzijds de kunstmatige zuigelingenvoedingen ('flesvoeding'), waarvan het merendeel (nagenoeg) geen LCPs bevatte toen het onderzoek zoals beschreven in dit proefschrift werd gestart. Prematuur geboren zuigelingen hebben zeer beperkte vetvoorraden en komen bovendien met een lagere LCP status ter wereld dan voldragen kinderen (Hoofdstuk 2). Het geven van flesvoeding aan premature pasgeborenen zou derhalve bij deze kinderen tot relatief lage LCP gehaltes kunnen leiden. Om deze hypothese te toetsen werd, gedurende de eerste vier levensweken, de LCP status 
van 12 met moedermelk gevoede prematuren vergeleken met die van 27 flesgevoede kinderen (Hoofdstuk 6). Hierbij werden een aantal significante verschillen gevonden tussen beide groepen: na 21 tot 28 dagen waren de absolute $(\mathrm{mg} / \mathrm{l})$ en relatieve (gewichts \% van totaal vetzuur) 22:6n-3 waarden en het absolute 20:4n-6 gehalte aanzienlijk lager in de plasma FLs van de flesgevoede kinderen dan in die van de moedermelk-groep. De invloed op de 22:6n-3 status bleek ook uit een hogere CADI-waarde in de flesvoeding-groep. In de RBC FLs was de daling van de 22:6n-3 en 20:4n-6 gehaltes in de flesvoeding-groep ongeveer tweemaal zo groot als in de moedermelk-groep, maar deze verschillen waren niet significant. De, op korte termijn, minder uitgesproken verschillen in de RBC FLs zouden het gevolg kunnen zijn van hun, vergeleken met plasma FLs, lagere vervangingssnelheid. Blijkbaar kunnen de zogenaamde 'moeder-EFAs' 18:2n-6 en $\alpha$-linoleenzuur (18:3n-3), die wel in de flesvoeding aanwezig zijn, het ontbreken van de LCPs niet voliedig compenseren; door hun nog niet volledig ontwikkeld enzymsysteem zijn de premature zuigelingen onvoldoende in staat om 18:2n-6 en 18:3n-3 zelf om te zetten in, respectievelijk, 20:4n-6 en 22:6n-3. Om de postnatale LCP status van flesgevoede prematuren op het niveau van de status van met moedermelk gevoede premature zuigelingen te brengen, zullen derhalve $n-3$ en $n-6$ LCPS aan de premature zuigelingenvoeding moeten worden toegevoegd. Een andere belangrijke bevinding van dit onderzoek (en dat van Hoofdstuk 8 ) was dat het postnatale vetzuurverloop in plasma FLs opvallend anders was, afhankelijk van of de vetzuurwaarden als mg/l (absoluut) of percentueel (relatief) werden uitgedrukt. De (doorgaans niet gepresenteerde) absolute vetzuurwaarden kunnen dus aanvullende informatie geven. De analytische methodieken van de diverse onderzoeksgroepen in de wereld dienen echter op elkaar afgestemd te worden om tot een zinvolle vergelijking van elkaars resultaten te kunnen komen.

Nadat de postnatale LCP voorziening duidelijk van invloed was gebleken op de biochemische postnatale LCP status van premature zuigelingen (Hoofdstuk 6), werd de invloed van de intra-uteriene LCP aanvoer op postnatale LCP waarden onderzocht in 28 premature kinderen (gemiddelde zwangerschapsduur; 32 weken; Hoofdstuk 7). Aangezien kinderen met zeer uiteenlopende LCP gehaltes ter wereld komen (Hoofdstuk 2, 4 en 6), kan een dergelijke invloed van groot belang zijn. Derhalve werd de LCP status bij de geboorte (gemeten in de fls van de arteriële navelstrengvaatwand en van navelstrengplasma of RBCS) die wordt bepaald door de LCP voorziening tijdens de zwangerschap, gerelateerd aan de LCP status die werd gemeten in plasma of RBC FLs uit bloed dat bij de premature kinderen was afgenomen in hun oorspronkelijke 'à terme periode' (37-42. weken zwangerschapsduur). Hierbij werd ook rekening gehouden met de enterale voeding (moedermelk of flesvoeding) als vertegenwoordiger van de LCP voorziening na de geboorte. Uit de resultaten van dit onderzoek bleek duidelijk dat de biochemische LCP status, in ieder geval tot 2 maanden na een premature geboorte, wordt bepaald door zowel de postnatale enterale voeding als de LCP status bij de geboorte: een hogere 20:4n-6 concentratie in navelstrengplasma resulteerde in een hogere 20:4n-6 plasmaconcentratie in de à terme periode, en hogere 22:6n-3 en 20:4n-6 gehaltes in de arteriële navelstrengvaatwanden gingen gepaard met hogere 22:6n-3 en 20:4n-6 RBC-gehaltes in de à terme periode. Deze bevindingen onderstrepen het belang van een toereikende LCP voorziening tijdens het intra-uteriene leven, met name wanneer er sprake is van een premature geboorte, een meerlingzwangerschap, of beiden. Aangezien deze prenatale LCP aanvoer alleen veranderd kan worden door de vetzuurinneming van de 
zwangere vrouw aan te passen, dient nader onderzocht te worden welke invloed een met EFAs verrijkte voeding tijdens de zwangerschap op de LCP status van het kind heeft. Bij het onderzoek van Hoofdstuk 7 werd tevens de studie van Hoofdstuk 2 naar de relaties tussen de EFA status, de zwangerschapsduur, en groeiparameters bij de geboorte verder uitgebreid door ook de LCP gehaltes in navelstrengplasma en -RBC F.s hierbij te betrekken. Na. correctie voor de zwangerschapsduur bij de geboorte bleken gewicht, schedelomtrek en lengte bij de geboorte echter alleen samen te hangen met LCP waarden in de wand van de navelstrengarteriën. Wellicht vertonen de LCP-gehaltes in navelstrengbloed geen duidelijke relatie met een langdurig proces als groei, omdat zij een indruk geven van de foetale LCP status op de kortere termijn.

Tenslotte werd via een dubbelblind gerandomiseerd onderzoek bestudeerd hoe het geven. van een met LCPS verrijkte flesvoeding de postnatale LCP status van te vroeggeboren kinderen beìnvloedt (Hoofdstuk 8). De verrijkte flesvoeding bevatte zowel 22:6n-3 (0.3\%) als $20: 4 n-6(0.6 \%)$ in hoeveelheden zoals die ook aanwezig zijn in premature moedermelk. De LCP gehaltes in het bloed van 15 kinderen die de met LCPs verrijkte flesvoeding kregen, werden vergeleken met die van 16. kinderen die een standaardflesvoeding (zonder LCPs) kregen, en met die van 12 met moedermelk gevoede prematuren. Tot en met de 35 ste levensdag werd wekelijks een bloedmonster afgenomen en van de flesgevoede zuigelingen werd ook een monster verzameld 3 maanden na hun aanvankelijke à terme datum. $\mathrm{Na} 4$ weken waren de 22:6n-3 en 20:4n-6 gehaltes in plasma en RBC FLs significant hoger in de met LCP-verrijkte flesvoeding gevoede groep dan in de met standaardflesvoeding gevoede kinderen. Bovendien waren de bloedwaarden van de verrijkte flesvoedinggroep vergelijkbaar met die van de prematuren die moedermelk hadden gedronken. De verschillen tussen de twee flesvoedinggroepen namen steeds verder toe "hetgeen 3 maanden na de à terme datum resulteerde in respectievelijk 4 en 2 maal zo hoge gemiddelde plasmawaarden voor 22:6n-3 en 20:4n-6 in de verrijkte flesvoedinggroep. Zowel in de plasma als in de RBCs, bleken de verschillen in 22:6n-3 status ook uit de twee indicatoren van de functionele 22:6n-3 status: CADI waarden waren. significant lager en CASI waarden significant hoger in de met LCPS verrijkte flesvoedinggroep. De bevindingen van deze relatief langdurige interventie-studie geven aan dat het toevoegen aan premature zuigelingenvoeding van $22: 6 n$ 3 en 20:4n-6 in een uitgebalanceerde verhouding, i.e. in gehaltes zoals aanwezig in premature moedermelk, een geschikte manier is om zowel de 22:6n-3 als de 20:4n-6 status van premature flesgevoede zuigelingen te verhogen tot in het bloed van met moedermelk gevoede prematuren gemeten waarden. De mogelijk gunstige gevolgen van deze gecombineerde LCP-toevoeging voor de algehele ontwikkeling van te vroeggeboren kinderen en die van hun CZS in het bijzonder, zullen in aanvullende studies nader moeten worden onderzocht.

De belangrijkste bevindingen van bovengenoemde studies en hun betekenis voor de huidige inzichten en toekomstig onderzoek worden besproken in Hoofdstuk 9. Hierbij wordt in het bijzonder aandacht besteed aan het potentiële nut van een met $n-6$ en $n-3$ EFAs verrijkte voeding voor zwangere vrouwen, foetussen en zuigelingen, alsmede aan het grote belang van het bepalen van de klinische en functionele relevantie van de biochemische resultaten. 



\section{Met dank aan...}

Alle premature zuigelingen en hun ouders, die in een voor hun vaak toch spannende en verwarrende tijd hun medewerking aan onderzoek wilden verlenen.

Gerard Hornstra, mijn eerste promotor. Ik heb altijd gevonden dat jij met recht mijn ecrste promotor zou zijn. Omdat jouw benoeming tot hoogleraar even op zich liet wachten, kon ik. niet anders dan de voltooiing van mijn proefschrift via 'twee kinderen ertussendoor' uitstellen. Ik heb heel veel van je geleerd en zal jouw mening altijd respecteren!

Prof. Blanco, mijn tweede promotor. Naarmate mijn onderzoek vorderde, nam uw belangstelling ervoer toe; dat was heel plezierig om te ervaren.

Tom Hasaart, mijn co-promotor. Ik heb je blijken van belangstelling voor wel en niet onderzoeksgerelateerde 'grote gebeurtenissen' in mijn leven zeer op prijs gesteld,

Rian van Houwelingen. Jij droeg zorg voor de dagelijkse begeleiding in al haar facetten. Een veelomvattende en dus moeilijke taak, die niet moet worden onderschat. Ik vind het fijn dat je oog had voor de mens achter de onderzoeker.

Prof. ten Hoor, mijn 'eerste eerste' promotor,

Thank you Prof. dr. G.J. van der Vusse, Prof. dr. S.E. Carlson, Prof. dr. M.P. van DieijenVisser, Prof. dr. H.N. Lafeber, and Prof. dr. J. Troost for your critical evaluation of this thesis. Prof. Carlson, it is very special to me that the author of the first paper I read on long-chain polyunsaturated fatty acids in preterm infants, has now reviewed my owni work.

Joke Westdorp. Jouw bijdrage aan de totstandkoming van dit proefschrift is wellicht groter dan je zelf denkt. Ik. heb altijd het gevoel gehad dat je het beste met mij voorhad en dat waardeer ik nog steeds.

Marie-Josée Slangen van het Kinderlab van het Academisch Ziekenhuis Maastricht. Een hele dikke dank-je-wel voor je fantastische inzet en prachtige capillaire bloedmonsters. Uiteraard ook dank aan alle anderen die bloed voor mijn onderzoek hebben afgenomen.

Alle verpleegkundigen van de afdelingen Neonatologie van het AZM (o.I.v. Janine Mouthaan), de Vroedvrouwenschool/het St. Jozefziekenhuis in Kerkrade (o.I.v. Miriam Staassen) en het de Weverziekenhuis in Heerlen (o.l.v. Peter Willems). Zonder al die voedingslijsten, moedermelkmonsters en 'voedingen-uit-de-flesjes-met-het-juiste-nummer' die jullie hebben verzorgd had ik nu geen dankwoord kunnen schrijven. Bedankt dat ik welkom was met mijn onderzoek.

Gera Opdam-van den Bergh, die garant stond voor een tijdige aanlevering van de 'voeding-uit-flesjes-met-nummer'.

De neonatologen, kinderartsen en arts-assistenten van het AZM (m.n. Madelon Ruige en Danillo Gavilanes), het St. Jozefziekenhuis (m.n. Dr. da Costa) en het de Weverziekenhuis (m.n. Dr. Wijnands), die zich voor de prematurenstudies hebben ingezet.

De hoofden van de verloskamers van het AZM (Claire Petillo), de Vroedvrouwenschool (Cara Simons) en het de Weverziekenhuis (Margriet van Hasselt), en alle verpleegkundigen, co-assistenten, verloskundigen (in opleiding), arts-assistenten en gynaecologen die (prematuur) partusmateriaal hebben verzorgd. Dr. Roumen (Vroedvrouwenschool) en Dr. Heineman (de Weverziekenhuis), dank voor de bereidheid tot samenwerking.

Agnès Gerritsen van de Vroedvrouwenschool. (Is je naam nu wel goed geschreven?)

Huub Nievelstein en Dr. Henk Hoogland en Kees Ruissen, die door hun begeleiding 
tijdens wetenschapsstages mij als studente plezier in het doen van onderzoek hebben bezorgd. Zonder die ervaring was ik wellicht nooit aan dit proefschrift. was begonnen.

Marianne Simonis, Hasibe Aydeniz en Threa Cremers. Ik zou ze niet kunnen tellen, al die. bloed- en navelstrengmonsters die jullie tijdens reguliere en helemaal-niet-zo-reguliere werkuren hebben verwerkt.

André de Jong en Taco van den Berg van het ABL in Assen.

Renée Vossen en Netty Hornstra, voor het meedraaien binnen de partusmaterialen-pendeldienst.

Mehnaz Bergers, voor haar loyale bibliothecaire ondersteuning.

Annemieke van der Zijden, Quila Schlundt Bodien en Evelijn Zeijdner, die tijdens hun afstudeerprojecten met groot enthousiasme en liefde-voor-het-vak binnen de prematurenstudies werkzaam zijn geweest. Ook dank aan de andere studenten, in het bijzonder Suzie Otto en Laury de Jonge, die bij het 'perinat-project in ruime zin' betrokken zijn geweest.

Arnold Kester, 'onze' statisticus. De hogeschool-statistiek die jij adviseerde werd steeds ingewikkelder; een prima stimulans dus om er een eind aan te breien voordat ik het echt niet: meer kon volgen.

Jan Talmon, designer en implementor van het vetzuurwaardeninterpolatieprogramma.

Riëtte van Elburg, kamergenote in het BMC. Ik hoop vooral voor jou dat het vaak goed weer zal zijn.

Monique Al en Anita Badart, mijn (ex-)kamergenoten, paranimfen en vriendinnen. Eén van de allermooiste kanten aan mijn promotie-onderzoek is ongetwijfeld dat ik jullie daardoor heb leren kennen. Ik zou willen dat Voorburg, Geulle en Eindhoven wat dichter bij elkaar lagen.

Pap en mam, mijn ouders. Dertig jaar zorgen voor en zorgen om hebben onder andere geleid tot dit boek, dat met recht aan jullie opgedragen is. Niet in het laatst omdat jullie zo'n: lieve (oppas-)opa en oma zijn voor jullie 'gouwe/boef' en 'Miepie'.

Peter van Drongelen, grafisch ontwerper. Ik ben heel blij met de omslag van mijn boek en met jouw als broer.

Yuri, mijn zoon en held! Hieperdepiep... mamma's boek is nu echt af. Het is tijd voor de meneren en mevrouwen met gekke hoedjes en een groot feest. Vooral ook voor jou, want je hebt je mamma vaker dan haar lief was moeten missen. Ik ben zóóóó trots op je! (Bij deze bedank ik tevens een bekende tekenfilmfabrikant uit de. Verenigde Staten voor het significant verhogen van het aantal ongestoorde schrijfuren, via het uitbrengen van hun films op koopvideo.)

Meryl, mijn dochter. Anders dan aanvankelijk de bedoeling was, werd jij geboren nog voordat het manuscript bij de beoordelingscommissie lag. Gelukkig maar: nu hebben jouw heerlijke lach en de herinnering aan een in alle opzichten perfecte thuisbevalling de laatste loodjes heel wat lichter kunnen maken. Groei maar fijn, mooi meisje van me!

Tim, mijn lief. Als ik volledig onder woorden zou moeten brengen wat jij in de afgelopen jaren voor mij hebt betekent, dan zou ik nog een boek moeten schrijven. Ik laat dàt voorlopig maar even aan anderen over en verheug me liever op de komende vijftig jaar of zo, waarin 'tijd maken voor elkaar' eindelijk niet meer hetzelfde zal zijn als tijd maken voor elkaars proefschrift.

Alle familieleden, collega's, vrienden en bekenden, die hun belangstelling voor mijn wetenschappelijk doen-en-laten hebben getoond. Een speciale groet aan mijn oom Theo: op momenten als deze doet het me bijzonder verdriet dat u er niet meer bent.

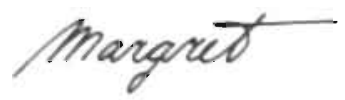




\section{Curriculum Vitae}

Margret Foreman-van Drongelen was born in Maastricht on the 30th of August 1965. After completing her secondary education (Gymnasium B) in 1983, she became a medical student at the University of Limburg in Maastricht. After graduating in August 1989 (clear pass), she joined the Department of Human Biology at the University of Limburg as a Ph.D.-student in December of the same year. The results of the research she carried out until January 1995 are for the greater part described in this thesis. She now works as a doctor at the child health centres of the 'Stichting Kruiswerk Peelland' in Helmond (from April 1995) and the 'Stichting Thuiszorg Eindhoven' (from May 1996). She is the mother of a four-year old son and a nine-month old daughter.

Margret Foreman-van Drongelen werd op 30 augustus 1965 in Maastricht geboren. Zij behaalde in 1983 het diploma Gymnasium $B$ aan het toenmalige Stedelijk Lyceum te Maastricht. In datzelfde jaar en in diezelfde stad begon zij haar studie Geneeskunde aan de Rijksuniversiteit Limburg, waarna zij in augustus 1989 het artsexamen behaalde (met genoegen). Op 1 december 1989 trad zij in dienst als assistent in opleiding bij de vakgroep Humane Biologie van de Rijksuniversiteit Limburg. De resultaten van het onderzoek dat zij hier tot januari 1995 verrichtte zijn voor het merendeel beschreven in dit proefschrift. Momenteel is zij als consultatiebureau-arts werkzaam bij de Stichting Kruiswerk Peelland te Helmond (vanaf april 1995) en de Stichting Thuiszorg Eindhoven (vanaf mei 1996). Zij is de moeder van een vierjarige zoon en een dochter van negen maanden. 


\section{Publications}

\section{Full Papers}

1. Ruissen CJ, v Drongelen MMHP, Hoogland HJ, Jager W, Hoeks APG. Characteristics of the umbilical artery velocity waveform as function of measurement site. Gynecol Obstet Invest 1990;30:212-6.

2. Ruissen $\mathrm{C}$, Jager W, v Drongelen $\mathrm{M}$, Hoogland $\mathrm{H}$. The influence of maternal exercise on the pulsatility index of the umbilical artery blood velocity waveform. Eur J Obstet Gynecol Reprod Biol 1990:37:1-6,

3. Foreman- $v$ Drongelen MMHP, Houwelingen AC v, Kester ADM, de Jong AEP, Blanco CE, Hasaart THM, Hornstra G. Long-chain polyene status of preterm infants with regard to the fatty acid composition of their diet: comparison between absolute and relative fatty acid levels in plasma and erythrocyte phospholipids. Br J Nutr 1995;73:405-22.

4. Foreman-v Drongelen MMHP, Houwelingen AC v, Kester ADM, Hasaart THM, Blanco CE, Hornstra G. Long-chain polyunsaturated fatty acids in preterm infants: status at birth and its influence on postnatal levels. J Pediatr 1995;126:611-8.

5. Foreman-y Drongelen MMHP, Al MDM, Houwelingen AC v, Blanco CE, Hornstra G. Comparison between the essential fatty acid status of preterm and full-term infants, measured in umbilical vessel walls. Early Hum Dev 1995;42:241=51.

6. Hornstra G. Al MDM, Houwelingen AC v, Foreman-v Drongelen MMHP. Essential fatty acids in pregnancy and early human development. Eur J Obstet Gynecol Reprod Biol 1995;61:57-62.

7. Foreman-v Drongelen MMHP. Zeijdner EE, Houwelingen AC v, Kester ADM, Al MDM, Hasaart THM, Hornstra G. Essential fatty acid status measured in umbilical vessel walls of infants born after a multiple pregnancy. Early Hum Dev, in press.

8. Foreman-van Drongelen MMHP, Houwelingen AC v, Kester ADM, Blanco CE, Hasaart THM, Hornstra G. Influence of feeding artificial formulas containing docosahexaenoic and arachidonic acids on the postnatal long-chain polyunsaturated fatty acid status of healthy preterm infants. $\mathrm{Br} \mathrm{J}$ Nutr, in press.

9. Hornstra G, Al MDM, Houwelingen AC v, Foreman-v Drongelen MMHP. Essential fatty acids, pregnancy and pregnancy outcome. In: Bindels JG, Goedhart AC, Visser HKA, eds. 10th Nutricia Symposium - Recent developments in infant nutrition. Dordrecht, Boston and London: Kluwer Academic Publishers, in press.

10. Houwelingen AC v, Foreman-y Drongelen, MMHP, Nicolini U, Nicolaides K, AI MDM, Kester ADM. Hornstra G. Essential fatty acid status of fetal plasma phospholipids; similar to postnatal values obtained at comparable gestational ages. Early Hum Dev, accepted for publication.

\section{Abstracts}

1. Foremañ v Drongelen MMHP. Westdorp JM, Houwelingen AC v, Hornstra G. Hasaart THM, Blanco $\mathrm{CE}$. The essential fatty acid status of premature infants with regard to the fatty acid composition of their diet. Am J Clin Nutr 1993;57:829S.

2. Houwelingen AC v, Foreman $v$ Drongelen MMHP. AI MDM، Hornstra G, Nicolini U. Fetal essential fatty acids during gestation. Am J Clin Nutr 1993:57:814S.

3. Foreman-v Drongelen MMHP, Houwelingen AC v, Koopman-Esseboom C. Kester ADM, Hasaart THM. Sauer PJJ. Hornstra G. Does the long-chain polyene status at birth affect the postnatal longchain polyene status? J Perin Med (Suppl 2nd World Congress of Perinatal Medicine), 1993.

4. Foreman-v Drongelen MMHP, Houwelingen AC v, Koopman-Esseboom. C, Kester ADM, Sauer PJJ, Hornstra G. Does the long-chain polyene status at birth affect the postnatal long-chain polyene status? In: Galli C, Simopoulos AP. Tremoli E, eds. Effects of fatty acids and lipids in health and disease. Basel: Karger, World Rev Nutr Diet 1994:76:119-21.

5. Foreman-v Drongelen MMHP. Houwelingen AC v. Koopman-Esseboom C. Kester ADM, Sauer PJJ. Hornstra G. Wordt de postnatale LCP-status beïnvloed door de LCP-status bij de geboorte? Voeding 1994:55:30. 

